\title{
Economies of atmosphere : the joint impact of scale, scope, and atmosphere on scientific performance in clinical medicine and economics
}

Citation for published version (APA):

Spangenberg, J. F. A. (1989). Economies of atmosphere : the joint impact of scale, scope, and atmosphere on scientific performance in clinical medicine and economics. [Doctoral Thesis, Maastricht University]. Rijksuniversiteit Limburg. https://doi.org/10.26481/dis.19890921js

Document status and date:

Published: 01/01/1989

DOI:

10.26481/dis.19890921js

Document Version:

Publisher's PDF, also known as Version of record

Please check the document version of this publication:

- A submitted manuscript is the version of the article upon submission and before peer-review. There can be important differences between the submitted version and the official published version of record.

People interested in the research are advised to contact the author for the final version of the publication, or visit the DOI to the publisher's website.

- The final author version and the galley proof are versions of the publication after peer review.

- The final published version features the final layout of the paper including the volume, issue and page numbers.

Link to publication

\footnotetext{
General rights rights.

- You may freely distribute the URL identifying the publication in the public portal. please follow below link for the End User Agreement:

www.umlib.nl/taverne-license

Take down policy

If you believe that this document breaches copyright please contact us at:

repository@maastrichtuniversity.nl

providing details and we will investigate your claim.
}

Copyright and moral rights for the publications made accessible in the public portal are retained by the authors and/or other copyright owners and it is a condition of accessing publications that users recognise and abide by the legal requirements associated with these

- Users may download and print one copy of any publication from the public portal for the purpose of private study or research.

- You may not further distribute the material or use it for any profit-making activity or commercial gain

If the publication is distributed under the terms of Article $25 \mathrm{fa}$ of the Dutch Copyright Act, indicated by the "Taverne" license above, 
Economies of Atmosphere 



\section{Economies of Atmosphere}

The Joint Impact of Scale, Scope, and Atmosphere on Scientific Performance in Clinical Medicine and Economics

\section{Proefschrift}

ter verkrijging van de graad van doctor aan de

Rijksuniversiteit Limburg te Maastrichl, op gezag van

de Rector Magnificus, Prot. Dr. F.I.M. Bonke, volgens het besiluit van hell College van Dekanen, in het openbaar te werdedigen op donderdag, 21 septlember 1989 om 16.00 uur

door

Johny, Ferdinand, Alexander Spangenberg

geboren te Djakarla in 1954 
Promotores: Prof. Or. G.H. Holstede

Prof. Dr. H. Schreuder

Beoordelingscommissie:

Prof. Dr. J.A.H. Waks

Praf. Dr. A.D. de Groot

Prol. Dr. J.M. Pennings

Prof. Dr. J.H.R. wan de Poel 
Dedicated to my parents and Greta 



\section{Contents}

PREFACE

NTRODUCTION

1

SECTION I. THEORY

CHAPTEA 1: The Economies of Almosphere Framework 8

1.1. Introduction 8

1.2. Rediscovery of Informal Organization 9

1.3. Theoretical Research Questions

1.4. Delinition of Culture 11

1.5. Defintion of Economic Efficiency 16

1.6. Economies of Atmosphere 19

1.7. Extemal and internal Economies 23

1.8. Concluding Remarks 24

CHAPTER 2: External Economies of Atmosphere 25

2.1. Introduction 25

2.2. Economies of Almosphere at the National Level 25

2.3. Economies of Atmasphere at the Indusiry Level 29

2.4. Within Industry Level: Comparative Static Analysis 33

2.5. Within Industry Level: Comparative Dynamic Analysis 36

2.6. Economies of Almosphere at the Business Group Level 41

2.7. Concluding Remarks 45 
3.1. Introduction 47

3.2. Microeconomic and Complementary Theories of the Firm 48

3.3. Team Theory: Mutual Gain of Team Production and the Assurance Game

3.4. Agency Theory: The Firm as a Nexus of Coniracts

52

3.5. Transaction Cost Economics: The Firm as a Governance Siructure 56

3.6. The Firm as an Information Processing Apparalus 71

3.7. Alternative Sources of Efficiency: Scale and Scope 77

3.8. Concluding Remarks 83

SECTION III. DESIGN AND MEASUREMENT

CHAPTER 4: Foundalions in Organizalional Science

4.1. Introduction 87

4.2. Ouchi: Markets, Bureaucracies, and Clans 88

4.3. Organizational Climate Research 92

4.4. Culture Riesearch 97

4.5. Concluding Remarks 101

CHAPTER 5: Universily Research Managemen! 103

5.1. Introduction 103

5.2. Universities as Organizations 10.4

5.3. The Research Unit as a Clan-like Organization 105

5.4. Methodological Considerations 106

5.5. Some Facls and Figures on Dutch University Fesearch 110

5.6. Incenlives and Constraints of Research Performance

5.7. Hypotheses 114

5.8. Measurement of Predictor Variables 115

5.9. Quality and Quantity of Scientific Performance 120

5.10 Theoretical Model: Analysis of Variance 125

5.11. Concluding Aemarks 127 
SECTION III: EMPIRICAL STUDIES

CHAPTER 6: Scientific Performance in Clinical Medicine

6.1. Introduction 129

6.2. State of the Art in Clinical Medicine 129

6.3. Measurement of Pertormance 130

6.4. Sample 131

6.5. Data Collection 132

6.6. Univariate Analyses 135

6.7. Covariance Analysis 139

6.8. Mullivariate Analyses 140

6.9. Economies of Almosphere? 149

6.10. Concluding Remarks and Discussion 152

CHAPTER 7: Scientific Performance in Economics

7.1. Introduction 153

7.2. Measurement of Performance $\$ 54$

7.3. Sample 158

7.4. Data Collection 159

7.5. Additional Hypotheses 161

7.6. Measurement of Additional Variables 167

7.7. Uniwariate Analyses 169

7.8. Multivariate Analyses 177

7.9. International Comparison $\quad 187$

7.10. Concluding Remarks and Discussion 192

CHAPTER 8: Quality Control in Science 193

B.1. Introduction 193

8.2. Consistent Predictor-Criterion Relations 195

8.3. Consistent Zero Prediclor-Criterion Relations 197

8.4. Inconsistent Predictor-Criterion Relations 199

8.5. Research Policy Implications 200

8.6. Concluding Remarks 204 
9.1. Main Research Findings 205

9.2. Strengths and Shortcomings 211

9.3. Suggestions for Continued Research 214

\section{REFERENCES 217}

APPENDICES (1-2) 237

SUMMARY

247 


\section{Preface}

"We are not ready to suspect any person of being defective in selfishness" (Adam Smith)

The neoclassical paradigm is a utilitarian and rationalist paradigm. It concelves economic agents as seeking 10 maximize their utility, and to choose rattonally the best means to attain their goals. Recently, these assumptions have been put somewhat in perspective. First of all, there is an increasing body of literature in economics and game theory on altruistic behavior and cooperative strategies in zero-sum game situations showing that agents do not always act selfishly in a narrow sense - certainly not when the time horizon of the parties is extended. The benevolent butcher may abstain from short-weighing; the producer may advertise his products truthfully when he need not; the agent does not cheat even though it may be 'rational economic behavior" to do so: some people care about future generations; some support development aid - not primarily to elicit reciprocal gifts nor adjusted in terms of 'marginal utilities to the recipient'.

In addition, the growing literature on human information processing and prospect theory shows that agents - although their behavior may be purposive - typically do not always take deliberate (or rational) decisions. They do not fasten their seat bells; they conlinue to smoke twenty years after the Surgeon General's report; they pay stock brokers for costly consultancy although the time series behavior of stack prices in the Dow Jones Index resembles a random walk. Of course, search costs have to be taken in account when the decision is made under budget and time constraints - which is typically the case. Anyone who tries to make fully-informed rational choices would make only a handful of decisions each week, leaving hundreds of important matters unattended. In accounting for search costs and the scarcity of information processing capacity, we rely partially on habits, operationall roultines, and rules of thumb which consist of fixed rather than flexible, rational responses. As a resull, most consumers shop at the same supermarket, even though some other markell will have lower prices for some products. We are aware that many of our decisions will be inferior to those a fully informed rational agent would have made. And yet we have no better allemative. Given scarce cognitive resources (and scarce energy and time), to rely, partially, on rules of thumb and other nonchoice decision rules may be fully rational. 
Some of these non deliberate decision rules are provided to individuals by their culture which affects their mental program and behavior - both at the national and the organizational level. Culture, or as we prefer to call it "atmosphere", is not the aggregation of individual decisions, but a common value and information system. This, however, does not imply that melhodological individualism is nol applicable to atmosphere. This investigation focuses on the economies and diseconomies of atmosphere, l.e. the profitable and harmful effect of atmosphere, especially at the levell of the firm. The theoretical Section of this study, Section 1. is concerned with the economic rationalle of atmosphere. As a result, the question is not only whether atmosphere can affect cosis and performance, but also why certain aspects of atmosphere would increase or decrease economic efficiency. Definitions of atmosphere and techmical efficiency will be given in the first chapter of this book.

The world of deductive reasoning and the empirical world are separated. Consequently, when it can be demonstrated that there is an economic rationale for atmosphere, this does not necessarily imply that there is also empirical evidence for economies of atmosphere. The empirical Sections of this volume (including Methodology and Design, Section II, and, Empirical Studies, Section III) are concerned with demonstrating empirical evidence for the socalled efficient culture hypothesis, the. the assumption that economies of atmosphere prevail in certain structures. Since it would be naive to think that almosphere is the only facilitiator of an organization's efficiency, the economies caused by atmosphere are compared with economies of scale and economies of scope. A special organizational structure has been selected to test the efficierit culture hypotheses, i.e. the university research unit. Working within the internal environment of a professional bureaucracy, the university research unit is characterized by a multi-utilly funclion (research, patient care, education), high task uncerfainty. decentralizalion, and mutual monitoring. This is the environment where the central coordinating mechanism is assumed to be atmosphere rather than (bureaucratic) rules or (market) prices. Although the university research unit has primarily been selected for pragmatic reasons, it fits perfectly in the design of the empirical studies which have been conducted within the framework of this study.

Polenlial readers of this study are confromled by an information choice problem. They know the book contains information but in deciding whether to invest real resources in reading it fi.e. the opportunity cost of the reader's time and possibly the purchase price), they need to know whether the benefits to be derived from the content are likely to exceed the expected costs. As for the opportunily costs of your time, I have tried to present a rich, yal parsimonious, treatment of each topic. 
On the benefits side, there are several reasons why the following chapters may be worthy of attention. First of all, the economics of atmosphere is ome of the few joint ventures of economics and organizational science , becausie it deals with the impact of non-economic factors like walues and information on economic efficiency. Neoclassical economists, like French chefs with regard 10 lood, have developed stylized models whose ingredients are limited. Just as traditional French cooking does not use seaweed or raw fish, so neoclassical models do not make assumptions derived trom neighbouring disciplines. Following George Akerlof, this study disagrees with the rules that limit the nature of the ingredients in economic theory. Since the purpose of scientific theory is to predict and to explain, we bellieve that it may be fruitful to sacrifice predictive efficiency to a limited extent in order to explain more of the variance of the economic behavior under study, while avoiding overdetermination.

As the saying goes, thalf a loaf is better than none. Organizational economics has, in general, more explanatory power than other organizational sciences. Organizational theory, for example, excels in descriptive analyses. Subtle as they may be, they are not particularly helpful in understanding economic phenomena, because of a tack of explanatory theory. In addition, the field of organizational behavior is well equipped for establishing validily, but it tends to emphasize measurement rather than theory, so that is not very helpful in understanding performance behavior either. Despite these criticisms, all the above mentioned approaches have appeared to be very useful when brought into action sellectively. It is nearly impossible to explore the costs, benefits, and limits of atmosphere, even in a relallively preformal way, without consulting economic theory (chapter 2 and 3). In additilion, organizational theory has been very useful in providing a descriptive typology to partition a sample for empirical research (chapter 4). The field of organizational behavior, finally, has been extremely helpful in providing valid measurement instruments to assess atmosphere and scientific performance (chapter 4 and 5 ).

Second, this is one of the first empirical attempts to compare compelitive advanlages in the scientific enterprise (Section III). Since the inpuls and outputs of university research units. can - In principle - be measured, they can be held accountable for the degree to which efficiency is altained. Three sources of efficiency are distinguished in the literature: economles of scale, economies of scope, and economies of atmosphere. As otten, the starting point of the study was rather practical. In 1986, the Ministry of Education and Science of the Netherlands commissioned an interdisciplinary team, composed of Bally. Spangenberg, and Starmans, to conduct an investigation into the factors facilitating and inhibiting scientific productivily in Dutch clinical medicine (study 1). The central hypothesis of the leam was that performance differences between medical research units were related not only to medical inputs, but also to the research infrastructure of which atmosphere represents the informal side. The Ministry 
had commissioned special audit panels to evaluate the scientific performance of Dutch medicine and economics. Without the large scale performance evaluations of the Raad voor Advies van het Welenschapsbeleid (RAWB) and the Verkenningscommissie Economische Wellenschappen (VEW), the empirical studies presented here could not have been conducted.

In order to answer the question whether the findings of the study in clinical medicine (study I) can also be generalized to other disciplines, I conducted a lollow-up study on scientific performance in economics in 1987 (study II). Consequently, the etiology of scientific performance in two unrelated scientific disciplines has become the central subject of the empirical part of this book (Section lill). Since the main interest is in the determinants of scientific performance, the book does not end with a number of guidelines for improving university research performance in general, although some hints are given along the way. The principal aim of the research project described in Section II and III is the dissection of the network of predictor and critterion variables. Special attention will be given to methodological considerations into the etiology of competitive advantages within the scientific enterprise.

It is incumbent upon me to stress the indispensable role that many have played in the design, execution, and analysis of the present study. First of all, I am very grateful to my thesis advisors. Working with and being coached by Geert Hofstede and Hein Schreuder has been a great privilege. They provided a stimulating learning environment in which 1 could capture many economies of atmosphere. Without their constructive criticism and rigorous quality control, the present study, I am afraid, would be no more than a collection of poorly organized ideas and statistics.

I am also grateful to Yvonne Bally and Rilchard Starmans who requested me to join the team which was commissioned by the Ministry of Education and Science. Just as Cees van Dorp, who as a science policy maker has always been a loyal supporter of study I, they have contributed signiflcantly to the present study. In addition, I would like to thank Frans Nijhuis (RL), Bert Breemhaar (IVA), and Arle wan Heeringen (RAWB) who supported me in numerous respects, and provided me with many useful suggestions regarding the design and analysis of the data. The assistance of Ward Alfenaar (RL) was indispensable for the statistical analysis of the empirical data, while Mr. van Westen (Intormatiebank. RAWB) provided me with indispensable literature on scientometrics and research policy. Of course, my primary tribute goes to the many anonymous scientists who participated in the present study. Without their valuntary cooperation there would have been no data at all to analyze. 
Among my colleagues from the Facully of Economics and Business Administration, I owe a special debt to Harry Juch who has always been an inspiring room mate (even when he deserted to become a management consultant). Furthermore, I would like to thank Maarten Vendrik, Harry Bierings, Geert Woltjer, George Hendrikse, Patrick van Cayseele, Arjen van Wittelloostuljn, and Steven Maijoor for being stimulating intelloctual sparring partners. Each of them has supplied me with relevant literature for this sttudy. In addition, I owe thanks to Sjoerd Romme and Paul Kunst for their collegiality, and their consummate cooperation in a joint research project which was conducted in a variety of private and public sector organizations. I would also like to thank Mieke van Zutphen who has supplied our research unit with a pleasant atmosphere to work in. Finally, I am grateful to Bob Wilkinson for assistance with the English style. Of course, any remaining errors are entirely the author's responsibility.

Last but not least, I owe a great debt to the working discussions that I have had with Tom Allen and Ed Schein (Massachuselts Instilute of Technology) " Harry Triandis and Robert Bontempo (Universily of Illinois), Michaell Bond and Kwok Leung (Chinese Universilty of Hong Kong). Gordon Redding (City University of Hong Kong), George Akerlof (Berkeley University), Arjo Klamer (University of lowa), Paul Adler (Stanford University)." Jennifer Bond (National Science Foundation), Masahiro Harimoto (Kyoto University and London School of Economics), and Chen Long (Academica Sinica, Beijing). They have taught me that the game of science is, in principle, international.

Most of the time, writing this book has been an undivided pleasure. When it was nol, I could always rely on the support of Greta Noordenbos. Offstage and without being aware of it, she has been the emotional co-author of this book. I would like to dedicate this book to her and to my parents. Without their lifelong support and stimulation, this book would never have been written. 



\section{Introduction}

Why are some organizations more efficient than others - even though they use the same production technology and operate under similar industry conditions? Which are the main internal sources of their technical efficiency? Is there an economic rationale for the efficiency function which has recently been attributed to atmosphere, and under which circumstances is it a liability rather than an asset? These are, in a very general sense, the main questions of the present study. Recently, a growing convergence between public and private sector organizations has been observable. On the one hand, it is increasingly recognized that public sector organizations are disciplined by the invisible hand, i.e. the competitive principles derived from the struggle for life al the market place. On the other hand, business enterprises are getting increasingly dependent on gowernmental regulation and jurisprudence. The present investigation reflects this convergence because the theoretical section of the study mainly focuses on firm behavior in a competitive environment, whereas the empiricial section centers. on performance differences in the public sector, l.e. university research units. The purpose of this introduction is to preview the main themes of the text and to explain the basic methodollogical approach.

Thiis book is composed of three Sections. The first Section (chapters 1-3) deals with the costs. benefits, and limils of atmosphere. The second Section (chapters 4-5) focuses on a (descriptive) basis to partition a sample. In addition, it deals with the measurement of almosphere and scientific performance, and the design of the study. In the third Section (chapter 6-7), results are reported of an empirical study on the determinants of sclentific productivity in medicine and economics. The consistency of the results is examined in order to answer the question whether the findings can be generalized to other discliplines. Moreover, some research policy implications are discussed (chapter 8). Finalli, the major strengths and shortcomings are discussed and suggestions for continued research are given (chapter 9 ). 
Chapter 1 - The lirst chapter provides a theoretical foundation for the investigation. In general, the criterion for organizing economic transactions is assumed to be cast minimization. After dealing with the newfound respect for corporale culture as an internal source of cost (in)efficiency, it is pointed out that many of the antecedents, mechanisms $s_{i}$ and consequences of the cognitive and intormal side of organization have already been discussed in the mainstream literature. Integrating the insighis of various authors leads 10 a definition of atmosphere. Essentially, it is defined as a set of shared values, and as a common stock of knowledge. Furthermore, a definition is given of technical efficiency, including production and transaction costs, and the level of performance. The cost and benefits/harms associated with culture are defined as (dis)economies of atmosphere. After giving definitions and examples of economies an overall framework is presented.

Chapter 2 - The main purpose of the second chapter is to review the implications of economies of atmosphere for our understanding of the national level, the between- and within-industry level, and the business group level. The review is guided by three research questions, i.e. (i) does atmosphere affect economic efficiency? (ii) If so, why should certain aspects of atmosphere increase or decrease economic efficiency? (iii) What are the costs of providing an (injadequate atmosphere? These questions are also dealt with at the organizationall level in the next chapter. They concern the benefits and costs of having an adequate atmosphere, and the economic rationale for the rellationship between atmosphere and efficiency.

Chapter 3 - The third chapter deals with economies of atmosphere at the organizational level. Three views of the firm are discussed: the microeconomic theory of the firm, organizational economics, and the information processing approach of the firm. (i) The microeconomic theory of the firm is a theory of the market rather than a theory of the firm. An intangible and internal resource such as atmosphere is not compatible with the theory of the firm. (ii) Organizational economics centers on the mulual gain from team production. An atmosphere of trust can be a solution to the assurance game in the team approach. Within agency theory atmosphere can be seen as a solution to a managerial problem - the difficulty of imagining all contingencies and specifying them in employment contracts. Although both agency theory and transaction cost economics deal with the complex equilibrium of contractual relations within the firm, only the latter discusses the antecedenls and consequences of atmosphere in an explicit manner. The role of atmosphere is analyzed in the peer group and the internal labor market. (iii) While organizational economics focuses on values and information, the information processing approach deals with atmosphere as a common stock of knowledge, i.e. a code, knowiedge of specific facts, and 
behawioral rules. It shows why an efficiency function can be attributed to atmosphere in terms of an increase in cost efficiency of the firm's responses.

Section I investigates the economic rationale for the attribution of a transaction cost minimization function to atmosphere. However, the economic problem is saving on the sum of transaction and production costs. Consequently, production costs should be considered as well. Neoclassical economics has emphasized scale economics as a mechanism for decreasing production costs. Recently, it has been recognized that under certain conditions economies of scope may contribute to both production and transaction cost minimization. The final sections of chapter 3 define the alternative sources of efficiency in order to enable a systematic comparison between the sources of internal efficiency.

\section{Section II: Design and Measurement}

The theoretical Section has attempted to show that there is an economic rationale for the existence of atmosphere. The tough question is to find out whether there is empirical support for this proposition. In order to test the hypothesis that amosphere affects internal efficiency. it is necessary to: (i) select organizational units where economies of atmosphere may reasonably be expected; (ii) select instruments for the measurement of atmosphere; (iil) select instruments for the measurement of efficiency; (iv) design controls for internal and external validity.

Chapter 4 - Organizational theory provides a theoretical basis for partitioning the sample. Chapter 4 focuses on a typology which is based on transaction cost ecanomics, l.e. Ouchi's distinction in markets, bureaucracies, and clans. Bullding on transaction cost economics, Ouchi has developed a typology which seeks to explain the cooperation between individuals who share partially congruent objectives. Ouchi conjectures that atmosphere is especially efficient in the clan organization. Consequently, his typology provides a useful theoretical basis for the empirical exploration of economies of atmosphere at the micro level.

Organizational behavior researchers have developed a strong measurement tradition. As a result, several instruments for the measurement of organizational climate and culture exist. Climate measures were designed by Litwin and Stringer, Schnelder, and Andrews, while Hofstede and co-workers have constructed measures for generral values at the national and organizational level. The construct validity of these measures is suggested by empirical studies relating values to performance. Chapter 4 discusses the background and the main dimensions of this measurement tradition. Furthermore, the instruments which will be used in the collection of data are discussed. 
Chapter 5 - A commission of the Metherlands Minisiry of Education and Sciences offered the unique opportunity to study (economies of atmosphere in) medical reseanch units of university hospitals. With time-lag of one year, this study was replicated in departments of economics and business administration. The research performance of clinical medicine and economics has been the subject of national evaluation studies which combined various scientometric indicators and peer reviews. Despite imperfections in the performance measurement, these evaluations provided the best avallable empirical database for the classification of research units in high and low performers. The empirical studies emphasize a managerial approach to university research. Chapter 5 deals with thits approach, and discusses some pros and cons of the qualitative and quantitative performance indicators mentioned above.

In order to check for internal vallidity, the research units have been matched with regard to their relative research performance within their discipline. In order to demonstrate external validity, the consistency of predictor-criterion relations in study 1 and $I 1$ is examined. Chapter 5 discusses the design of these studles. Furthermore, hypotheses are formulatted concerning the predictors of research performance. In addition to atmosphere, hypotheses are formulated concerning economies of scale, scope, atmosphere and various managerial factors. A Dutchlanguage questionnaire has been designed to measure these predictors in research units. The iltems of this questionnaire are included in Appendix 2.

Note that the empirical studies have focused on a restrictive range of the economies of atmosphere framework. Since measures were only available of general and specific values, no attention has been paid to atmosphere as a stock of common knowledge. Since the evaluation studies of medical and economics research performance have focused primarily on performance measurement, no data were available on costs - certainly not at the unit level. Consequently, the investigation of economies of atmosphere had to be restricted here to the relation between values and research performance in a university environment.

\section{Section Ill: Empirical Studies}

Two empirical studies were conducted in a chronological order. In order to get an impression of incentives and constraints and the measurement of scientific performance, in-deplh interviews were held with research managers in multinational firms, policy makers in governmental research institutes, and high performing research professors in university departments. Although the results of the interviews are not reported in the study, they substantially contributed to our tacit understanding of research management and performance evaluation in the privale and public sector. The list of interviewed persons is given in Appendix 1 . On the basis of the performance evaluation of the Raad voor Advies Wetenschapsbeleid (RAWB), study 
I focuses on the incentives and constraints of scientific performance in clinical science in the Netherlands. The report of study $\mid$ will be published by Research Policy (North-Holland). The extended version has already been published in the Sclence Policy Series of the Netherlands Ministry of Education and Science. On the basis of the performance evaluation of the Verkenning|scommissie Economische Wetenschappen (VEW), study II centers on facilitating and inhibiting factors in Dutch economics. The reports of study II will be published by Scientometrics (Elsevier Science Publishers).

Chapter 6. Economies of atmosphere are explored in clinical departments of umiversity hospitals. Addlitional hypotheses are tested concerning the competitive advantages of scale, management "control " and communication. Ideally, economies of scope would be investigated as well, but relevant data were not available in the RAWB report. The chapter starts with a discussion of the performance evaluation concerning clinical medicine. Then it focuses on the procedures concerning sampling, data collection, and data analysis - including the Fisher linear discriminant analysis. Finally, the univariate and multivariate results will be discussed, especially regarding the evidence for economies of atmosphere.

Chapter 7 - This chapter makes an attempt to explain why performance records differ among departments of economics. It is assumed that, in principle, the same set of incentives and consiraints influence research effectiveness as in clinical medicine. The findings of the VEW have been used for classifying research units into high and low performers. After collecting data on the organization of research units, univariale and multivariate statistics, including multiple regression analysis, have been applied to explore the research questions regarding competitive advantages in the scientific enterprise. To examine external validity, the findings are compared with large scale performance studies conducted in economics (USA and UK) and accounting (USA).

Chapter - The previous chapters hawe reported results concerning the determinants of scientific productivity in these disciplines. Chapter 8 summarizes the main results, and tocus on their consistency. When consistency between the findings of study I and II can be observed, despite the considerable variation between the disciplines, this would give confidence in the external validity (generalizability) of the findings to other disciplines. Thus, the findings may give a quantitative basis for quality control in science. After examining the consistency of the findings, a review is giwen of the strengths and weaknesses of the studies presented here. The main finding is that economies of scale, scope, and atmosphere can be captured by university research units. Scale especially, is an important condition for high performance, although scope and atmosphere may contribute as well when a unit is operating with sufficient critical mass. In addition, the results confirm the importance of recent policy measures, i.e. 
decentralization of university research management, and internationalization of Dutch university science.

Chapter 9 . The final chapter will summarize and discuss some of the main findings of the study aglainst the background of the available data on economies of atmosphere. Then the main strengths and shortcomings of the research project will be discussed. Finally, surggestions are given for continued research. The main conclusions of the investigation are the following: (i) from an empiricall perspective, economies of atmosphere have less impact than is generally belleved - although there is certainly an economic rationale for the existence of atmosphere from an analyticall point of view; (ii) it is the dynamic interplay between atmosphere and other sources of efficiency rather than atmosphere alone which accounts for the variance in technical efficiency between organizations; (iii) economies of scale tend to be more important than economies of atmosphere.. Units working without sufficient 'critical mass' may not be able to compensate their scale disadvantage by developing a superior atmosphere. 


\section{1}

\section{The Economies of Atmosphere Framework}

"A concern for atmosphere evidently makes the supply of a satisfying exchange relation part of the economic problem" (Williamson)

\subsection{Introduction}

This chapter provides a theoretical foundation lor the book. After dealing with the recent rediscovery of corporate culture, it is pointed oult that many of the antecendents mechanisms, and consequences of the cognitive and informal side of organization thave already been discussed in the mainstream of the organizational theory literature. In contrast to this literature, this book focuses on the economic rather than on the social or psychological consequences of culture. The main research questions of the theoretical part concern the benefits and costs of having an adequate culture, and the economic rationale for informal organization. Combining the insights of various authors yields a definition of culture. Furthermore, a definition is given of economic efficiency including production and transaction costs, and the level of performance. The cost and prodluction advantages associated with culture are defined as economies of atmosphere. Examples and definitions are given of economies and diseconomies of atmosphere. Finally, the economies of atmosphere framewark is presented.

While chepters $4-3$ of this study deal with the full spectrum of interrelations between dimensions of atmosphere and economic efficiency, the remaining chapters will focus on a limited set, i.e. the relationship between values and performance only. By contrast with the formal modeling apparatus associated with much of the microeconomics literalure, the economies of atmosphere framework is of a relatively preformal kind. Inasmuch as subisequent formalization of economies of atmosphere would be feasible, that condition is not necessarily grounds for objection. since the relevant reduced forms are unlikely to be discerned without first explaining the underlying microanalytics. 


\subsection{Rediscovery of Informall Organization}

In 1977, a wisit by two McKinsey consultants to the leading schools of business in the United States and Europe resulted in a statement which is still current today: "The state of the art is in refreshing disarray, but moving towards a new consensus; some few researchers continue to write about structure (...). But primarily the ferment is around another stream of thoughts that follows from some startling ideas about the limited capacity of decision makers to handle information and reach what we usually think of as rational decisions, and the even lesser likelihood that large collectives (i.e. organizations) will automatically execute the complex strategic design of the rationalists" (Peters and Waterman, 1982: 5).

By this innovative 'stream of thoughts' the authors referred to the literature on informal organization or 'culture', the key variable in their analysis of excellent Fortune 500 companies. Since their description of the consequences of culture in terms of the financial performance of large U.S. companies, many conferences, arlicles, books, and special issues of journals have proliferated on corporate culture (Administrative Science Quarterly, 1983; Organizational Dynamics, 1983; Frost et al. 1985; Killmann et al., 1985; Schein, 1985; Journal of Management Studies, 1986; Barney, 1986). From a theoretical point of view, the concept of "corporate culture' appears to be very fruitful. Several scholars have investigated the relationship of culture to other organizational key variables including "strategy" (Schwartz and Davis, 1981; Fombrun, 1984; Weick, 1985), "control" (Ouchi, 1979 and 1980), and "structure" (Wong and Birnbaum, 1988). The relationship with economic efficiency has been explored by Wikins and Ouchi (1983), Kreps (1984), Crémer (1987), and Camerer and vepsalainen (1988).

The new stream of thoughts affected not only mainstream management theory, but also common business practice. Since the publication of Peters and Waterman's bestseller "In Search of Excellence", managers have been increasingly interested in their company's culture, especially. of course, in its impact on productivity and product quality. In addition, culture is increasingly associated with the success and failure of new product innovations (Gupta et al.n 1986 ), joint ventures, and vertical integrations. Having a "strong" culture, however, is not necessarily an asset. Since 'it may take ages and cost fortunes' to change a culture (Deal and Kennedy, 1982), it may also be a liability. If the corporate culture is strong and myopic, it will contribute to fallure rather than to success (Schein, 1984). Moreover, managers have learned, by trial and error, that corporate culture can be a serious constraint in the implementation of strategic decisions (Lorsch, 1985; Wikins and Patterson, 1985), especially in the case of mergers and takeovers. 
It is often assumed that 'corporate culture' is a new concept doomed to fade away like so many popular management subjects before (Hofstede, 1986: 257). "To name a few: Management By Objectives, the rage of the early fiftles, was followed by the Total Marketing Concept, only to be superseded by Long Range Planning. In the early seventies, Strategic Planning emerged as the "Uitimate Answer". Then came Boston Consulting Group Matrices and Experience Curves" (Ansoff and Baker, 1986: 82). Corporate Culture is simply the latest. We believe, however, that culture or related concepts have always been part of the mainstream liherature. After all, the antecedents, mechanisms, and consequences of the informal side of institutions have been extensively discussed in classics such as 'Theory of Moral Sentiments' (Smith, 1759). 'De la division du travail social' (Durkhaim, 1893), 'Wirtschaft und Gesellschatt' (Weber, 1922), 'The Functions of the Executive" (Barnard, 1938). "The Changing Culture of a Factory' (Jaques, 1951), 'Administrative Behavior' (Simon, 1954), 'Leadership in Administration' (Selznick, 1957). 'A Comparative Analysis of Complex Organizations' (Etzioni, 1961), and 'Standards for Morale. Cause and Effect in Hospitals' (Revans, 1964). Even though the term 'culture' has not been specilically used, the importance of 'mental programming' has been clearly undeistood in the organizational behavior literature on 'atmosphere' or 'climate' as well (Schneider, 1985; Glick, 1985). Frequently cited publications include 'Patterns of Aggressive Behavior in Experimentally Created Social Climates' (Lewin, et all., 1939). "New Patterns of Management" (Likert, 1961), "Motivation and Organizational Climate" (Litwin and Stringer, 1968), and 'Some Relationships between Job Satisfaction and Organizational Climate' (Schneider and Snyder, 1975).

Consistent with the observations of $\mathrm{De}$ Groot (1982) and Lammers (1986) that there is a widespread tendency in the social sciences to sell old wine in new bottles, organizational theorists are still creative in considering new names for culture in organizations. Ouchi (1980), for example, thas reserved the name 'clan' for organizations with 'efficient cultures' (Wilkins and Ouchi, 1983), whereas Mintzberg (1983) has extended his well-known organizationall "pentagon" with a sixth configuration: the 'missionary" which is rather similar to Etzionits 'normative organization' (1961). A more comprehensive review of some of these theoreticall antecedents is given in Burrell and Morgan (1979). Their review is written in the spirit of Newlon's remark: "If I have seen further it is by standing on the shoulders of giants" - expressing at once a sense of indebtedness to a common heritage, and a recognition of the essentially cooperative and selectively cumulative quality of scientific achievement (Merton, 1982). 


\subsection{Theoretical Research Questions}

The emphasis of this book is on culture's consequences rather than on culture per se (ct. Frost, 1985). Moreover, the interest here is in the consequences rather than the antecedents (ct. Schein, 1983) of culture. Consequently, this study is not concerned with the conceivable effect of economic efficiency on culture. This, of course, does not mean that this influence is assumed to be absent. In contrast to the organizational behavior literature which generally deals with the impact of corporate culture an "emotional well-being" (Ouchi and Johnson, 1978), "motivation" (Litwin and Stringer, 1968) or 'job satisfaction" (Schneider and Snyder, 1975), the locus here is on the economic rather than the psychological consequences of culture. The research questions which will be explored in the theoretical part of this study, chapters 1-3, are the following lin order of importance):

1. Does culture affect economic efficiency?

2. If so, why should certain aspects of culture increase or decrease economic efficiency?

3. What are the costs of providing an (in)adequate culture?

The key variables of our investigation are 'culture' and 'economic efficiency'. In order to explore the above-mentioned questions in a straightforward manner, it is necessary to define these terms precisely.

\subsection{Definition of culture}

The first thing to be said about culture is that it does not exist. Lewin (1951) and Hofstede (1980) have rightly pointed out that like 'forces' in physics, 'culture' and 'almosphere' are intangibles. The terms we use to describe them are constructs. A construct is "not directly accessible to observation but inferable from verbal statements and other behaviors and usefull in predicting still other observable and measurable verbal and nonverbal behavior" "Levitin. 1973, quioted in Hofstede, 1980: 14). Like all scientific constructs "Lakatos, 1970)" "cullure" does not exist in an absolute sense. Rather it is defined into exislence for predictive reasons. In the next sections an attempt is made to define this very construct on the basis of the work of Hofstede, Crémer, Polanyil, and Boisot.

\subsubsection{Hofstede: Values}

'Culture" has been defined in many ways. Let us adopt" as a working definition that of Geert Hofstede: "the collective programming of the mind which distinguishes one category of people 
from anotheris (Hofstede, 1980: 25). The key-words of his definition are: (i) collective. (ii) distinctive, (iii) mental programming.

(i) 'Collective' means that group of people share a mental program

(ii) "Distinctive' implies that the mental program is shared with some but not with all people.

(iii) Mental programming" is a process leading to a specific end product, viz. a mental program.

While the first wo are self-evident, the third poses a problem. What exactly can a 'mental program" mean? For Hofstede, the core construct for describing mental programs are values. A value is defined as "a broad tendency to prefer certain states of affair over others" (Hofstede. 19810" 19). This definition reserves the word 'value' for mental programs that are relatively unspecific. An example is "uncertainty awoidance" - a complex of work-related factors found in Holstede's (1980) IBM study. "Uncertainty avoidance' can be activated in a variety of situations. For mental programs that are more specific, for example 'safety-orientation in industrial organizations' (Zohar, 1980) or 'customer service orientation in banks' (Schneider et al. 1980), the terms 'attitudes' and 'bellefs' are used. In general, it is assumed that values are at a deeper level than attitudes (Schein, 1985). As a consequence it is harder to change values than attitudes. Attitudes, on the other hand, are better predictor variables than values (despite their greater variability), because alliludes - especially the 'attitude toward the behavior in question' (Fishbein, 1980: 114) - are at a lower level of abstraction, i.e. more specific (Poole, 1985: 96). Instead of the words 'values' versus 'attitudes', the use of the words 'generall values' versus "specific values" is preferred here. In practice, the general values are often used as indices of national culture (e.g. Hofstede's (1980) dimension "uncertainty avoidance') and organizational culture (e.g. Hofstede's and co-workers (1988) 'results versus process oriented' dimension), whille both general values (e.g. Litwir and Stringer's (1968) dimension 'responsibility") and specific values (e.g. the UNESCO (Andrews, 1979) dimensilon 'research unit working climate") may refer to organizational climate. In general, the time horizon is long when it is a question of culture, and it is believed to be extremely hard to change - especially when deeper levels are affected (Hofstede et al.; 1988). As Deal and Kennedy (1982) put it: it takes ages and costs. lortunes. As a consequence, it is easier to reinforce the existing values by socialization of organizalional members, whille new values are more smoothly introduced by personnel selection (Sooters and Schreuder, 1988).

\subsubsection{Crémer: Common Stock of Knowledge}

Though salient, it may be argued that Hofstede's definition of culture as a mental program is not exhaustive. A complementary definition of culture has been given by Jacques Cremer (1987). He defines corporate culture as "the stock of knowledge that is common to the members of the firm 
but not to the general population from which they are drawn" (Cremer; 1987: 11). Note that Cremer stresses two of the elements that are also included in Hofstiede"s definition: culture is (i) collective and (ii) distinctive. However, the focus of Cremer's paper is on culture as a set of knowledge, not at all as a set of values. His starting point is the description of the firm as an information processing apparatus that receives messages from its environment, processes them, and responds by a message or puts some of its physical resources into play (Galbraith, 1974). Within this framework, the acquisition of common knowledge is an investment, and Cremer explores the benefit from this investment. Cremer analyzes culture as a stock of knowledge by decomposing it in the following elements:

1. A common but distinctive language or "code" (cf. Arrow, 1974a)"

2. A common but distinctive knowledge of specific facts - which may be interpreted as a collective, cognitive "specific skill" (cf. Becker, 1964; Doeringer and Priore, 1971);

3. A common but distinctive competence or adhesion to specific though simple "rules of action' (Crémer, 1987) or "routines' (cf. Nelson and Winter, 1982).

All these elements are closely linked to the literatures on "economics of informalion' (Arrow, 1984, Galbraith, 1974), "internal labor markets', (Doeringer and Piore, 4974), and 'organizational capital" (Prescott and Visscher, 1980). The economic literature may be considered as a valuable complement of the anthropological tradition to which Hofstede's work is. referring. As a consequence, a mental program may be seen as a combined sel of values, code, information, and competence. Values refer to (i) general values (values) and (ii) specific values (attitudes and beliefs). Code refers to the common langulage. Information refers to the knowledge of specific facts, and competence to the ability of orglanizational members to apply specific simple rules (routines). The lest of the members' tacit knowledge of the written and unwritten rules of the firm is their ability to interpret them and use them in practice (Wittgenstein, 1978). One of the interesting conclusions of Cremer's paper is that adhesion to rules plays the same role as the knowledge of facts, since they jointly contribute to the cost efficiency of the firm's responses within the information processing approach.

\subsubsection{Polanyl: Tacll Knowledge}

An important shartcoming of Cremer's paper is that the author does not specify the nature off knowledge in his cognitive definition of organizational culture. Obviously, the knowledge embodied in the corporate culture of Shell or IBM is not the type of knowledge that can be found in wellknown handbooks like Samuelson's. 'Economics' (1980) or in the average how-10-do-itt pocketbook. Rather it can be compared with the knowledge embodied in a scientific 'paradigm". In his famous book on 'The Structure of Scientific Revolutions', Thomas Kuhn has written that the 
existence of a paradigm "does not depend upon the formulation of rules and assumptions (...). Indeed, the existence of a paradigm need not even imply that any full set of rules exists" (Kuhn, 1970: 44). In addition. Kuhn refers to the late philosopher scientist Michael Polanyl (1958) who develloped wery similar theme, arguing that much of the scientist's success depends upon "lacil knowledge". Tacit knowledgle is knowledge that is acquired through practice and that cannot be articulated explicitly.

Though Polanyl's treatment of tacil knowledge was meant to provide a useful perspective on the realm of scientific knowledge, economists have recognized the importance of the concept for the study of organizational competence and operational routines (Williamson, 1980; Nellson and Winter, 1982). In business it is a common situation where one is able to do something and at the same time to be unable to explain how it is done. Chester Barnard [1939]. for example, observed numerous examples of tacit knowledge in managers who make competent judgments without evidence that they have been englaged in systematic reasoning, and without their being able to report the cognitive processes that took them to their solution.

An example which illustrates the importance of 'lacit knowledge' is given by Polanyi (1958: 52). "The attempt to analyse scientifically the established undustrial arts has everywhere led to similar results. Indeed even in the modern industries the indefinable knowledge is still an essential part of technology. I have myself watched in Hungary a new, imported machine for blowing electric lamp bulbs, the exact counterpart of which was operating successfully in Germany, failing for a year to produce a single flawless bulb". Polanyi has shown that characterizing the firm exclusively in technological terms is a bankrupt idea. The productive wealth of the economy is not only embodied in factories and machines, but also in the tacit knowledge and skills stored in members of the firm. As a consequence, the team knowledge embodied in the corporate culture adds value to the capital assets.

That theme is carried forward in Polanyi's discusston of craftsmanship (tacit compettence, skill or routine), especially idiosyncratic craftsmanship where individual skills are significant. Individual skills are hard to imitate because the set of rules determining skillful performance are often "nol known as such to the person following them" (Polanyl, 1958: 49). According to Palanyi. an art which cannot be specified in delail cannot be transmitted by prescription. Tacit knowledge can only be transmitted by example from master to apprentice, in a learning-by-doing process. Obviously, this restricts the range of diffusion of tacil knowledge to that of personal contacts, and we find accordingly that craftsmanship tends to survive in closely circumscribed local tradilions. It follows that an art which has fallen into disuse for the period of a generation is lost altogether. As. Polanyl (1958: 53) has put it: "It is pathetic to watch the endless efforts equipped with microscopy and chemistry, with mathematics and electronics - to reproduce a 
single violin of the kind the hall literate Stradivarius turned out as a matter of routine more than 200 years ago".

\subsubsection{Boisot: Uncodified Information}

In a recent paper, Max Boisot (1986) has used the concept of 'codification' of information for the analysis of the modern corporation. Although Boisot does not explicitly refer to Polanyi's work, his classification of corporate knowledge into operationally distinct levels is flluminating. Boisot distinguishes three levels of corporate knowlledge:

"1. Uncodified knowledge which cannot be put down on paper and can therefore only be transmitted by force of example in face-to-face situations - i.e. the countless 'tricks of trade' available to skilled workers $(\ldots)$

2. Semi-codified knowledge, part of which can be put down on paper, but which still needs faceto-face situations for its elaboration. It can only be fully transmitted and understood through personal interaction - i.e. the discussions that follow the presentation of a report to the board.

3. Codified knowledge that can be completely set out on paper and transmitted by impersonal means - i.e. company staff rules and regulations" (Boisot, 1986: 146).

In Boisot's terminology, Polanyit's tacit dimension can be conceived as uncodilied lknowledge, although some elements may be semi-codified or even codifed, e.g. the company philosophy or the statement of corporate objectives. Nelson and Winter (1982) have argued that the (complete) productive knowledge of a firm is unlikely to be codified in any useful way within the firm, and may not be known to any single member of the firm. A large amount of the firm-specific knowledge is learned by doing, and remembered by storage in the corporate culture, inciuding the organizational production routines - the firm's memory. Several authors have noted that this lack of codified production knowledge not only makes outside imitation difficult, but may be a partial explanation for why some firms have difficulty in replicating their own successful plants (Teece, in: Yao, 1988: 67). Referring to causal ambiguity regarding the production process, Rumblt (1987: 146) writes: in the end "competitors cannot extract the innovator's secrets because even the innovator does not know the causes of success".

To conclude, the knowledge embodied in a culture can be characterized as "lacli' or 'uncodified" knowledge', while the routines embodied in that culture can be be characterized as a 'tacit competence: One of the characteristics of tacit knowledge and tacit competence is that they impede their own diffusion (sometimes even within the firm), because they are so hard to imitate. Tacit knowledge and routines can only be learned by doing. in the appropriate face-to-face environment. 


\subsubsection{Definition of culture}

Integrating the insights of Hofstede, Cremer, and Polanyi/Boisot, we may define culture as a distinctive mental program. It is common to the members of a group (collective), but not to the general population from which they are drawn (distinctive). The mental program consists of (i) (general and specific) values, (ii) more or less tacit forms of knowledge (the code and knowledge of facts) and (iil) competences (routines or simple rules). ln general, the mental program has a tacil nature which refers to the fact that it is (hardlly) uncodified. Consequently, it: is difficult to imilate.

\subsection{Definition of Economic Efficiency}

Few concepts are more widely used within economics than that of "efficiency'. It usually means 'not wasteful, or 'doing the best one can with available resources'. However, there are specialized usages, for example the concept of "efficient markets" in the finance literature, or Leibenstelin's (1980) concept of 'X-inefficlency' (New Palgrave, 1987). McGuire et al. (1988) distinguish between three aspects of economic efficiency which are, of course, not completely independent: (i) allocative efficiency, (ii) social efficiency and (iii) technical efficiency. Although reference will sometimes be made to aspects of allocative or 'Pareto efficiency' (iit is not possible to make any Individual better off without making some other individual worse off) which is a subset of social efficlency (maximize, given the budget constraint, the welfare of the population), this study will focus on technical efficiency.

A definition of technical efficiency may be found in Robert Anthony's lucid treattment of this subject. Anthony (1965) uses the term in a comparative (rather than in an absolute) sense as a criterion for judging the performance of a responsibility or input-output center. We do not ordinarily say that responsibility center $X$ is $75 \%$ efficient, but rather that it is more (or less) efficient than center $Y$ (level analysis), or that it is more (or less) efficient than it was in the past (trend analysis). Efficiency is the ratio of outputs (benefits) to inpults (costs), or the amount of output per unil of input. Center $X$ is more efficient than $Y$ either (i) if it uses fewer resources than $Y^{\prime}$ but has the same output (find a minimal cost with the constraint that output is flxed), or (ii) if it usies the same resources as $Y$ and has more output than $Y$ (find a maximum output with the constraint that lotal cost is fixed). The next sections will center on the concepts of costs (expenditures, inputs) and performance (benefits, outpuls). 


\subsubsection{Production and Transaction Costs}

At the input-level, we distinguilsh between costs of production and transaction costs. The neoclassicall theory of production begins with specific input information. Adam Smith argued that competition would thend to establish the 'natural prices' of commodities produced, i.e. the prices at which the 'the price of any commodity is neither more nor less than what is sufficient to pay the rent of land, the wages of labour, and the profit of stock employed ... according to their natural rates" (Smith, quoted in: New Palgrave, 1987: 698). Costs of production may be defined as the costs of using the factors of production: a certain amount of land, labor, capital, machines, and raw materials. Defined for a given state of technological knowledge, costs of production determine the production function - "the technical relationship telling the maximum amount of output capable of being produced by each and every set of specified inputs (or factors of production)" (Samuelson, 1980: 501). Like technological know-how, brand reputation, and marketing information, atmosphere is a non-physical resource (Itami, 1984). The cost advantages associated with the possession of these intangible resources will concern both production and transaction costs. Regarding production costs, it is not difficult to conceive that the more information available on optimal production processes, the less the waste of labor "materials and energy. Thus, the existence of reliable information is one of the conditions for effective production cost minimization. Concerning transaction costs minimization, it may be argued that the existence of common professional values of medical and nursing staff of an intensive care unit facilitates mutual adjustment and purposeful behavior. Consequently, the intensive care unit economizes on transaction costs such as the costs associated with coordination and control.

Like production costs, transaction cosls are a catch-all term for a heterogeneous assortment of inputs. Transaction costs, however, do not comprise all cosis not directly incurred in the physical process of production. They are the ex ante and ex post costs necessary to complete a transaclion. The parties to a contract have to find each other, to communicate and to exchange information. The goods must be described inspected, weighed and measured. Contracts are drawn up, lawyers may be consulted, title is transferred and records have to be kept. In some cases compliance needs to be enforced through legal action and breach of contract may lead to litigation (New Palgrave, 1987: 676). In sum, transaction costs may be viewed as a broad spectrum of institutional costs including those of information, negotiation, drawing up and enforcing contracts, delineating and policing property rights, monitoring performance, coordination, changing institutionall arrangements, and excluding nonbuyers from the use of a product or service (New Palgrave, 1987: 56). Transaction costs are often cited as a basic cause for the nonexistence of markets in certain areas (Arrow, 1974a). Although it is highly plausible that economies of atmosphere affect transaction and production costs, the mainstream literature focuses on transaction cosis rather than production costs when economies of atmosphere are concerned, while production costs 
are emphasized when economies of scale and scope are considered. Except for the framework which will be presented in section 1.6.4. this book will not deviate from this custom - although It is realized that economizing on product expenses and transaction casts is not independent. Consequently, the emphasis of the theorelical part of this investigation is on transaction costs. Production costs will be dealt with in the sections on economies of scale and scope.

\subsubsection{Level of Economic Performance}

At the output-level, we emphasize the level of economic performance. Maximizing the level of economic performance for given inputs is consistent with the profit-maximization hypothesis which is part of the theoretical hard core of Adam Smith's and Alfred Marshall's classical model of the firm. Rumell (1987) has argued that the appropriate profit concept is that of "rent" once the source of high protits is located in the firm's resource portfolio rather than in its membership in an industry. Fiumelt's rent-earning firm looks much like the successful enterprise of the competitive strategy literature, because it exhibits a high level of performance (profit, growth), and "at its core rest unique specilalized resources that cannot be freely expanded or imitated" (11987: 143).

Profit-maximization has been put in perspective by the emergence of the management model of the firm (implying a separalion between management and ownership) and the open model of the firm (implying a coalition of stockholders)(Schreuder, 1981: 7.48). An example of an alternative goal which can set by a firm is performance stabilization.

Performance stabilization, i.e. decreasing the variability of economic performance, reflects the risk attilude implying the separation of management from ownership. Alfred Chandler (1977) has pointed out that in making administrative decisions, managers preferred policies that favored the long-term stability and growth of their enterprise to those that maximized current profits. The costs of management fallure may be much larger for managers (and workers) than for shareholders, because the latter can diversify their portfolio risk, while the former are in a situation where it is impossible to diversify their human capital (Aoki, 1984a). Under these circumstances, management and workers tend to be more risk-averse than the owners (shareholders). The generation of stable performance levels reflects the risk attitude of the management which seeks to stabilize long-term economic growth at the possible cost of lowering the level of short-term performance (Morita, with Reingold and Shimoruma, 1987). Although, the insurance motive will not be ignored in the next sections, the study will mainly focus on the performance (for example, the profit-) maximization motive. The distinction between technical ('real') and pecuniary economies is particularly useful for the welfare implications of economies of atmosphere. While technical economies of atmosphere result in a real increase of the 
performance level, pecuniary economies result in a redistribution of income. For example, in a business group (section 2.6), the pecuniary economies are indicated by performance stability. The next sections will focus on technical rather than on pecuniary economies of atmosphere.

\subsection{Economies of Atmosphere}

We define economies of atmosphere as the impact of culture on technical efficiency. Technical efficiency is indicated by cost minimization or performance mazimization. The concept 'economies of atmosphere' was first introduced by Oliver Williamson (1973; 1975). 'Atmosphere' is the environmental factor in his original formulation of the organizational failure framework (OFF). Within the OFF, atmosphere is a general condition describing the attitudes of economic agents toward the institutional setting of the transaction. Why is atmosphere considered to be important? Standard economics assumes that individuals regard transactions in a strictly neutral, instrumental manner. Subject only to the condition that transactions are technologically separable, each transaction can be priced separately and metered (controlled) independently. Williamson believes that is more accurate to regard the exchange process itself also as an object of value. He refers to the altruism in Titmuss' (1971) study of blood donors. Titmuss has found that the creation of a market for blood transformed the nature of the transaction, and consequently reduced the altruism embodied in giving blood. According to Williamsom, concern for atmosphere tends to raise a comparable system issue. In particular, the influence of metering intensity on work attitudes needs to be assessed with care. Efforts to divide the employment rellation into parts and to assess each part separately in stricily calculative, instrumental terms can have counterproductive consequences. Rather than regard transactions in strictly 'quid pro quo' terms, with each account to be settled separately, at least some individuals look instead for a favorable balance among an interrelated set of transactions. Modes of organizalion which would probably have superior productivity consequences if implemented within a group of pecuniary gain maximizers, may be rejected by a group with a different set of values. As Williamson (1975: 58) has put it: "A concern for atmosphere evidently makes the supply of a satisfying exchange relation part of the economic problem".

Williamson's findings are consistent with Alchian and Demsetz: (1972) well-known treatment of the effects of metering intensity, and Sen's (1983) observalion that worker's involvements are important because it is costly and may be impossible to devise a system of rewards and pumishments such that no shirking incentive remains. Every economic system, therefore, tends to rely on the existence of attitudes toward work which supersede the calculation of net gain from each transaction. As Arrow (1968; 1971: 221) has put it: "One of the characteristics of a successful economic system is that the relations of trust and confidence between principal and 
agent are sufficienily strong so that the agent will not cheat ewen though it may be "rational economic behavior" to do so".

Prior to Williamson's work, the concept of 'atmosphere' had been used within a behavioral context, namely, as an environmental tactor in Kurt Lewin"s (1951) classic formulation of behavior $(B)$ as a function of tension systems within the person $(P)$ and the pressures emanating from the surrounding environment (E),

$B=f(P, E)$

In seeking to describe the essential dynamics that linked human behawior to generalized environmental stimuli, Lewin $(1941: 241)$ stated: "To characterize properly the psycholagical field, one has to take into account such specific items as particular goals, stimuli, needs, social relations, as well as more general characteristics of the field as the atmosphere (for instance, the friendly, tense, or hostile atmosphere)". Lewin et al. (1939) studied atmosphere as an "empirical reality" in an experiment involving the behavioral effects of three different leadership-induced atmospheres. In nearly all cases, behavioral differences could be attributed to differences in the experimentally induced atmosphere rather than to member characteristics. In addition, it was found that previous group history (preceding atmosphere) has an irreversible effect on the perception of leadership in the next game.

Both Lewin and Williamson have explored the effects of atmosphere as an environmental variable. In contrast to Williamson, however, Lewin focussed on the psychological consequences of atmosphere. Williamson's work is more appropriate for the purpose here, because his 'Economics of Atmosphere' (Williamson and Ouchi, 1981: 360) emphasizes the impact of general and specific values on ecomomic efficiency - especially ${ }_{i}$ transaction cost minimization. In comparison with Crémer's treatment of culture, however, Williamson's approach is somewhat incomplete, because it pays no attention to culture as a stock of common code, knowledge, and competence. This study will extend Williamson's concept of atmosphere (values) with the aspects of coding, Information and competence. Consequently atmosphere becomes congruent with the definition of culture as given above (values, information, compelence), and the two concepls can be regarded as equivalents. 


\subsubsection{Deffinition of Economies of Atmosphere}

Economies of atmosphere are defined as the joint positive impact of a distinct set of (i) values, (ii) more or less tacit knowledge (codes and information), and (iii) competences on the technical efficiency of a unit. Technical efficiency is indicated by production/transaction cost minimization or performance maximization (for giver inputs).

\subsubsection{Diseconomies of Atmosphere}

Atmosphere can be an asset and a liability. We define the harmful effects of atmosphere as diseconomies of atmosphere. Diseconomies of atmosphere may be conceived from a comparative static and a dynamic perspective. The static point of view emphasizes that the decline of costs associated with atmosphere is not infinite. Sooner or later a point is reached at which all opportunities for making further (net) cost reductions through improved atmosphere are exhausted. From a dynamic point of view, Nelson and Winter (1982: 126) have described the trade-off between routines and deliberale choice. "One cannot infer from the fact that an organization functions smoothly and successfully in a particular range of observed environments that it is a rational and 'intelligent' organism that will cope successfully with novel challenges. If anything, one should expect environmental change to make manifest the sacrifice of flexibility that is the price paid for highly effective capabilities of limited scope". If we regard atmosphere as a distinct (limited scope) competence (capability), it would not be very realistic to assume that increasing atmosphere would minimize cosis infinitely - especially not in a changing envitonment. Since corporate culture is conceived as a distinctive compelence, the firm's flexibility may be constrained by its limited range of available routines (Teece, 1984). From the dynamic point of view, diseconomies of atmophere exist when atmospheric variables lead to 'myopia" (overlooking important signals) or 'inertia' (when the culture is not timely in adapting to environmental changes). Numerous dysfunctional examples of myopia and inertia can be cited, e.g. Henry Ford"s decision to persist in the production of model $T$, and Xerox"s inability to perceive the growing threat of Japanese competition in the 1970s (Leberman and Montgomery, 1988: 49). Bankruptcy is the ultimate consequence of diseconomies of atmosphere for firms. operating in a competitive environment, while inferior performance is generally the consequence of diseconomies for organizations working in the public sector. 


\subsubsection{Definition of Diseconomies of Atmosphere}

Diseconomies of atmosphere are defined as the joint negative impact of a distinct set of walues, lacit knowledge and tacit competences on the lechnical efficiency of a unit. From a comparative slatic point of view, it is emphasized that the decline of costs associated with atmosphere is not infinite: sooner or later a point is reached at which all opportunities for making further cost reductions through improved atmosphere are exhausfed. From a dynamic perspective, diseconomies of atmosphere are the negative consequences of the inability to adapt to changing environmental conditions.

\subsubsection{The Economies of Atmosphere Framework}

Now that the salient aspects of culture and economic efficiency have been identified, we are ready to explore the questions about the nature of the relationship between culture and performance, viz:

1. Does cullure affect economic efficiency?

2. If so, why should certain aspects of culture increase or decrease economic efficiency?

3. What are the costs of providing an (in)adequate culture?

A matrix can be designed to review the full spectrum of conceivable interrelations between atmospheric dimensions and aspects of economic efficiency in a systematic mode. This matrix is defined as the economies of atmosphere framework. Exhibit 1.1. shows the full spectrum of alternatives. The matrix is not a starting point for an investigation of all conceivable alternatives. Rather it is meant as a simple framework which allows a positioning of the chapters of this book. In particular, the framework shows the limits of the theoretical and empirical analyses which follow. The theoretical chapters, 2 and 3, will mainly focus on the interrelations between dimensions of atmosphere and transaction cost minimization/performance maximization, that is, they will ignore production costs (cells 1, 4, 7, 10, 13). The empirical chapters, 6 and 7. will center on the relationship between values and performance (cells 3 and 6). Obviously, they ignore the intormation and competence aspects of atmosphere, and cost minimization. 
technical efficiency

costs (min)

performance (max)

culture production transaction performance level

\section{values}

general values

specific vallues

1

23

456

\section{codes}

common language

78

9

\section{information}

knowledge of tacts

10

11

12

\section{competences}

simple rules/routines

$13 \quad 14$

15

\subsection{Externall and Internal Economies}

The distinction between external and internal economiles has been introduced by Marshall. "We may divide the economies arising from an increase in the scale of production of any kind of goods, into two classes - firsily, those dependent on the general development of the industry; and secondly, those dependent on the resources of the individual houses of business engaged in it, on their organization and the efficiency of their managemenk. We may call the former external economies, and the latter internal economies" (Marshall, 1949, in: Schreuder, 1981: 51).

In this study, the economies of atmosphere framework will especially be used to explore the impact of culture on technical efficiency at the firm level. We will center on internal oconomies rather than on external economies of atmosphere. The firm, however, operates within an industrial and a societal context. Moreover, it can operate independently and as a member of a 
business group. In attempting to articulate the economics of atmosphere in the firm, it is important to recognize the external context in which it emerges. As Fombrun (1984: 204) has put it: "Understanding the nature of culture at various levels of analysis is cruciall if we are to properly position the concept of corporate culture as a unique and worthwhile level of analysis". Fombrun distinguishes three levels: the national, industry, and firm level. The next chapter will concentrate on the relationship between culture and economic efficiency at the nationall level "the industry levell, and the business group level. These relations will be referred to as external economies. The subsequent chapter will deal with internal economies of atmosphere, i.e., the impact of atmospheric variables on performance at the firm level. At each level of analysis, the three research questions mentioned abowe will be explored.

\subsection{Concluding Remarks}

This chapter has provided a theoretical foundation for the rest of the text. Following the positioning of the concept of 'atmosphere' in the mainstream literature, definitions have been given of the relevant dimensions. They include atmosphere, technical efficiency, production and Iransacion cosis, level of performance, and (dis)economies of atmosphere. Finally, a matrix has been designed which shows the full spectrum of conceivable relations. Note that the matrix is not meant as a starting point for the investigation of all relations (cells 1-15). Rather it shows the limits of the theoretical analyses which will follow (ignore production costs) and the empirical research which will be reported in Section $\mid\|l\|$ of this book (focus on cells 3 and 6).

The subsequent theoretical chapters extend the analysis to consider external and internal economies of atmosphere. External economies consider the competitive advantages of atmosphere at the national level, the (within- and between) industry level, and at the level of the business group. Internal economies are discussed with respect to the (within) firm level. 


\section{External Economies of Atmosphere}

\subsection{Introduction}

The main purpose of this chapter is to review the implications of economies of atmosphere for our understanding of the national level, the between industry and within industry level, and the business group level. The review is guided by the three research questions conceming costs and benefits of atmosphere.

First, at the national level the focus is on the Japanese management style as a competitive advantage. Furthermore, the literature is reviewed regarding the Confucian hypothesis which suggesils a correlation between nationall values and economic growth. Second, at the between industry level, attention will be paid to Meade's distinction belween 'unpald factors" and "creations of atmosphere". Third, comparative static analysis at the within industry for between firm) level show that atmosphere is especially important as a distinctive competence. while hilgh switching costs explain diseconomies of atmosphere. Comparative dynamic analysis at the within industry level emphasizes the importance of atmosphere in the theory of contestable markets, particularly where tacit knowledge or uncertain imitability is concerned. Fourth, when atmosphere is considered al the business group level, the emphasis is on mutuall insurance rather than on profit maximization. While the profit maximization molive results in a higher level af performance as compared to the costs, the mutual insurance motive primarily results in a higher stability of performance. Consequenily. atmosphere at the business group level is not associated with (technical) economies of atmosphere.

\subsection{Economies of Atmosphere at the national level}

Culture is a key-variable at the national level of analysis. Several authors have attributed the recent discovery for corporate culture in the management literature to the decline of U.S. competitiveness in the world economy in the 1970s (Kirkbride. 1987), and the economic success of Japan in "beating the Americans at their own game, played with different management rules' (Holstede, 1986: 253). The charge that 'Japan Inc.' was Number one 
influenced management writers who argued that the U.S. could learn from Japan (Pascale and: Athos, 1981), and by reorientation could regain its former pre-eminence (Ouchi, 1981).

Several differences in performance between Japanese and American organizations have been observed. According to Robert Kaplan (1983), Japanese manufacturers produce higher quality goods with fewer workers and lower inventory levells than comparable U.S. firms. While Ford Motor Company"s better plants turn out an average of two engines a day per employee using 777 square feet of plant space, the average Toyota plant turns out nine engines a day per employee, using only 454 square teet of plant space per engine. While Ford's plants have up to three weeks of backup inwenlory and use over 200 labor classifications, Toyota has only one hour of backup inventory and has only seven labor classifications.

\subsubsection{Japanese Management Style}

Numerous explantions have been given for the economic success of Japanese firms: protection from the market, tax advanlages, subsidies, long working days, company unions, long term contracts, etc. In addition, the high productivity of Japanese enterprises is often explained by the unique features of Japanese management style which are rooted in the traditional Japanese society (Ouchi, 1981; Itawa, 1982; Itami (with Roehl), 1987; Morita with Rheingold and Shimoruma, 1987). Key and Miller (1984) identify three factors characteristic of Japanese management: long-term planning, lifetime employment and collective responsibility. Long term planning encourages making long-range investments which are crucial for the future of the company (Morita with Rheingold and Shimoruma, 1987). Lifetime employment is consistent with extensive on-the-job training. since bilateral investments in specific skills are less likely to be lost with turnover. Moreover, lifetime employment stirmulates trust relations between firm members. When people frequently move from one company to another, the situation arises that "if you trust your colleague today, he may be your competitor tomorrow" (lbid.: 175). This is not particularly helpful for collective action. Collective responsibillty is related to company unions, firm loyalty, participative management, and to an emphasis on teamwork "coooperation, and consensual decision making (Takatera and Harimoto, 1987). The worker's (including the management's) mission is to contribute to the company"s welfare.

The Japanese management slyle, however, should be put in perspective. Econometric analyses, for example, have shown that the difference in the prevalence of long-run employment between Japan and the United States is smaller than popularly believed (Tachibaraki, 1984). Lifetime employment in Japan is only assured for the better educated male employees of the large firms. In addition. Takatera and Harimoto (1987) have pointed out that the strength of Japanese 
business is the coexistence of cooperative and competitive relations. Aoki (1984b), finally, made an economic analysis of the Japanese firm. In his introdiuction, Aoki begins with the observation that Japan's economic success has given rise to the Japanese myth. Rather than attributing the specific features of Japanese firms to national culture, he looks for an economic rationale to explain the intermal structure of the Japanese firm. Agency theory, transaction cost economics, and game theory are especially helpful in the analysis. We will deal with some of these issues in the next chapter on internal economies.

\subsubsection{The Confucian Hypothesis}

The hypothesis concerning the impact of non-Western management styles on the level of economic performance may well be generalized to other South East Asian NICs (newly industrialized countries) such as South Korea, Taiwan, Hong Kong, and Singapore. "The East Asia group has outperformed the rest of the world in GDP annual average growth rate for two decades and has dramatically outstripped other areas in export growth" (Hicks and Redding. 1983: 25). World bank data on the average annual growth rate of per capila GNP confirm the East Asian lead. Together the five 'Dragons', as these countries are sometimes called, head the list with average annual sustained-growth percentages over a 20-year period of $7.6 \%$ for Singapore, $7.2 \%$ for Taiwan, $6.6 \%$ for South Korea, $6.11 \%$ for Hong Kong, and $4.7 \%$ for Japan (Hofstede and Bond, 1988: 5).

Hicks and Redding (1983) believe that the key to the economic growth of South East Asia is national culture. In particular, they emphasize the role of the Confucian ethic. In the spirit of Weber's [1920] classic, 'The Protestantic Ethic and the Spirit of Capitalism' "which is, however, not mentioned un their paper), the authors argue that there is a relationship between ethical principles and economic growth. They quole Kahn (1979) who states that the Confuclan

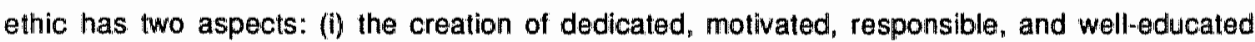
individuals, and (ii) the enhanced sense of commitment, and loyalty to institutions - facilltated by the protection against being tired. Kahn believes that both aspects of the Confucian ethic will result in all Confucian societies having at least potentially higher growth rates than other societies. Although Kahn supports his contention with arguments which explain the limpact of Confucian values on East Asian modernization and industrialization, he lails to explain the agelong coexisience of Confucian ethics and lack of ecomomic growth in South East Asia. Moreover, the Confucian hypothesis was not really tested by empirical research.

Recently, an interesting correllation between values and economic growth has been revealed. Michael Bond constructed a survey of general Chinese values which was administered to university students in 22 countries around the world. An ecological factor analysis was run on 
the means for the 40 scale items and revealed four cultural dimensions. In the search for validity, country scores on these four factors were correlated with those derived from a Western survey of work-related values (Hofstede, 1980). Three of the factors from the Chinese Value Survey correlated at high levels with three of Hofstede's four. The fourth factor, called 'Confuclan work dynamism' (CWD), was unrelated: to any of Hofstede's, but correllated .70 (p<.001) with annual economic growth from 1965 to 1984 . CWD was made up of values such as persistence and thrift on the one side (positive signs), and values concerning respect for traditions, and reciprocity on the other side (negative signs). Four of the five Dragons Hong Kong, Tawan, Japan, and South Korea - hold top positions on the CWD scale. The next highest scores are found for Brazil, India, Thailland, and Singapore. These results may be Interpreted in light of the recent speculation on the Confucian hypothesis. The data tend to support the conjecture that Confucian ethics is at least partially responsible for the East Asian economic miracle (Hofstede and Bond, 1988). They will also help focus the discussion, because only certain of the Confucian values are predictive of economic growth. The authors suggest that the values 'thrift' and 'persistence' are assets to economic growth. "The value of 'thrift" leads to savings, which means availability of capital for reinvestment" (Hofstede and Bond, 1988: 18), while "persistence suggests a general tenacity in the pursuit of whattever goals a person selects for himself or herself, including economic goals"' (lbid.). The negative importance of values such as "respect for tradition" and 'reciprocity' are also believed to facilitate economic growth in South East Asia. "The 'reciprocation of greetings, favors, and gifts" is a social activity more concerned with good manners than with performance. Too much 'respect for tradition' impedes Innovation; part of the secret of the Five Dragon's economic success is the ease with which they have accepted Western technological innovations" (lbid.).

While the authors argue that culture (as a set of dominant values) is a necessary condition for economic growth, they contend that culture alone is not sufficient for such growth to occur. Other mecessary conditions are the existence of a market and a political context that allows development. "The first condition explains why the growth of the Five Dragons started only after 1955, when for the first time in history the conditions for a truly global market were fulfilled. The supportive political context was fulfilled in all five dragons, although in quite different ways, with the role of government varying from active support to laissez-faire" (lbid.).

In general, the emphasis of the cross cultural research is on establishing validity and generalizability rather than on explanation and prediction (cf. Hofstede and Bond, 1984; Bosland, 1985; Triandis and Bontempo, et al., 1987). Since Hofstede and Bond emphasize validity and explanation in their recent contribution, their paper may be conceived as an 
innowative attempt to understand national culture as a critical variable in the explanation of economic growth.

\subsubsection{Interim Conclusions}

Regarding the three research questions, the preceding sections permit the following conclusitions to be derived:

1. Little is known about economies of atmosphere at the national level. The existing crossnational studies, however, tend to give an affirmative answer to the question: does atmosphere affect economic efficiency? The focus is on differences in general value systems and their economic consequences, especially in terms of annual growth levels. At the national level, economies of atmosphere (in the case of South East Asia) can be pointed out.

2. Why should certain aspects of atmosphere increase or decrease economic efficiency? In the case of CWD, it is argued that the value 'thrift' leading to high saving quotas (capital for new investments) can be conceived as an important asset to economic growth, while the negative importance of 'respect for tradition' facilitates economic growth, because too much respect for tradition impedes technological innovation. More generally, it is argued that certain values are stimulating or inhibitive for economic growth in particular time periods and economic conditions.

3. Concerning costs, it can only be said that the costs of an inadequate culture is less growth in particular time periods. The costs of providing an adequate culture have not been considered at the national level. This may be explained by the fact that national culture is extremely stable. Since no alternatives for having a national culture exist, considering the costs of having a national culture may not be a very fruilful enterprise. In that sense there is also no alternative for industry or organizational culture - you always have one. The only alternative is another culture. However, the smaller a unit of analysis (e.g. a firm instead of a national state). the easier a change of culture over time may be, since change is relatively casier to implement.

\subsection{Economies of Atmosphere at the industry level}

The next sections dislinguish between the between-industry level (2.3) and the within. industry (or between-firm) level (2.4). To understand the relationship belween almosphere and performance, it may be stated that atmosphere has been conceived as a 'public good' at the between-industry lewel, whereas it is mainly conceived as a 'private good' in the stralegic management literature on the compelitive behavior of firms within an industry. 


\subsubsection{Befween-lndustry Levell}

Although little research has been done on the nature of an industry culture, it is well documented that the motion picture industry has norms and values that differ markedly from those of the banking industry (Fombrum, 1984). Similarly, the textile industry is different from the automobile industry, the health industry, or the telecommunications industry - both in terms of norms, career patterns, and the individuals attracted to it. The nature of an industry culture is dependent on several dimensions, e.g. the nature of the product, the industry life cycle stage, the nature of the technology, the market structure, the degree of governmental protection, and the legisilative structure. Few economists have dealt with the relationship bettween atmosphere and performance at the industry level. One of the most influential papers (Meade, 1952) has focused on atmosphere as a public good.

\subsubsection{Unpald Factors and Creations of Atmosphere}

In 1952 Meade published a paper called 'External Economies and Diseconomies in a Competitive Situation'. It has become an important contribution to the theory of external consumption effects. Because this theory is extensively covered in the literature (Schreuder, 1981), it will be discuissed only briefly here. The concept of externalities was introduced by Marshall in 1910. A externality or external economy is a favorable (consumption) effect on one or more industries or firms that comes from the action of a different industry or firm. An external economy shifts the cost or utility curve of each industry or firm it helps, and such an externally caused shift is distinguished from any internal movement along the affected indusiry or firm's own cost curve. An external diseconomy is defined in the same way, except that it reffers to the external harm that is done to others. Smoke nuisance and water pollution are familiar examples of such external diseconomies (Samuelson, 1980: 449). It is frequently accepted among economists that in the production sphere these (technological) externalities result from services (and disservices) rendered without compensation (free) by one producer to another market participant, and that these externalities are a reason for the failure of perfect competition to lead to an optimum situation (Nijkamp, 1977: 43). External (dis)economies shift the cost or utility curve of each individual they help or harm. Moreover, whenever there are externalities, a strong case can be made for supplanting complete individualism by some collective action (Samuelson, 1980: 450). Externalities are an important concept in economics, especially in the theory of public finance, for their "general role in connection with free pricing to be nonoptimal "thereby creating a prima facie case for zoning. government controls, effluent taxes and penalties, and planning" (lbid.). 
Meade contributed to the theory of externalities with his distinction between two types of technollogical externalities: (i) unpaid factors (of production) and (iil) creations of atmosphere. An example of unpaid factors is given in the story about the bec-master and the corn-grower. "...if all of us in a neighborhood keep bees, I may find that I gain more wandering bees from your nearby acres when total $Q$ of the honey industry rises. On the other hand, when total honey $Q$ is small, $I$ find that some of my bees wander uselessly off to neighboring cornland and my neighboring corn-grower has few bees that might in return wander back to me" (Samuelson, 1984: 449). Since the utility functions of the honey-master and the corngrower are interdependent, "constant returns to scale" can only be expected for the society as a whole (all industries) - not for the single industries.

Meade gives the following example of a "creation of atmosphere" (cf. Schreuder, 1981: 70): "If due to forestry the climate in a region improves, all farmers will take advantage of it". Thus, given perfect competition there are constant returns to scale for all single industries, while there are 'increasing returns to scale' for society as a whole (lbid.). As Meade has put it: "Both a factor of production and an atmosphere are conditions which affect the outpul of a certain industry. But the atmosphere is a fixed condition of production which remains unchanged for all producers in the industry in question without anyone ellse doing something about it, however large or small - within limits - the scale of operations of the industry is. On the other hand, the factor of production is an aid to production which is fixed in amount, and which is therefore available on a smaller scale to each producer in the industry if the number of producers increases, unless someane does something to increase the tolal supply of the factor" (Meade, in: Schreuder, ibid.). Consequently, unpaid factors (of production) can be conceived as "private goods' which are sources of conflicts of interests. Creations of atmosphere have the character of a 'public good' which is (by definition) characterized by jointness of supply and consumption, and non-jointness of production (Samuelson, 1984).

\subsubsection{Atmosphere as a Public Good}

Apparently, the above-mentioned forestry example refers to physical atmosphere (climate)not to culture or atmosphere as earlier defined. Nevertheless, evidence suggests that in some cases the non-physical atmosphere may - within limits " have a comparable impact on industry performance.

An example of culture as a public gaod is the Swiss bank reputation reflecting the current professional values within that industry. Within the Swiss bank industry, the reputation is a public good, because it ffavors all Swiss banks. If some Swiss bankers were accused of helping large drug dealers to launder illicitly earned money, this would certainly affect the Swiss bank 
reputation in a negative way. Consequently, all Swiss banks would be affected - including the 'innocent' banks. There is jointness of consumption of the spoiled reputation. Thus, decreasing returns would be expected for the industry as a whole.

Culture is also a public good in industries with an elaborated internal labor market when they are contrasted with those that buy human resources at the spot market. Since the internall labor market facilitates employees' firm loyalty, productivity losses and turnover costs for the firm are reduced. An example of a creation of intangible atmosphere is the knowledge transfer caused by the mobility of workers in the microelectronics industry to the telecommunicalions industry. The costs of their specific skills (on-the-job training) are borne by the former industry while the benefits are also consumed by the latter industry.

Obviously, atmosphere as a public good will not be particularly helpful for single firms in their compettion with rivals within their industry. Consequently. the strategic management literature, the focus of discussion in section 2.4. has emphasized atmosphere as a private good.

\subsubsection{Interim Conclusions}

1. First of all, the literature suggests that atmosphere may affect economic efficiency at the industry level. However, diseconomies of atmosphere may also exist. Little is known about the net effect.

2. Why should certain aspects of atmosphere increase or decrease economic efficiency? Attention has been paid to "creations of atmosphere' which are contrasted to "umpaid factors of production". Creations of (physical and intangible) atmosphere are public goods leading to constant returns to scale for the single industries, and increasing returns to scale for the society as a whole. Unpaid factors are private goods leading to constant returns to scale for the sociely as a whole (i.e. the two industries), and to increasing returns to scale at the level of single industries. Insofar as the intangible atmosphere (i.e. reputation) can be conceived as a public good or bad, general rather than specific values (or distincive competences) are stressed.

3. There is jointness of consumption, and non-jointness of production concerning creations of atmosphere. Consequently, costs are not necessarily born by the industry consuming the public good. 


\subsection{Whin-lndustry Level: Comparatwe Static Analysis}

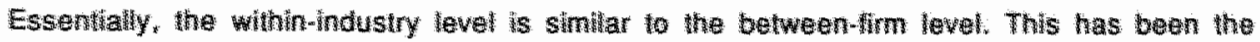
source of contusion cortaned in the so-called (handbook) theory of the fim' (such as: Kowsoyianis, 1979 which is a microeconomic heory of the competive dyamios with the hdisty rather than a heory on Marstalls intemal sconomies. The analysis of economies of amosphere at the whin-industry or rather the beween fim lever, bouses on the strategio Wherature about distinctive compefence. Swithing costs and the Hahure to knore sunk costs dernonsulate the existence of diseconomies of atmosphere.

\subsubsection{Dismetve Competence}

Obulousy, the collective dimension of amosphere is stressed when amosphere is referrad to as a "public good. However, according to the delinition above, atmosphere is collective anc distinctive. When the latter dimension is emphasized, atmosphere can be considered as "private good. In contrast to welare economics. the strategic managrament herature has aways emphasized he distinctive dimension of amosphere beause of the compethive advantages it offers for indwidual whs (Poter, 1980).

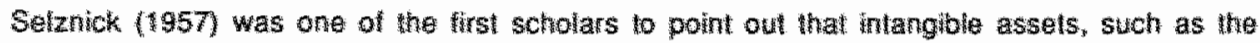
ldenty or a company and a distincwe techological or manageral know-how, natter. Selznick

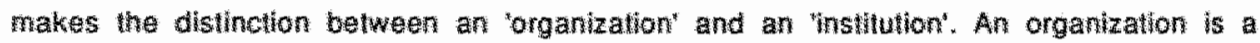
technical instrument tor mobizzing human onergies and dirocting them toward given ams. white an instituton is an organic product of social needs and pressures. "As an organization acquires a selt, a distnctive idently, becomes an institution. This involves the taking on of values, ways of acting and believing that are deemed mportant for their own sake. From then

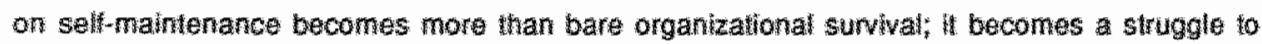
preserve the uniqueness of the group in the face of problems and altered circumstances" (Selznick 1957: 21). Since "organizations become institutions as they are infused with values" (Ibid.: 40), the emphasis is on the embodiment of distinctive (i.e. specific) values in an organizational struclure through the ellaboration of committmenis. The emergence of organizational identity refiects an irreversible eliement of choice. The acceptance by the management of irreversible commitments - by which it readily limits its own freedom - is the process by which the identity of an organization is set. 


\subsubsection{Fallure to Ignore Sunk Costs}

Apparently, having a distinctive identily or reputation is an asset because it distinguishes the firm and its product from other firms within the industry. The firm has a 'face' in the anonymous market of numerous buyers and sellers, so that it can profile itself. Product differentiation strategies are dependent on the firm's ability to develop the distinctive skills required for the development of a product that is recognized as distinctive in the market place. However, there are also costs associated with irreversible commitments and skills. In the development of a narrow repertoire of distinctive skills, the film sacrifices flexibility. Selznick (lbid: 54) gives the following example:

"The first boats made by Gar Wood were high quality craft, made of the finest materialls by master boat builders. Later, the company decided to mass-produce a comparatively low-cost speed boat for wide distribution. It developed that the entire organization found itself incapable to cope with the effort to shift commitments. Workmen and shop supervisors allike continued to be preoccupied wilh high cost quality craftsmanship. Members of the seiling staff, too, could not shift emphasis from 'snob appeal' to price appeal. The quality commitment was so strong that an entirely new division - operating in a separate plant hundred miles away and therefore recruiting from a different labor market - had to be created to do the job successfully."

The example shows that the existence of a strong quality orientation impedes the attempts of the management to implement diversification within the plant. The attempts to reorganize the existing competence failed. The company structure became multi-divisional to avoid diseconomies of atmosphere. Essentially, the development of distinctive competence or 'asset dedication" - so that once committed, investment decisions involve some degree of irreversibility - reflects the sunk cost principle. "Costs are sunk when they cannot be eliminated even by ending production $n_{\text {. }}$. . costs that cannot be recovered by exit from the market" (Yao, 1988: 62). The existence of sunk costs (irreversible investments), however, does not explain the relative immobility of the firm. Teece (1984: 106) has argued that a firm's flexibility is constrained not only by irreversible investmenls, but also by its limited range of avallable routines. "lf a firm has only a limited range of repertoires, its range of strateglic choices is correspondingly limited." Since the range is limited, strategy will emphasize the exploitation of those distinctive assets which are socially efficient. That is, the assels must result in products which provide a sufficient increment in value over pre-existing substitute products to justify the costs of the irreversible invesitment (Rumelt, 1987: 144).

Thus, the firm may be 'locked' into a specific sel of irreversible, fixed assets inibibiting the ability of the firm to respond to environmental changes or compelitive threats (incumbent 
inertia). In their discussion of strategic first-mover advantages, Leberman and Montgomery (1988) have focused attention on 'incumbent inertia'. Even though incumbent inertla may lead to organizational decline, it is often a rational profit-maximizing response. For example, it can be rationalized that most U.S. Steel producers continued investing in open-hearth furnace technology even after it had become clear that basic oxygen furnaces were superior. As the authors put it: "A firm with heavy sunk costs in fixed plant or marketing channels that ultimately prove sub-optimal may find it rational to "harvest" these invesiments rather than attempt to transform itself radically" (Lieberman and Montgomery, 1988: 48). Consequently, the appropriate choice between adlaptation and harvesting from initial investments depends on how costly it is to convert the firm's existing assets to alternative uses. Obviously, the existence of high switching costs will lock the firm in the existing atmosphere. In other words. the switching (reinvestment) costs may effectively prevent the mobility of the firm to a more profitable atmosphere.

Economic theory implies that only incremental costs and benefits should affect decisions. This is the sunk cost fallacy: sunk costs are irrelevant for current decisions, since they are history. But do (non-economist) organizational members ignore sunk cost in their everyday decisions? Using prospect theory, Kahneman and Tversky (1974) have found empirical evidence for the sunk cost effect, i.e. that paying for the right to use a good or service will increase the rate at which the good will be utilized, ceteris paribus. For example, betting on longshots increases during the course of a racing day implying that betters have not adapted to their losses. Similar behavior is well known to anyone who plays poker. Finally, there are many examples of the government failing to ignore sunk costs. Thaler (1980) reports that ${ }_{n}$ despite hazards which might emerge during the course of construction, there is hardly any example of a dam whose construction was halted or interrupted temporarily once the physical construction processes actually began. In the same spirit, firms may fail to ignore sunk cosis with regard to atmosphere. In the cognitive accounting system of a firm, the existence of sunk costs may play a critical role in the decision not to switch to an alternative atmosphere, because it has taken ages and has cost fortunes to create the present atmosphere. The failure to ignore surk costs may indicate that the sunk (investment) costs have become psychological switching (reinvestment) costs (personal communication $M$. Vendrik).

\subsubsection{Interim Conclusions}

What can be learned from strategic management literature is that atmosphere (including distinctive values and competences) is a two-edged sword. On the one hand, a distinctive atmosphere - especially a distinctive competence - may be conceived as a "competitive advantage" (Porter, 1980) within the industry. On the other hand, a distinctive atmosphere is 
an Ireversible investment which locks the firm into a particular course of action. Consequently, the firm may be unable to reorganize. The former is a case of economies of atmosphere' showing that aimosphere has benefits in terms of profit-maximization or castminimization, whereas the latter is a (dynamic) case of 'diseconomies of atmosphere' demonstrating that switching costs are associated with the supply of an appropriate aimosphere.

\subsection{Within-Industry Level: Comparative Dynamic Analysis}

The competition between firms within an industry can be analyzed from both a comparative static and a comparative dynamic point of view. Whille the static analysis is concerned with cross-section interfirm differences in efficiency, the theory of uncertain imitabillty is an attempt to explain sustaining supra-normal efficiency levels. The dynamic perspective is important. After all, the firms which are successful today can be bankrupt tomorrow. The tacit dimension of atmosphere appears to be especially relevant at the between-firm level, because the fact that the distinctive competence is uncodified effectively prevents unwanted spillovers. In contrast to the static analysis, first-mover advantages become relevant too in the dynamic multi-stage perspective. Of course, the definition of dynamic analysis presented here can also be interpreted as 'quasi-static' or as the 'analysis of moving static equilibria', but this does not really affect the conclusions which may be derived from the next section.

\subsubsection{Contestable Markets and the Theory of Uncertain Imitability}

Whille the preceding section has emphasized distinctiveness in value orientations and competences, this section will focus on another dimension in our definition af atmosphere, viz. the tacil dimension of atmosphere.

Recently "Barney (1986) related corporate cullure to the origin and persistence of interfirm differences in financial performance. From a dynamic perspective, Barney has argued that it is not enough for a corporate culture to be valuable (to add economic value) and rare (uncommon, distinctive). In order to be the source of sustained competitive advantage, the culture has also to be imperfectly imitable.

In microeconomics, the financial performance of firms is divided in three categories: normal performance, above normal performance, and below normal performance. Normal economic performance is that rate of return on a firm's investment just enough to keep a firm's assets engaged in their currenl activities (survival). Technically, a normal return is the expected rate of return in perfectly competitive markets in the long run. Superior financial 
performance is a rate of return greater than normal return and indicates that the firm is prospering (excellent company). Firms that obtain below normal financial performance for a relatively long period of time are not expected to survive (bankiruptcy constraint). Superior financial performance can be either temporary or sustained. The neoclassical argument runs as follows "Under conditions of free entry, where no one firm has any particular advantages of Hocation, skill , or resources specialized to this industry, one can expect in the long run that such free entry of would-be competitors will compete away any excess profits earned by existing firms in the industry" (Samuelson, 1980: 451).

Obviously, distinctive values, information sets, and distinctive competences are intangible firm assets which may initially encourage supranormal performance. Especially when the firm is timely, first-mover advantages can be exploited and monopoly rents can be earned (Lieberman and Montgomery, 1988). In the long term, however, these advantages are rewarded not by supranormal profits but by survival. Other firms, enviously observing their rival's success, will seek to abtain the same level of performance by duplicating whatever they perceive as success factors. If they succeed, imitation increases the competition facing the initially successful firm, reduces margins, and decreases the level of financial performance. Increased competition through imitation of values and competences will continue until all firms obtain approximately normal economic returns. Thus, given certain imitability of firm skills the market would be 'perfectly contestable' (Baumol, Panzar, and Willig, 1982), 1.e. accessible to potential entrants with essentially tree entry and costless exit. Consequently, sustainable above normal performance would not exist.

Nevertheless, we do observe excellent companies that make excess rents over a long time horizon. Assuming that these observations are not just statistical artifacts, Lippman and Rumelt (1982) have proposed the theory of imperfect imitability to account for such outcomes. The authors assume that there is a basic ambiguity concerning the causal connections between firm's actions and results. As a consequence, the factors responsible for performance differentials will resist precise identification. Under such conditions the uncertainty altaching to entry and imitative attempts persists, and complete homogeneity (leading to competitive pricing) is unattainable. Lippman and Rumelt have suggested that high rents, ceteris paribus, may well signal the presence of very successfull competitors who are difficult to imilate, and thereby impede (costly) entry attempts. The firm earning entrepreneurial rent looks much like the excellent company of the strategy literature. It exhibits a high profit rate and substantial discretion in the allocation of its profit stream. Moreover, at its core rest unique specilalized resources that cannot freely be expanded (Rumelt, 1987: 142-143). Since, management is far from an exact science, the ambiguily surrounding the linkage between action and performance in large firms virtually guarantees the existence of substantial uncertain 
imitability. Demsetz has argued that these inputs are undervalued because competitors fail to recognize them: "It is not easy to ascertain just why GM and IBM pertorm better than their competitors. The complexity of these firms defies easy analysis, so that the inputs responsible for their success may be undervalued by the market for some time" (in: Lippman and Rumelt, 1982: 420).

The issue, however, is more than one of information sharing, since "it may never be possible to produce a finite unambiguous list of the factors of production responsibile for the success of such firms" (lbid.). Moreover, frequent transactions between people give rise to unique transaction-specific skills that are tacit or "unspecifiable'. Here we find dedicated factors of production that are immobile not only because they are unique (distinctive), but also because their replication is a difficult and uncertain endeavor. Uncertainty in the identification and imitation of production functions explains the persistence of interfirm differences in efficiency. This uncertain imitability is a direct consequence of the tacit dimension of intangible firm assets.

\subsubsection{Economies of Atmosphere as a Barrier to Imitation}

Due to the tacit dimension, a valuable and distinctive atmosphere (distinctive values, competences) inhibits a contestable market which is subject of "hit and run" entry. The concept of entry barriers has been developed within the structure-conduct-performance paradigm in industrial economics. The most notable early developers of the 'structuralist" paradigm were Edward Mason at Harvard during the 1930s and Joe Bain at Berkeley during the 1950s. The essence of strategic management in the structuralist framework is to shield the firm, to the maximum extent legally possible, from competitive forces (Teece, 1984). The principall focus was not one of how to select antilust policies to increase consumer welfare by enhancing competition, but rather how to maximize rents (and if necessary, reduce consumer welfare) by restricting competition. Consequently, "isolating mechanisms' such as patents, trade secrets and tacit knowledge (Rumelt, 1987) rather than regulatory policies were stressed. The principal weapon in the business war is the erection of various forms of entry barriers.

Recently. Porter (1980) listed seven different barriers to entry at the between-industry level: economies of scale, product differentiation, capital requirements, switching costs, access to distribution channels, govermment policy, and a grouping which may be referred to as 'barriers to imitation' (Yao, 1988). Although not included in the list, economies of atmosphere can be classified as an effective barrier to imitation as well, since the values and lacit competences included in the firm's atmosphere resist imitation and prevent spillover effects. Even if the success factor were recognized by the other firm, the routine "may involve so much 
idiosyncratic and difficutt-to-unravel tacit knowledge that even if the organization thed to replicate itself, success would be highly problematic, and imitation from a distance would be completely impossible" (Teece, 1984: 107). As a result of imperfect imitability, atmosphere can function as an 'entry barrier (when the focus is on entry to an industry), and as a 'mobility bartier' (when the locus is on entry to another strategic group within the industry).

\subsubsection{Atmosphere as a Durable First-Mover Advantage}

First-mover advantages arise endogenously within a multi-stage process. Lieberman and Montgomery (1988: 41) define first-mover advantages in terms of the ability of firms to earn positive economic rents, i.e. rents in excess of the cost of capital. "In the first stage some asymmetry is generated, enabling one particular firm to gain a head stant over rivals. This first-mover opportunity may occur because the firm possesses some unique resources or foresight, or simply because of luck. Once this mechanism is generated a variety of mechanisms may enable the firm to exploit its position; these mechanisms enthance the magnitude or durability of first-mover rents".

It will be apparent that the early entrant firm can only exploil cost advantages if its distinctive competence and the associated learning curve (unit production costs falling with cumulative output) can be kept proprietary. Interfirm-diffusion of competence diminishes first-mover advantages. Moreover, there is a strong incentive to imitate existing innovations, since imitation costs are lower than innovation costs in most industries. Mansfield (1985) found that process technology leaks more stowly than product technology. Lieberman and Montgomery have argued that organizational innovations are very slow to diffuse, and hence may convey a more durable first-mover advantage than product or process innovation. "Chandler (1977) describes managerial innovations that enabled producers to exploit newly available scale economies in manufacturing and distribution in the late nineteenth century. Many of these firms - e.g. American Tobacco, Campbell Soup, Quaker Oals, Procter and Gamble - still retain dominant positions in their industries" (Lieberman and Montgomery, 1988: 44) "If an innovative almosphere is the unique resource contributing to the first-mover advantage, it may well be conceived as a durable one, because the tacit nature of atmosphere effectively impedes the interfirm spillovers which destroy the rents on existing innovations. 


\subsubsection{Markel Imperfections for Human Capital}

What does require attention is the need for the market for (collective) human capital to be imperfect, before economies of atmosphere can become a mobility barrier. If this market were perfectly efficient, uncertain imitable skills and routines could be purchased in the same way as any other factor of production. Head hunters and corporate acquisitions provide the mechanisms by which the market for experience may be said to operate. This market is clearly active, and reasonably effective at disseminating firm specific knowledge.. In the case of collective tacit knowledge, however, the market for experience breaks down. Moreover, in the case of 'organizational capilal' (Prescolt and Visscher, 1980), the knowledge possessed by individual employees may not in itself prove very useful, since individuals may only reach their full potential as part of a specific team. Moreover, they may only be productive if employed in conjunction with equipment which has been developed within their firm which would, perhaps, not be readly reproducible by competitors. Hall and Howell (1985) have argued that this nom-iransferability becomes more subtle where learning by doing is onlly rellevant within organizations reflecting a particular ethos. As a result, a Dutch company which thires a Japanese manager, in the hope of reproducing Japanese performance, is nol expected to be very successful.

\subsubsection{Interim Conclusions}

With regard to the research questions, the preceding seclions permit the following conclusions to be derived on the industry level.

1. First of all, the literature shows that atmosphere may affect economic efficiency. However, there are limits to the cost advantages assaciated with atmosphere. Moreover, diseconomies of atmosphere may also exisl - especially when atmosphere is conceived from a dynamic point of view.

2. Why should certain aspects of culture increase or decrease economic efficiency? The answer to this question varies. At the between-industry levell, attention has been paid to "creations of almosphere' which are contrasted with 'unpaid factors of production'. Whille creations of (physical and intangible) atmosphere are public goods leading to increasing returns to scale for the society as a whole, unpaid lactors are private goods leading to increasing returns to scale for the single industries. In so far as the intangible atmosphere (i.e. reputation) can be conceived as a public good, general rather than specific values (or distinctive competences) are stressed. 
From a within-industry or between firm perspective, the essential aspect of atmosphere is its distinctiweness. If the culture is distinclive (rare) and valuable from an economic point of view, it may explain interfirm differences in efficiency. The static analysis, however, cannot explain the existence of sustainable above normal rents. From a comparative dynamic perspective, the theory of uncertain ilmitability shows how atmosphere as an entry barrier impedes rapid imitation to reduce the entrepreneurial rentl to normal levels, and prevents the development of a contestable market with free entry for potential hit and run competitors. Thus, atmosphere functions as a quasi-property right where appropriability is low. What does require attention, however, is the condition that the market for erganizational capital is imperfect before economies of atmosphere can become an entry or mobility barrier.

3. Much attention has been paid to the costs of supplying an appropriate atmosphere. The existence of sunk costs and especially switching costs explains why atmosphere (irreversible commitment) affects the flexibility of the firm, especially when valuable irreversible commitments are concerned. While the exploitation of economies of atmosphere may lead to prosperity, diseconomies of atmosphere facilitate inertia and organizational decline. The cost of supplying atmosphere is the sacrifice of organizalional flexibility. In the terminology of Nelson and Winter (1982), organizational routines are a suppression of deliberate choice. When risk is concerned (probability distribution known), routines may be a rational procedure for decision making. However, in the case of uncertainty (probability distribution unknown), routines may have counterproductive consequences.

\subsection{Economles of Atmosphere at the Business Group Level}

The preceding sections have dealt with the industry or markel level (externall economies). The concern with external versus internal economies does not onlly reflect Marshall's dichotomy. Since Coase's (1937) famous observation that markets and firms are alternative organizational mechanisms for supporting transactions, the literature has been mainly concerned with two institutions: the market mechanism (competitive pricing) and the firm's internal organization. The comparative efficiency of markets and hierarchies has been analyzed by Oliver Williamson (1975). Resource allocation in a market economy is implemented through the market by the price system, and within the firm under the direction of the manager. The division of labor between these wo modes is determined by their comparative efficiency as alternative instruments for completing a related sell of transactions.

Recently, Goto (1982: 61) argued that there is an alternative between market and hierarchy, i.e. the interfirm relationship called the 'business group' in the context of a market economy. Japan provides a typical example of an economy within which business groups play an 
important role. These ("Zaibatsu" or 'Keiretsu") groups are extremely relevant when economies of atmosphere are considered, because "their coordination is secured by a set of tacit, informal rules that emerge through a long history of exchange of intormation and recognition of interdependence, substantiated by financial linkages and interlocking direciorales" (lbid.). The member firms are linked together through shared competence and shared values. Their collectivism is effectively reinforced by institutional and financial thes such as crossstockholdings, loans, CEO meetings, and interlocking directorships.

There are various reasons why firms decide to form (or join) a business group:

(i) risk sharing. In an industry where the level of technology is high, firms may have the incentive to establish a jolnt subsidiary with other firms to spread the risks associated with the new venture.

(ii) capitalizing on new technology. The R\&D unit of a food industry may discover chemicals that can be developed as a medicine. The firm has three alternatives: (i) manufacturing the new product, (ii) selling the information, (iii) cooperating with another firm. The firm will not be inclined to sell the informalion, because "the reward for an innovation captured through the selling of technology alone is significantly smaller than that realized through the selling of the product embodying this innovation" (Von Hippel, quoted in: Goto, 1982: 67). Lacking disiribution networks and an established brand name, the foad processing firm will tend to choose to set up a joint subsidiary with a pharmaceutical firm to capitalize on this new discovery, rather than attempt to develop it into a new product and manufacture and sell it alone.

(iii) information sharing. The market mechanism may not be an effective device to trade information because of the characteristics of information as a public good and the related difficulty of preventing diffusion or excluding nonbuyers from its use. Under these conditions, information costs may be decreased by sharing the information with certain other firms.

(iv) Iransaction of intermediate goods. In the intermediate goods market "buyers" demands tend to vary over detalled speciffcations. The number of suppliers and buyers of a specific product is exceedingly small so that bargaining costs may be high. Uncertainty and transaction costs associated with transactions through the market can be reduced by integrating vertically, and thus internalizing the intermediate goods market. However, the coordination of various vertical stages of production is difficult and inhibitively costly. Moreover, firms may find it difficult to raise the capital necessary to integrate vertically. Under these circumstances, market and hierarchy are no efficient alternatives. Firms can secure intermediate goods at lower cost and 
with less uncertainty by forming groups rather than by procuring them through the market or integrating vertically.

(v) efficient capital allocation. Its external relation to the firm places the capital market at a serious information disadvantage. Although the general office of the multidivisional firm organization has superior properties in this respect, the M-form has its own drawbacks as a means to allocate capital, because it is able to assign cash flows to only a fairly narrow range of alternatives at any point in time (Williamson, 1975). The business group may provide an efficient alternative. By joining the group and investing in member firms of the same groups, firms can secure more broad investment opportunities than multidivisional firms that allocate funds only to their own divisions.

Obviously, the members of a business group have a competitive advantage in comparison with the firms "outside" at the expense of foregoing the opportunities of competitive behavior towards member firms. The firm is extremely vulnerable to free riding behavior, and opportunism of other members in his group. Since moral hazard will effectively destroy the rents associated with group membership, the business group construction can only be exploited in an atmosphere of mutual trust. Thus, the sharing of a general value system can be conceived as a condition for the exploilation of group membership.

\subsubsection{Transaction Cost-Minimization versus Mutual Insurance}

Consistent with the transaction cost approach, Goto (1982:61) has attributed the formation of Jlapanese business groups to a desire for cost-minimization."From the standpoint of the firm, by joining or forming a group, it can economize on the transaction cosis that it would have incurred if the transaction has been done through the market, and at the same time, it can avoid the scale diseconomies or control loss which would have occurred if it had expanded internally and performed that transaction within the firm. If the net benefit of forming or joining a group exceeds that of implementing transactions within the firm or through the market, the firm has the incentive to form or to join a group" (lbid.). Consequently, the business group is concelved as an institutional device designed to cope with market failure and organizational inelficiencies.

Although Goto's hypothesis is plausible, empirical research has demonstrated that firms affiliated with (intermarket) business groups are not per se profit-maximizers. As well as having a lower return on investment (ROI) rate, member firms tend to show a somewhat slower growth rate than independent firms. However, there is clear evidence that the variability of performance (both the rate of profits and the growth rate) of the member firms is smaller than that of the independent firms. Reviewing the research on business groups. 
Nakatani (1984) atributes this tendency to the risk attitude of the management which sceks to stabilize corporate performance at the expense of returns on investment. One of the essential functions of the capital market is to allocate risks efficiently among different investors in the economy. But if the capital market is imperfect due to the separation of management and ownership, management is in a position lo worry about the business risks. In contrast to Goto (1982). Nagatani (1984) conceives firm grouping as a solution to the problem of the nonexistence of insurance markets for entrepreneurial risks.

Since (intermarket) business groups can be compared with owing a full diversified portfollio of business, Nagalani (1984) emphasizes the risk sharing in business groups. The llogic of risk sharing is straightforward: when some firms are having a bad year, others will be having a good year; thus, the overall sales and profits of the business groups will be relatively stable over time if member firms help one another in times of serious business hardship. When a financial difficulty arises, the member bank usually renders assistance, sometimes at a far greater cosl and risk thian normal business reciprocity requires. Likewise, in a buyer-seller relationship, the buyer will accept a somewhat higher price if the seller is in the same group and is facing business difficulties. In the reverse case, when the buyer is in difficulty, the seller is willing to sell at a below market price. This sort of business reciprocity shelters the group from the competitive market forces to which independent firms are exposed. The recipracity may be taken to imply an implicit 'mutual insurance scheme' in which member firms are insurers and insured al the same time.

Financial research in portiolio theory suggests that the expected rate of return of business groups - like fully diversified portiolio of firms - is a market rate of return. On the average, business groups can expect to perform no better than a well-managed, fully diversified porltolio of slocks (Barney and Ouchi, 1986). While economies of atmosphere are captured by firms with a valuable, distinctive competence and sustained by uncertain imitability, empirical research suggests that the membership of (intermarket) business groups affect the stability rather than the level of the performance, l.e. the net effect of business group membership is not cost-mimimization or profit-maximization, but a redistribution of income between member firms. From this perspective, it might be speculated that pecuniary rather than technical economies of almosphere dominate with respect to the business group. Assuming that membership of a business group reduces the risks of bankruptcy. it may be argued that uncertainty avoidance and a wider spread of risks rather than performance stabilization as a goal in itsell are the main molives for the members. Thus, by reducing the risk of bankruptcy, membership may equally affect the average performance level in the long run. 


\subsubsection{Interim Conclusions}

Regarding the three research questions given in chapter 1, the preceding sections permit the following conclusions to be derived:

1. Although the theory suggests that transaction costs are minimized by forming or foining a business group, empirical research has suggested that business group membership reduces the variability in performance rather than the level of performance. Member firms even tend to show lower return on investments and slower growth rates than independent firms. Comparing performance levels, the current empirical answer to the question whether the atmosphere of business groups affects the technical efficiency of member firms is negalive. Since there is a positive effect of membership of a business group, l.e. performance stability caused by redistribution of income between member firms, it might be speculated that (at least in the short term) pecuniary rather than technical economies of atmosphere dominate with respect 10 the businiess group.

2. Research question two (why should certain aspects of culture increase or decrease economic efficiency?) is only applicable when the answer on the previous question is affirmative.

3. What are the costs of supplying an appropriate atmosphere in the business group? Obviously, an investment has to be made to learn the tacit rules of the group. Since the information sharing with other group members makes each of them extremely vulnerable lowards moral hazard, an initial investment in trust is a necessary condition to benefit from business group membership advantages.

\subsection{Concluding Remarks}

This chapter has extended the analiysis of the previous chapter by considering external economies of atmosphere. Research questions with regard to costs and benefits of atmosphere have been explored at the national level, the between industry level, the within industry level, and the business group level. The specific items of the interim conclusions will not be repeated here. Rather some general remarks will be made regarding the research questions. This chapter permits the following conclusions to be derived from the preceding sections.

1. Although atmosphere is not a factor of production like capital and labor, it may be conceived as a productive factor because it affects economic efficiency. Economies and diseconomies of atmosphere appear to exist at the national and industry level. At the business group level, pecuniary rather than technical (real) economies of atmosphere seem to be captured.

2. The economic rationale for economies of atmosphere is dependent of the level of aggregation. Alt the national level, general values like loyalty and thriftiness feature prominently. At the 
(intra-)industry level, distinctive competences play a major role. The values of reciprocity and mutual risk sharing are important at the business group level.

3. Generally, the only alternative for atmosphere is another atmosphere. It is apparent that switching costs are associated with the creation of an alternative almosphere. When atmosphere is a public good, a cost is made by the industry creating atmosphere that other industries do not have to bear themselves. The cosis associated with atmosphere - in therms of sacrificing innovation and flexibility - may be so high that the whole industry will be driven out of business. Economies of atmosphere as a private good may be regarded as a durable competitive advantage, especially in exploiting first-mover advantages, and to prevent entry of hit and run competitors by the barrier of imperfect imitability. 


\section{3}

\section{Internal Economies of At mosphere}

"One of the characteristics of a successful economic system is that the relations of trust and confidence between principal and agent are sufficiently strong so that the agent will not cheat ewen though it may be "rational economic behavior" to do so" (Arrow).

\subsection{Introduction}

This chapter deals with economies of atmosphere at the organizational level. Three vlews of the firm are discussed: the microeconomic theory of the firm, the organizational economics approach to the firm, and the information processing approach of the firm.

(i) The microeconomic theory of the firm emphasizes tangible rather than intangible resources. It is, moreover, a theory of the market rather than a theory of the firm. Consequently, an intangible organizational resource such as atmosphere is not really compatible with the theory of the firm.

(ii) Three centrall paradigms of organizational economics will be discussed here: team theory (TT), agency theory (AT), and transaction cost economics (TCE). This chapter will particularly focus on the latter paradigm, since only TCE explicitly discusses antecedents and consequences of atmosphere. Team theory centers on the exploitation of a mutual gain by interpersonal cooperation. However, the mere technical possibility of a mutual gain does not guarantee that the cooperation needed to secure that mutual gain will aclually be forthcoming. The temptation to sthirk may inhibit cooperalion. More typical is the game in which each player would prefer to be cooperative, if he knew that the other party was going to cooperate (also without being forced to). An atmosphere where team members have trust in the consummate cooperation of the other party may be conceived as a possible solution to the so-called Assurance Game in the team organization.

Within the contractual perspective (AT and TCE) atmosphere may be conceived as a solution to a managerial problem - the difficulty of imagining all contingencies and specifying them in employment contracts. Particularly, atmosphere may be conceived as a means to complete incomplete contracts by providing guiding focal principles. There is, however, an optimal span of 
atmosphere as implict contracting. Although both AT and TCE deal with the complex equilibrium of contractual relattons within the firm, only the latter discusses the antecedents and consequences of atmosphere in an explicit manner. The role of atmosphere is analyzed in the peer group and the internal labor market. The internal labor market is a govemance structure where an $e x$ ante large number condition is transformed into an ex post small number bidding situation as a consequence of thuman asset specificity. Specific skills have to be embedded in a protective governance structure lest productive values be sacrificed if the employment relationship is unwittingly severed. Where asset specificity is great, employee and employer are effectivelly "locked into the transaction, and special efforts will be made to design an atmosphere of fairness, i.e. an exchange relationship that has good continuity properties. Incomplete contracting offers the opportunity to economize on bounded rationality.

(iii) While the team approach focuses on values and information, the information processing approach deals with atmosphere as a common stock of knowledge, i.e. common codes, knowledge of specific facts, and behavioral rules. It shows why an efficiency function can be attribuled to atmosphere in terms of an increase in cost efficiency of the firm's responses.

In general, the criterion for organizing economic transactions is assumed to be cost minimization. The theoretical part of this study attempts to show that there is an economic rationale for the attribution of a transaction cost minimization function to atmosphere. Since the mainstream literature on atmosphere (TCE) focuses on transaction costs (in the production process), the review presenled here has neglected production costs. The economic problem, however, is not to save on transaction costs, but to save on the sum of transaction and production cosis. Consequently, production costs should be considered as well. Neoclassical economics has emphasized scale economies as a mechanism for decreasing production costs. Recently, it has been recognized that under certain conditions economies of scope may contribute to both production and transaction cost minimization. Economies of scope, scale, and atmosphere are complements rather than subsititutes. The final sections of this chapter define the alternative sources of efficiency in order to enable a systematic comparison between sources of technical efficiency.

\subsection{Microeconomic and Complementary Theories of the Firm}

The microeconomilc theory of the firm is, in principle, the most exact and appropriate theory to deal with internal economies of atmosphere. However, microeconomic theory hardly louches upon the internal organization. What has been developed as a 'theory of the firm' can be characterized more adequately as a theory of the market. In the theory of the firm, the firm is no more than a combined decision criterion, traditionally profit maximization (economic criterion) and a production function (technical criterion). The construct called 'the firm' receives its information 
from the markets, and adjusts its market behavior in accordance with the assumed decision criterion. The theory of the firm examines the effects of applying this criterion in different markets. By simultaneously examining the behavior of the various parties involwed, microeconomics attempts to explain and predict the resulting market phenomena such as supply. demand, and prices. While treating the firm as a production function (IKoutsoyiannis, 1979) or a technological black box (Leibenstein, 1987), the theory of the firm is silent on the internall processes which have led to the firm's response to changing market conditions (Schreuder, 1983; Hendrikse and Schreuder, 1987). Recent developments in economics have generated complementary theories of the firm (Putterman, 1987). Those will be dealt with in the next sections of this chapter.

Itami (1984) describes three views of the firm: (i) the firm as a physical transformation agent, (ii) the firm as an input mix of human resources, (iii) the firm as an information processing apparatus.

(1) The firm as a physical transformation and market exchange agent takes inputs from the environment and produces certain outputs which are then sold to the outside parties in the market place. The members of the firm perform operating activites in the production process. The firm itself is a technological black box. Into this box go labor and capital and out come products. The mechanism is driven by profit maximization, and governed by the law of diminishing relurns, that is, an increase in some varying inputs relative to other fixed inpuits will, in a given state of technology, make total output increase; but after a point the extra output resulting from the same additions is likely to become less and less (Samuelson, 1980). In standard price theory, the firm is a primitive atom of the economy - a singlleminded agent interacting with similarly singleminded consumers and factor suppliers in the market economy. This is the (ideal typical) view which is central in the microeconomic theory of the firm. With the firm as atom or lechnological black box, the price system appears to be the exclusive mechanism of resource allocation and economic coordination. Prices as sufficient statistics are the efficient units of information.

Today it is increasingly recognized that whether better characterizations of microeconomic reality are provided by ordinary price theory or the developing economics of organization depends upon the questions in which we are interested (Putterman, 1987). Thus, they are complements rather than substitutes. Once the focus of attention shifts to the firm litself, the complex of interacling agents, resources, information, and routines presents itself as a means of organizing economic activities in its own right. Economic theory describes the price system itself as a spontaneous coordination mechanism imparting rationality and consistency to individual agents' behavior in the market. The firm is one such agent responding to price signals in 
formulating its internal plans. However, the princlpals and agents within the firm do not directly respond to price signals when determiring their behavior. Instead, they operate within a decision-making structure and a given atmosphere. In a simple model, the signais given to intrafirm agents and determining their behavior can be thought of as commands, which serve as the analogue of price signals in the market. More subtle models will replace the concept of external command with one of internalized (psychological) structures motivating agents to perform the required task, making such behaviors rationall from their own stanipoints. Atmosphere may appropriately be conceived as an internalized structure which transmits the appropriate signals in the latter model.

(ii) Organizational economics focuses on three paradigms. One of them, team theory, stresses the problem of cooperation between agents with heterogeneous interests. The organization of cooperative economic activity we call the firm is regarded as an input mix of human resources, composed of people with various skills, traits, tastes, and objectives. Itami's second view of the firm further includes agency theory and Iransaction cost economics. What these approaches share is a common interest in the firm-market relationship, and the internal nature of the firm. In addition, all the approaches are (at least partially) concerned with the problem of agency, i.e. how one actor (e.g. the owner of an asset) induces another actor (e.g. the manager of that asset) to behave in ways consistent with his or her interests. Finally, the paradigms are concerned with

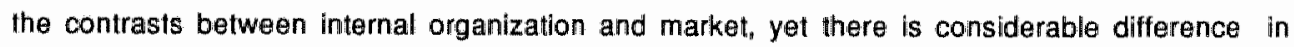
the emphasis placed upon these modes of coordination. With this caveat in mind, Putterman (1987: 5-14) summarizes some of the main differences between markets and firms:

- Agents interact as "free' individuals and as 'equals" in markets, but under organizational directives and in accordance with their station in a hierarchy in firms;

- Intrafirm relations are long-term and exchange is relational, whereas pure market relationship are short term and anonymous;

- Whereas "history does not matter" for pure market exchange, intrafirm relations and firm structures are significantly thistorical in character. As Putterman put it: "Put differently, the firm is a social institution which has developed and which likewise can effect changes in its specticic norms, "culture", and routines only over time" (ibid: 9):

- while markets are often measured against the ideal of perfect competition, the enterprise is a leam whithin which the attenuation of competition and the promotion of cooperation may be a requirement for technical efliciency.

(iii) The firm as an information processing apparatus engages in information processing and information exchanging aclivities. According to Itami, this is the other side of the operating activities in the production process. Operating activities consist not only of physical 
transformation processes, but also, inevitably, of information processing within the firm, and information exchange with the enwironment. The third view is promoted by information economics (Arrow, 1985), and organizational theory (Galbraith, 1974).

The microeconomic view of the firm emphasizes monetary and physical capital - thus, excluding atmosphere which is not a tangible factor of production like capital or labor. The second and third view regard the intangible resources intrinsically connected with the people working in the firm as important assets as well. Examples of such 'invisible resources', in Itami's terms, are technolagical skills, marketing savvy, production routines, brand reputation, and organizational culture. The next sections of this chapter focus on the relationship between atmosphere and efficiency as conceived by the second and third concept of the firm. The second approach mainlly deals with atmosphere as the value system of a firm, whereas the information processing approach deals with atmosphere as a common stock of knowledge. With regard to the economic problem, it may be said that the microeconomic theory of the firm emphasizes minimization of production costs, and the complementary paradigms center on minimization of transaction costs.

\subsection{Team Theory: Mutual Gain of Team Production and the Assurance Game}

Alchian and Demsetz (1972) consider team organization as a special kind of "market" within which resources compete for assignment to particular uses. The long-term nature of relations among agents allows the team to enjoy certain adwantages as a resource allocating mechanism. It is argued that efficient team production with heterogeneous resources is a result not of having better resources, but in taking adwantage of the richer knowledge of factor imputs. As Putterman (11987: 10) has expressed: "While competition for scarce resources is assumed to allocate inputs to their most productive uses in the market, since the most productive user would also (rationally) be the highest bidder, the market process assures optimal resource allocation only to the extent that the characteristics of the inpuls are known 10 markel participants. If, on the other hand, the special qualities of inputs as they work independently and in interaction with sets of complementary inputs can be known best through use, and/or information about input qualities is poorly communicated across markets (...) allocation of resources by an organization controlling them over a period of time may lead to superior resource utilization".

Economies are realized in team production activity in which Joint use of inputs yield a larger output than the sum of the products of the separalely used inpuis. Interdependence of agenis" productivities creates special conditions under which output may be maximized, e.g. one agent"s productivity enhances another's. However, the mere technical possibility of a mutual gain (Marschak and Radiner, 1972) does not guarantee that the interpersonal cooperation needed to secure that mutual gain will actually be forthcoming. First of all, the persons presented with the 
lechnical possibility are susceptible to moral hazards - they are vulnerable to tree rider temptations, or they are simply uniscrupulous opportunists. Only in a non-zero sum game with repeated games and an infinite lime horizon (Axetrod, 1984), may mutual gains by voluntary cooperation be realized. Leibenstein's (1987) treatment of team production as a Prisoner's Dilemma is exemplary for this type of situation. Quite different is the Assurance Game in which seach player would prefer to do the cooperative thing, even if the other party could not enforce that, if he knew that the other party was going to cooperate (also without being enforced). Here the stumbling block to cooperation is not the temptation to shirk or generally to act selfishly. The obstacle to cooperation is the lack of confidence, or assurance, that the other party is going to cooperate because he or she is confident of the first party's cooperation" (Phelps, 1985: 128). When the venture is an Assurance game, the mutual gain of team production is dependent of the ability to trust and to believe that the partner can be trusted. Apparently an atmosphere of trust and fairness may be helpful in effective team production by offering a partial solution (complementary to imperfect monitoring) to the Assurance Game. With respect to the issue of control, the team approach is consistent with agency theory and iransactlion cost economics which have focused on the problem of unloreseen contingencies, and the fundamental issues of adverse selection and moral hazard.

\subsection{Agency Theory: The Firm as a Nexus of Contracts}

The leam approach of the firm is consistent with agency theory and with transaction costs economics. The advocates of these paradigms exploring transaction costs, however, sett out on two very different expeditions. Agency theory, guided by the notion of 'moral hazard" and 'adverse selection" "headed off in the direction of insurance and risk, and ventured into generalized principal-agent relationships. AT conceives the firm as a legal fiction which serves as a nexus for the bundle of long term contractual relations with the owners of human and financiall resources as well as business partners. In a sense, the behavior of the organization is like the equilibrium behavior of a market with the individual agent as the elementary unit of analysis. "The behavior of the organization is the equilibrium behavior of a complex contractual system made up of maximizing agents with diverse and conflicting objectives" (Jensen, 1983: 327). Of course, whether one chooses the "technological black box" or the "nexus of contracts' definition of an organization depends on the question at hand. However, when using the black box metaphor, it is important to remember that it is a convenlient abstraction. Jensen has argued that the danger in its use arises because it encourages the tendency to personalize organizations by attributing motivations and preferences to what is in fact a complex equilibrium system. Essentially. AT is a label for a number of theories that are based on a neoclassical economic paradigm. It deals with the separation of decision (management) and risk-bearing function (ownership), and with the economic relationship between two or more parties, e.g. arrangements between employer and 
employee. The paradigm specifies the phenomenon of contracting under conditions of uncertainty, implicating information assymetries between principal and agent. The firm is a collection of contracts between internal and external participants or stakeholders, and these contracts structure relations of accountability between stakeholders, especially by the design of incentives. schemes (Van de Poel, 1985). Since there is a multitude of explicill and implicit contractual relationships with respect to the firm, the behavior of the firm is the outcome of a complex equilibrium pracess. As Jensen and Meckling $(1976: 311)$ put it: "The agency paradigm implles the view that individual behavior in organizations depends on the nature of contracts between individuals and the allocation of (property and decision) rights that follows from their execution. The specification of individual rights determines how costs and benefits are allocated among the participants.".

\subsubsection{Incomplete Contracts and Focal Principles}

From a contractual perspective, which is common to AT and TCE, the atmosphere of a firm can be seen as a solution to a managerial problem, i.e. the difficulty of imagining all contingencies and specifying them in employment contracts. Given the managerial problem, the most efficient contracting mode is incomplete contracting. which means that parties to a contract will be cognizant of prospective distortions and the need to realign incentives and to craft governance structures that fill gaps, correct errors, and adapt more effectively to unanticipated disturbances. From this perspective, atmosphere may be conceived as the unwritten aspect of contracts among managers, employees, stockholders, and directors who constitute a firm. The tacitly known values and rulles within the firm can administer incomplete contracts between the internal and external participants. As Camerer and Vepsalainen (1988: 115) put it: "Corporate culture solves the problem by specifying broad, tacitly understood rules - 'the ways we do things around here' - for appropriate action under unspecified contingencies". Since wrilten contracls fail because it is too expensive to make them complete, corporate culture - consisting of tacitly known rules of behavior which are broad but clear enough to specify optimal employee action in the face of unanticipated contingencies - may be an adequate substitute.

In terms of Schelling $(1963,1984)$ the incomplete contract is completed by focal principhes such as tradition, simplicity, and equity. Since it might be cosily to specify every time what has to be done once an unforeseen contingency has arisen, "what is necessary is to coordinate predictions, to read the same message in the common situation, to Identify the one course of aclion that their expectations of each other converge upon. They must 'mutually recognize' some unique signal that coordinates their expectations of each other. We cannot be sure they will meet, nor would all couples read the same signal, but the chances are certainly a great deall better than if they pursued a random course of action (Schelling. 1963: 54). In this world where nearly all 
decisions thave to be made under uncertainty, the importance of atmosphere emerges. The value of atmosphere is derived in reducing uncertainly and ambiguity - in guiding cooperative behavior in siluations where many courses of action are possible. The rules of behavior help employees fill in the gaps between the formal contract and actual contingencies, because they can dictate the choice of a specific focal point in a wide variely of situations (Hendrikse. 1988).

Camerer and Vepsalainen have given two examples of Schelling's focal principles. (i) In densely populated Japan, "save space" is an appropriate focal principle for guiding manufacturing activity. This focal principle may lead to low-inventory "just in time" scheduling, and quality control which creates fewer defects, and saves on repair costs. (ii) The focal principle in Western job shops is "a fair pay for a day's work" - workers should be rewarded on the basis of their eftort. Workers' mistakes are absorbed by buffer inventories and production quotas are established. According to the authors both focal principles help workers to respond to unforeseen contingencles, but they may differ in long-run competitive advantage (Ibid.: 120).

\subsubsection{Optimal Span of Implicit Contract}

Kreps (1984) has argued that the reason for (dis)economies of atmosphere is the combination of incomplete contracting and a focus principle, which reduces the range of contingencies with which the implicit contract must deal. An original extension to considerations of the 'optimal size of a firm" is his concept of the optimal span of the implicit contract. "Of course, insofar as the implicit contract permits greater transactional efficiency, an expansion in the span of contract will be beneficial. But weighted against this is the problem that as the span of contract is increased, the range of contingenclies that the contract must cover also must increase. And then either it will be harder for participants to delermine, ex post, whether the contract was applied faithfully, or the contract will be applled to contingencies for which it is not well suited" (libid.: 45). At some point, the benefits from increasing the span of contract are autweighed by the Inefficlencies engendered by the fact that the corporate cuiture is applied in contingencies to which it will be less and less appropriate. Hendrikse (1988) has argued that this argument is consistent with the welfare analysis in the literature on product difterentiation stating that there is a tradeoff between innovation (increasing the span of implicit contracting in order to prevent myopia and excess inertia) and standardization (keeping the same clear focal principle) in order to have all noses pointed in one direction, i.e. facilitating teamwork and effective decision making (Farell and Saloner, 1985). At the firm level, Kreps' argument is supported by Nelson and Winter (1982) who conceive organizational routines as a suppression of deliberate choice, i.e. rational decision making. The costs associated with an investment in atmosphere (standardization) become sunk costs once the focal principles have established. From that moment, the relevant costs are re-investment costs caused by the transition 10 an alternative 
atmosphere (innovation). The rational decision maker will only make these transition costs in the expectation that they will be outweighed by the benefits of the new atmosphere.

\subsubsection{Interim Conclusions}

Regarding the research questions stated in chapter 1 , the preceding sections yield the following conclusions:

1. Although TT does not explicitly discuss atmosphere, there certainly is a role for economies of atmosphere. Whether the technical possibilities of a mutual gain in team production will be realized is dependent of the solution of the assurance dilemma. Atmosphere may be conceived as a partial solution to the uncertainty about the voluntary cooperativeness of the other party.

2. It may be argued that internal economies of almosphere are consistent with the contracting perspective, because they include focal principles which guide cooperative behavior. The focal principles complete incomplete contracts in a world where comprehensive ex ante contracting is constrained by unforeseen contingencies.

3. Costs are undoubtedly associated with developing focal principles learn to read the same message in a common situlation. However, these costs are unavoidable in the organization of cooperative economic activity, because the history of a firm plays a decisive role in the formation of that firm"s culture. The relevant costs are not the sunk costs associated with the standlardization of atmosphere, but the transition costs, 1.. $\theta$. the reinvesting costs which have to be considered when an alternative focal principle is to be developed (innovation). In real life situations, however, sunk costs can matter, because firms may fail to ignore historical investment costs. e.g. because they function as psychological switching costs.

Finally, the literature points out that there are limits of atmosphere from a static point of view, because there is an optimum span of the implicit contracting. At some point the benefits from increasing the span of the implicit contract are oulweighed by the inefficiencies engendered by the fact that the culture is being applied to contingencies to which it is not well suited. From this moment it is worthwhile innovating. that is, mowing into a new local equilibrium. 


\subsection{Transaction Cost Economics: The Firm as a Governance Structure}

While AT is defined by several neoclassical authors such as Jensen and Meckling (1976), Fama (1980), Fama and Jensen (1983a-b), TCE is mainly defined by Willamson (1975; 1979; 1981; 1985). TCE is very similar to AT in that both wark out of a managerial-discretion setup. They also adopt an efficient-contracting orientation to economic organization. Both TCE and AT take issue with the neoclassical theory of the firm whereby the firm is regarded as a production function, to which a profit-maximization objective has been ascribed. In addition, both approaches have elaborated a microanalytic theory of contracts at the intrafirm level.

In contrast to AT and TT, TCE explicitly deals with the concept of 'atmosphere*. ACcording to TCE, the essence of the firm lies in teamwork which involves the nexus of long-term contracts, because it creates dependencies calling for contractual restraints. Emphasizing the transaction as unit of analysis, TCE deals with fundamental aspects of industrial organization. The classic transaction cost problem was posed by Ronald Coase in 1937: when do firms produce to their own need (integrate backward, forward, or laterally), and when do they procure in the market? Coase argued that transaction cost differences between markets and hierarchies were responsible for the decision to use markets for some transactions and hilerarchical forms of organization for others. Coase has stated that if all costs of transactions are zero, the use of resources will be similar no matter how production and exchange activities are arranged. Not only would economic organization be randomly determined, there actually would not be any hierarchy. Consequently, the existence of orglanizations would be inconsistent with economic theory. Coase's observation is supported by Arrow's famous analysis of the limits of organization. Arrow (1974: 33) states that "organizations are a means of achieving the benefits of collective action in situations where the price system fails".

\subsubsection{The Organizational Fallure Framework}

Williamson (1975) starts with the observation that a large number of organizational issues can be usefully addressed in efficiency terms if transaction cosis are taken inlo account. This is accomplished by making the transaction rather than the commodity the basic unit of analysis, and by assessing governance structures in terms of their capacities to economize on transaction costs. Williamson's organizational failures framework (OFF) attempts to identify and link the various factors involved in determining the choice between market and hierarchy. 


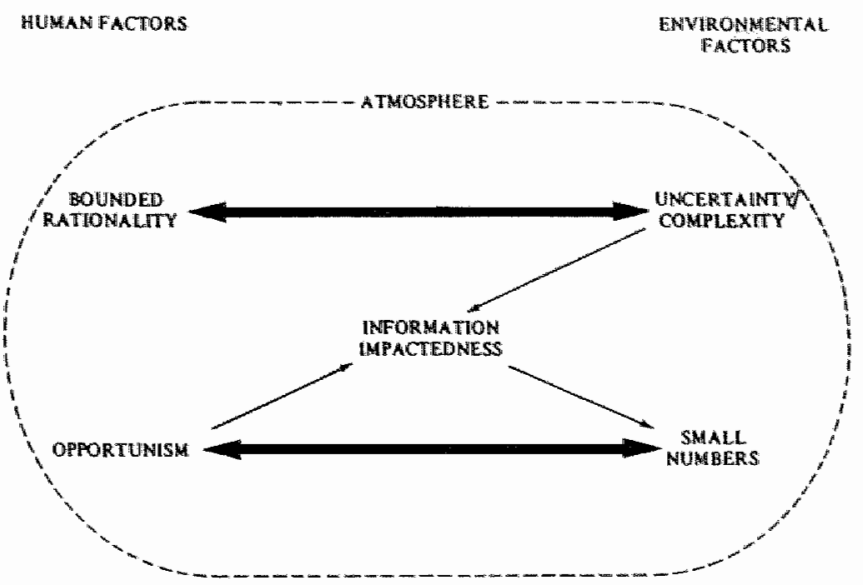

The OFF makes assumptions about human nature (bounded rationality and opportunism) and about the state of the world (uncertainty/small versus large number condition). Most of all, it points out the importance of the following three relations: (i) the pairing of bounded rationality with uncertainty, (iii) the joining of opportunism with small number conditions, and (iii) a derivate condition referred to as as information impactedness'. The last factor mentioned in the original formulation of the organizational failure framework is atmosphere, which is a general condition describing the attitudes of economic agents toward the institutional setting of the transaction.

The principle of bounded rationality refers to the fact that the capacity of individuals for formulating and solving complex problems is very simall compared with the size of the problems whose solutions are required for rational economic behavior in the real world (Simon, 1961). Human behavior is intentionally rational, but only limitedly so. Thus, economic behavior is essentially 'purposive' (Schelling. 1978). Bounded rationality refers to neurophysiological limits on the one hand, and language limits on the other. The former take the form of limits on the capability of individuals to receive, store, retrieve, and process information without error. Language limils circumscribe the ability of individuals to articulate their knowledge by the use of symbols. The classic example is given in Polanyi's (1958) treatment of "lacit knowledge". Bounded rationality is, of course, onlly a problem under conditions where uncertainty or environmental complexity is high. Under these conditions, comprehensive ex ante contracting becomes impossible. 
Opportumism refers to the attitude towards realizing individual gains through dishonesty in transactions. It is an extreme variety of selfinterest seeking. i.e. self-interest seeking with guile. Opportunism can appear in a precontractual stage during original negotiations (e.g. adverse selection), during coniract execution (e.g. moral hazard), and during all contract renewal stages. Strategic behavior is involved in all cases, especially regarding information inequalities, sitrategic manipulation of information, and misrepresentation of intentions. An example of opportunistic behavior is 'shirking' - the act of seeking to avoid performance of contractual duty. Shirking is originally couched in terms of a utility-maximizing employee"s labor-leisure tradeoff (Alchian and Demsetz, 1972). The theory of shirking assumes that individuals might shirk contractual responsibilities if beniefits exceeded the costs. The classical explanation for shirking behavior is given by Staten and Umbeck (1982: 1023): "Given a time constraint, an individual will allocate his labor to equate the gains from income with the gains from leisure at the margin. If labor rewards are not perfectly correlated with productive effort, then the incentive to produce is diminished - shirking results". The authors assume that shirking intensity is dependent on the costs of monitoring. "If shirking could be costlessly detected, neither party to a contract would have an incentive to shirk, since the full costs of shirking could be brought to bear on the guilty party through renegotiations of the terms of trade. However, if detecling shirking through some monitoring mechanism is costly, the guilty party will not generally be forced to bear the full costs of his behavior" (lbid). In addition, it is argued that "Monitoring will be undertaken so long as the marginal gains from reduced shirking equal or exceed the marginal costs of detecting" (ibid). It is concluded that "less-than perfect monitoring implies some shirking incentives remain" (lbid).

Williamson does not state that all economic agents necessarily behave this way. The assumption is that some agents show opportunistic behavior, and that it is very costly to sort out those who do from those who do not. For an opportunistic problern to be posed, a further necessity is that a small numbers bargaining condition prevails. In circumstances where a large number of bidders exist and with perfect monitoring. (perfect) competition will obtain and fair returns will be reallized. Where such market conditions break down, the self-policing benefils of compelition are no longer assured and concern with opportunism is accordingly warranted.

What happens when bounded rationality and opportunism are joined? This is the world with which TCE is concerned: planning here is necessarily incomplete because of bounded rationality; while promise predictably breaks down because of opportunism. In the nonzero transaction cost world, efficiency emerges under the imperative: organize transactions so as to economize on bounded rationality, while simultaneously safeguarding against the hazards of opportunism (Williamson, 1975). 
Information impactedness appears in conjunction with changing conditions (uncertainty). It is. the inability of all the interested parties to be costlessly informed of the changes which have occurred (bounded rationality), and the (opportunistic) inclination of some of the parties to withhold or distort the information to which they have preferential access. e.g. by exploitation of first-mover advantages. Information impactedness is a dynamic concept, because uncertainty and opportunism give rise to a small numbers bargaining result.

\subsubsection{Atmosphere in the OFF}

The last factor mentioned in the original formulation of the organization fallure framework is 'atmosphere' which is a general condition describing the attitudes of economic agents toward the institutional setting of the transaction. According to Williamson, standard economic theory assumes that individuals regard Iransactions in a strictly neutral, instrumental manner. Subject only to the condition that transactions are technologically separable, each transaction can be priced separately and controlled independently. The piece wage is one of the reward systems based upon this very assumption. However, it may be more accurate to regard the exchange process itself as an object of value. Williamson refers to the matter of altruism in a study of blood donors (Titmuss ${ }_{n}$ 1971). It appeared that the creation of a market for blood has transformed the nature of the transaction and decreased the altruism embodied in giving blood. Concern for atmosphere tends to raise a comparable system issue. It is conjectured that transactions which affect conceptions of self-esteem and well-being are especially important. Consequently, the influence of control intensity on work attitudes needs to be assessed with care. Efforts to divide the employment relation into parts and assess each part separately in strictly calculative. instrumental terms can have counterproduclive consequences. Rather than regard transactions in strictly quid pro quo terms, with each account to be settled separately, at leasi some individuals look instead for a favorable balance among an interrelated set of transactions.

Alternative models of organization may differ in atmospheric respect. Market exchange tends predominantly to encourage calculative relations in a transaction. By contrast, internal organization is often better placed to make allowance for reciprocal, moral involvements among the parties. Moral involvement resembles reciprocal altruism in that there is a domation made for which nothing is immediately received in relurn (Gouldner, 1960). It is reciprocal altruism rather than true altruism (Becker, 1976), because there is another side to the transaction: the expectation of reciprocity in the future. Recognition that alternative modes of economic organization give rise to different exchange relations, and that these relations are valued by economic agents requires that organizational effectiveness is viewed more broadly than the usual efficiency calculus would dictate. Thus " modes of organization which would have superior productivily consequences if implemented wilhin a group of pecuniary glain maximizers, may be 
rejected by groups with different values. Consequently, a concern for atmosphere makes the supply of a satisfying exchange relation part of the economic problem.

Whereas technological interactions effects play a prominent role in economics, attitudinal interactions are commonly neglected. An example is the impact of control (meter) intensity where this is easy to control on the attitudes of agents concerning difficult to measure performance behaviors (Alchailn and Demsetz, 1972). The authors refer to indiscretions in a university environment, discussed below. Suboptimality will result if the fiction of independence is maintained when in fact 'attitudinal spillovers" (Willamson, 1975) exist - especially when an employment relationship is involved. Generally, a reduction in monitoring gives rise to an increase in opportunism. Monitoring the employment relation, however, needs to be done with special care, because progressively increasing the intensity of surveillance can elicit resentment, and have counterproductive results, e.g. work-10-rule. As Sen (1977) has pointed out, almosphere is iimportant for economic efficiency, because it is costly and may be impossible to devise a system of supervision with rewards and punishments such that everyone has the incentive to exert himself. While less than perfect monitoring implies that some shirking incentive remains, running an organization on incentives for short term personal gain may be counterproductive. Every economic system therefore has to rely on the existence of work-related values which supersede the calculation of net gain from each transaction. As Arrow (1968) put it, "one of the characteristics of a successful economic system is that the relations of trust and confidence between principal and agent are sufficiently strong so that the agent will not cheat even though it may be 'rational economic behavior" to do so".

Williamson assumes that the requisite degree of cooperation between parties to a transaction arises nol from a pre-existing harmony of interests, but from active efforts to craft mutual safeguards and harmonizing struclures between coalitions (Cyert and March, 1963), i.e. parties whose interests are often opposed. In the end, the team is better off with team spirit and loyalty, because of the reduced shirking, not because of some feature inherent in loyalty or spirit as such (Alchian and Demsetz, 1972). Williamson, Wachter, and Harris (1975) distinguish two contrasting attitudes toward cooperation: consummate and perfunciory cooperation. Consummate cooperation is an affirmative job attitude - including the use of judgement, filling gaps, and laking iniliative. It involves working in a fully functional, undistorted mode. Efforts are not purposefully withheld, neither is behavior of unknowingly inapt kind undertaken. In contrast, perfunctory cooperation is a job attitude which appeals more to the letter than to the spirit of the employment contract. The contract obligates employees to perform only a set of duties in accordance with minimum standards, and does not assure their striving to achieve optimum standards. It is not difficult 10 imagine that consummate cooperation is associated with higher productivity rates than perfunctory cooperation (Peters and Waterman, 1982). 
Consummate cooperation, however, is a very delicate force - which may easily be disrupted (debunked) by an intensive metering atmosphere. A classical example is given by Alchian amd Demsetz (1972) who refer to office telephones, paper, and mail for personal use by umiversity members beyond strict university productivity. Extending metering with regard to such (costly to meter) indiscretions will presumably elicit resentment. As a consequence, all cooperative attitudes will be impaired with the result that tasks such as teaching or research, which can be metered only with difficulty and for which consummate cooperation is required, will be discharged in a highly perfunctory, lie. ineffective way. Alchian and Demsetz" example shows that a less intensive effort to control costly to meter issues might yield system gains, especially in professional bureaucracies where monitoring is far from perfect. Perhaps the organization should be become less 'efficient' in order to become more 'effective'. The neglect of attitudinal spillovers is encouraged by an insensitivity to atmosphere. Atmosphere explains why individuals abstain from maximizing their expected utility in circumstances where the pressures are weak. It is central to the problem of work motivation and voluntary cooperation, the importances of which for increasing production performance or minimizing 'X-inefficiency' (Leilbenstein, 1980) can hardly be ignored.

\subsubsection{Efficlency attributes of the Peer Group}

Williamson (1975) reserves the term 'atmosphere' for those transactions for which attitudinal spillovers are thought to be especially strong, in particular those in the governance structure called the peer group. Peer groups are small groups which involve collective and usually cooperative activity. Workers are compensated on the basis of the average product of the group. They do not entail coordination. They are characterized by the joining of a non-marginal productivity sharing rule with democratic decision making (Williamson, 1979, 1981). They have an advantage over the market to the extent that they are better able to limit membership in an ex ante discriminating way (adverse selection problem), and check ex post manifestations of morall hazard, especially when tasks are integrated. Members of peer groups or "clans" (Ouchi, 1980) not only know the requisite attributes 10 look for in admilting a new member (belter screening devices) but are able, as a byproduct of their working relations, mutually to monitor each other virtually automatically - at little incremental monitoring expense. As a result, the organization of transactions in the peer group is consistent with the efflciency imperative to economize on bounded rationality, while safeguarding against the hazards of opportunism.

Generally, a transformation of involvement, from a calculative to a reciprocal mode, is the result of the shift from the market to the peer group, especially if the metering of Iransactions among the members of the group is consciously suppressed and kept on an inlormal basis. Although the simple hierarchy, a governance structure dominated by centralization, has superior bounded 
rationality' properties, the peer group is nol allways replaced by the simple hierarchy - even when public goods are concerned which result in the tree rider problem (Buchanan, 1971). The reason is that the peer group affords valued involvement relations that are upset, in some degree, by hierarchy. Moreover, atmosphere as an idiosyncratlic stock of knowledge is apt to be superior to market organization in screening and experience rating respects, and in matching workers to workers (teambuilding). Hence the 'organizational capital' (Prescott and Visscher, 1980) of the team economizes on bounded rationality. Of course, the productivity loss which is inherent in the peer group form is only acceptable to the members, provided that surwival is not threatened. Since individuals differ in their preferences for exchange relations; effectiveness may be increased by supplying a mixture of structures which vary in the intensity of metering, thereby allowing individuals to match themselves to organizations in accordance with their involvementproductivity tradeoffs (Willamson, 1975).

\subsubsection{Beneflts and Limits of Aimosphere}

Adam Smith [1776] pronounced that it is not from the benevolence of the butcher that we expect our dinner but from his own self interest. Typically, neoclassical economists are concerned with market equilibria in which individual actors behave selfishly under the Walrasian postulate of perfect information and foresight. As a result, nonselfish values incorporated in fairness, trust. altruism and cooperation (in the absence of enforcement) pose serious anomalies for economic theory. But recently, an increasing number of authors have argued that the price system and the principle of reciprocity are essentially complementary (Arrow, 1974; Phelps, 1975) and that trust, i.e. contidence in each other's voluntary compliance, can be extremely efficient (Mckean, 1975; Noreen, 19818). It saves a lot of trouble to have a fair degree of reliance on other people's. word even or perhaps especially in business situations (Macaulay, 1963; Mckean ${ }^{1975)}$. While Akerlof (1979) showed the costs of dishonesty, Titmuss (1971) dealt with Kantian altruism in voluntary bload markets, and Arrow (1971) focused on the welfare economics of professional behavior in medical care, TCE has emphasized that consummate cooperation and reciprocal trust ail the wheals of the implicit contract. Like the bulk of an iceberg, an enormous portion of mutual understanding is invisible in the contract, since il would be extremely expensive to write every aspect of an agreement - the precise degree of craftsmanship in every task, the exact quality of malerials, or the precise nature of every dimension of performance (McKean, 1975). Without a

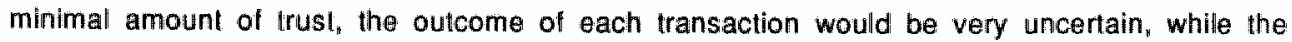
costs of writing complete contracts would be excessive. Consequently, an atmosphere of trust may be conceived as an important institutional source of economic structure (Zucker, 1986).

There are "however, also important limitations to the extent to which the general values mentioned above will actually be efficient. According to Collard (1978), spontaneous cooperation 
turns out to be more likely (i) the smaller the number of players, (ii) the grealter the advantage of cooperation, and (iii) the greater the marginal impact of the individual. Conditions (i) and (iii) are interdependent and are related to the question of increasing returns. To some limited degree this lends support to Schumacher's thesis that 'small is beautiful'. Even if people are only moderately cooperative, there is a far greater chance of woluntary cooperation in a small than in a large community. Collard (1978) refers to the fact of human nature, that (wo)men's loyaltes are not to society at large but to particular groups or clubs. (Wo)men are generally only capable of limited altruism, directed towards a small circle of family and friends. Whille small groups. are managed effectively through loyalty and trust, the sentiment of altruism lends to lose its practical effectiveness as we attempt to extend it to more distant individuals, that is, when the number of players is large (Buchanan, 1985). In Becker's (1976) terminology, there is altruism in the familly, and selfishness in the marketplace.

By contrast, numerous authors have given examples of large firms which capture oconomies of atmosphere. For example, Fortune-500 companies such as IBM, MacDonalds, 3M Company, and Procter and Gamble (Peters and Waterman, 1982), and Japanese multinationals such as Mitsubishi, Sony and Toyota Motor Company (Ouchi, 1981; Aoki, 1984a; Itami, 1984; Morita with Rheingold and Shimomura, 1987). It may be argued that Japanese employees are more collectivistic (Hofstede, 1980), and hence their consummate cooperation is less constrained by a large number condition. But what about the relationship between atmosphere and performance in U.S. firms with such large numbers of pecuniary gain maximizers? in the spirit of TCE, the literature on internal labor markets (Doeringer and Plore "1971; Okun, 1981) provides an economic rationale for the relation between atmosphere and efficiency in the large firm. In Williamson's terms, the internal labor market demonstrates the importance of asset specificily in the fundamental transition of the precontractual situation with a large number of buyers and sellers to the contractual execution stage where a bilateral monopolistic sittuation prevails. 


\subsubsection{Efficiency Attributes of the Internal Labor Market}

The effect of large numbers is, on the one hand, that the individual has no decisive influence on the system, and is unable to appropriate the collective gain that would obtain were he voluntarily to forgo individual self-interest seeking (Olson, 1965). Hence, there is no incentive for consummate cooperation for large firm employees. On the other hand, it may be argued that the large firm has a higher tolerance for perfunctory performance, since the contribution of each individual in the large firm is small in relation to the whole, so that the average effect of opportunistic individual behavior will be insubstantial. The latter argument, however; is not very adequate, since all individuals shirk, the effect will be substantial. Does this imply that the concept of atmosphere is only wiable under small number conditions? The literature on the internal labor markets operating in large firms shows that this is not necessarlly the case, because an atmosphere of fair values which are structurally embedded in rules, may increase productivity by reducing labor mobility and increasing stability. This atmosphere, however, is part of the governance structure called internal labor market in order to protect valuable human assets.

The classical description of the intermal labor market (ILM) is provided by Doeringer and Plore (1971). They define the internal labor market as an administrative unit within which the pricing and allocation of labor is gowerned by a set of administrative rules and procedures. The rules governing internal labor allocation and pricing accord certain rights and privileges to the ILM forces which are not available to workers in the external labor market. For example, the employees have 'property rights' to jobs filled internally, and continuity of employment is protected from external competition. The utility of the ILM as a theoretical construct depends upon the rigidity of rules which define the boundaries of ILMS, and which govern pricing and allocation within them. If these rules are not rigid and respond freely to variations in economic conditions, their independent economic role will be minimal. If, however, the rules are rigid, they will interrupt or transform economic influences causing the ILM to respond to dynamic economic events in a manner not readily predictable from conventional economic theory, e.g. relatively stable wages and turn-over rates under different business cycles. Doeringer and Piore discovered three sources of constrained flexibility: (i) skill specificity, (ii) on-the job training, and (iii) custom. They will be dealt with in the next sections. 


\subsubsection{General and Specific Skills}

Becker (1964) has made the classic distinction between specific and generial training. Specific training is defined as training that has no effect on the productivity of trainees that would be usetul in other firms. As a consequence, costs are associated with turnover - both for the employee and the present employer, because both parties make an investment in specific human capital. General training increases the marginal productivity of trainees by exactly the same amount in the firms providing the training as in other firms. Thus, turnover will have no impact on productivity. According to Doeringer and Piore (11971), training is more or less specific according to the type of skill it provides. They distinguish general and specific skills with the latter skill in particular important for the analysis of the ILM. Skill specificity refers to the inability of workers to transfer their skills to alternative employment, and thus requires that the firm functions as an insurance institution. As skills become more specilic it becomes increasingly difficult for the worker to utilize elsewhere the enterprise specific training he receives. This, undoubtedly, reduces the incentive for him to invest in such training, while simultaneously increasing the incentive for the employer to make such investment. Labor becomes a quasi-fixed factor of production, and management incurs costs if a worker leaves and must be replaced. Moreover, skill specificity tends to increase the absolute cost of training because the less prevalent the skill in the labor markel "the less frequent provision there is for training in that skill so that economies of scale cannot be realized. Both of these effects encourage the employeir to seek to reduce labor turnover, for example by supplying safeguards.

While attributing an efficiency function to the ILM, Doeringer and Piore use an internalization argument which is rather similar to the comparative governance approach of TCE. They assume that ILMs are initiated at the discretion of the management, and that managers seek to minimize labor costs. It follows from the latter assumption that jobs will be awarded to the lowest bidder untess the high price of a competing worker is compensated by high productivity. The competitive market procedure will be replaced by the ILM arrangement if total labor costs, including the costs associated with turnover, are thereby reduced - 1.e. where specific skills are concerned.

\subsubsection{On-the-Job Training}

The second factor critical in the development of ILMS is on-the-job training. To the extent that skill specificity leads to unrecorded knowledge, it necessitates the process of direcl skill transmission from incumbent to successor in the production process. This is the essence of onthe-job training. Such training is more economical than formal instruction in several 
respects. Because it is derived from the content of the job, it is confined only to those skills required for the job and involves no excess training. Further, the costs of on-the-job training is reduced by future output which is unawallable when training is conducted outside the plant. On the other hand, on-the-job training frequenily involves waste of material, machine damage. reduction in product quality, and sacrifices in the productivity of both the trainee and the instructor.

Skill specificity and on-the-job training place a tremendous amount of power in the hand of the experienced labor force, lie. the power to threaten turnover which may be very costly for the employer, or to refuse to Iransfer their specific skills to the newcomers, thus wrecking the learning-by'doing process. Besides, the employee may perform in a perfunctory manner in the knowledge that consummate cooperation is necessary to do the job. Informal training requires an attitude of consummate cooperation in the experienced workman. Where skills are specific, the tacit knowledge of the experienced work force is indispensable to training. Allocalive and pricing rules which respond freely to variations in the supply of trained labor may, inadvertently, create ar incentive for workers to frustrate the training process whenever possible. A certain degree of wage rigidity and job security is therefore necessary for on-the-job training to operate at all, especially in plants where interaction among workers is an important part of the production process. In Okun's (1981) terminology, the employment relation is more fficiently governed by an "invisible handshake" than by the inwisible hand. In these firms, an atmosphere of fairness may be a necessary condition for high productivity. For instance, a common way to promote the transmission of specific skills is seniority. In the case of strict seniority, jobs are allocated to workers in the order in which they entered the internal market. Because senior workers are guaranteed precedence in employment and promotion over those with less seniority, competition between workers decreases, and senior workers are cooperative in instructing the 'green hands' which enter the firm after them.

\subsubsection{Customs in the ULM}

According to Doeringer and Piore, custom is the third of the major forces important to the understanding of the ILM. Custom at the workplace is defined as an unwrittem, and therefore flexible, set of rules based largely upon past practice. These rules can govern any aspect of the work relationship from discipline to compensation. When employment is stable, the same workers come into regular and repeated contact with each other, resulting in the workers developing an interdependent utility function, and communities being formed within the ILM. Communities of this type tend to generate 'shop llaw' - a sel of unwritten rulles governing the actions of their members. Adherence to these idiosyncratic "rules of fairness" (Kahneman et al., 
1986) tends to be viewed as a moral issue. Often supported by a special arbitration apparatus, the custom provides an internal code which permits idiosynoratic conditions to be communicated ${ }_{n}$ thus economizing on bounded rationality. Moreover, reputation damages and utillity losses may be associated with disobedience of customs, so that sociall customs that are costly for the individual to follow nevertheless persist (Akerlof, 1980). In Sen's (19*) terminology, alltruistic behavior is facilitated in the ILM. The care for each other's welfare functions indicate sympathy between workers, while the adherence to customs indicates commitment (non-adherence, it will be recalled, under the right circumstances is of pecuniary advantage to the person who disobeys).

Thus, Doeringer and Piore have demonstrated that an atmosphere of faimess generating consumate cooperation is not necessarily inconsistent with a large number condition. As a matter of fact, the ILM shows a transition from a precontractual (large numbers situation in the external labor market) to a postcontractual (small number bidding situation in the internal labor market) situation as caused by joint investments in specific, non-transferable human capital. The ILM case is consistent with transaction cost economics because ex post contractual costs are emphasized, i.e. the costs incurred in subsequently administering. informing, monitoring, and enforcing the contractually promised performance. Williamson labels the transition mentioned above from precontract to postcontract as the fundamenlal transformation. Options available in the former stage are lost in the latter. As a consequence, the value of some resources becomes dependent on particular unique other parties because a loss of significant substitutability by equivalent resources.

Adherence to work customs is not costless. Where customs are in conflict with economic demands, economic constraints begin to affect profits, wages, and employment. Diseconomies of atmosphere may emerge even where work rules may have initially reflected economic forces, because customs constrain flexibility and make it difficult to change in response to dynamic economic forces. Customs which are suboptimal in their adaptation to the environment are a competitive disadvantage to the firm with bankruptcy as the ultimate sanction.

\subsubsection{Human Asset Specificity, Atmosphere, and ILM Effliciency}

The ILM is the institutional form of Williamson's economics of atmosphere replacing the invisible hand by the invisible handshake in the large firm. Obviously, economies of atmosphere are not relevant in the firm's spot market cantractual relations with employees who are only in the possession of general skills. The fundamental transformation, i.e. the transformation of a large number situation in the precontractual stage to a small number bidding situation in the contractual execution stage, is only executed when human asset: 
specificity exists. Humian asset specificity is critical because, once an investment has been made, the buyer and seller of labor are effectively operating in a bilateral exchanige relation for a considerable period thereatter. Doeringer and Piore's skill specificity refers to human assets that arise from learning by doing. They are skills that are required in a learning-bydoing fashion and that are imperfectly transferable to other employers. Thus, a nonmarketability problem arises for the seller. Specific skills have to be embedded in a protective governance struclure lest productive values be sacrificed if the employment relationship is unwittingly severed. Inasmuch as the value of specific human capital in other uses is, by

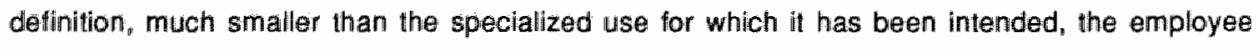
is effectively "locked into the Iransaction". This is symmetrical, in that the employer cannot turn to alternative sources of supply and obtain the item on favorable terms, since the cost of supply from unspecialized human capital is presumably great. Where human asset specificity is great, employer and employee will make speciall efforts to design an exchange rellationship that has goad continuity properties. The ILM case explains why the creation of an atmosphere where thairness and reciprocity are emphasized is efficient: as a consequence of human asset specificity, the parties to the contract are locked into the transaction'. As a result, there is an incentive for the employer and employee to design an exchange relation that has good continuity properties. Atmosphere is the informal side of the protective governance structure which protects the durable investment in transaction specific assets. Valuable as it may be, however, atmosphere is not a substitute for more struclural measures like tenure, seniority, internal promotions, company unions, rigid wage rates, and "golden parachutes'.

Regarding the efficiency of the ILM, opportunism is altenuated by a wage structure which forecloses individual bargaining, by internal promotion procedures such as the seniority system, and by offering long term employment contracts. These procedures encourage trust relations and consummate cooperation. They stimulate the transfer of specific knowledge within the firm. Moreover, they offer long term manitoring opportunities. The ILM oconomizes on bounded rationality by writing contracts in general and flexible terms, and supplying the parties with a special arbitration machinery. Rather than attempting to anticipate all bridges that might conceivable be faced, which is excessively costly, bridges are crossed as they appear. But however attractive incomplete contracts are in bounded rationality respects (Llewellyn, 1931; Goldberg. 1963; Macaulay, 1963; MacNeil, 1974; 1978), admitting gaps also poses hazards. Where parties are not indifferent with respect to the manner in which gaps are to be filled individual bargaining or litigation may result. The firm"s specific arbitration apparalus is devised for prevenlion purposes. It serves to overcome information impactedness, in that the arbitralor is able to explore the facts in greater depth and with greater sensitivity to the idiosyncratic attributes of the enterprise than could judicial proceedings. Furthermore, once it becomes recognized that the arbitrator is able to apprise 
himself of the facts in a low cost way. opportunistic mistepresentation of the data is discouraged as well. The arbitration machinery associated with the ILM is apt to be valued not only for efficiency reasons, but also because a greater sense of justice results. Unlike the commercial arbitrator, the firm specific arbitrator not only finds facts, but also pours meaning into the general phrases of a document.

\subsubsection{Equilibrium of Asset Specificity, Price, and Contractual Safeguard}

A simple contraclual schema elaborating within the firm the complex equilibrium of contractual relationships, entailing the simultaneous determination of asset specificity, price, and contractual safeguards, is given in exhibit 3.2 (Williamson, 1985: 33). The purpose of this schema is to summarize the previous arguments in a somewhat more general manner.

Exhibit 3.2. A Simple Contractual Schema

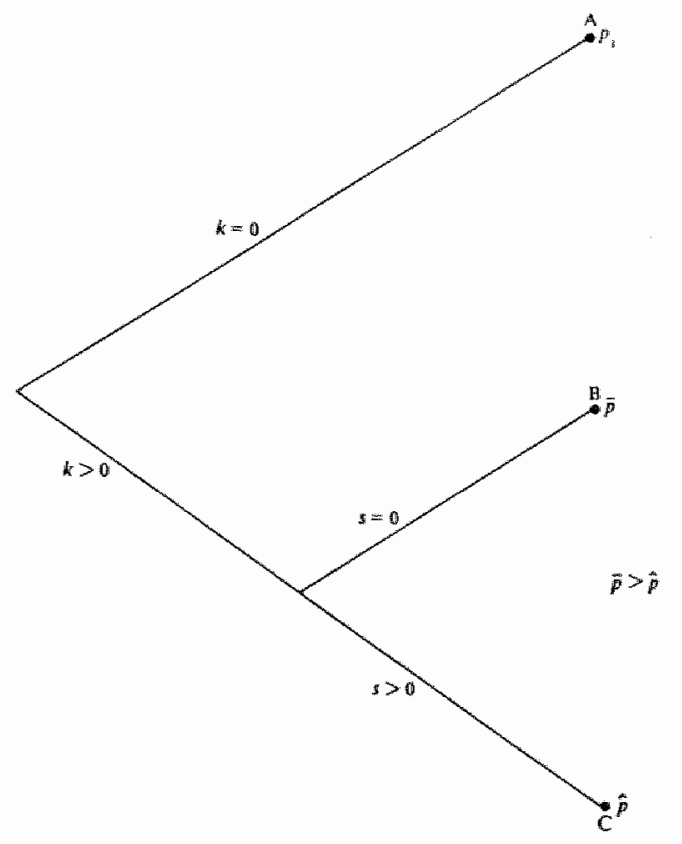


Williamson uses $k$ as a measure of transaction specific assets, i.e. general technologies or skills are ones for which $k=0$, while specific skills are ones for which $k>0$. Since productive values would be sacrificed if $k>0$, a billateral monopoly conditions applies to the latter transaction. Whereas classical market contracting - sharp in by clear agreement, sharp out by clear performance - suffices for transachions of the $k=0$ kind (MacNeil, 1974), unassisted market governance poses hazards when a $k>0$ condition exists. As a result, parties have an incentive to devise safeguards (s denotes magnitude of the safeguard) to protect investments in tranisactions of the latter kind. An $s=0$ condition is one in which no safeguards are provided" while a decision to provide safeguards is reflected by an $s>0$ result.

Exhibit 3.2. displays the three contracting outcomes corresponding to such a description. The equilibrium contractual relationship between technology, price, and safeguards are described as follows: "Associated with each node is a price. So as to facilitate comparisons between nodes, assume that suppliers (1) are risk neutral, (2) are prepared to supply under either technology, and (3) will accept any safeguard condition whatsoever as long as an expected breakeven result can be projected. Thus node $A$ is the general purpose technology $(k=0)$ supply relation for which a breakeven price of $p_{i}$ is projecled. The node $B$ contract is supported by transaction-specific assets $(k>0)$ for which no safeguard is offered ( $s=0)$. The expected breakeven price here is $\ddot{p}$. The node $C$ contract also employs the special purpose technology. But since the buyer at this node provides the supplier with a safeguard $(s>0)$, the breakeven price, $\hat{p}$, at node $\mathcal{C}$ is less than $\bar{p}^{\prime \prime}$ (Williamson, 1985: 33 ). Transactions at node $B$ enjoy no safeguards on which account the projected breakeven supply price is great $(\overline{\mathrm{p}}>\hat{\mathrm{p}})$. Contractually, such transactions are conceived as unstable. They may revert to node A (in which event the special purpose technolagy would be replaced by the $k=0$ lechnology) or be relocated to node $C$ (by introducing contractual safeguards that would encourage the continued use of the $k>0$ technology).

\subsubsection{Feciprocity as a Credible Commitment}

The simple schema demonstrates that cosis are associated with incentive contracts that do not share risk efficiently (Noreen, 1988). As Williamson put it: "Inasmuch as price and governance are linked, parties to a contract should not expect to have their cake (low price) and eat it too (no sateguard) (lbid.: 19). An atmosphere emphasizing reciprocity and mulual risk sharing may be conceived as the informal side of the $S>0$ condition. Reciprocity and other 'credible commitments' (Williamson, 1983) such as buy-sell agreements, most-favouredcustomer clauses, and joint ventures are underlaken in support of alliances and to promote exchange. These commitments involve reciprocal acts to safeguard a relationship, and to protect asset specific investments from holdup. They can serve as means of creating 
compelitive, economical mutual reliance and self-enforcing contracts. For the purpose of studying economic organizations, the important lesson is that transactions that are subject to ex post opportunism will benefit if appropriate safeguards can be devised ex ante. Rather than reply to pre-emptive opportunism (which is a very primitive response) the parties of firmspecific transactions seek to give and to receive credible commitments (Alchian and Woodward, $1988 \%$.

\subsubsection{Interim Conclusions}

Regarding the research questions posed in chapter 1 , the following conclusions may be derived from the preceding sections:

1. TCE shows that economies of atmosphere exist at the firm levell. When human asset specificity is great, opportunism is attenuated by creating (among others) an atmosphere of fairness, while bounded rationality is economized by incomplete contracting. Atmosphere is, of course, only a partial solution to the managerial problem. In the internal labor market, for instance, it has to be supported by structural measures such as rationalization of the wage structure, an internal promotion procedure, and a special arbitration apparatus.

2. The main antecedent of economies of atmosphere is human assel specificity. Given a world characterized by bounded rationality and opportunism, employer and employee are locked into the transaction when an invesiment is made in specific human capital. As a result, special efforts will be made to create an atmosphere of fairness, i.e. 10 design a protective exchange relationship that has good continuity properties. Reciprocity thereby is among one of the possible credible commitments.

3. Credible commitments are given in the expectation that credible commitments will be received and that, as a consequence, the system will function more efficiently and there is more to be consumed by everyone. It is clear that a great deal of time has to be investied in creating such an atmosphere of reciprocal altruism - particularly under large number conditions. Consequently, it is only expected to be done when the parties to the contract are sufficiently locked into the transaction, for instance, when specific technology is required to do the job, and turnover costs are high.

\subsection{The Firm as an Information Processing Apparatus}

The next sections will focus the attention to the information processing view of the firm. Econiomic theory is founded on the assumption that firms will behave as if they are able to maximize, regardless of how complex their decision problems might be. Consequently, the theory has never investigated the consequences of a genuine gap between human decision making 
capacity and the difficulty of a decision problem. In a seminal article, Heiner (1983) has argued for a new approach to the realm of behavior under uncertainty. He proposes that an action will only be added to the repertoire of actions if cerlain criteria of reliability are satisfied for that action. He argues that given increased uncertainty, the repertoire of actions will be limited. With few actions from which to choose, savings on decision costs can be made, and the individual's behavior will be more predictable. Predictable or 'fllexibility constrained" behavior evolves to the extent that uncertainty prevents agents from successfully maximizing. Heiner then suggests that this explains behavior in a surprisingly wide range of applications, Including the evolution of social institutions. Uncertainly is the main source of observed regularities in economic behavior including the predictable behavior of buyers and sellers in financial markets (Kaen and Rosenman, 1986).

Heiner bellieves that when uncertainty exists, flexibility to react to more information or administer a more complex repertolre of actions will not necessarily enhance an agent's performance. On the contrary, sequential replication games of the basic prisoner's dilemma empirically showed that the worst performance came from the most sophisticated strategy. whereas the simplest strategy was identified as dominant over all the others (Axelrod, 1984) In addition, Simion [1954] showed that decision makers in a variety of contexts systematically restrict the use and acquisition of information compared to the potentially avallable informaltion. Thus, an agent's overall performance may actually be improved by restricting flexibillity to use information or to choose particular actions. Note thal restrictions in flexibility or regularities in economic behavior introduces the role of history. This contrasts with economic analyses in which the weight of the past is generally disregarded. For instance, the principal-agent tramework, one of the dominant paradigms in the economic theory of organization, assumes that the principal and the agent meet once and sign a contract which is then executed (Gremer, 1987).

\subsubsection{Economizing on Information}

Arrow (1978) discusses uncertainty as a consequence of the role of time in economic affairs. Generally, there is an emphasis on the economic future as against the fleetingness of the present. For example, economic decisions are mostly seen as concerned with decisions on holdings of assets rather than on choices of cash flows. Decisions to hold assets are determined by anticipations of the future. The dominance of the anticipated future has led to an increasing emphasis of uncertainty, as it is recognized that forecasting is uncertain, and that we can newer known the fulure in detail. In contrast to the Arrow-Debreu model (Arrow and Debreu, 1954) implying a set of 'futures markets for all commodities for all future dates', it is recognized that the requirement of perfect foresight cannot hold literally. 
Information processing ability is scarce. Moreover, in a decentrallized economy, individuals have different information, and each individual is specialized in certain activities and has only general knowledge about other activities. Given the scarcity of information processing ability, agents concentrate on acquiring the information most useful to them, and will crowd out the information which is less useful. Information broadly pertinent to the economy as a wholle may have very little predictive power for the future of that agent. Each agent bases his anticipations on all the information at his disposal and this may include a great many facts and observations not available to others. Thus, the agent, as an economizer of information, will make forecasts on information which is not common to the general population. In a diecentralized (competitive) economy, he will specialize in idiosyncratic rather than in general knowledge (Arrow, 1974 a).

\subsubsection{Information Processing Approach to Atmosphere}

Clearly, atmosphere can be seen as a response to uncertainty, because it is a perfect example of constrained flexibility, especially in the domain of information processing behavior. In his discussion of the cognitive aspects of corporate culture, Cremer (1987) asks the fundamental question: why is corporate culture a factor of efficiency in the internal treatment of information within organizations? His basic thesis is that culture can enable the organization to respond better to the information it receives. Corporate culture is defined as a stock of knowledge that is common to a substantial portion of the employees of the firm, but not to the general population from which they are drawn. It is the portion of specific human capital that is common to many employees of the firm. Organizations have speciallized in specific knowledge as a response to the strategic problem of external adaptation (Itami, with Roehl, 1987). whereas their internal integralion is promoted by investing in a stock of knowledge which is common to the members of the firm (Crémer, 1987). As mentioned before, Crémer analyzes culture by decomposing it into three elements: (a) a common code, (b) a common knowledge of facts, and (c) a common knowledge of (behavioral) rules. The next sections investigate how these aspects are related to efficiency from an information processing perspective.

\subsubsection{Common Code}

In fact the first aspect has been extensively discussed by Arrow (1974a). According to Arrow, the functional role of an organization is to take advantage of the superior productivity of joint actions. An organization can acquire more information than any one individual, for it can have each member performing different experiments (specialization). But there is a price to be paid. The information has to be coordinated if it is to be of any use to the firm "ile. 
communication channels have to be created within the firm. If all information received by any member of the organization were uransmitted to all others, there would be no gain in iritormation processing costs. The information has to be reduced without loss of value. Much of the information received is irrelevant, so that what is received by one member of the organizalion is transformed into a much smaller volume for retransmission without losing value for decision making. The firm should develop its own system of 'sufficient statistics'. This need for efficient retransmission explains the utility of an organizalion for information processing. Since information is scarce, it is optimal to reduce the internal transmission still further. Since internal communication channels can be designed, their structure can be chosen with a view to cost minimization. As Arrow points out, the efficiency of a channel can be increased particularly by the choice of a suitable code.

The code refers 10 all the known (formal and informal) ways for conveying information. It is efficient to generate a specialized code when some type of information is to be transmitted repeatedly. The code is the common language and becomes the way of looking at the world, because it is the idiosyncratic filler through which all information inputs are processed. Coding has two economic implications: (i) It creates an irreversible capital commitment of the firm; (ii) while coding permits a greater number of individual intormation sources to be pooled usefully, there are increasing costs of coordination as scale grows.

With regard to the first point, it is necessary to have made an adequate investment of time and effort in order to be able to receive and retransmit signals - comparable with learning a foreign language. Others have found it economical to use a large number of possible codes, and for any newcomer it is necessary to make an initial investment to acquire it. The learning of a (specific) code is both an act of irreversible investment for the employee, and an irreversible capital accumulation for the employer. Such investment, being locked up in individual minds, is irreversible, because it remains in the possession of the individuals. Once the investment has been made, and an information channel acquired, it will be cheaper to keep on using it than to invest in new channels. Once created, organizations dewelop an identity (Selznick, 1957), because sunk cosis have been made, and the (transition) costs of changing the code are nontrivial. Apparently, history mallers. The code is determined in accordance with the best expectations at the time of the firm's creation. Since the code is part of the firm"s sunk capital, and transistion costs may be high, the code of a given firm will be modified onlly slowly over time. In order to economize on information costs the code constrains flexibility.

Concerning the second point, the limited computationall capacity of the decision maker for acquiring and using information is a fixed factor in information processing, and one may expect certain dilminishing returns in response to increases in other information resources, cf. the 
"span of control" in management science. In addition, the organization's gains from increasing scale are derived by specialization, that is "by having its members make different experiments. Members will be accumulating different types of skills in information processing, i.e. they learn more in the direction of their activity, and will unlearn elsewhere. Obviously, it is easier to communicate with individuals with whom one has a common code. As a result, communication among them becomes more difficult, and the codes used in their intercommunications have to become more complex. As a function of increasing scale, there is a growing need for codes to be mutually understandable within the organization imposing a uniformity requirement on the behavior of the participants (Arrow, 1974a).

Cremer (1987) describes the firm as an information processing apparatus. It receives messages from its environment, processes them and responds with a message. By analogy with standard definitions of technical efficiency, this response is cost-efficient when a set of decisions of a given quality is taken at the lowest possible costs. The quallity of a response is defined by its appropriateness (in serving the interests of the firm) and its speed. Increasing the speed of the response decreases the costs as the decision maker spends less time processing information. A common code influences the appropriateness of response, because the code is specialized, i.e. specific ("to the point") rather than general signals will be given. The presence of a code increases the speed of the response because it carries large amounts of meaning with relatively few symbols. Organizations find blueprints, product number systems, and occupational jargons helpful in increasing the efficiency of their internal communications.

\subsubsection{Knowledge of Specific Facts}

Coding is only ane aspect of culture. Culture, it will be recalled, may be regarded as a stock of accumulated information, and thus another aspect of culture is the common knowledge of specific facts. A certain number of facts (including the fact that others know them) are known by most members of the organization. Employees learn aboul the general background: the objectives of the firm, how the product is conceived and sold. In addition, functional aspects are known throughout the firm, including the location of factories, telephone codes, and the responsibilities of different execulives. The presence of a common set of known facts will increase the effectiveness of communications, especially if agents know what the others. know. If many facts are known by every recipient, less communication is required. Moreover, only the relevant information is transmitted. Furthermore, common knowledge of facts about the organization enables agents to take more appropriate decisions. It enables them to compute more accurately the benefits and costs of the organization, because they can predict better the reactions of the rest of the organization. Moreover, it allows more specific reactions to environmental messages as the agents have a more subtle understanding of the range of actions 
that cam be laken. Finally, 'personnel information', which may be part of the common knowledge, facilltates the matching of workers to tasks at which they have a comparative advantage, whereas team information lacilitates teambuilding " the matching of workers to workers. Following Alchian and Demsetz (1972) treatment of the team as an altemative allocating mechanism using "Inside" information on input factors of production. Prescott and Visscher (1980) have argued out that personnel and team information are part of the organizational capital , and that a poor match between workers, tasks and team members is, in general, not indifferent to the firm.

\subsubsection{Rules of Behavior}

The third element of Cremer's decomposition of culture is the knowledge of the rules of behavior which employees must agree to follow. These rules can be conducive to greater efficlency if they are at the same time simple and broadly applicable enough. They must serve as guides to decision making under uncertainty. The knowledge of simple rules (and the knowledge that others know them, and will adhere to them) enables the agent to predict the actions of others. Rules make the actions of the different employees of the firm more predictable. An extreme case of the role of simple rules to ease decentralized decisions is given by Arrow (1974a). Military culture stresses obedience. During combat, officers have to make rapid decisions. For coordination purposes, they need to know preciselly what their subordinates are doing. Hence, it is better that the latter obey orders even when they have information that shows them to be suboptimal. In this example, simple rules restrict the aclions of subordinates and help predict their behavior for coordination purposes. In addition, simple rules facilitate computations because they cut off some branches of the decision tree. As Cremer (1987) illustrates, if the culture emphasizes the smooth running of the production process, a salesman will not have to explore the biranches of his decision tree that involve modifying a product extemsively in order to please a client.

\subsubsection{Interim Conclusions}

Regarding the research questions, the preceding sections permit the following conclusions to be derived:

1. If atmosphere is conceived as a common stock of knowledge, the information processing approach shows that an efficiency function can be attributed to atmosphere.

2. Why is atmosphere efficient? It is argued that the more developed the common stock of knowledge, the more it will facilitate appropriate and fast responses - by providing easy 
access to information, increasing the predictabillty of the other agent's behavior, and by coordinating the bounded rationality of the different members of the organization. Atmosphere is stronger the greater the stock of knowledge (of a code, facts, and rules) common to the employees, whereas the strength of atmosphere is determined by the degree of common learning within the organization (socialization) and the degree to which personnel selection is focused on special subgroups of the population (standardization of skills).

3. Knowledge may decrease errors (waste), and enhance technical efficlency. Monetary and time resources have to be sacrificed in order to invest in a common stock of knowledge. It pays to do so, but not unlimitedly. When firms overinvest in on-the-job training or select employees with a Ph.D. degree where an ordinary M.A. dlegree sufflices, the production costs are unnecesarily high.

\subsection{Alternative Sources of Efficlency: Scale and Scope}

In general, the criterion for organizing economic transactions is assumed to be cost minimization (Knight, 1921). In addition, Williamson has stated that "the criterion for" organizing commercial transactions is asumed to be the strictly instrumental one of cost economizing. Essentially this takes two parts: economizing on produclion expenses and economizing on transiaction casts. In fact, these are not independent and need to be addressed simultaneously" (Williamson, in: Chandler, forthcoming: 34). Elaborating upon TCE, this chapter has attempted to dewelop a theoretical rationale for the attribution of a transaction cost minimization function to atmosphere. Transaction costs are reduced by economizing on bounded rationality, while simultaneously attenuating opportunism. Williamson has rightly pointed out that the economic problem is not saving on transaction costs "but saving on the sum of transaction and production costs. Consequently, production costs should be considered as well. Neoclassical economics has emphasized an important mechanism which may decrease production costs, l.e. economies of scale (Stiglitz, 1958). Recently, it has been recognized that economies of scope may also contribute to least cost profit maximization (Panzar and Willig. 1975; 1981). Regarding the economic problem. one might say that economies of scale, scope, and atmosphere are complementary rather than substitutes. The following sections define the alternative sources of efficiency in order to enable a systematic comparison to be made with the economies of atmosphere principle. 


\subsubsection{Economies of Scale}

Scale economies permit relatiwely large producers to manutacture and market their products at lower average cost per unit than relatively small producers. The concept is especially important in the field of industrial economics (Scherer, 1971; Shepherd, 1979). The principal basis of scale economies is specialization or the division of labor. In Adam Simith's view [1776], great reductions in production costs were due to three repercussions of the division of labor: an increase in worker dexterity, the saving of lime, and the invention of machines enabling one man to do the work of many. In large firms, a vicher division of labor is. possible than in small firms. The low volume production line sacrifices ellther specialization or fulf utllization of specialized resources, and thereby suffers some cost disadvantage. Identical principles apply in the use of machinery. Special machinery can be designed to perform special tasks at considerable savings of time and labor. But the small scalle producer may find no advantage in adopting them, because they cannol be scaled down and would. therefore, be idle much of the time, leaving a small number of units of output to bear the full burden of their capital costs.

Another benefit of size arises from reserves. A firm anxious to maintain continuity of praduction must hold equipment in reserve against machine breakdowns. A firm which is just Uarge enough to use only one specialized machine may be forced to double its capacity if it insists on hedging against breakdown. The larger firm with numerous machines can obtain virlually the same degree of protection by holding only a small proportion of its capacity in reserve. Moreover, the large firm can spread overhead costs over a range of products. In addition, size offers advanyages in maintaining capacity sufficient to meet fluctuations in demand, for the larger the number of customers a given production center serves, the more the random peaks and valleys in individual customer demand tend to cancel out, allowing the large firm to maintain less reserve capacity relative to the average level of demand.

From a dynamic poinl of view, the economies of scale principle is related to the phenomenon of learning cunves (Hall and Howell, 1985). When a new product is introduced, the cost per unit at plant level is initially high, but as cumulative output increases, the costs per unit fall in an orderly way, such that the $\log$ of the current average cost is related linearly to the $\log$ of cumulative output to date. This learning-by-doing phenomenon can have first mover advantage implications, since the firm which gets in first and accumulates experience may be able to maintain a continuing cost advantage over later entrants. Of course, the decline in costs does not continue indefinitely. In nearly all production and distribution operations the realization of scale economies is subject to diminishing returns. Sooner or later a point is reached at which all opportunities for making further cost reductions through increased size are exhausted. The 
sources of economies can become causes of diseconomies if they are pushed too tar. Thus, excessive specialization has bred such alienation among workers that frequent breakdiowns, and careless work result. In addition, it is possible that rising unit costs related to the difficulty of managing an enterprise of increasingly large scale will ofiset and eventually overwhelm the savings attributable to high volume and distribution.

Two hypotheses in this vein have been advanced. For one, the entrepreneur or the chilef executive officer is a fixed, indivisible input. Whenever increasing doses of variable inputs (worlkers, middle managers, machines) are used in combination with some fixed input sooner or later diminishing marginal returns take hold. A related hypothesis asserts that as the enterprise increases in size, it becomes more difficult to keep each unit's operations in harmony with those of every other part. The coordination problem results in upward pressure on costs. At some critical point the diseconomies of large scale management overpower economies of scale, and unit casts begin rising with output, giving the long run average total costs curve its familiar U-shape. The downward segment of the 'U' is governed by scale economies, the upward thrust by managierial diseconomies which may be overcome only partially by a system of checks and balances which reduces the probability that important aspects of decisions will be overlooked.

Economies of scale may be real (those which reduce the inputs of factors per unit of output) or pecuniary (those which result from paying a lower price for the inputs purchased by the firm). The latter do not reduce the quantity of inputs, but rather the money costs of the inputs for the particular firms. Real economies are technical (resulting from using more efficient large scale machinery), managerial (resuiting from spreading the managerial fixed input over a larger amount of output) and labor economies (arising from the greater specialization of the labor force). The distinction between real and pecuniary is useful for the welfare implications of these economies. Technical economies raise allocative efficiency, whereas pecuniary economies mainly imply a redistribution of income - benefitting large firms at the expense of input suppliers.

Whatever their nature economies of scale, whenever present, do form an important barrier to entry for new firms. In discussing barriers to new competition, the concept of minimum optimal (efficient) economies of scale is especially relevant. It is assumed that for each industry there exists a minimum optimal scale of plant, that is a minimum plant size at which the economies of scale are fully realized. Furthermore "costs are assumed to remain constant beyond the minimum optimal scale. Finally, the minimum optimal scale is the same for all firms, the established ones and the poiential entrants, since technology is the same for all. The advantage of the established firms is that they have already reached scales of outputs larger 
than the minimum optimal scalle, while the entrant will have to establish itself gradually. starting perhaps from suboptimal levels of production. In this event, it must be assumed that the entrant expects eventually to reach the minimum optimal scale, otherwise it would not enter the market. If the actual state of the entrant is equal to or greater than the minimum optimal scale size of plant, there is no barrier to entry (Koutsoyiannis, 1979 ).

There is no minimum efficient scale for all industries. Chandler (forthcoming) has rightly emphasized that different production technologies have different scale economies. In some industries, such as oll, steell, and aluminum, the cost-curve gradient is steep and the penalties of producing below minimum efficient size are severe. In others, such as soap, cereal, and similar branded packaged products, the gradient is less steep and the penalties of operating bellow minimum efficient size not as severe.

\subsubsection{Economies of Scope}

Economies of scope exist when for all outputs, $y_{1}$ and $y_{2}$, the cost af joint production is less than the cost (c) of producing each outpull (y) separately. That is, it is the condition for all $y \|$ and $y_{2}$, (Panzar and Willigl, 1975),

$c\left(y_{1}, y_{2}\right)<c\left(y_{1}, 0\right)+c\left(0, y_{2}\right)$

With economies of scope, joint production of two goods by one enterprise is less costly than the combined cosis of production of two specialty firms. Whereas economies of scalle refer to declining average costs associated with increasing output of a single product function. economies of scope are realized when it is less costly to combine two or more product lines in one firm rather than produce them separately. Examples are deparment stores which enjoy significant economies of scope in their retailing function by carrying many products and brands, or the common utilization of new distribution systems for the transport of ice, meat, and fruils (Chandler, in: Hendrikse and Schreuder, 1987). In Chandler's forthcoming work on scale and scope economies, he compares the American oil industry and the German chemical industry. "In the same years that Standard Oill was investing in lits large refineries to exploit the economies of scale, the German dye makers were maken an even larger investment to exploit fully the economies of scope. The eniarged plants produced literally hundreds of dyes as well as pharmaceuticals from the same raw materials and the same intermediate chemical compounds, The first three enterprises to make such investments to exploit the cost advantages of scale and then those of scope - Bayer, Hoechst, and BASF - were able to reduce the price of a new, synthetic dye, red alizarine, from 270 Marks per kilo in 1869 to nine marks in 1886 and to make comparable price reductions in their other dyes" (Chandler, forthcoming: 42). 
In contrast to industrial organization economists such as Scherer, Chandier emphasizes throughput, i.e. the lechnological advantages of scale cannot be achiewed without managerial coordination. Regarding scope in the chemical industry, it is argued that the addition of each dye involved the dievelopment of a specialized product - requiring constant supervision to assure the necessary quality - and steadily increase the need for arganizalional coordination. With regand to distribution, Chandler argues that, just like manufacturers, wholesalers and retailers as well were organized specifically to exploit both economies of scale and scope. Concerning distribution, it is argued that the cost advantages of joint distribution or scope are reduced when products require specialized facilities and skills in marketing and distribution. This is also true for transaclions. "ilf the transactions were complex, however, if the products required specialized knowledge in order to sell "to install, to imainlain, and to make the necessary credit arrangements, and if costly specialized facilities were required to distribute the goods, the intermediary had to hire personnel with specilalized skills and invest in specialized facilities - skills and facilities that were often applicable only to one particular

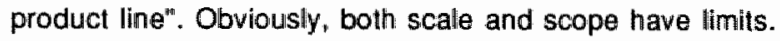

Whereas minimizing production costs is the main abjective of economies of scale, Teece (1984) has shown that the internalization of economies of scope within one firm can only be explained when both production and transaction costs are taken into account. If the technology displays scope economies, but market transactions can be used to transfer the advantages of joint production to another firm, the production of two goods by two firms will not be more costly than the produclion of the goods by a multiproduct firm. According to Teece, the organizational implications of scope are only clear when there is a market fallure, so that unless production is centralized in only one firm, it is impossible to cash in on the advantages of joint production. One explanation for market failure is to be found in the nature of the commodity sold, especially when the commodity is information. Market exchange may break down because of the problems of disclosing value to buyers in a way that is both convincing and does not destroy the basis for exchange. A very severe information impactedness problem exists, in which the less informed party (the buyer) must be wary of opportunistic representations by the seller. If, moreover, there is insufficient disclosure to assure the buyer that information possesses great value, the 'fundamental paradox' of information arises: its value to the purchaser is not known until he has the information, but then he has in effect acquired it without cost (Arrow, 1971). Teece argues that the multiproduct enterprise is an efficient way of organizing economic activity, if the fundamental paradox of information is not resolved, and if economies of scope are based upon the common and recurrent use of proprietary knowhow or the common and recurrent use of a specialized and indivisible physical asset. In addition, Jones and Hill (1988) have argued that economies of scope are 
difficull to realize using the market mechanism, because of transaction difficulties. In a world characterized by bounded rationality and imformation impactedness, the very fact that inpuls are shared or uttized jointly makes contingent claims contracts aimed at realizing economies of scope difficull to draft, monitor, and enforce, particularly because the normal risks associated with opportunism apply.

\subsubsection{A Comparison}

In contrast to the formal modeling approach associated with much of the literature on economies of scale and scope, the economies of atmosphere principle is of a preformal kind. Inasmuch as subsequent formalization would appear to be feasible, that condition is not necessarily grounds for objection. Some problems, of which economies of atmosphere is arguably one, are so complex that they first need to be approached on their own terms. Focus is nevertheless required, and TCE offers one focused perspective on economies of atmosphere. Exhibit 3..3. deals with the similarilies and differences between the above mentioned complementary sources af efficiency. By economies, technical rather than pecuniary economies should be understood. 


\begin{tabular}{lll} 
Economies & Basic Principles & Minimize \\
\hline scale & $\begin{array}{l}\text { "specialization/standardization } \\
\text { "spreading fixed inpuls over } \\
\text { large amount of outputs }\end{array}$ & production costs
\end{tabular}

scope

- exhausting of common resources by multi-product functions

production costs + transaction costs

atmosphere

* human asset specificity

- reciprocity

- information advantages

Iransaction costs + production costs*

\begin{abstract}
- Since the mainstream literature on the economics of atmosphere focuses on transaction costs rather than production costs (TCE), production casts were neglected in this study. This does not imply that atmosphere does not affect production costs. Since atmosphere affects the productive/cooperative attitudes of agents, their job satisfaction, and the appropriateness of their stock of production information, it would be highly implausible if the firm's production cosis would be totally unaffected by it. Moreover, economizing on production expenses and economizing on transaction costs are nott independent.
\end{abstract}

\title{
3.8. Concluding Remarks
}

This previous sections have identified three views of the firm which may be relevant for exploring economies of atmosphere.

(i) The microeconomic theory of the firm is nol parlicularly helplul, since it is a theory of markets rather than a theory of the firm. In addition, tangible rather than intangibile assets are emphasized - at least in the handbook versions of the microeconomic theory of the firm.

(ii) Team theory, agency theory and transaction cost economics are more promising. The main emphasis of this chapter is on TCE, since it has integrated atmosphere as an environmental variable in its central (OFF) framework. Regarding the research questions, the preceding sections yield the following conclusions:

1. It maly be argued that the concept of economies of atmosphere is consistent with the economics of organization which is complementary to the microeconomic theory of the firm. 
2. An atmosphere of trust and faimess may be helpful in realizing the mutual gain "where this is technically possible, in team production. From a contractual perspective, economies of atmosphere are captured when the focal principles of the firm complete incomplete contracts. In order to be competitive, these focal principles have to be adequate. TCE discusses the peer group atmosphere as a favorable condition for economizing on bounded rationality and attenuating opportunism. In large number conditions, for instance the internal labor market of large firms, human asset specificity is regarded as an antecedent condition for an atmosphere of reciprocity. Atmosphere is efficient when human assel specificity exists, because it offers sacurity to the employer, and economizes on labor and turnower costs from the employer's: point of view. Diseconomies of atmosphere are captured when the the optimum span of implicit: contract is exceeded. At some point, the benefits from increasing the span of contract are outweighed by the inefficiencies engendered by the fact that the culture is applied in contingencies to which it is not well suited.

3. Costs are positively associated with the development of focal principles. These cosis are especially thigh in formulating and implementing alternative focal principles when the traditional principles prove to be inadequate. The simple contraclual schema shows that the costs of providing safeguards are compensated by the lower supply price of human capital. Thus, it costs time and money to provide an atmosphere of mutual risksharing, but it pays to do so.

(iii) The information processing approach of the firm deals with atmosphere as a common code, common knowledge of specific facts, and common knowledge of behavioral rules.

1. Each of these dimensions is believed to affect the cost efficiency of the firm's responses.

2. Why are these dimensions afficient? It is argued that the more developed the common slock af knowledge the more it will facillitalle appropriale and fast responses - by providing easy access 10 information, increasing the predictability of the other agent's behavior, and by coordinating the bounded rationality of the different members of the organization.

3. Costs are associated with atmosphere because it takes joint efforts and thime to develop a common stock of knowiedge. Diseconomies of atmosphere are captured when an inadequate stock of knowledge has been developed. Since the efficiency of a firm can only be identified as compared to the efficiency of olher firms (or to its efficiency in the past, absiracting from technical progress), (dis)economies of atmosphere can only be conceived as a competitive (dis)advantage. 
The previous chapters have focused on economies of atmosphere at the industry and the firm level. An attempt has been made to make plausible that an efficiency function can be attributed to atmosphere. Moreover, explanations have been given why economies of atmosphere exist at the industry and the firm level. These are preformal explorations in economic theory suggesting that there is a rationale for economies of atmosphere. Following Aoki (1984), it is believed that it is not necessary to rely exclusively on historical or (descriptive) cultural explanations to understand the economic structure of the Japanese firm, business group sitrategies, the success of the excellent firm or the internal labour market of large firms, where an economic rationale can be found for the understanding of these economic phenomena.

The world of deductive reasoning is not similar to the empirical world. It is a quite different thing to demonstrate that there is a rationale for economies of atmosphere, and to demonstrate that there is empirical evidence for economies of atmosphere. Thus, the tough question is how to study economies of atmosphere. Since the economic problem is saving on production and transaction costs, empirical studies on the impact of atmosphere on efficiency have to take economies of scale and economies of scope into account as well. (As mentioned before, atmosphere is expected to affect production costs as well, but the theoretical part of this study did not deal with them, since the mainstream TCE literature focuses on transaction cosls minimization).

Besides, valid instruments are needed for the measurement of atmosphere and performance. Finally, a selection has to be made of organizational units where economies of atmosphere can reasonably be expected. The next Section (II) of this book deals with the sampling and measurement problem. The subsequent Section (III) reports the results of two empirical studies which deal with the joint and the differential impact of economies of scale, scope, and atmosphere on scientific productivity in clinical medicine and economics. 
SECTION II. DESIGN AND MEASUREMENT 


\subsection{Introduction}

The first section of this chapter discusses the contribution of organization science in the empirical studies presented here. Researchers in organizational theory (often originating from sociology) and organizational behavior (often originating from psychology) have paid much attention to general and specific values in organizations. Their approach has provided in-depth insights in atmosphere at the organizational level. Several typologies of organization have been developed in organizational theory which enable meaningful comparisons to be made between organizations (Burrell and Morgan, 1979; Lammers, 1986). These typologies may provide a theorretical basis for the partitioning of samples in organization studies. The present chapler will discuss Ouchi's typology (1980). Building on the work of Willamson. Ouchi has developed a typology of markets, bureaucracies, and clans. Following TCE, Ouchi hypothesizes that the probability that economies of atmosphere will be captured is dependent of the organizational form. In a sense, Ouchi has formulated a contingency approach of atmosphere which focuses on the efficiency properties of the clan organization in comparison with the bureaucracy and the market. These organizational forms are, of course, ideal types in the sense of Weber. Consequently, the pure form will seldomly be observed in real life orgainizations. As a heuristic device, however, his typology may provide a useful basis for the empirical axploration of economies of atmosphere at the micro level.

1 Sections discussing the psychometric properties of instruments are partially based an research conducted in cooperation with Triandis and co-workers, University of Illinois (USA), and Holstede.

Triandis, H.C. and Bontempo, R., Betancourt, H., Bond, M. arid Lelung. K., Brenes, A., Georgas, d., Hui, C.H., Marin, G., Setiadi, B., Sinha, J.B.P. and Verma, J., Spangenberg, J.F.A., Touzard, H. and de Montmollin, G., The Measurement of the Etic Aspects of Individualism and Collectivism across Cultunes, Australian Journal of Psychology, Vo!. 38, No. 3, 1986: 257-267.

Hofstede, G.H. and J.F.A. Spangenberg, Measuring Individualism and Collectivism at Occupational and Organizational Levels, in: C. Kacitcibasi (Ed.), Growlh and Progress in Cross-Cultural Psychology. Berwyn: Swets North America Inc., and Lisse: Swets and Zeillinger B.V., 1987: 113-122. 
Subsequent sections will discuss the contribution of organizational behawior research in the empirical studies presented here. Coming from a rich measurement tradition (Price and Mueller, 1986), organizational behavior researchers have designed several measures of related concepts of atmosphere particularly organizational climate and culture. The focus of these concepts is on atmosphere as a set of values rather than as a stock of knowledge. Unfortunately, the psychometric properties of the instruments are not always prowided in the literature. More information is provided about their construct validity (which can be idenlified by testing hypotheses concerning their relation with dependent variables), which proves to be fairly good. Other chapters focus on the psychometrics of the measures, i.e. their internal consistency in the specific samples being investigated, whereas the present chapter will mainly discuss their background, content, and relation with performance in a variety of organizations.

\subsection{Ouchi: Markets, Bureaucracies, and Clans}

The comparative basis for Ouchi's typology is the nature of the transaction. Building on transaction cost economics, Ouchi has developed a typology which seeks to explain cooperation among a collection of individuals who share only partially congruent objectives. When a team of individuals collectively produces a single output, the problem develops of how to distribute the rewards emanating from that output in such a manner that each team member is equitably rewarded. If equitable rewards are not forthcoming, it is assumed that rnembers will adjust their efforts in future cooperative ventures in such a way that all will be worse off. In a number of papers Ouchi and colleagues have distinguished three different mechanisms through which organizations can seek to cope with the problem of performance evaluation and control. The three are referred to as (i) markets, (ii) bureaucracies, and (iii) clans.

(i) As a pure model , the market is a very efficient mechanism of control. Linder the assumption off perfect competition, prices are sufficient statistics in the market. They convey all of the informalion necessary for rational decision making. In addition, prices provide a mechanism for soiving the problem of goal congruity. Given a frictionless price mechanism, the firm can simply reward each employee in direct proportion to this contribution - no more, no less - so that an employee who produces little is paid little, and all inducements, being exactly in proportion to the contribution, are tair.

(ii) In marked contrast to the market, the bureaucracy described by Weber [1922] is subject to a variety of explicit routines of monitoring and directing. The fundemental mechanism of control involves close personal surveillance, and direction of subordinates by superiors. The information necessary for task completion is contained in rules which gre partial rather than 
complete bundles of information, and which consume a good deal of administrative overheads. Generally, prices are more efficient means of controlling transactions than rules are. However, the conditions necessary for frictionless prices can rarely be met. In such conditions the buireaucratic form is prefierred.

(iiii) In the clan, the information is contained in the rituals, stories, and ceremonies which convey the values and beliefs of the organization. Thus, the clan has a very efficient set of symbols with which to communicate complex ideas, which fits the very limiled information processing capacity of the organization. The information system does not require an army of middle managers, controllers, and accountants. Moreover, outsiders cannot quickly gain access to information concerning the decision rules in the organization. A classic example of a clan are the ethnic enterprises in America (cf. Ouchi, 1980). The Chinese American 'Hui' "and the Japanese American 'Tanomoshi", are revolving credit lending socleties which provida venture capital for starting new business. They carry out all the functions of any Wall Street investment bank, but within their ethnic group they are able to make loans which would be far too risky for any bank because they enjoy considerable advantages in obtaining, interpreting and evaluating information about potential borrowers or members. None of their practices are explicit - even the rate of interest paid by borrowers is left unspecified and implicit. The clan has also comparative advantages with regard to controlling and disciplining its members. Entry into these ethnic groups is strictly limited by birthright, a practice which guarantees that each member is a part of a social and kinship network which will support the values upon which the control mechanism is founded.

\subsubsection{The Efficient Culture Hypothesis}

Clearly, a clan is more demanding than either a markel or a bureaucracy in terms of the socilal agreements which are prerequisite to its successful operation. Because the clan lacks the explicit price mechanism of the market, and the explicit rules of the bureaucracy, it relies for its control upon a deep level of common agreement between members of what constitutes proper behavior. In contrast to the market and the bureaucracy, not only reciprocity (market) but the combination of reciprocity and legitimate authority (bureaucracy) are normalive requirements. For the clan, intensive commitments and common values are important as well. Despite the costs assaciated with the development of a clan "the clan will be more efficient than competing bureaucratic or market forms under conditions of ambiguity, complexity, and interdependence of transactions. This is the efficient culture hypothesis (Wilkins and Ouchi, 1983) On the basis of collective interests, decisions can be made relatively quickly, and with a high level of agreement, which allows the clan to function under conditions of great uncertainly (Ouchi, 1979). 
Wilkins and Ouchi have argued that clan control requires the development of shared knowledge in two areas: (i) a general paradigm that helps participants determine what is in the best interest of the collective, and (ii) the perception of goal congruence, i.e. the belief in a general or long term equity. The paradigm provides members with a sort of master routine that enables them to solve two probilems stemming from their bounded rationality. The first problem is that they are limited in their ability to comprehend and process information. The paradigm may give them categories, processing routines, and examples of good and bad solutions which will greatly increase their ability to determine how to operate. The second problem is that boundedly rational members of an organization must communicate with other boundedly rational members. This allows for misunderstandings, especially in transactions which are complex and uncertain. The paradigm of the clan, however, prowides shared frameworks (values, code, knowledge of facts) that can help members to start from similar assumptions in deriving solutions to previously unfamiliar problems.

The clan is similar to organizational torms which are described by other authors; e.g. Etzioni's (1961) "normative organization", Selznick"s (1957) "institution", Peter and Waterman's (1982) 'excellent company', and to one of Mintzberg's (1979) configurations, i.e. the missionary configuration (standardization of values). While some degree of ideology can be found in every organization, that degree can vary considerably. At the one extreme are organizations where direct supervision or standardization of the work process are dominant. In most of these organizations ideology is less important than in those organizations where standardization of norms is the central coordination mechanism. One of the consequences of standardization of norms is that members need not be closely supervised. For example, the long intensive training of scientists is a guarantee that wherever they go afterwards, they will be able to do their work in accordance with the methodological and professional standards of the scientific forum. Other characteristics of clan-like organizations are charismatic leadership (Wober, 1922; Etzlonl, 1961), and non-market or altruistic relationships. More or less pure examples of this form have been found found in utopian communities (Kanter, 1973), the Royal Navy (Lammers, 1963), and R\&D units (Ouchi, 1980). The empirical studies presented here, however, will only deal with the general and specific values as a characteristic of a clanlike organization. Moreover, they will locus on the content rather than the strength of these values.

The efficient culture hypothesis suggests that economies of atmosphere are to be expected in clans, because the price mechanism and central authority are iniadequate to deall with the complex informatlon that has to be processed in the clan. The hypothesis can be tested in two 
Ways: by comparing the coordination mechanisms of a sample of markets, bureaucracies, and clans, and by comparing clans which operate within the same sector.

When it can be demonstrated that the clan is better off with economies of atmosphere than with sufficient statistics (price mechanism) or bureaucratic procedures, or that the buteaucracy is better off with rules than with atmosphere "the hypothesis is confirmed. In order to compare the efficiency of these different governance structures, it is necessary to measure their performance in a slandard way. This, however, will in general not be feasible, because different governance structure are often associated with different technologies and different outputs. The performance of a financial market, a paper mill (bureaucracy) and a university hospital (clan-like), for instance, are yet difficult to compare.

Consequently, the design here is to compare the performance levels of clan (-like) organizations which are active within the same sector. The advantage of this allemative approach is that the production technology, the type of skills required to do the job, and the performance criteria are fairly constant. The efficient culture hypothesis here states that economies of atmosphere are captured by high performers rather than by low performers.

The organizations included in the sample here are university research units. On the one hand, it should be mentioned that these units are not organized as clans. Since they work within the university they are operating part of a multi-level professional bureaucracy (Mintzberg. 1979; Hazeu, 1989). In addition, they are subject to centralized decision making (government, central administration). Since the members of a university research unit are differentiated by rank (traditionally, assistant, associate, and full professor) "the decision making in the unil will generally be hierarchical. On the olner hand, university research units have similarities with the clan organization. First of all, the members share professionall values. The research unit relies for its control upon a deep level of common agreement between members of what constitute proper scientific behavior. Loss of reputation (which is their main scientific capital) is associated with disobeying the methodological norms of the international scientific 'Forum' (De Groot, 1984). Since reputation in sclence is comparable with brand name in industry, income effects can be expected when the scientific capilal of individuals or units (funding) increase or decrease. In addition "the work process cannot be coordinated by centrallized rules, so that bottom-up planming rather than top-down planning, and consummate rather than perfunctory cooperation are required. Furthermore, universily research is characterized by high task uncertainty. As a result, incomplete contracting is unavoidable, and focal principles are required to complete the incomplete contracts. Thus, atmosphere can be an efficiency inducing mechanism in the university research unit. However, since it is a hybrid 
organization, having both bureacratic and clan features, its performance is dependent of a combination of rules and atmosphere rather than atmosphere alone.

In sum, provided that the efficient culture hypothesis is lested in the empirical studies presented in chapter $6 * 7$, it is certainly an imperfect test of the hypothesis. First of all, instead of comparing markets, bureaucracies, and clans, high and low performers are compared within a sample of university research units. These units represent a hybrid form combining both bureaucratic and clan features. However, assuming that the (central) bureaucratic features of university research units operating within the same country and scientific discipline will be rather constant, it may be conjeclured that high performers in university science capture economies of atmosphere rather than bureaucratic economies.

\subsubsection{Interim Conclusions}

Organizational theory provides a theoretical basis for partitioning the sample. The preceding section focused on Ouchi's dislinction of markets, bureaucracies, and clans. Since Ouchi assumes that atmosphere is especially efficient in the clan organization, his typology provides a theoretical basis for studying economies of atmosphere at the microlevel. Arguments are given for a design which enablles the comparison of performance levels of clan -like organizational units operating within the same sector and the same governmentall structure. The advantage of this approach is that the production technology, the skills required to do the job, the central (governmentaly decision making, and the performance criteria are fairly constant. The efficient culture hypothesis here states that economies of atmosphere are captured by high performers rather than by low performers, i.e. that organizational climate and culture will be positively correlated to performance. Since a hybrid form rather than a typical clan organization has been included in the sample, due to practical reasons, the efficient culture thypothesis is imperfectly tested.

\subsection{Organizational Cllmate Research}

Wilkins and Ouchi deal with the benefits of supplying an adequate atmosphere in the clan organization. The tough question is, of course, how to study their efficient culture hypothesis. Obviously, the availability of instruments for the assessment of atmosphere is important for the conduct of this research. Organizational behavior as a research field has specialized in the design of instruments to assess organizational dimensions (Van de Ven and Ferry * 1980; Price and Mueller, 1986). Regarding atmosphere, the literature has focused on the measurement of organizational climate and culture. No instruments are yet available with regard to atmosphere as a common stock of knowledge. Consequently "the efficient culture hypothesis can be tested 
only with regard to atmosphere as a set of values. The next section focuses on the measurement background of general and specific values in organizational climate, and general values in culture research at the national and organizational level. Furthermore, attention is paid to empirical research in which these measures have been used to test construct validity.

\subsubsection{General Climate Measures}

The first studies of organizational climate were initiated by Kurt Lewin in the 1930s. Lewin believed that it was possible to undertake experiments in the social sciences comparable with those in physics and chemistry. Lewin and colleagues attempted to study atmosphere as an empirical reality in an experiment involving the behavioral effects of three different leaderinduced atmospheres. In nearly all cases, differences in behavior were altributed to differences in the experimentally induced climate rather than to constant characteristics of the group members. In addition, it was found that the climate had an important effect in determining the perception of leader behavior and the reaction to it by the group members. A group which had passively accepted an authoritarian leader in the beginining of its group history, for example, was resistant to a second authoritarian leader (Lewin, et al., 1939).

Litwin and Stringer (1968) experimentally created three simulated firms competing in a realistic, competitive industrial market under simulated business conditions. Three different climates were created: an authoritarian climate, a democratic climate, and an achlewing climate. The differing orientation of the president of each firm was the means by which the three climates were created. The differing leadership styles had a marked effect in creating different organizational climates. Once created, the styles had significant elfects on participants. Subjects in the achieving climate produced the most, whereas the democratic climate resulted in high levels of job satisfaction. Field studies of organizationall climate have been conducted in R\&D organizations (Pelz and Andrews, 1966), industrial organizations (Zohar, 1980), and the services seictor (Schneider and Bowen, 1985).

In their field research, Litwin and Stringer measured climate by alsking organizational members to respond to questionnaire items pertaining to categories like responsibility, reward, risk, support, standards, conflict, and identity. These categories were then used to develop some 50 specific items for a questionnaire. Each item was measured on a 4-point scale. When administered to the members of an organization, the tabulated results were considered to be a measure of the perceived climate of that organization. In their book on Motivation and Organizational Climate, Litwin and Stringer (1968) reported the first climate findings in services and manufacturing units. Their dimensions have been developed through their theoretical and empirical studies. In contrast to recent investigations on organizational 
climates: or practices (Hofstede et al., 1988), Litwin and Stringer did not use factor analysis but content analysis and MANOVAs. In addition, they preferred laboratory studies rather than the survey method.

The dimensions included by Likert (1967) to measure the human characteristics of organizations include, in large part, the dimensions assessed by Litwin and Stringer. Likert's questionnaire has been used to assess the degree to which organizations are perceived as system 1, as opposed to system 2-4 types. Likert called these organizational types: exploitive authoritative, benevolent authoritative, consultative, and participative. In the Likert model, each type is conceived as an internally consistent whole of which organizational climate is a major part. In terms of Burns and Stalker (1961), the system 1-2 types are more mechanistic, whereas the system 3-4 types are more organistic.

Litwin and Stringer's dimensions were originally designed to describe motivalional climates. Redding (1977) successfully applied Litwin and Stringer's climate questionnaire in a study on the climate-performance relation in supermarkets, thus establishing convergent validity of the motivalional climate measure. However, the questionnaire has also been used to measure general values. Poole (1985) has argued that this general use of the measure is not always justified by empirical research, for example because factor analyses in other studies isollated considerably different dimensions from those found by Litwin and Stringer. This should not be very surprising given the fact that Litwin and Stringer's dimension were not isolated by factor analysis. Moreover, they used laboratory studies which have high internal but low external validitly.

\subsubsection{Specific Climate Measures}

Problems with general climate dimensions have given rise to an approach which identifies climates at a lower level of abstraction, i.e. climates of specific organizations. Schneider and Bartletl (1970) have explored climates in life insurance agencies. Schneider (1980) isolated dimensions of customer service climates for banks. He hypothesized that service customers are exposed to the same climate that affects employees, and that customers would be better served if service organizations were structured 10 meet and satisfy the needs of their employees. The logic of this hypothesis is that employees in service agencies desire to give good service, due to a self-selection effect, and when those desires are made easier by management's support, both employees and consumers are ilkelly to react positively. Since service organizations are extremely dependent on goodwill, the study of Schneider and co-workers (1980) have focused on the goodwill perceptions of bank customers. 
Poole (1985) has observed that the rellation between climate and performance measures tends \#o be stronger when specific climate measures are used. For example, using a specific measure of customer service climate, Schneider and colleagues (1980) found higher zero-order correlations between climate dimensions and customer perceptions of quality than Johnes and James (1979, in: Poole, 1985) who used general climate dimensions for two samples of naval divisions. An example of the specific climate approach is Zohar's (1980) paper on the safety climate in industrial organizations. Zohar constructed a 40-item measure of organizational climates for safety. This measure reflects employees" perceptions about the relative importance of safe conduct in their occupational behavior. It can vary from highly positive to a neutral level, and its average level reflects the safety climate in a given company. Zohar shows that there is an agreement regarding safety climate in their company, and that the level of safety climate is correlated with safety program effectiveness as judged by safety inspectors.

In the first half of the 1970s, the literature on organizational behaviar contained discussions regarding the possible overlap of job satisfaction and organizational climate research. It has been argued that the new climate measures have been created from oll measures of job satisfaction (Guion, 1973). In addition, Johannesson (1973) found that most of the variance in a perceptual measure of organizational climate could be subsumed in factors traditionally found in job satisflaction research. However, the data from which this was inferred are from studies in which the unit of analysis was predominantly the individual. Schneider and Snyder (1975) have argued that an empirical distinction between the concepts of satisfaction and climate is possible if each variable is assessed according to an appropriate unit of analysis which is the individual in satisfaction research. In contrast, organizational climate is mostly conceptualized as an aggregated perception which people have of their organization, so that the appropriate unit of analysis is the organization rather than the individual (Glick,1985).

\subsubsection{Productive Climates in R\&D}

The utility of specific climate measures for the understanding of organizational effectiveness has also been demonstrated by Pelz and Andrews (1966). Their book on productive climates for research and development was one of the first major studies to examine the relationship between scientific performance and the organization of the laboratory which, in essence, implies a managerial approach to science. Rigorous methods of research were applied to answer the question what constitutes a stimulating atmosphere for R\&D. Information about technical performance, working relationships, and motivation was collected from 1300 scientists and engineers located in eleven industrial and governmental laboratories, and seven university departments. The data were analyzed to determine what conditions - either in the environment or in the individual's orientation towards it - actulally accompanied a high or low level of 
periormance. Pelz and Andrews (1966: 80) give the following description of a typical atmosphere: "In some laboratories the air seems to hum with excitement. Investigators are absorbed in what they are doing - their lindiwidual projects or the laboratory's mission. Coffee breaks buzz with shop talk instead of baseball; $50^{\circ}$ clock quitting time is the exception instead of the norm. The morale, in one sense of that overworked term, is superb".

\subsubsection{Selection of a Specific Climate Measure}

Pelz and Andrews have attempted to measure such an atmosphere of excitement and dedication by quesilionmaires. Concerned with the reliability of their measures, they examined the extent to which answers were stable over a two-month interval. Their climate measures showed highly consistent results. Concerning the construct validity of their standardized measures, the extent to which the empirical relationships based on using the measures are consistent with theory about the concept, the expected relationship between climate and performance were empirically verified. Since all data in Pelz and Andrew's study were collected in American laboratories, and it was noll clear how applicable the findings would be in other countries, UNESCO commissioned an international research team to conduct a large scalle European study on the organization and performance of research units. One of the most important findings of their investigation was that the R\&D process seems to be responsive to similar organizational factors whatever the particular national setting in which research units happen to be located. Although signifficant differences appeared in the survey data between the participating European countries as regards R\&D management and climate of work, the rellations that emerged between these factors and the scientific productivity of research units tend to show the same directional patterns (Andrews, 1979: 9). Furthermore, the major relationships observed in the data from European countries tend to be consistent with the findings from Pelz and Andrews. "General atmosphere of the (research) unit' is the climate measure which is most rellevant for the purpose of study $I$ and $I I$ (Andrews, 1979: 453-54). This measure was selected to be used in the empirical studies reported in part $I I \|$ of this study. In order to oplimize the UNESCO measure, it was extended with items which were specific for the Dutch samples. In addition, factor analysis was used to determine latent variables in the extended measure. As a result, two climate dimensions were found. One of them was llabeled "innovattive climate', the other 'publication cllimate". Detailed results of the factor structures are given in Bally et al. (1987; statistical appendix). 


\subsection{Culture Research}

Cultural anthropolagy is the discipline which has specialized in studying customs and values of distinct groups of people - in exceptional cases, of whole nations. As compared to the qualitative mainstream of anthropological research, Hoistede's (11980) work stands out as having provided a scientific advance, because it seeked to compare cultural dimensions on a quantitative basis. Measurements in more than 40 countries were collected pertaining to different subsidiaries of one multinational company. The results reflect both national and organizational characteristics. They are based on 116,000 questionnaires completed by respondents matched by accupation. age, and sex, at two different points in time. One of the sirengths of the study is that it relates the general values identified among the employees of that multinational to numerous other studies (thus obtaining convergent validity), as well as to the antecedents and consequences of these values. Looking for nationall patterns in work-related values, factor analyses revealed that the value patterns dominant in these 40 (later expanded to 50 ) countries varied along 4 dimensions which were called (i) individualism versus collectivism, (iii) large or small power distance, (iii) strong or wealk uncertainty awoidance, and (iv) masculinity versus femininity. According to Hoffstede all 4 are related to fundamental issues in human socielles, but issues to which different societies can produce different answers. The next section discusses the relation between two of these dimensions and organizational theory.

\subsubsection{Work-Related Values and Organizational Theory}

Power distance and uncertainty avoidance are subjective indices of two organizational dimensions, i.e. centralization (distribution of power) and formalization (reduction of uncertainty). Combining the two dimensions, Hofstede distinguishes 4 organizational types: the pyramid, the well-oiled machine, the village market, and the family.

Exhibit 1. Images of Organization

power distance

high

high

machine

pyramid

low

market

familly 
The pyramid is a hierarchical structure held together by the unity of command as well as by rules and procedures. The exercise of personal command is largely unnecessary in the machine because the rules seltle everything. The market is characterized by a lack of decisive hierarchy and flexibie rules. The family is characterized by undisputed charismatic authority of the leader but few formal rules. Hofistede's findings suggest that the dominant underlying model of an organization for the French is the pyramid, for the Germans the well-oiled machine, for the British the village-market, and for the Indonesians the family. Although national data are the basis for Hofstede's typology, it tends to be consistent with the classification of Likert (system 3-4 versus system 1-2 organizations). Ouchi (markets, hierarchies, and clans), and Mintzberg (adhocracy, bureaucracy, and missionary). This would imply varying national preferences for specific organizational forms.

\subsubsection{Robustness, Convergent Validity, and Test-Retest Rellabllity of the VSM}

Bosland (1985) has addressed the temptation of confusing Hofstede's culture dimensions with dimensions of personality, measured at the individual level of analysis. Like the Value Survey Module (VSM) which permits the replication of Hofstede's (1980) comparison among countries, cultural scales are composed of items collected from individuals, but for which the mean country scores are strongly correlated across countries. The same items do not necessarily correlate across individuals within a country, and thus the VSM should not be used as a personality test.

Nevertheless, the findings of other researchers testify to the convergent validity of Hofstede's methad. Independent of Hofstede's work, Hui (1984) developed a 63-item individualismcollectivism scale showing discriminant validity in the various subscales, 1.e. one can predict some phenomena from one of the scales but not from the other scales. Triandis (1985) used the most promising items of Hui in a new instrument that was administered to samples in nine countries. Since these countries were included in Hofstede's study, scores and ranks obtained for the nine countries in the two sludies could be compared resulting in a significanl rank correlation coelficient of $\mathrm{rho}=73$, and $p<.013$ (Triandis and Bontempo, et al. 1987).

Hofstede and Spangenberg (1987) have found that correlation patterns of the same dimensions differ not only between individual data and aggregated data, but that the level or type of aggregation is equally important. Factor analyses showed that the fourteen items which formed the basis for measuring individualism and masculinity. two meaningful and repeatedly validated measures at the national level, cannot be used at either the occupational or the organizational level. Other operationalizations are required to apply these concepts for those levels, based on how they manifest themselves as characteristics of an occupation or 
organization. Concerning the remaining dimensions, it appears that power distance can be measured with the same questions at the country, occupation, and organizational levels, while the measurement of uncertainty avoidance is specific to the country levels. Concluding, the VSM is not an adequate instrument for the measurement of work-related values at the organizational level - except, perhaps, for the power distance index.

Hofstede's data bank contains data from two points of time (around 1968 and 1972). Consequently, it is possible to examine the test-retest reliability of the VSM. It appears that the country answers on the items composing the Power Distance Index do not shift together over the four-year period, nor do those composing the Uncertainty Avoidance Index. This means, that, as far as the shift over time is concerned, PDI and UAl are not homogeneous indexes. The two remaining dimensions, masculinity and individualism, show more or less homogeneous. shifts, so that an overall shift toward stronger individualism and masculinity could be identified. Compared with the shift in individualism, however, the shift in masculinity is relatively minor (Hofstede, 1980: 361).

\subsubsection{Interaction befween National and Organizational Level}

As mentioned before, the concept of culture can be studied at different levels of analysis. Lewin (1948) and Hofstede (1980) explored cultural differences between countries. Lammers and Hickson (1979) have studied the influence of national culture upon organizations, whereas other authors explored corporate cultures in a variety of organization like the Royal Dutch Navy (Lammers, 1963) and high tech multinational firms (Schein, 1985). The interaction between national and organizational cultures was investigated by Soeters and Schreuder (1988). Using the VSM, the authors describe the cultural differences between local and international (USA) oriented accounting firms operating in the same national culture. From Hofstede's study it could be hypothesized that, if any differences exist between the Dutch and the international (U.S.-oriented) firms, they would be especially pronounced on the dimension of masculinity (achievement motivation). Since the members of international offices were found to be more oriented towards high income and good career perspectives, this hypothesis was confirmed, thus validating the VSM at the national lewel. With respect to uncertainly avoidance, Soeters and Schreuder found a deviation from Hofstede's findings whilch has been altributed to an industry-specific difference between the accounting firms and Hofistede's multinational company (IBM).

In addition, Soeters and Schreuder $(1986 \mathrm{~b})$ have studied the relationship between workrelated values and performance in accounting firms. The performance of individual accountants was measured by self ratings of their work performance, contribution to the corporate goals. 
Iatest overall evaluation, and promotion opportunities as compared to their colleagues. Reilating these (individual) pertormance indices to Hofstede's dimensions, the authors found that accountants who valued income and career perspectives higher than tenure and good relations with colleagues (higher masculinity) make more than average effort and perform better. In addition accountants who expect to work longer for the organization (higher uncentainty avoidance) make more than average efforts. This result is explained as follows: first of all. accountants who expect to stay longer than average are the members with the best career perspectives in the "up or leave" reward system. Second, long term perspectives increase the Identification with the firm which is generally expected to result in increasing work efforts and productivity. The relevant conclusion for the present study is that the authors, more or less, showed construct validity of the WSM with regard to work performance.

\subsubsection{Organizational Practices}

In a recent paper, Hofstedie distinguishes 4 cultural levels: symbols, heroes, rituals, and values. Symbols are the most superficial expression of culture, while values are at the deepest level of mental programming. The previously mentioned sludy of Hofstede (1980) has omphasized the differences in values at the national levell. Recent work focuses on heroes and rituals as well (Holstede et al , forthcoming). Unlike the first study which kept the organizational environment constant while maximizing the variance between countries, the second study maximizes the variance at the organizational level within the same countries. Organizations in the private and public sector were included, and within these organizations marketing, production, and $R \& D$ units participated in the study $(N=20)$. Factor analyses of the answers across the 20 units revealed six dimensions of 'practices' (symbols, heroes, and rituals), together explaining more than $70 \%$ of the variance in the unit means. They were process versus results arlented, employee versus job oriented, parochial versus professional, open versus closed, tight versus loose, and flexible versus rigid. Factor analyses concerning work-related vallues ylelded similar dimensions to those from the and uncertainty avoldance) and one new dimension (work centrality). The range of mean scores across the units is much smaller for the value questions than for the practices questions composing the six dimensions which are the core of the organizational cillture. Practice differences are only partly related to value differences, which suggests that a change in organizational culture is feasible without a change in values.

The organizational culture dimensions found by Hotstede and colleagues show some resemblance to Litwin and Stringer's (1968) general climate measures. For example, an organization which sets high standards for performance (Litwin and Siringer"s 'standards") is likelly to be 
results rather than process oriented; an organization in which members of the organization support each other ("support") is likely to be employee rather than job oriented.

\subsubsection{Interim Conclusions}

The organizational behavior literature has provided valid and reliable instruments for the measurement of organizational climate and culture. Measures of specific climate dimensions which are relevant for the purpose of study \| and II have been designed by Andrews (1979), while Hofstede (1980; Hofstede et al. forthcoming) has constructed measures for general 'values' or 'practices' at the national (value survey module) and organizational (organizational culture module) level. Apart from the latter, these standardized measures prowed to be useful in organizational research. Empirical studies testing the extent to which these measures are associated with performance suggest construct validity.

\subsection{Concluding remarks}

The tough question is how to study economies of atmosphere. In order to test the hypothesis that amosphere affects internal efficiency, it is necessary to: (i) select organizational units where economies of atmosphere can reasonably be expected, (iii) select instruments for the measurement of atmosphere, (iii) select instruments for the measurement of efficiency, and (iv) design controls for internal and external validity

This chapter has concentrated on (i) and (ii). Orglanizational theory provides a theoreticall basis for partitioning of the sample. The text has particularly focussed on Ouchi's typology of markets, bureaucracies, and clans. Since Ouchi assumes that atmosphere is especially efficient in the clan organization, his typology provides a useful theoretical basis for studying economies of atmosphere at the micro levell.

The organizational behavior literature has prowided useful instruments for the measurement of organizational climate and culture. This chapter has discussed several climate and culture measures of which have been selected for further use: an UNESCO measure of work climate in research units, and Holstede's measures for general values or practices at the national (VSM) and organizational level (OCM). Although research has shown that, except for power distance, VSM items do not provide robust operationalizations at the organizational level, the WSM has been selected for the studies which are reported in the next chapters. The reason for selecting the VSM is a pragmatic one: allernative measures were not yel available when the first study started. When the second study started. Hotstede and co-workers had just finished their psychometric work, resulting in the formulas required for the computation of OCM dimensions. 
Consequently, the follow-up study could explore economies of atmosphere in lerms of workrelated culture (VSM: 4 dimensions) and organizational culture (OCM: 6 dimensions).

This chapter has discussed the background and the main dimensions of this measurement tradition. Since the research reported in the next chapters will focus on scientific organizations; a selection has been made of one specific climate measure. In addition two geneial measures were selected for the assessment of work-related values and organizational culture. In sum, the following measures of atmasphere were inserted in the questionaire of the present studies:

(i) spocific research unit climate measure designed by UNESCO (Andrews, 1979) (study I and II);

(ii) a general work-related values measure, i.e. the VSM which is composed of 13 items measuring 4 work-related values (Hoistede, 1980) (Study I and 11):

(iii) a general measure for organizational cullure - the OCM which is composed of 18 items measuring 6 organizational practices (Hofstede et al., 1988)(study II).

While measures (ii) and (III) are used in a previously standardized way, measure (i) has been extended with items specific to the samples being investigated. The factor analyses resulting in two new climate dimensions, labeled "innovative climate" and publicalion climate", are discussed in Bally et al. (1987: Statistical Appendix). They include principal components analysis and Varimax rotation (SPSS ). 


\title{
5
}

\section{University Research Management:}

\begin{abstract}
"Before the twentieth century, most research and development was conducted by a single scientistengineer who worked alone or with a few assistants. Today, institutes and research centers are multiplying in mainy parts of the world. Most of today's scientists and engineers depend on these organizations for equipment and support" (Pelz and Andrews).
\end{abstract}

\subsection{Introduction}

This chapter is based on the premise that research organizations provide more than facilities for their members. They also provide an atmosphere which may either stimulate or inhibil the scientist's performance. Despite the immense resources used in the support of university research, little is known from scientific evidence about the best way to operate a university department. Until recently, all data were collected in R\&D laboratories (Pelz and Andrews, 1966; Andrews, 1979; Allen, 1977). Only recently, has the managerial approach to science been applied to university depariments (Keller, 1986).

Two empirical studies have been conducted: a study in medical research clepartments of Dulch university hospitals, and a study in comparable units in economics. The first study was carried out in the period 1986-1987 by a team consisting of $Y$. Bally. J. Spangenberg. R. Starmans, B. Breemhaar, and F. Nijhuis. It consisted of a qualitative part (coordinated by Starmans and Bally), and a quantitative part (coordinated by Spangenberg). The report of sludy I has been published by the Nederlandse Staatsuitgeverij (Bally, Spangenberg, and Starmans, 1987). The design and main results of the quantitative part of study I are reported in chapter 6 of this book. The study departments of economics - study 2 - emphasized the quantitative aspects, and was carried out in the period 1987.1988 by Spangenberg with statisticall assistance of Alfenaar. The results of study 2 are reported in chapter 7.

1 A review of the comparative methodology on which this chapter is based has been accepted for publication: Hofstede, G.H. and J.F.A. Spangenberg. Technike der Internationale Vergleiche. Macharzina, K. und M.K. Welge, Handwörterbuch der Internationale Untermehmung. Enzylklopädie dẹr Betriebswissenchaftslehre. Stuttgart: C.E. Poeschel Verlag. 
Both studies were conducted in academic research departments. The research question was simple to formulate but hard to investigate, viz,: which factors facilitate (incentives) or inhibit (constraints) academic research performance, and to what degree? This question has also been raised in llarge-scale performance evaluations of the Dutch contribution to the iniernational growth of medical knowledge (Raad voor Advies Wetenschapsbeleid (RAWB). $1983 \mathrm{~b}$ ) and economics knowledge (Verkenningscommissie Economische Wetenschappen (VEW). 1986). Until 1970 the Ministry of Education and Science's strategy towards university research had been an 'emergent' strategy (cf. Hardy et al. 1984; Mintzberg and Waters, 1985). If patterns of consistency were realized, they were realized in the absence of deliberate intentions. In the last two decades, however, Dutch research policy has dropped its laissez-faire attitude concerning academic research. On the one hand it was realized that 'academic freedom' is a valuable intermediate good that may generate untoreseen technological and humanitarian progress. Seeking excellence has to be encouraged because basic research in universities continues to be the national "think tank" - the crucial resenvir for new ideas and methods (OECD, 1986). On the other hand, there was an increasing recognition that an overvaluation of this academic freedom may have counterproductive consequences. Von Humbold1's concept of "die reine Wissenschaft, in Einsamkeit und Freiheit" (quated in Dynamus, 1987, p. 6) was only loosely coupled with academic excellence. The above mentioned evaluations demonstrated that the international standing of Dutch medical and economics research is, on average, moderate or even low. Notwithstanding this general observation, many individuals and groups of researchers were able to maintain high quality standards. The lack of uniformity in research performance at the organizational level - even within the same specialty - has been the slarting point of our studies on the organizational determinants of academic research performance.

\subsection{Universities as Organizations}

In contrast to industrial research and development (R\&D) units, academic research units operate within universilies which are known to be very special organizations. Several authors have stressed that university monitoring devices are extremely underdeveloped. Cohen and March (1974) describe universities as 'organized anarchies' characterized by ambiguity of goals and fuzzy decision making procedures. The most appropriate melaphor the authors could think of was the 'garbage can'. Universities are largely populated by professionals. In addition, there is an unusually high degree of task specialization. It is frequently difficult for faculty members to understand fully the research of colleagues in their own department, let alone those in other departments. The university shares few characteristics with supermarkets, governmental agencies, banks or insurance companies. 
Weick (1984: 27) describes the university as a very exotic animal: "the university organization is an adhocracy organic organization, clan, decentralized structure, loosely coupled system, organized anarchy, garbage can, or situation of pooled interdependence" ${ }^{m}$. He believes that" "an organizational culture consistent with relative inattention to coordination and control is reinforced within universities" (lbid.: 28 ).

In contrast to the literature mentioned above, there is an increasing recognition, of late, that university performance can, in principle, be monitored and improved, and that the differences between the university and other organizations are matters of degree. Many of the "unique" characteristics attributed to universities have been found and studied in such diverse locations as Japanese companies, Swedish automobile plants, law firms, and hospitals (Vroom, 1984), In his typology. Mintzberg has emphasized the common elements between accounting firms, law firms, hospitals and universities. He defines them as professional bureaucracies (Mintzberg, 1979). In this type of organization, skills and knowledge have been standardized through long years of training. The skills have a 'general' rather than a specific character (Becker, 1964), i.e. they are trained in educational systems - not on-the-job. In a sense academic members have been programmed through their own doctoral or professional sludles to do "Normal Science" (Kuhn, 1970), that is to approach their field of endeavor in generally accepted ways. von Humboldt's 'academic freedom' may be explicit freedom from administrators, but it is not explicit freedom from professional control (Hardy et al., 1984). Another characteristic of universities is that many of its members are 'cosmopolitans", that is, they are oriented to the (external) international scientific forum - in contrast to the 'locals' who are mainly orienied to life within the organization (Ritti" 1968).

\subsection{The Research Unit as a Clan-like Organization}

Given the extreme degree of specialization of academic research units (AUs), the whole university organization would not be an appropriate level of analysis for this invesligation. If one wants to compare performance levels, research units have lo be compared with other units within the same specialty (like with like). Therefore the focus of the two investigations described below has been on teams. Research teams are small peer groups. According to the literature (Williamson, 1975; Ouchi, 1980), economies of atmosphere are more likely to be found in small groups than in large systems - especially when the team consists of peers. Wilkins and Ouchi's (1983) typology of markels (where the price mechanism is efficient), bureaucracies (where rules are efficient) and clans (where culture is efficient) may provide a theoretical justification for the selection of academic research units when economies of atmosphere are explored. If culture is especially efficient in the clan - as has been argued by 
Wilkins and Ouchi - this should be empirically demonstrated by studying the determinants of performance in a typical clan. As part of the bureaucratic university system the universily research unit cannot be conceived as a a typical clan. Al best, it can be characterized as a hybrid organization (Mintzberg, 1983) having both clan and (professional) bureaucratic features. Since the clan is an ideall typical configuration which is hard to find in reality, no attempt has been made to select a typical clan. Moreover, sampling decisions were influenced by practical considerations as well. The main clan characteristics of academic research units are the shared values of the members, the combination of a small number condition with the impossibility to control the work process (requiring consummate rather than pertunctory cooperation), the dominant control mechanism (professional control/mutual monitoring), and the high task uncentainty - scientific research is conducted in a sea of unforeseen contingencies, so that ciear focal principles are needed to complete the incomplete contract. As a result, prices are considered to be less elficient in research units than in the market form of organization. However, since university research units represent a mixture of the cllan and bureaucratic form, rules cannot be excluded from the efficlency callculus. Consequently, atmosphere is not a substitute for rules, but assumed to be a compensating efficiency-inducing mechanism in the university research unit. Given the fact that the units studied here operate under the same governmental (bureaucratic) constraints, and given the low variance between university research policies as compared to, for example, U.S. universities, it may be conjectured that high performers in Dutch universily science capture economies of atmosphere rather than bureacuratic economies.

\subsection{Methodological Considerations}

Before tackling the substantive issues which forms the empirical core of this investigation, it is necessary to consider the methodology and design of our study. In this seclion, the design and methodology will be described. The succeeding sections focus on hypotheses, and the measurement of the independent (predictor) and dependent (criterion or performance) varlables. Finally, the chapter concludes with a discussion of the research model and the assumptions regarding causality. There are silx main elements to methodology which will be dealt with in the succeading sections.

\subsubsection{Inputs, Throughputs, and Outputs}

First, it is based on an input-throughput-output approach - that is, it involves identifying and evaluating the various inputs (e.g. number of scientists), throughputs (e.g. managerial coordination and atmosphere) and outputs (e.g. publications and citations), and then relating the outputs to the inputs and throughputs. The basic premise of the model is that scientific 
research can be considered as a conversion process in which inputs are converted into outputs by the coordination of throughputs. Throughputs are conceived as the charactieristics of the comversion process. Since there aro no exact criteria to classify variables into inputs and throughpuls, the main classification is between predictor (independent) and criterion (dependent) variables. All input and throughput variables are called predictor $(X)$ variables, Whille all output variables are called criterion $(Y)$ variables. In general, there are more than one measures for a predictor variable. For example, $X 4$ (altmosphere) has been measured by $X 41$ (work-related values), $X 42$ (organizational culture), and $X 43$ (research climate). In one of the studies (II) combined and single criterion variables are distinguished. The overall performance $(Y)$ is indicated by the membership of a unit (high versus low performance). Single performance can be indicated by the peer review (Y1), and the number of publications (Y2) and citations (Y 3 ). The research model is presented in exhibit 5.4. of this book.

\subsubsection{Managerial Approach}

Second, our approach differs from thall lypically used in science and lechnology studies. Philosophers of science primarily focus on the internal lagic or "context of justification' of science - thereby emphasizing methodological implications (Popper, 1959; Lakatos, 1970). Here we simply report the differences between research units with high and low performance levels - thereby looking for quality control implications. Historians and anthropologists of science concentrate on the "context of discovery" (Fleck, 1935; Kuhn, 1962; Latour and Woolgar, 1979). Operating from an ethnomethodological or symbolic interactionistic point of view, the results are often qualitative, explorative and descriptive. Although recognizing the vallue of their approach (De Groot, 1961), the orientation here is a different one emphasizing quantification of variables and multivariate testing of hypotheses. Our approach may be characterized as a 'managerial' or "research pollicy' approach of science (Pelz and Andrews, 1966; Andrews, 1979; Allen, 1977; Keller, 1986; Dobrow and Tonkal, 1985). In essence, it represents the lasit stage in Simon's (1982) 'municipal methodology" - that is the analysis of factors which facilitate or inhibit public effectiveness in order to improve it. Many studies in the field of research policy utilize cost-benefit analyses (RAWB "1983a, 1983b). Unlike these studies " our approach pays attention not only to inputs (though not expressed in monetary values) and outputs (performance), but also to organizational throughputs.

\subsubsection{Team as Unit of Analysis}

Third, the approach is focused on the team. Thus, the unit of analysis is not the individual scientist., the discipline (Whitley, 1984), the institution (Irvine and Martin, 1985), or the Dutch inter-university "conditionally financed" (VF) research programme, but the research 
unit (in Dutch: 'vakgroep"). It is recognized that the major capital investment decisions in science tend to focus on institutions rather than the individual or the specialty. The research units within instututions, however, may represent a wariefy of fields which, moreover, may vary considerably in their performance levels.

Robinson (1950) has argued that individual (within-system) and group (between-system) correlations should not be confused. The 'ecological fallacy' is committed when group correlations are interpreted as if they applied to individuals. This is attractive, because group correlations are often stronger than individual correlations (Nijhuis, 1984). The 'reverse ecological fallacy" (Hofstede, 1980) is committed in comparing research units on indices created for the individual. In order to avoid this reverse ecologicall fallacy, all inputs, throughputs, and outputs in this study - iff not measured at the level of the research unit - have been aggregated to the level of the research unit.

The term 'research unit' is used here as defined in nomenclature adopted by the UNESCO project (Andrews, 1979). In order to regard any group of individuals as a research unit the following criteria had to be met: (i) the group has at least one recognized leader who is significantly involved in its work: (ii) the group has to include a tolal of at least three people (including the leader) who are significantly involved in its work, and each of these people has been a member of the group for at least half a year; (iii) the group has an expected life span of at least one year; (iv) the group members have, grosso modo, the same specialty.

\subsubsection{Comparative Method}

Fourth, because an absolute quantification of research performance is virtually uninterpretable, here the approach is comparative, with the added condition that one can only compare 'like with like'. The comparative method, it has been argued (e.g." Campbell and Stanley, 1966; Warwick and Osherson, 1973), is the core of the scientific method; without comparison, co-variation and causality cannot be observed or inferred. As Irwine and Martin (1985) have noted, one cannot compare directly the performance of a large oplical telescope with that of a radio telescope, but one can compare it with the performance of similar-sized opticall lelescopes at other observatories. Several bibliometric studies have demonstrated the existence of large wariations in publication and citation characteristics between specialties. even within disciplines (Moed et al., 1985a). Therefore, the concept of high and low performance should be applied in a relative rather than an absolute sense. This study compares the performance of research units within the same specialty at different institutions. Hypotheses are tesited by examining the differences in high and low performers. This approach was inspired by project SAPPHO - an attempt to substantiate generalizations about industrial innovation by the systematic comparison of pairs of successful and unsuccessfull industrial 
attempis to innovate in several branches of industry. By matching attempted innovations it was hoped to discriminate between the organizational characteristics of success and failure (Freeman, 1982).

\subsubsection{Triangulation of Performance Indicators}

Fifth, the approach involves the combined use of several performance indicators. These indicators reflect different facets of research performance, although they are to some extent interrelated. The method of converging imperfect indicators (Irvine and Martin, 1985) is based on the application of a range of indicators to malched research groups. When the indicators all point in the same direction, the results are regarded as reliable. What Irvine and Martin refer to as reliability or internal consistency is comparable with the concept of "convergent validity" in Campbell and Fiske's (1959) classic multitratt-mullimethod matrix approach. Campbell and Fiske suggested that convergent validity is demonstrated when the parlial indicators are correlated. Webb and colleagues (1966) call this process 'triangulatlon'

- where constructs cannot be measured directly, we should use at least two measurement approaches with different error sources. The more convergence in the results the more accurate the measurement (Hofstede, 1980).

\subsubsection{Internal and External Validity}

Sixth, our approach is concerned with internal and external validity. Internal validity pertains to the justifiability of conclusions within the research design, and therefore affects the controls of the design - a relevant question is, whether, for example, scale or almosphere really makes a significant difference. External validity or 'generalizability' is concerned with the extent to which an observed relation between, for instance, atmosphere and performance can be generalized. Kerlinger (1973) has pointed out that in basic research, generalizability is not the first consideration, because the central interest is the relations among variables (co-variation) and why the variables are related as they are (explanation). This puts an emphasis on the internal (design controls) rather than the external aspects of the study. In applied research the central interest forces concern to be more direcled lowards external validity because one wishes to apply the results to other populations and to other conditions.

In order to check for internal validity the research units (RUs) in the sample have been matched with regard to their performance. An attempt has been made to maximize the variance in their performance levels. In order to investigate generalizability to science in general, the design of the first study (medical research units in university hospitals) is replicated in a different field, i.e.n economic research units in Departments of Economics and Business Administration. Although economic and medical research units are both working within a 
university ervironment - so that they can be compared - they represent disciplines that operate at a different scale (in terms of expenditures, manpower, and output), and require different skills and technologies. Whitley (1984) has developed a typology of scientific disciplines. Comparing economics and medicine, he concludes that economics is characterized by hilgh technical task uncertainty and low functional dependence, while medicine is characterized by low technical task uncertainty and high functional dependence. These are of course relative chacterizations. Although the task uncertainty of medical research units is regarded as low in comparison to other scientific disciplines, ill will be high in comparison to, for instance, cleaning firms. On the basis of Whitley"s typology, variance may be regarded as maximized in a sample which includes the above mentioned disciplines. When replication of the design in economics yields similar results as in medicine, the results may to some extent be expected to be general to academic research departments in general. The design of our study is summarized in the following table.

Exhibit 5.1. Design of the study

\section{External Validity}

\section{Field I}

Field $\|:$

High performance Medical units Economics units

Internal Validity

Low Performance Medical units Economics units

\subsection{Some Facts and Figures on Dutch University Research}

Facts and figures on Dutch university research have been presented in a recent report of the Ministry of Education and Science, the Higher Education and Research Plan (in Dutch: HOOP) (1988). Dutch expenditure on university research in dollars per head of population in the period 1975-1982 was \$52 - i.e. higher than other OECD countries (including Japan and the U.S.). Expenditures on university research as a percentage of overall expenditure on research is $15.7 \%$ (1630 million guilders). The expenditure per university researcher in 1983 is $\$ 101,000$ (third in the OECD IIst). Expenditures on human resources and capital resources are $225(55 \%)$, and 186 million guilders (45\%) respectively for medicine, and $44(86 \%)$, and 7 million guilders (14\%) respectively for economics. Manpower levels stand at 4,630 scientists working at departments of medicine/university hospitals, and 420 scientists 
working at departments of economics. Spending levels are 760.6 million guilders for medical university research, and 102.5 million guilders for economics university research. With respect to output, the statistics show that the number of doctoral theses in the period 19801985 was 1892 for the health sector and 199 for economics. According to the Central Bureau of Statistics (1985), the average time spent on university research is approximately $30 \%$ for medicine and $36 \%$ for economics. The difference is explained by the time-consuming patient care in medicine. These numbers show that medicine and economics are not only different in their subject, their task difficulty and mutual dependence (Whitley), but also in capital intensity, and scale. The health sector has a closer resemblance to "big science' (de Solla Price, 1963) than economics does in all respects.

\subsection{Incentives and Constraints of Research Performance}

In Section 1, the relation between corporate culture and performance was explored. The literature has suggested that economies of atmosphere may be expected in small groups, especially when members are homogenous in their goals and values. We would argue that although some hierarchy exists - the research unit may be regarded as a fair approximation to what Williamson (1975) referred to as a 'peer group" and Ouchi (1980) as a 'clan'. Research units are small groups consisting of peers - people who have been exposed to similar professional training where their basic objectives, standards, routines, values, and skills may have been 'standardized' (Mintzberg, 1979). Culture is assumed to be efficient in the research unit because (i) it provides excellent (ex ante) screening and (ex post) monitoring devices, (ii) research performance is difficult to measure, (iii) research performance is often the result of teamwork, so that it is difficult to attribute the performance to individual contributions (especially in medicine), and (iv) task uncertainty is relatively high. The professional values incorporated in a cooperative attitude and an untrinsic research molivation are required in order to do the job well.

\subsubsection{Scale, Scope, and Atmosphere}

The first hypothesis is that atmosphere facilitates academic research performance. The emphasis is on the selective meaning of atmosphere as a set of general values (organizational culture) and specific values (research climate - Pelz and Andrews, 1966) "In contrasi to the other aspects of culture, general and specific values have been operationalized and validaled fairlly well by behavilioral scientists (Hofstede, 1980; Andrews, 1979). In addition, the impact of culture on scientific productivity is emphasized. We have neglected production and transaction costs, since the evaluation studies (RAWB-report/NEW repori) which have provided the basis for our investigation did not include financial data at the unit level. 
Moreover, transaction costs are very difficult to measure. Thus, the empirical studies focus on the impact of general values and specific values on the performance level of academic research units in two unrelated disciplines. As a consequence, the impact of this study is restricted to cell 3 and 6 of the economies of atmosphere framework.

Atmosphere, of course, is not the only source of efficiency. In chapter 3 , two competitive sources have been recognized: economies of scale, and economies of scope. It is assumed that the scale and scope of production influence the level of research outputs as well. Economies of scale in academic research departmenits have been demonstrated by Graves, Marchand, and Thompson (1982), while Pelz and Andrews (1966) found a relationship between diversification of activities (scope) and research performance in academic and industrial environments.

In the terminology of this study, the model consists of factors related to economies of atmosphere (culture and climate variables) "economies of scale (capital and human resources, and time spent on research), and economies of scope. In order the operationalize the concept of "economies of atmosphere", we may further specify our definition given in chapter 1 . In the empirical studies, 'economies of atmosphere' are defined as the increase in performance level due to culture (general values, e.g. work-related culture) and climate (specific values, e.g. innovative climate and publication climate) variables. Economies of scale refer to the increase in performance level due to the size of factor inpuls (capital and human resources). Economies of scope have been defined as the performance increase due to having a multi-product function, l.e. producing different kinds of output (publications in various fields). It is hypothesized that diseconomies of scalle exist concerning time spent on non-research activities (especially, time spent on palient care (study IX, and time spent on teaching - study II).

Related to scale is the input mix or composition of factor inputs (i.e. the age, research experience of the staff, and interdisciplinary $m(x)$. Pfeffer (1986) has shown that demographic variables are important for organizalional effectiveness. By analogy to the wellknown experience curve (total cost per unit being a decreasing function of the cumulative number of units produced), it is hypothesized that high performing research units have more research experience than low performers, although they do not differ in age. Furthermore, it is hypothesized that high performers may capture synergy effects (which affect performance levels in the long term) by having a more interdisciplinary mix of staff members in their team. 


\subsubsection{Additional Predictors}

Are scale, scope, and almosphere the only predictor variables? In selecting the vartables for the modell for the first study, the following information sources were consulted: (i) the international literature on research management and scientific productivity: (ii) the literature on cross-national differences in the infrastructure of medical research - especially those countries with a high reputation in this field: the U.S., the U.K., and Sweden; and (iii) professors in clinical medicine themselves. These experts 16 medical professors, 1 policy maker) were the members of a medical advisory council. They were requested to indicate the main facilitating and inhibiting factors of research performance in their fleld. The results of each of these procedures are reported in Bally et al. $(1987: 9-30)$. The variables idenlified by these three pracedures converged with the results of the interviews with experts in the field of health sciences, held by the Dutch Advisory Council for Research Pollcy (RAWB, 1983b). Following discussions with the medical advilsory committee on the content of the variables identified by these procedures, a theoretical model - inclluding the most criticall variables was advanced.

Three additional important factors weire identified in our revilew of the literature, i.e. management, control "and communication. These "throughput" factors are presumably related to culture, but they are conceptually different. Although culture may save on coordination and control cosis, it is no substitute for management and control. Research management refers to the craftsmanship and the leadership qualities of the research supervisor. The craftsmanship of the supervisor may have a major impact on the quality of the learning environment of the staff, whereas leadership (Selznick, 1957) may influience the unit atmosphere and the cooperative attitude of the staff. In her study of scientific elites, Zuckerman (1977) showed that most Nobel prize winners have worked under the supervision of former Nobel prize winners. The imporlance of research management in university environments has been pointed out in De Groot's Forum Theory of Science (1984), and has been demonstralled in large scale studies conducted in the U.S. (Pelz and Andrews, 1966), and in European countries (Andrews, $1979)$.

Management control is the process by which managers assure that resources are obtained and used effectively and efficiently in the accomplishment of the organization's objectives. Anthiony (1965) conceives 'management control" as the planning and control level between 'strategic planning" (goal formulation) and "operational control' (assuring that specific tasks are carried out). Strategic decisions are made by the top management (e.g. The university or hospital management). In peer groups, operational control is exercised by the operating core (i.e. the 
scientific staff). The middle management (t.e. the supervisor of the unit or responsibility center) is responsible for the management control.

Recent literature suggests that organizational effecifweness can be increased by quality control procedures. In line with the arguments of Hofstede (1981) and Ouchi (1979), Merchant (1985) distinguishes three types of control: personnel control, action control, and result control. Action controls put behaviloral constraints on the work process and is generally assumed to play marginal role in task environments where uncertainty is high. This is the case in academic research departments. Personnel controls (e.g. research motivation Andrews, 1979) and result control (e.g. pecuniary rewards) are considered to be very important in relatively uncertain task environments. Consequently, positive relations are assumed between motivation (personnel control) and pecuniary rewards (result control) on the one hand, and research performance on the other.

What would science be without the diffusion of public knowledge? The information flow linking various scientists through formal and informal communications has been seen as the central nervous system' of science (Allen, 1977). In our study, we have made a distinction in working communications (i) those within the unit (within-unit communication), (ii) those with other Dutch units (between-unit communication), (iii) those with units abroad (international communication), and (iv) those with other disciplines (interdisciplinary communicallion). Considering the results of the large scale U.S. study of Pelz and Andrews (1966), and Allen (1977), and the European UNESCO study of Andrews (1979), we assume that high performance is related to a high frequency of the above mentioned working communications. Caution, however, is needed in interpreting the results, because communication (especially inlernational communication) may be the cause as well as the effect of high research performance. Since a cross-section design has been used, this applies to the other predictor variables as well. The design enables the test of hypotheses concerning the sign of the predictor-criterion relations, but not concerning the cause-effect relation (direction) between two variables. With regard to interdisciplinary communication, moderate positive correlations (Andrews, 1979) as well as negative correlations (Nijhuis and Spangenberg, 1986) have been observed in previous sludies.

\subsection{Hypotheses}

A set of hypotheses based upon the model and on the previous literature was generated. It was hypothesized that research units classified as 'high performers' show the following characteristics in comparison to other research units within the same specialty or field. These 
hypotheses particularly apply to study 1 (clinical medicine). In chapter 7 (section 5) some additional hypotheses and modifications will be given for study 2 (economics).

\section{Exhibit 5.2. Hypotheses}

In comparison with low performers, high performers $\left({ }_{n+\ldots}\right)$

\section{X1. Scale}

1. have critical mass in human resources

2. have a larger unit size

3. have larger research projects

4. spend more time on research

5. spend less time on patient care/education

6 . have critical mass in capital resources

X2. Input Mix

7. have the same age distribution

8. have more research experience

9. have more staff members from other discipl

X3. Scope

10. conduct research in more fields

X4. Atmosphere

11. have a more innovative climate

12. have a more stimulating publication climate

13. have different general values (VSM)

X5. Management

14 have a superior research management

15. have superior leadership

X6. Control

16. are more motivated for research

17. expect more pecuniary incentives from research

X7. Communication

(18-21) communicate more often with peers of:

18. their own unit

19. other units in the Netherlands

20 . other units abroad

21. units of other disciplines
HUMAN RESOURCES

UNIT SIZE

PROUECT SIZE

TIME RESEARCH

TIME NON-RESEARCH

CAPITAL RESOURCES

\section{ACE}

HUMAN CAPITAL

INTERDISCIPLINARY MIX

\section{SCOPE}

INNOVATIVE CLIMATE

PUBLICATION CLIMATE

WORK-RELATED CULTURE

CRAFTSMANSHIP

LEADERSHIP

MOTINATION

REWARD EXPECTATION

WITHIN UNIT COMMUNICATION

BETWEENN UNIT COMMUNICATION

INTERNATIONAL COMMLINICATION

INTERDISCIPLINARY COMMUNICATION

\subsection{Measurement of Predictor Variables}

In order to measure the input and throughput variables, using standard and new scales, a questionnaire has been designed. Standard scales have been developed by the Institute for Social Research of the University of Michigan (Pelz and Andrews, 1966), the Massachusetts Institute of Technollogy (MIT: Prakke, 1974). UNESCO (Andrews, 1979), the linstitute fior Research on Intercultural Cooperation (IRIC: Hofstede, 1980), and the University of Pennsylvania (Van de Ven and Ferry, 1980). The scales were translated into Dutch (among others by Kunst, 1986) with adapted or new scales being constructed to measure specific aspects of the two disciplines. The medical version of the questionnaire was pretested in a 
department of medicine (Bally el al., 1987), and the economic version was tried out in a department of economics before data collection was started. Discussions with members of these departments led to improvements in the design of the Dutch-language questionnaires fcf. Appendix 2).

Below are examples of one or two measurement fitems for each variables as an example. The scales include semantic differentials (item 1) and Likert type 5-point scale (item 13) (Kerlinger, 1973). The numbers of the items $(1-21)$ refer to the variable names in exhibit 5.2 .

1. The research team is too small to conduct the research effectively $(1-2-3-4-5)$ The research team has enough staff members (critical mass) to conduct the research effectively.

2. Indicalion of the number of staff members in the research unit: (1) 1-4 FTE (3) 10-FTE (5) $>20$ FTE (rating by the unit's secretary)(FTE=full time equivalent for research).

3. Indicate the average number of colleagues with whom you cooperate in your research projects: (1) zero (5) $\geq 10$.

4-5. Please indicate in percentages how much of your total work time $(=100 \%)$ you have spent this year on: research (\% time research), patient care $1 \%$ time patient care in the hospital; \% patient care off the hospital- only study D), teaching (\%time teaching), and administration (\%time administration).

6. The current budget of the unit is inadequate to allow successful completion of the unit's current research tasks (1-2-3-4-5) The current budget is adequate to allow successful completion of the unit's current research tasks.

7. How old are you? ( $1=\leq 30$ years; $3=41-50$ years old; $5=\geq 60$ years old).

8. How much research experience have you had (a) during your study leading to your masters degree? (b) after your study? (c) abroad ? $(1=$ no experience; $3=3-5$ years; $5=\geq 10$ yours).

9. What is your original discipline? (aggregation of answers at the unit level shows the (inter)disciplinary composition of the team).

10. Raling of the number of fields in which the unit conducts research (source: the VEW report - the number of fields in which a unit publishes has been laken as an index of the diversification of its research activitiesi).

11. Very fow new ideas for research or other technical matters are given adequate consideration (1-2-3-4-5) Nearly all new ideas for research or other lechnical matters are given consideralion.

11. There is the feeling that everyone in the unit only works to make a living $(1-2-3-4-5)$ 
There is an atmosphere of great dedication to work in the unil.

12. Members of this unit are not encouraged to publish their research $(1-2-3-4-5)$

Members of this unit are strongly encouraged to publish their research.

12. In our unit nobody manages to do research $(1-2-3-4-5)$ In our unit everybody manages to do research.

13. How long do you think you will continue working for this organization? (1) Two years at the utmost, (2) from two to five years, (3) more than five years (but I probably will leave before I retire), (4) until I retire.

13. An organization's rules should not be broken - not even when the employee thinks it is in the organization's best interest (1) strongly disagree (3) undecided (5) strongly agree.

14. I am very dissatisfied with my immediate superwisor as regards his knowledge of the fields in which the unit is active (1-2-3-4-5) I am very satisfied with my immediate supervisor as regards his knowledge of the fields in which the unit is active (These questions were answered by non-supervisors only. Unit supervisors were requested to pass over all questions regarding variable 14-15).

15. It am very dissatisfied with my immediate supervisor as regards his leadership qualities (1-2-3-4-5) I am very satisfied with my immediate supervisor as regards hils leadership qualities. (Supervisors were requested to pass over this scalle).

16. I invest more energy in my (a) patient care tasks (study 1), (b) educational tasks (study 11) than in my research tasks (1-2-3-4-5) I invest more energy in my research lasks than in my (a) patient care tasks (study I), (b) educational tasks (study I).

17. If your performance with regard to research is fine, what is the probability that you will achieve promotion in your research department? (1) no chance (3) $50 \%$ (5) almost certain.

17. If your periormance with regard to (a) patient care (study I), (b) education (sludy II) is fine, what is the probability that you will achieve promotion in your research department? (1) no chance (3) $50 \%$ (5) almost certain.

18. How often do you discuss your work with ather members of your own research department? (1) annually or less (3) monthly (5) daily.

19. How often do you discuss your work with members of other Dutch research departmenis working in the same field? (1) annually or less (3) monthly (5) daily.

20. How often do you discuss your work with members of other research departments abroad? (1) annually or less (3) monthly (5) daily.

21. How often do you discuss your work with members of other disciplines? (1) annually or less (3) monthly (5) daily. 
Measurement sources and reliability of the standard and adapted scales are given in exhibit 5.3 . For climate (4-5) and management (7-8) the raw data were subjected to factor analysis to provide a basis for combining items to form latent variables. The factor structures are reported in Baliy et al. (1987: 135-36). Factor analysis reduces a large number of items to a smaller number of presumed underlying constructs called factors. Explained variance of factor solutions and Cronbach's alpha coefficients were sufficiently high to warrant confidence in the measurement qualities of the scales. The average Cronbach's alpha is 0.72 for medicine and 0.69 for economics. The factors found in study I were used as scales for study II. These scales proved to be rather reliable (cf. variables $4-5$ and 7-8). Work-relaled cullure (5) was asserssed by the Value Survey Module (VSM) which includes four work-related values: power distance, uncertainty avoldance, individualism, and masculinity. The dimensions are computed on the basis of formulas developed in a 40-country study in national subsidiaries of a large multinational business corporation (IBM) (Hofstede,1980). Since the VSM has been developed at the national level, it is essentially unsuitable for discriminating units at the organizational level. Despite this drawback, we used the WSM because better measures were not available at that time. 
Variable Name

(number of items)
Source

( $A=$ author)
Reliability: Alpha or \% Expl. Var. (decimal points have been omitted)

\section{Medicine Economias}

\begin{tabular}{|c|c|c|c|}
\hline $\begin{array}{l}\text { Scale } \\
\text { critical mass (3) }\end{array}$ & Andrews & 76 & 63 \\
\hline unit size (1) a & A & $@$ & $@$ \\
\hline project size (1) & A & @ & 9 \\
\hline time research (1) & Pelz and Andrews & $@$ & $@$ \\
\hline time non-research (4) & Adwisory ColPelz \& Andrews & n.a. & n.a. \\
\hline $\begin{array}{l}\text { capital resources (2) } \\
\text { Staff Mix }\end{array}$ & Andrews & 77 & n.a. \\
\hline age (1) & A & $@$ & $@$ \\
\hline human capital (3) & A & n.a. & n.a. \\
\hline $\begin{array}{l}\text { îterdisc mix (1) } \\
\text { Scope }\end{array}$ & A & (1) & $@$ \\
\hline $\begin{array}{l}\text { scope (1) a } \\
\text { Atmosphere }\end{array}$ & A & 0 & $@$ \\
\hline innovative climate (5) & Andrews + factor analysis & $30 \%$ & 83 \\
\hline publication climate (3) & Advisory Council + factor an. & $8 \%$ & 88 \\
\hline $\begin{array}{l}\text { work-related culture (13) } \\
\text { Management }\end{array}$ & Hoistede (original formulas) & @ & $@$ \\
\hline craftsmanship (2) & Andrews + factor analysis & $11 \%$ & 86 \\
\hline $\begin{array}{l}\text { leadership (5) } \\
\text { Control }\end{array}$ & Andrews + factor analysis & $49 \%$ & 87 \\
\hline motivation (7) & Van de Ven & 79 & 75 \\
\hline $\begin{array}{l}\text { reward expectation ( } 8 \text { ) } \\
\text { Communication }\end{array}$ & Van de Ven & 8. 0 & 77 \\
\hline within unit comm (2) & Andrews/MIT & 65 & 64 \\
\hline between unit comm (2) & Andrews/MIT & 66 & 58 \\
\hline international comm (3) & AndrewsMIT & 63 & 87 \\
\hline interdisc comm (2) & Andrews/MiT & 74 & 68 \\
\hline
\end{tabular}

Key:@= not applicable (1 item only-Cronbach's alpha indices the consistency between a number of items); n.a. = not applicable (items do not form a scale); a All data (except two) were collected at the individual level, and subsequently aggregated to the unit level. The exceptions regard 'unit size' and 'scope'. The former was defined as the number of staff members. The information regarding unit size was transmitted by the unit's secretary. The latter was detined as the number of fields in which the unit has been active. This information could be derived from the evaluation report of the VEW (economics). Unfortunately, data regarding the scope of units were not available in the RAWB report (medicine $=0$ ). As a result, the ecanomies of scope hypothesis is only explored in study II. 


\subsection{Quallty and Quantilty of Research Performance}

Scientific performiance is a multi-dimensional concept. Consequently several indices hawe to be used in evaluating performance. Both qualitative and quantitative evaluations of scientific performance exist. The main qualitative type of evaluation is the peer review, whille publication and cltation numbers are the main quantitative types of science evaluation. Each of these indices covers another dimension of scientific performance. This section reviews some of the pros and cons of each of these measures, and argues that a multi-indicator approach is the best way to evaluate scientific performance.

In the past, empirical studles of the relationship between culture and work performance have floundered to some extent because of an inability to measure satisfactorily the performance or quality of the output. Soelers and Schreuder (1986b), for example, have studied the rellation between culture and work performance of staff employees in accounting firms. Their performance measurement was based upon self-ratings, so that subjectivity bias may affect the validity of the conclusion - a fact that is well recognized by the authors. Since virtually all organizational effectiveness studies depend upon assessing the calibre of output produced by arganizations (Cameron and Whetten, 1983), an adequate and relalively simple measure has to be found. Without such measure it would be impossible to determine the independent influence of the atmosphere on performance. We believe that substantial progress has been made towards solving this measurement problem in research departments. Concern about the quality of research in sclence has increased in recent years (Elkema et al., 1978; De Groot, 1984: Becker and Van Raan, 1986). Scientisits and policy makers agree on the importance of quality in all the links of the research chain. It is, however, virtually impossible to operationalize the concept of quality. Thus reliable and acceptable surrogate measures have to be found.

Cole and Cole (1973) have pointed out that quality may be defined in two different ways. A traditional historian of science might apply a set of absolute criteria in assessing the quallity of a scientific paper. Those papers which embody scientific truth and enable us to understand better empirical phenomena are high quality papers. The fact that a particular set of works may be momentarlly in fashion or temporarily ignored tells us nothing about the quality of the work, if we use the absolute definition (Lakatos and Musgrave, 1970). Another way to conceptualize quality is built upon the philosophical view that there is no absolute truth. Since what is belleved to be true today may not be true tomorrow, few if any scientific discoveries will ever meet the absolute criteria. In the long run all discoveries will be seen as being in some fundamental aspect incorrect. Therefore high quality work is defined as that which is currently thought useful by one's colleagues. This relativistic view emphasizing the demand- 
side of science is rather similar to the 'perceived quality' view (product qually is how the consumer sees it) that has been adopted in marketing science (Jacoby and Olson, 1985).

Consistent with the demand-side approach of quality is the argument that we can only gain insight into the contribution of a publication to the growth of knowledge by assessing its impact at the research front (Moed et al. 1985a). Thus $s_{n}$ the scientific quality of a publication is defined by its use by peers. The authors assume that there is a resealch front in every scientific field. At this front scientists develop theories about the structure of reality and these theories are confronted with each other through experimental research. In the end certain theories will triumph and be added to the basic knowledge in the field. The authors distinguish long-term and short-term impact. Looking at impact over a long period offers the possibility of relating impact to 'durability' - the degree to which a research group has made a more permanent contribution to scientific advance. Short-term impact refers to the impact of researchers at the research front a few years after the publication of research results. The short-term impact indicates how groups maintain themselves at the research front, whereas the long-term impact indicates to what extent they eventually succeed in scoring 'triumphs'. However, for research to have impact, it is necessary that colleague researchers do have the opportunity to form an opinion about the basic quality of that research. According to this view, one aspect of successful research performance is that researchers are active in presenting their research findings to peers. Scientific quality thus defined includes basic quality as well as the extent to which researchers successfully perform "public relations' activities.

\subsubsection{Convergence of Partial Indicators}

A judgement of basic quality is based on criteria intrinsic to scientific research. Therefore only colleague researchers - peers working within the same specialty (de Groot, 1984) - can evaluate quality. The peer-review system is the method for evaluating research performance most favored by scientists. Within the context of research policy, Irvine and Martin (1985) have argued that the peer system is coming under increasing strain. The successful operation of peer-reviews depends on the existence of "disinterested" peers able to provide independent expert judgements - that is, there must be sufficient scientists familiar with the research for which funds are being sought, but whose own material circumstances will be unaffecled by the decision outcome. When the number of distinct research groups working in a specialty is large, this condition is approximately mett. However, this sttuatlon lhas changed, at lleast for 'Big Science' (De Solla Price, 1963). "lnstead of the free market of scientific ideas, all competing for funding solely on the basis of scientific merit, there has been a trend towards a situation of "oligopoly" in which a few large centers and interest groups can exert a dominant influence over claim on resources. As a consequence, the perceived implication of evaluation resulis of 
competitors for their own center may affect the qually judgements of scientists. This problem can only be partially overcome by using a complete sample or a large representative sample of peer reviewers.

Irvine and Martin (1985) have argued that evaluation based upon triangulation of performance measures is more reliable than a single-indicator approach. Their comparative method of converging imperfect indicalors is based on the application of a range of performance indicators to matched research groups. When the indicators all point in the same direction the results of evaluation are regarded as being relatively reliable, and certainly as being more reliable than those based on a single indicator like peer-review (Porter et al., 1988). The approach involves the combined use of several indicators. These indicators reflect different facets of research performance, although they are, of course, to some extent interyelated. For example, numbers of (high quality) papers per researcher reveal something about the basic quality and productivity of that group. The average number of citations per paper gives an Indication of the impact those publications have on the scientific community. Moed and colleagues (1985a) consider a three-year citation-counting period as a standard period for short term impact. Short term impact should be related to the visibility of a group at the research front, and can be ranked with other wisibility indicators such as international contacts, awards, and invitations to take part in important conferences. While the short term impact is an indicator of "visibility", the 'durability' of scientific work is indicated by a citation-counting period larger than three-years. Citation counting is consistent with the view that highmquality work is that which is currently thought usefull by peers (Cole and Cole, 1973). Peer rankings (where peers rank in order the performance of similar research groups according to their relative scientific contributions over a given period) provide evidence of the perceived significance of the results from different groups.

All these measures are, of course, partial measures. They reflect partly the relative magnitude of contributions to scientific knowledge, and partly a variely of institutional, psychological, and economic factors. Scientific performance is a multi-dimensional concept. Consequently, several indices are needed to assess the dimensilon. As mentioned before, measures of scientific performance can be divided in qualitative and quantitative measures. The main qualitative measure is (i) the peer roview, the quality evaluation of colleagues. The main quantitative measures are the number of (ii) publications and (iii) citations. The oligopolistic bias in peer-evaluation (the effect of perceived implications of their judgement on prospective resource allocation) has already been mentioned. Problems also exist with regard to publications and citations. One probllem with publication counts or similar "scientific productivity' measures (Andrews, 1979) is that each publication clearly does not constitute an equal contribution to scientific knowledge. A second problem is that publication traditions vary 
among specialties. This is one reason why comparisons can only be drawn between "matched" research groups using similar research facilities, and publishing in the same body of international journals subject to comparable refereeing procedures. Use of citation analysis (Garfield, 1979) presents a number of technical problems; for example, incomplete coverage: of journalls by the Science Citation Index and the Social Science Citation Index which provide the source data for citations. In addition, a paper containing results subsequently found to be mistaken may be heavily cited, at least until the error is clearly revealed. Here one must distinguish between the intrinsic quality of a paper and ils impact at the research front. Only for the latter does citation frequency provide a reasonable indicator. Another problem with citations is the variation in citation rates among specialties. Moed and colleagues (1985b) have demonstrated that rankings of publications from different fields, based on citation counts, can be affected seriously by differences between citation characteristics in those fields. High short term citation levels, for example, were found in Biochemistry, medium citation levels in Experimental and Molecular Physics, and low citation levels in Mathematics and Inorganic Solid State Chemistry. However, as with publication counts, this problem can be overcome by applying citation analysis only to matched research groups within a single specialty. Glearly each of the indicators has its own pros and cons, and each of the criticisms has well-known replies. As Leamer (1981, in Palmer and Liebowitz, 1988: 93) humorously put it: "Many of you will conjure up reasons why the number of citations should be ignored. There are fads; there are self-citations; there are citation conspiracies; there are derogatory citalions; there are bribes to editors and referees; there are sycophantic students:" and there are subjects capable of direct understanding only by the few. But why didntt your paper starts fads; why don't you publish more and cite yourself; why did your conspiracies fail; why don't you become an editor; why don't your students care about your welfare; and why do you insist on writing about obscure issues?'".

The method of converging imperfect indicators is essentially comparative, with the added condition that one can only legitimately compare llike with Ilke". One cannot, for example, compare directly the performance of a medical research unit with that of an economic research unit, but one can compare it with the performance of medical groups within the same specialty at other university hospitals. The combination of a comparative methodology (Campbell and Stanley, 1966; Warwick and Osherson, 1973) with trianguiation of imperfect measures (Hofstede, 1980), regarding the results as more reliable when the indicators all point in the same direction, is Irvine and Martin"s (1985) contribution to the comparative method of converging partial indicators. In general, bibliometric techniques, including publication countings and citation analysis, tend to be correlated with more conventional measures such as peer-reviews. Using the Science Citation Index, Cole and Cole (1973) have shown that Nobel Prize laureates, who can be safely assumed to have made outstanding contributions, have a 
higher average number of citations than other scientists - even before they won the prize (ct. Nederhof and Van Ralan, 1987). Narin (1987) has pointed out that bibliometric results are seldom counter-intuitive. The results are often in substantiall accord with the opinions and expectations of knowledgeable research administrators. Moed and co-workers (1985a) interwiewed researchers in the lacuities involved in their citation analysis. These interviews were meant as an "acceptance test", l.e., to examine whether their results and interpretations differed or agreed with the ideas of the scientists in the field (peer-review). The authors found that in many cases the researchers interviewed did not reject their results and interpretations, but tried to find explanations for the observed output and impact of the research group. Irvine and Martin (1985), finally, applied their method to compare the past performance of the accelerators at CERN, the joint European Laboratory for Particle Physics, with that of the world's other main accelerators (research facillities). Comparing the bibliometric indicators and the peer-review assessments made by high-energy physicists, they found some consistency between the results yielded by these independent measures. Certainly, there was a "self-ranking effecl" in the peer evaluation- a tendency to rate one's own work more thighly than do others - but (except in one case) this was not significant. On the other hand, it should be noted that imperfect or even lackl of correlation between the results of bibliometric indicators and the results of peer judgement have been found too. A systematic comparison of these (wo types of past performance analysis (Moed et al, 1985a), for example, revealed a serious lack of agreement between citation analysis and peer-review results. Therefore the convergence of imperfect indicators should be tested, and not be regarded as a priori given.

\subsubsection{Selection of Performance Measures}

Scientific performance is a multidimensional concept. The above mentioned indicators measure different dimensions of scientific performance. They measure "basic quality" (peer-review), 'scientific productivity' (publication counting), 'short term impact' or "visibility' (short term citation analysis), and "long term impact" or "durabillty' (long term citation analysis). Obviously, long term impact would be the best proxy, since "growth of knowledge" has been recognized by varlous authors as the ultimate criterion for scientific effectiveness (Nagel 1974; Popper, 1966; Lakatos, 1970). Unfortunately, long term impact evaluations are hardly useful for research policy "because permanent contributions can only be determined after a considerable period of time (Moed el al."1985a, and 1984). Although the other indicators provide less good proxies, they are certainly more feasible. Thus, we conceive (i) the (qualitative) peer review, (ii) the number of publications, and (iii) the number of (short term) citations as the main indices of academic research performance. More detailed information regarding the measurement of performance in medicine and economics will be 
given in the subsequent chapters. The pros and cons of each of the science indicators mentioned above are more extensively discussed in Rigter (1986). Becker and Van Raan (1985), and Bally and colleagues (1987). The main performance measures used in the studies presented here are: $(Y)$ overall performance which is the convergence measure of partial indicators, $\left(Y^{\prime} 1\right)$ peer review, ( $\left.Y_{2}\right)$ number of publications, and (Y3) number of (short term) citations. The preceding sections have focussed on the measurement of inputs, throughputs, and outputs in research units. The next section discusses the research model which presents the expected predictor-criterion relations mentioned above in a nutshell.

\subsection{Theoretical Model: Analysis of Variance}

Exhibit 5.4. summarizes the model which forms the theoretical foundation of study I and II. Predictor variables include scale, staff mix, scope, atmosphere, management, control, and communication. whereas criterion variables include peer reviews " and the amount of publications and citations.

The model suggests causal relations between inputs, throughputs and outputs. However evidence for causal chains between variables in a specific direction can only be given by process or trend analysis. Study I and II use a cross section design. They are typical examples of variance or level analysis (Miller and Friesen, 1984; Moed et al., 1985a). It is standard methodology to state that the use of a cross-section design does not permit the identification of cause-effect chains. Although the model suggests that; for example, atmosphere affects scientific performance, it is possible - and even plausible- that the relation between atmosphere and performance might have a reverse or two-sided causally, with higher performance: (also) resulting in increasing almosphere. Although longitudinal designs are often assumed to generate more accurate causal propositions, the problem of causality is not solved by time series designs when simultaneous models are used, i.e. $X_{t}$ (instead of $X_{t-1}$ ) and $Y_{t}$ (instead of $Y_{t-1}$ ) are measured in order to compare the consumption effects of income with the income effects of consumption.

The static model enables inspection of the (positive, neutral or negative) nature (sign) rather than the direction of predictor-criterion relations. Thus, it allows falsification of hypotheses. Hypotheses are falsified when the nature of the predictor-criterion relation deviates from the expected statistical association. In addition, the model enables a comparison of the relative contribution of each predictor in 'explaining' (in a restricted statistical sense) the variance in the performance of research units. Consequently, answers can be given to the question whether economies of atmosphere are more important than economies of scale or that interdisciplinarity is more important than economies of scope. Nevertheless, since reverse 
causality cannol be ruled out with the data collected in the cross-section design of study I and If: the results have to be interpreted with caution. Future research should attempt to address this issue with a longitudinal (Van Heeringen and Dijkwel, 1987) or a quasi-experimental design (Allen, 1977).

Exhibit 5.4. Theorelical Model

PREDICTOR VARIABLES

CRITERION VARIABLES

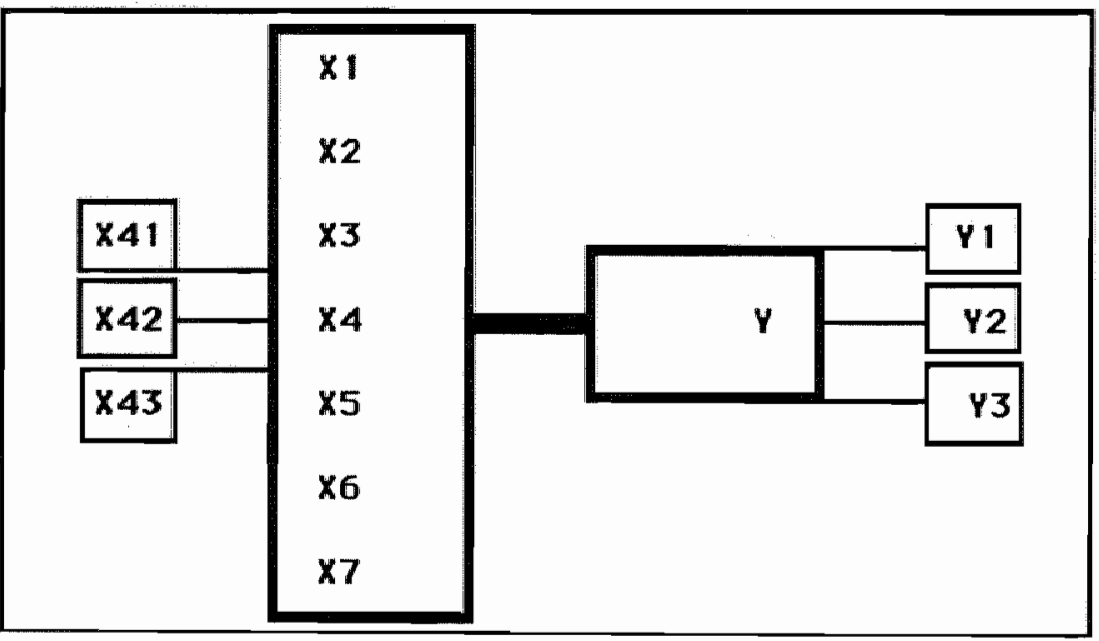

Key

Varlablas

Measures

predletor varlable

$X 1=$ economies of scale

Predlctor measures:

$x_{2}=$ input mix

$X_{3}=$ conomies of scope

$Y 1=$ peer review

$X_{4}=$ economies of almosphere

$Y_{2}=$ number of publications

$X_{5}=$ management

$X 6=$ control

$X 7=$ communication

Crilterlion varlable

$\gamma$ overall sclentific performance

$Y_{3}=$ number of citations

Criterlon Measures

$X 4.1$ = work-related culture (example)

X42 = arganizational culture (example)

$X_{43}=$ research climate (example) 


\subsection{Concluding Remarks}

In order to test the hypothesis that atmosphere affects internal efficiency, it is necessary to:

(i) select instruments for the measurement of efficiency

(ii) design controls for internal and external validity

(i) A commission of the Netherlands Ministry of Education and Sciences has offered the opportunity to study economies of atmosphere in medical research units of university hospitals. This study was replicated in departments of economics and business administration. The research performance of these fields has been the subject of large scale evaluation studies which have combined partiall indices like publications, citations, and peer reviews. These studies provide the empirical basis for our classificalion in high and low performers. The empirical studies emphasize a managerial approach to university science. Chapter 5 deals with this approach, and discusses some pros and cons of the monitoring devices mentioned above.

(ii) In order to check for internal validity, the research units thave been matched with regard to their relative research performance. In order to demonstrate external validity, the results of study I (medicine) and II (economics) are compared with each other. Given the variance beween these disciplines, it is apparent that consistency would provide confidence in the generalizability of the findings. This chapter has discussed the design of study I and II. Furthermore, hypotheses are formulated concerning the predictors of research performance. In addition to atmosphere, they include economies of scale, scope, and various managerial factors. A questionnaire has been designed to measure these predictors in research units.

While Section | of this book deals with the economic rationale for economies of atmosphere, Section II has focussed on design and measurement. Section III, finally, will report the results of the empirical studies concerning scientific performance in medicine and economics. 
SECTION III. EMPIRICAL STUDIES 


\section{Scientific Performance \\ in Ci inical Medicine1-2}

\subsection{Introduction}

This chapter will explore economies of atmosphere in clinical departments of university hospitals. Additional hypotheses will be tested concerning the advantages of scale, staff mix, management, control, and communication. Ideally, economies of scope are investigated as well, but no empirical data were available regarding joint production in medical flelds. The chapter starts with a discussion of the performance evaluation concerning clinical medicine (in Dutch: patientgebonden onderzoek). Then it will focus on the procedures concerning sampling, data collection, and data analysis. Finally, the univariate and multivariate results will be discussed, especially regarding to economies of atmosphere.

\subsection{State of the Art In Clinical Medicine}

Clinical research seems to be in trouble in several countries on both sides of the Atlantic Ocean. The decline in the number of clinical researchers and the shortage of clinical faculty, especially the faculty that could do research, has been noled in many prestigious medical journals such as The Lancel (1979) and The New England Journal of Medicine, viewing clinical

1 The research on which this chapter is based was supported by a grant of the Netherlands Ministry of Education and Science. The research team consisted of Y.W. Bally, J.F.A. Spangeniberg, R. Starmans" F.J.N. Nijhuis, and B. Breemhaar. The team was supported by a national advisory committee consisting of A.Th. Schweizer (Leiden University Hospital). E. Mandema (Groningen University Hospital), J.L. Touber (Amsterdam University Hospital), W.C. Hulsman (Rotterdam University Hospital), H.J.J. Wellens (Maastricht University Hospital), A. Querido (Leiden University Hospital), and C. van Dorp (Netherlands Ministry of Education and Science)

2 Accepted for publication: Spangenberg, J.F.A., Bally, Y.W., Starmans, A., Breemhaar, B., Nijhuis, F.J.N., and wan Dorp, C., Prediction of Scientific Performance in Clinical Medicine, Research Policy, Journal devoted to Research Policy, Research Management and Planning, North-Holland, Elsevier Science Publishers (forthcoming 1989 issue). 
medicine as a "threatened institution", and the clinical investigator as an "endangered species". Heyssel (1984) sets out the quality problems in Academic Medical Centers. In the U.K. doubts about the quality of clinical research are often echoed by those who should be the natural partners of the clinical researchers - the biological scientists. The Stoker Report on the future of the Clinical Fesearch Center refers to a "malaise affecting clinical research" (Swales, 1986) shown by, for example, the fall in numbers of granl applications received from clinical academic departments. It concludes that clinical research in the United Kingdom is at present not well placed to take advantage of the remarkable advances in basic medical research. In the Netherlands, the past performance of clinical research was measured by the National Advisory Council for Research Policy (in Dutch: RAWB). The concept of clinical research covers medicall research activities inspired by the illness of the patient. It takes place in clinical departments of university hospitals, and may be focused on prevention, cure or care. In general, the evaluation study of the RAWB indicates that medical research in The Netherlands has a reasonable Internatlonal standing. Newertheless, none of the medical disciplines appear to be uniformlly strong. Large variance in research quality between units appears to exist between units within medical disciplines. With regard to clinical research, the RAWB concluded that research quality on average is low.

Consequently, the Dutch government commissioned a team of the University of Limburg, consisting of Bally (Faculty of Health Sciences), Starmans (Faculty of Medicine), and Spangenberg (Faculty of Economics and Business Administration), to analyze the main organizalional factors influencing the research performance of clinical units in Dutch University Hospitals. The team (which included two additional researchers, Breemhaar and Nijhuis, as well) issued uts report in May 1987 (Bally, ef al., 1987). With special attention given to the competitive advantages captured by economies of scale and almosphere in the scientific enterprise, the subsequent sections will present findings of the quantitatiwe part of this investigation.

\subsection{Measurememt of Performance}

The hypotheses are tested by examining the differences belween successful (high) and less successful (low) performers. The concept 'performers' refers to tearms (clinical units) not to individuals. The distinction between high and low performers is based on large scale evaluations of the performance of clinical research (RAWB, 1983b; Rigter, 1986). The evaluation of the RAWB included five measures of clinical research performance at the unit level. All these measures were aggregated to - if nol already defined at - the unit level. 
Aligter gives the following description of the measures:

1) measuring the output of the research units in terms of the papers published in the international literature in the period between 1976-80 [productivity];

ii) estimating the influence of these papers on the international scientific community by determining the extent to which this work is cited between 1978-81 [impact];

iii) estimating the standing enjoyed by Dutch scientists in the international scientific community by assessing how often they are asked to edit leading scientific journals (these individual data were then aggregated to the unit level)[editorship];

iv) obtaining the views of a large number of foreign scientists as to which Dutch researchers carry out work of outstanding quality (the individual data were then aggregated to the unit levelyinternational peer review];

w) interviewing prominent Dutch scientists working in many fields of clinicall research to establish their view on the quality of units in their field [national peer review].

Evidently, each of these measures has its own limitations. The pros and cons have been extensively discussed by Rigter (1986), and Moed and co-workers (1985a, 1985b, 1985c). Despite the limitations of each measure, the overall evaluation produced a reasonably consistent picture. The concordance of the various approaches is evident from the following findings reported by Rigter (1986): "All groups excelling on the citation measure and all groups excelling on the editor measure, in each case except one, were judged positively by the Dutch experts. All groups mentioned by the foreign experts were also mentioned appreciatively by the Dutch experts". Recently, the evaluation of the RAWB has been updated by the Foyal Netherlands Aciademy of Sciences (in Dutch: KNAW). The KNAW (1985) used, broadly, the same combination of performance measures. Their updating did not significantly deviate from the evaluation of the RAWB. Taken together, the performance measurements provide information of relatively high validity on the past performance of clinical research in the Netherlands.

\subsection{Sample}

The selection of units with a thigh and low performing research performance was carried out after careful consultation with experts of the RAWB and KNAW who were involved in the evaluation studies. In addition, these experls were famillar with the (shifts in) management, internal organization and performance of the units. Several bibliometric studies (Moed et al., 1985) hawe demonstrated large variations in publication and citation behavior of fields within 
disciplines. Therefore the term high and bow performance should be applied in a relative rather than an absolute sense. Clinical units perform better or less well in comparison with other units of the same field. A wide variety of medical fields sere selected for inclusion in the study: gastroenterology, haemalology, clinical immunology. nephretic diseases, endocrinology. clinical pharmacology, anesthetics, clinical genetics, social psychiatry, child psychiatry, orthopaedics, otorhinolaryngology (TNE diseases), gynaecology, cardiology, urology, neurosurgery, child surgery, neurology, and child medicine (19 fields representing the major basic, intermediate, and top specialisms in medicine). Per field, a selection was made of two or more high performers and two or more low performers. High performers are units with above average performance on three or more of the above mentioned indicators (produclivity. impact, editorships, (inter)national peer reviews). If no unit met this criterion, units with above average performance on at least one measure were selected. Units which did not perform above average on any of the performance measures were classified as low performers. In consultalion with the experts of the RAWB and the KNAW, an attempt was made to match units in each discipline that differed most in their performance (highest performance or second best versus low performance), and that differed as little as possible with regard to other sample characteristics such as unit size, age, and mobility. In total 27 high performing units and 34 low performing units were requested to participate in the study. These 61 clinical units were spread over 19 medical fields. All Dutch university hospitals $(\mathrm{N}=8)$ were represented.

Evidently, the selection was not random: a bias was introduced to ensure sufficient numbers of scientists in high and low performing units. This bias does not distort our empirical analysis since we are concerned with estimating the relationships between organizational factors and performance, and not with establishing the size, scope or atmosphere of the representative clinical unit (Philipsen, 1969). Having "pure" samples of high and low performers (maximizing the variance in performance levels) is more appropriate for the present research purpose than having large numbers or having a representative sample of the population.

\subsection{Data collection}

A mail questionnaire accompanied by a letter of recommendation from the advisory committee was sent to the selected clinical unils, addressed to all staff employees of the unit, who (i) were academically educated (thus, excluding administrative and support staff), and (ii) were appointed to participate in clinical research (thus, excluding those staft members with exclusively patient care medical training and administrative duties).

These criteria produced a population of 680 respondents of whom 337 were warking in units with high performance, and 343 were working in units with low performance. In total 53 
unils $(70 \%)$ decided to participate in the study. Analyses were made of 43 units only, because 10 units were represented by less than $25 \%$ of their researchers. The sample consisted of 20 high performers and 23 low performers. The degree of nonresponse of high and low performers is rather similar because more low than high performers were requested to participate in the sudy. In order to prevent response bias, the research units were not hntormed about our classification in high and low performers.

Exhibil 6.1. shows the response distribution of high and low performers over university hosplitals, whille Exhibit 6.2. shows the response distribution over medical fields. The tables with the facts and figures are given in Bally ef al. (1987: statistical appendix).

Exhibit 6.1. Response distribution university hospitals

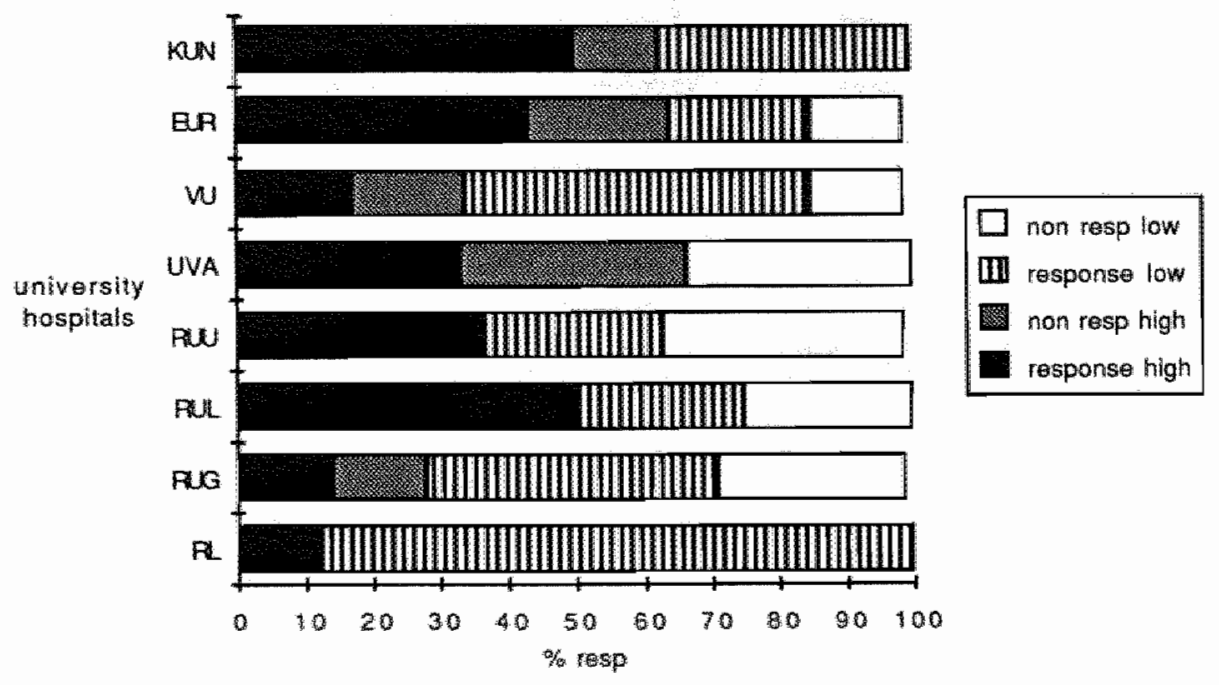

Key

KUN Katholake Unwersiten Numegen

EuR Erasmus Unvorsileil Roverdam

WU Vrije Unversilete Amsterdam

UA Unwersilent van Amsterdam
RUU Rhksunersiteät utrecht

RUL Rinksuniversite Leiden

RLG Ringsunersine Croningen

Al Rijksuniversteit Limburg 


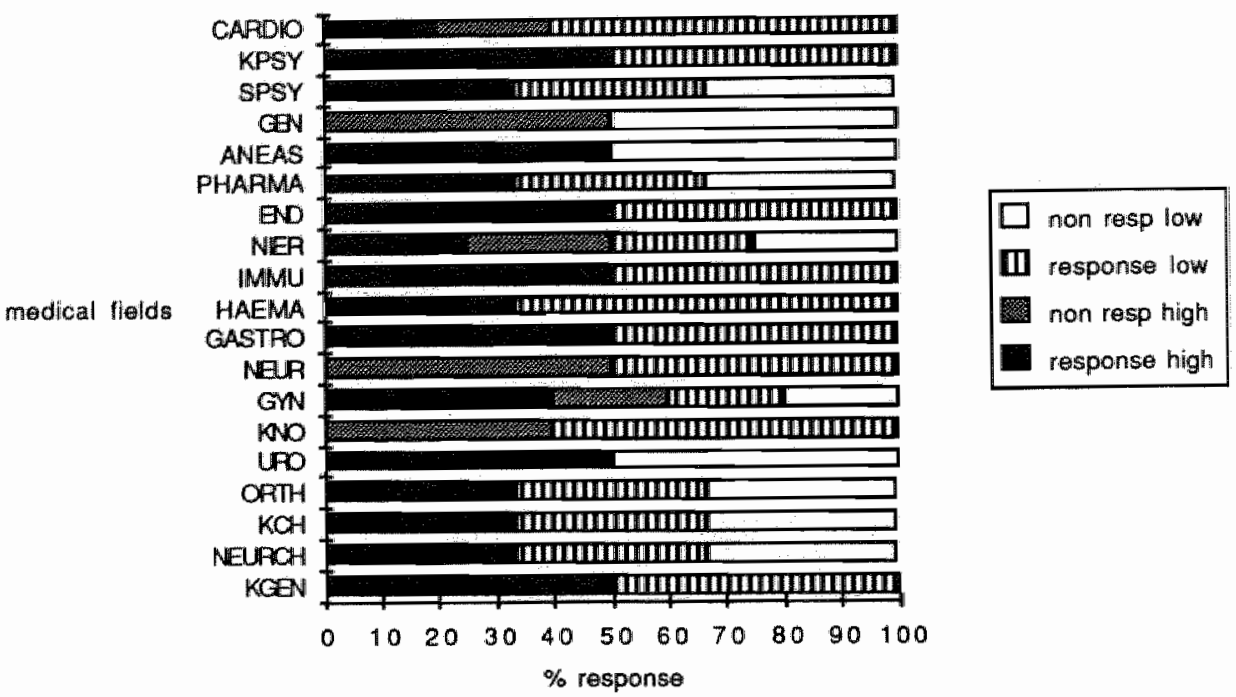

Key (Dutch Abbreviations versus U.S. Spelling)

\begin{tabular}{llll}
\hline cardio & cardiology & gastro & gastroenterology \\
kpsy & child psychiatry & neur & neurology \\
spsy & social psychiatry & gyn & gynecology \\
gen & clinical genetics & kno & TNE diseases \\
anaes & anesthesiology & uro & urology \\
pharma & pharmacology & orth & orthopedy \\
and & endocrinology & kch & child surgery \\
nler & nephretic diseases & neur & neuro surgery \\
Immu & immunology & kgen & child medicine \\
haemai & hematology & & \\
\hline
\end{tabular}

Exhibit 6.2. shows that clinical genetics is the only field that is not represented in the sample. A total of 274 (of which 259 usable) questionnaires were returned by the 43 units (individual response: $45 \%$ ) from researchers in units with a high performance $(48 \%)$ and with a low performance $(53 \%)$. Nonresponse analysis - including interviews with non-responding unit supervisors - showed that the following factors account for nonresponse on the unit or individual level: 
(1) lack of time, caused by work pressure lpatient care on the one hand, and colleagues holiday on the other hand - note that the data were collected in the period June-August). This is rather plausible for clinical staff members who repeatedly have been found to work more than 58 hours per week (CBS, 1985).

(ii) questionnaire lassitude: these clinical units have been subjected to several output evaluations and time dettermination studies in the recent past;

(iii) one unit did not respond because it differed in opinion with regard to our selection of variables; while another unit did not respond because it did not conduct "clinical research" - at least not according to our definition.

What about the representativeness of the response sample? Oppenheim (1966) has suggested that late responders resemble nonresponders rather than early responders. If it is true that the answers of late responders are a fairly good estimiate of the answers of nonresponders, the similarity belween late and early responders in this survey provides ground for confidence in the representativeness of the response sample. Early and late responders could be easily identified in our sample. Data were gathered in the period June-September. Postal questionnaires were sent in the third week of June. From the month July, units were reminded three times to send the questionnaire back. Early respondents were defined as those who sent their questionnaire back in the period June-July, that is within 6 weeks (212 subjects). Late respondents were defined as those who send their questionnaire back in the period AugustSeptember (62 subjects). T-tests did not show significant differences between early and late respondents on relevant items (Bally, et al., 1987), thus indicating that the individual response is fairly representative for our sample of clinical research units in Dutch university hospitals.

\subsection{Univariate Fesults}

As mentioned before, the instruments appeared to be relatively reliable with average Cronbach's alphas of .72. Data analysis was performed at the unit level. For this purpose the individual scores per unit have been aggregated to the group level. Several organizational studies have found that aggregated scores tend to increase the reliability of organizational measures (Nijhuis, 1984). To check the reliability of our aggregated scores, we tested the differences between units of variance in the individual scores (Bartlett-Box F). This test revealed no substantial differences between units in the homogeneity of the answers of individual scientists, thus permitting the conclusion that high and low performers are similar in the degree to which their aggregated scores are a reliable representation of the measured variables. 
The univariate data analysis include t-tests, cross tabs, (partial) correlation analyses, and ANOVAs. Different procedures were employed because of their greater appilicability to specific data sets or substanilive questions. Whenever possible, more than one technique was used to analyse the same data sel, although only one procedure is reported. In general substantive conclusions have been found to be supported by all forms of analysis. This should be no surprise, since essentially all of the statistical modes of analyses rest on similar logical foundations (Nunulally, 1981). Exhibit 6.3 shows the correlations between the predictor variables and the performance measure. The next section will discuss the univariate results, whille the subsequent section focuses on the covariance analysis including the partialized correlations. 
variable

correlation with performance

(decimal points have been omitted) partialized for

time research

\section{Scale}

human resources

unit size

project size

tìme research

time non-research:

(i) patient care hospital

(ii) patient care off the hospital capinal resources.

2. Staff (Input) $m$ ix

age

human capital:

(i) research experience during study

(ii) research experience on the job

(iii) research experience abroad

interdisciplinary mix

4. Almosphere

innovative climate

publication climate

work-related culture

5. Management

craftsmanship

leadership

6. Control

molivation

reward expectalion

7. Communication

within unit commmunication

between unit communication

international communication

interdisciplinary communication
$37^{* *}$

n.s.

n.s.

$35 *$

n.s.

$-31 *$

$30 * *$

n.s.

n.s.

n.s.

n.s.

n.s.

n.s.

$34^{*}$

n.s.

$38 * *$

n.s.

n.s.

$-32 * *$

$32 *$

$33^{* *}$

$38^{* * *}$

n.s.
$30 * *$

n.s.

n.s.

n.a.

n.s.

$-29 *$

n.s.

n.s

n.s.

n.s.

n.s

n.s.

n.s.

n.s.

in.s.

$30^{\circ *}$

n.s.

n.s.

$-33^{* *}$

n.s.

n.s.

30 * *

n.s.

" Significant at the .1 level; "** the .05 level of significance; "*** the 01 level of significance

\subsubsection{Economies of scale}

Univariate analysis provided positive confirmalion for the economies of scale hypothesis - both with respect to human and capltal resources. In comparison with low performers, high performers conceive their human resources and capital resources to be adequate to do the research successfully. Moreover, they spend more time on research, and less time on patient care outside their university hospital (private practices) than low performers. Surprisingly, high and low performers do not differ in size - neither in absolute unit size (in terms of absolute number of staff members) nor in project size. An explanation for thils finding is that the present study did not take into account the full time equivalents. (FTEs) for research. Large 
groups thay be small groups in terms of FTE, and vice versa. The main difference in scale is lhuman resources, le. the critical mass of high performing units was adequate compared to that of low pertormers.

Regarding the input mix of high and low performers, no differences could be detected. This finding confirms the sampling procedure which has focused on homogeneity in demographic respect. Consequently, other than demographic variables are accountable for the variance in research performance in clinicall medicine.

\subsubsection{Economiles of Almosphere}

High and low performers only differ significantly in the factor publication climate. In other words, "scientists were encouraged to publish research results", and "it is ensured that everybody in the unit manages to do research" (see Dutch language items in Appendix 2). It is uncertain whether the non-correlation between work-related values and performance is due to inappropriate measurement or to a true non-relationship between work-related culture and performance. As mentioned before, the present study has applied the value survey module in order to assess work-related culture. This measure, however, was originally designed for use at the national rather than the organizational level. A measure which is more appropirate to differentiate between organizational units is the organizational culture module (Hofstede et all, 1988). Buil this measure was not yet available when the present investigation started.

\subsubsection{Management}

The craftsmanship of the supervisor is evaluated as more favorable by members of units that are classified as high performers. No relationship could be demonstrated between the leadership qualities of the unit supervisor and research performance.

\subsubsection{Control}

Neoclassical economic theory assumes that people are profit mazlimizers. Unexpectedly, we found that high performers expected fewer rewards when they performed well in research efforts than when they performed well in patient care. This finding is inconsistent with their time spending paltern i.e. more time is spent on research. It is, however, highly consistent with the fact that less time is spent on (private, and more profitable) patient care outside the university thospital - than that spent by scientists from low performing units. These findings suggest that (pecuniary) profit maximization does not pay in terms of scientific productivity - 


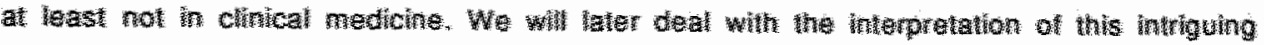

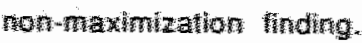

\subsection{5: Communteation}

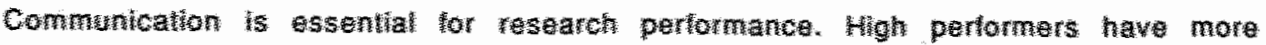

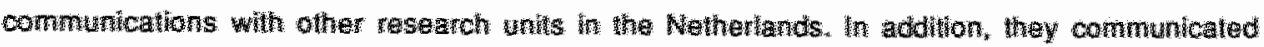

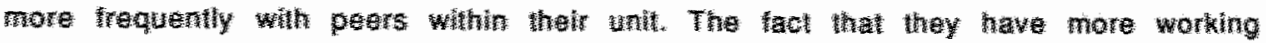

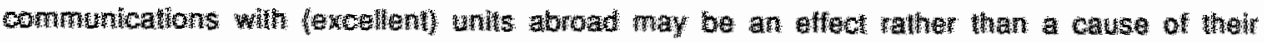

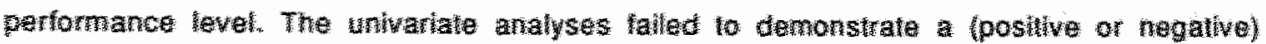

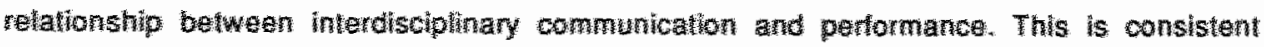

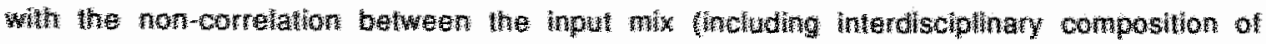

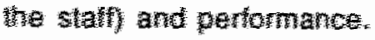

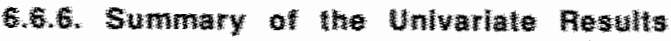

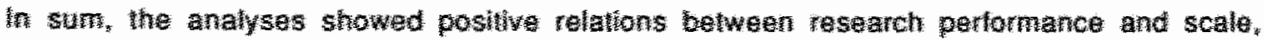
commumication, and managemen. Patal suppon was lound for conomes of atmosphore

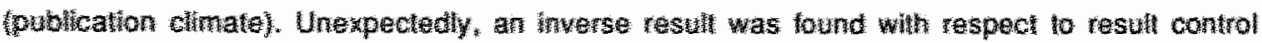

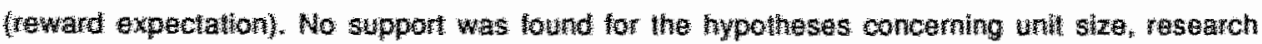

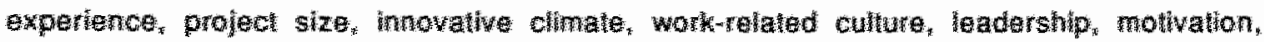

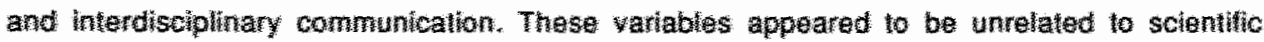

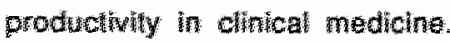

\subsection{Covariance Analysts:}

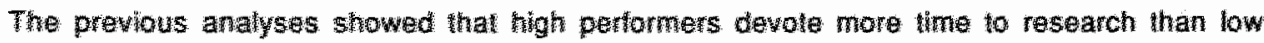
performers. Clearly, the differences with regard to capital resources, publicallon climate and international communication may be correlated with the amount of time spent on research. Consequently, the value added by these variables in explaining clinical research performance would range from low to zero. in order to lest the alternative plausible hypothesis that fime spent on research exclusively accounts for the variance in research pertormance, the analyses were repeated correcting for time devoted to research. The results of the co-variance analysis (with time spent on research as co-variate) and the partial product moment correlations (where we eliminated differences in time spent on research between the units) are shown in the following table. 
Exhibit 6.4. Differences between high and low performers after correcting for time devoted to research (results of the MANOVA)

Covariance Analysis Partial Correlation Significance

Variables

human resources

fime patient care off the hospital

capital resources

publicallon climate

craftsmaniship

reward expectation

within unit communication

between unit communication

international communication
$\mathrm{F}$

3.89

6.34

1.75

4.04

2.40

2.00

3.89 p

ก.s.

TI.S.

.05

.07

.18

n.s.

M.S.

.01

The table is consistent with the partial correlation matrix (Exhibit 6.3). It shows that, similarly to time spent on research, the following factors appear to be related to performance in a fairly independent way: scale (human resources, and time patient care off-hospital). communication (international), management (craftsmanship), and control (reward expectation). The other variables, including publication climate, are strongly correllated to time devoted to research, so that they do not explain extra variance. Including these variables in a predictive model of past performance would generate diminishing relurns and decreasing 'predictive efficiency' (Kerlinger, 1973).

\subsection{Mullivariate Results}

The next seclion focuses on the multivariate analysis - particularly on the Fisher linear discriminant analysis. First, the background of the technique will be disculssed. Then, the multwarlate results will be presented. While these results pertain to the between-unit variance, section 6.8.4, examines the between-discipline variance with regard to the discriminemt function.

\subsubsection{The Fisher Linear Discriminant Analysis}

In the mid 1930s Sir Ronald Fisher developed a method for the solution of the two-group case known as linear discriminant analysis. To explain more fully the difference between high and low performers, discriminant analysis was conducted with the uniwariately significant predictor variables (time devoted to research, and the variables which were related to 


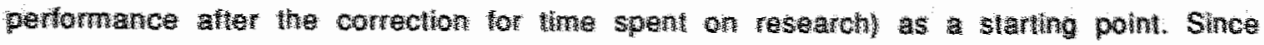

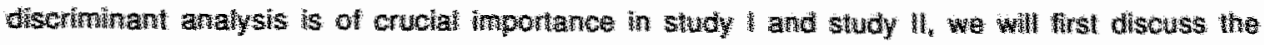

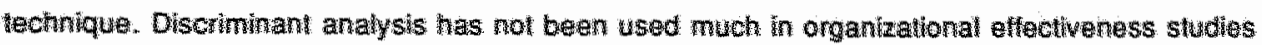
1 Cameron and wheten, 1983 , but has interestho potentaluthes.

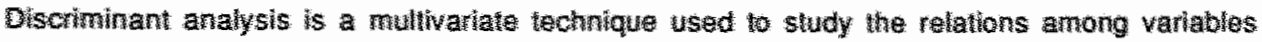

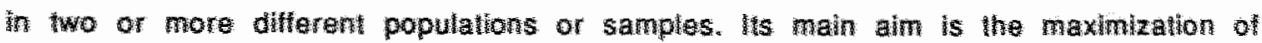
mutuanate group means. Essenulaly. addresses itsel to whe queston how indwidual ases can best be assigned to groups on the basis of severa yartables. pumoses Kewnger and Pedhazur, 1973, and classification purposes in vartous disciplines such as bology and medicine (Anderson, 19731, business administraton (bankwptcy prediction, Aman, 1982), and personnel psychology personnet selection, Tatsuoka, 1970 ) - measures hat h the past successuthy predicted pertomance can be combined into a discriman function, and future individuals whey not differ 100 much from the ofoinal samplet can be classited on the basis of them.

A disctiminant bnction is a regression equation with a (dicholomous) dependent (criterton) variable that rapresents group membership. The uncton maximally discthinates the units of a sample - lells us to which group each unil probably betongs. When dealing with two groups, for example high and wow pertormars, the discriminant wumction is a multple regression equation with the dependen variable a nomnal variable (coded $0_{2}$ 1) representing group membership. The discriminant function maxtmally discriminates unts of aiven sample. In additon, provides us wh information which variables "oxplain the discrimination, since the (standardized) disctmmant whetion coeticients show the relative weights of the predictor varables in the discrimathation function. The selection wlo for vatables to enter hio the discriminan function is Wiks Lambda minimizalion. Thus, weighed birear combinations of variables are computed in order lo maxinize the mulvariate group difference. The discriminant function, $Z$, can be expressed as:

$Z=B_{1} X_{1}+B_{2} X_{2}+\ldots+B_{p} X_{p}$

where $\mathbb{B}_{\mathrm{i}}(\mathrm{i}=1, \ldots, \mathrm{p})$ are weights, socalled (standardized) discriminant function coefficienls. and $X_{i}(i=1, \ldots, p)$ are the predictor variables. In discriminant analysis, the weights in a discriminant function are estimated to achieve the best possible separation between, in the present case, high and low performers (Tatsuoka, 1970).

A stepwise discriminant analysis was carried out, using SPSS (Norusis, 1985: 75-122). In this type of analysis only a limited set of the predictor variables are included in the 
discriminant function. By defintion, only the non-redundant variables are selected which cannot predicted from any linear combination of the remaining variables. In following such a stepwise procedure one can control for multicollinearity (statistical interdependence between predictor variables). Multicollinearify is indicated by statistical criterion, called tolerance, defined as the within-groups variance which is not accounted for by other predictor variables in the analysis. If a variable passed the (arbitrary) tolerance level of .01 , it was included. In the next step (s) the remaining variable(s) with the largest tolerance was (were) included. In this way, variables were included according to their unique contribution in establishing maximal group differences. Three types of results from the discriminant analyses will be presented.

(i) The standardized discriminant function coefficients which represent the relative importance of each variable included in the discriminant function. Their importance for the discriminant function is indicated by the order of inclusion, the most important variables being included first. The standardized discriminant functions can be interpreted proportionally (Tatsuoka, 1970: 54-55). Coefficienis with an absolute value of .30 were considered too low to be interpreted.

(ii) The squared canonical correlation, $\mathrm{A}^{2}$, can be interpreted as the discriminatory power, representing the proportion between-group variance explained by the discriminant function (Tatsuoka, 1970: 43-48). A significant value of $R^{2}$ indicates that two group centroids (i.e. multivariate discriminant score means) produced by the particular set of predictor variables differ (Schaufeli, 1988: 200-201).

(iii) The classification success of a particular function refers to the degree to which the probabillity of misclassification is minimized. A discriminant function selects predictor variables on the basis of their relative contribution to classifying cases correctly into predefined groups (Schreuder, et al., 1988). Values result from efforts to classify cases (aresearch units) on the basis of the discriminant function. In all cases the base rate for correct classification was $50 \%$. The significance of the function, $\mathbf{p}$ (function), is tested by a chisquare test.

A potential problem with discriminant analysis is that it disregards cases with missing values of the specified variables (Schreuder et al., 1988). To partially offset this problem several analyses have been performed. In order to minimize chance capitalization, the discriminant analyses were restricted to the univariately significant variables. 
First, a stepwise discriminant analy'sis is performed on the scale varlables. Then the scale and atmosphere variables are analysed together. Finally, a stepwise analysis is performed on all univariately significant variables including management, control, and communication. More sets of alternative variables were tried out in search for an optimal discriminant function. We conceived a function, $Z_{i}$, as optimal when (i) the probability of misclassification is minimized; (ii) the function has a larger discriminatory power $\left(R^{2}\right)$; (iii) $p$ (function) has a higher significance; (iv) the sample contains more cases. Since there are tradeoffs between these criteria, judgement is required to select a satisfactory function. This is not unusuall, because human judgement is always necessary in the methodological cycle - not excluding the data analysis stage. 


\subsubsection{Multivarlate Results}

\section{$Z_{1}$ (scale)(scale and atmosphere)}

Regarding the univariately significant scale variables, a significant discriminant function emerges $\left(R=.62 ; R^{2}=.38 ; X^{2}=19.00 ; d . f=5 ; P\right.$ function $\left.=.002\right)$ which is a linear combination of the following predictor variables for 43 cases in our sample:

$Z_{1}=.70$ TMRS -.79 TMPC + .56 HMRS,

where: TMAS = time researich

TMPC = time patient care off the hospiltal

HMRS = human resources

correct classification $=77 \%$; maan discriminant score high performers $=.88$; mean discriminant score low pertormers $=-.69$

$Z_{1}$ was not changed when atmosphere variables were introduced into the analysis.

\section{$Z_{2-3} \quad$ (all variables)}

When various sets of univariately significant variables were analyzed, more than one significant discriminant function emerged. $Z_{2}$ shows the linear combination of the following predictor variables for 42 cases of our sample $\left(R=.59 ; R^{2}=.35 ; \quad X^{2}=14.11 ; d . f_{*}=4 ; p\right.$ (function) $=.002$ ):

$\mathrm{Z}_{2}=.46 \mathrm{HMRS}+.50 \mathrm{TMRS}-.74 \mathrm{TMPC}+.37 \mathrm{CRFT}$,

where: HMRS = human resources

TMRS = time research

TMPC = tlme patient care of the hospital

CPFT = crattsmansih of the management

corract classification $=76 \%$

mean high parformers .79

malan low performers $=-.65$ 
Having the most classificatory success and the largest discriminatory power, the optimal function for 42 cases of our sample, $Z_{3}$, is a linear combination of five predictor variables $\{R$ $=.64 ; R^{2}=.41 ; X^{2}=19.7 ; d . f_{.}=5 ; P($ function $\left.)=.001\right):$

$Z_{3}=.56$ CRFT +.51 TMRS +.28 HUMRS -.83 EXPR +.38 INTC,

where CRFT $=$ craftsmanship management

TMRS $=$ time research

HMRS = human resources

EXPR $=$ expectation rewards

INTC = international communication

correct classification $=81 \%$ (lotal number of cases $=42$ )

mean discriminant score high performers $=.89$

mean discriminant score low performers $=-.73$

Exhibit 6.6. presents graphically the match between observed and predicted (correctly classified) research performance in the function that was conceived as most satisfactory, l.e. $\mathbf{Z}_{3}$. There is a match when units with a discriminant function score $>0$ (predicted high performance) are abserved to be high performers, and units with a discriminant function score < 0 (predicted low performance) are observed to be low performers. The figure shows that there is a match for $15 / 19(79 \%)$ high performers and $19 / 23(83 \%)$ low performers (mean correct classification is $81 \%$ ). 


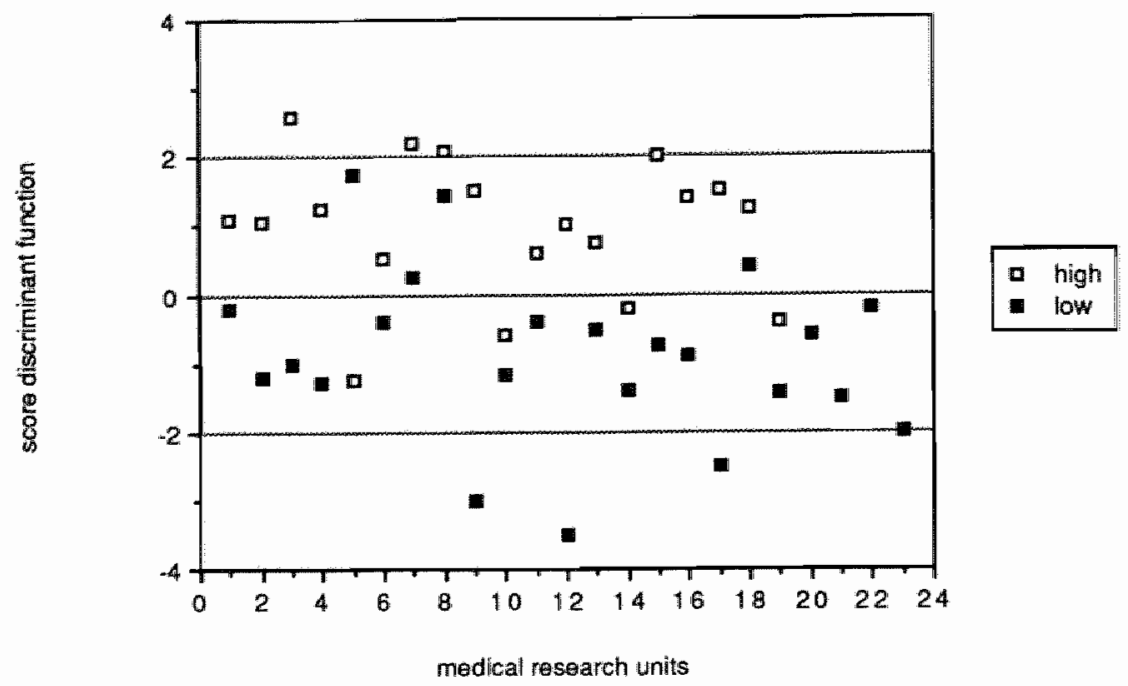

Exhibit 6.7. presents all predictor variables which have entered the above mentioned significant functions.

Exhibit 6.7 . Standardized canonical discriminant function coefficient variables

$$
\text { variables }
$$

times entered

sign

\section{scale}

human resources a

time research a

time patient care off the hospital a

Management

Craftsmanship

Control

expectation rewards

Communication

intemational communication

$\begin{array}{ll}3^{*} & + \\ 3^{*} & + \\ 2 & - \\ 2 & + \\ 1 & + \\ 1 & +\end{array}$

- Variable has entered the discriminant function first, i.e. it optimizes the Wilks' Lambda minimizing selection rule; a Note that the variables mentioned above have not had an equal number of opportunities to enter a discriminant function. 


\subsubsection{Summary of Multivariate Results}

Explaining large percentages of variance in the criterion variable, the discriminant analysis confirm a number of univariate findings.

1. Regarding scalle, it was found that high performers evaluate the 'critical mass" of their human resources for research as adequate compared with low performers. Besides, high performers spent more time on research, and less time on patient care outside their hospital. Repeatedly, human resources and time spent on research entered a significant discrimimant function, thus, minimizing Wilks" Lambda.

2. Regarding atmosphere, no relation with scientific productivity could be detected. With regard to work-related culture, this is at least partially due to inappropriate measurement.

3. Regarding management, it was found that craftsmanship is of importance for clinical research. Repeatedly, craftsmanship entered a significant discriminant function.

4. Regarding control, it was found that reward expectation for research is inversely related to performance in the multivariate analysis.

5. Regarding communication, it was found that high performers have more international communications than low performers. Like all other predictor-criterion relations presented in this study, it is unclear whether this is the cause or the effect of their superior scientific productivity. As mentioned before, the procedure used in the present study does not allow a test of the direction of the relationship between variables. Since a cross-section design was used, only the nature of the relationship can be investigated.

\subsubsection{Varlance between Medical Disciplines}

Rigter (1986) has observed that medical disciplines are not uniformlly strong or weak in their performance. The data of the study presented here suggest that a similar abservation can be made with regard to the predictor variables. The next exhlbit, 6.8 " shows the variance within and between 16 medical flelds with regard to their discriminant score. For each medical discipline, the units with the maximum and minimum discriminani function score arre represented. Two of the medical disciplines, area 15 and 18 in the figure, are excluded from the analysis because they contained only one observation. In order to maintain anonymity of those who participated in our investigation, names of the disciplines are not mentioned. Exhibit 6.8. shows the differences in variance between 16 medical disciplines. 


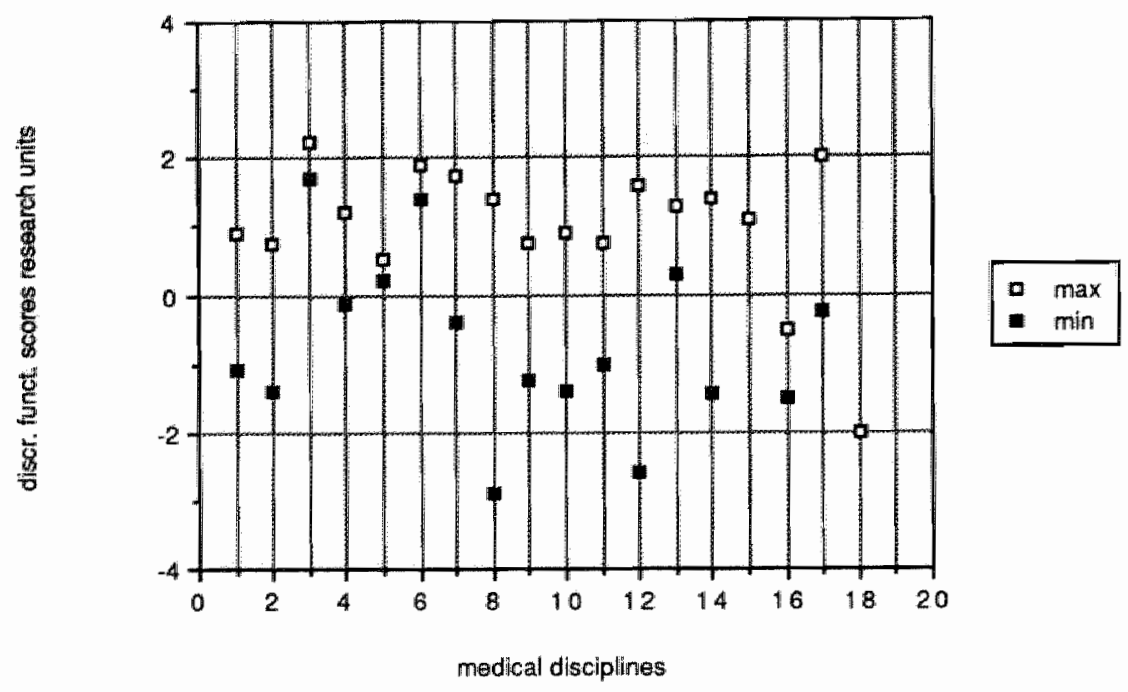

Consistent with Rigter's observation regarding performance, large differences in input and throughput levels appear to exist between the disciplines. Some disciplines score homogeneously high or low in their international communication, managerial craftsmanship. human resources, time spent on research, and result control. Most of the disciplines, however, appear to be very helerogeneous. They include both units with negative scores and units with positive scores on the discriminant function. Since the discriminant function may be interpreted as the degree to which the management and organzation of a clinical research unit is appropriate for conducting high quality research, we may conclude that mosil of the medical disciplines are not umiformly 'equipped' with the professional organization to conduct clinical research that can meet international standards, and that may contribute to the growth of clinical medicine as a science.

Following Filgter's conclusion, the analysis shows that variance between research units within disciplines not only exists with regard to performance, but also with respect 10 the organizational infrastructure. Of course, these are correlations which cannol substitute causal analyses. Nevertheless, since this chapter has uncovered some organizational features that are associated with scientific performance in a non-trivial manner, we have some indication to believe that future research policy should pay attention not only to the differences between fields, but also to those between resiearch units within fields. Research policy emphasis on selective stimulation within disciplines may improve the future performance of clinical research (Bally el al., 1987). 


\subsection{Economies of Atmosphere?}

One of the purposes of this empirical study is to study the relationship between culture and pierformance. In contrast to our conjectures, evidence was found for economies of scale. economies of scope, and the efficiency function of management and control varlables in a clanlike organization, but no substantive evidence has been found for economies of almosphere. So it is legitimate to ask why the present study failled to support the 'efficient culture' hypothesis.

Two alternative arguments will be considered. First, it may be conjectured that the noncorrelation has been caused by inappropriate measurement of work-related culture. ilmproving the measuring qualities would then expected to show a relationship.

Second, it may be conjectured that salient differences between high and low performers do exilst, but that they are unfortunately" not labelled as "culture'. Note that several authors have argued that leadership (Schein, 1985) and control (Merchant, 1985) are related to the concept of culture. Note that culture is a holistic concept - it is related to several organizational variables such as structure (Mintzberg), strategy (Weick), and clan control (Ouchi). Reinterpretation of the data, however, has the serious disadvantage of 'facts in search of a theory:. It is generally known that nearly all statisticial correlations can be explained on a post hoc basis - even random ones. Consequently, a reinterpretation of the data in flavor of economies of atmosphere is a debatable enterprise risking the criticism of post hoc speculation. The only legitimate basis for this speculation is its plausibility which, in the end, may only be usefully addressed in future research. In this respect, the next chapter will explore economies of atmosphere with a more adequate instrument in departments of economics.

\subsubsection{Inappropriate Measurement Argument}

The work-related (organizational) culture has been assessed with the value survey module (WSM)(Hofstede, 1980). Holstede has developed this instrument by factor analyses at the country llevel of analysis. However, an instrument that has proven to be valuable at one level of analysis is not necessarily appropriate at other levels of analysis. Hotstede and Spangenberg (1987) have shown that the same VSM ttems form differrent clusters when factor analyzed at the individual, occupaltional, organizational or national levels. Since we used the original VSM formulas, our assessment of organizationall culture is probably invalid. 
In order to look for the salient cultural dimensions hidden in our sample of research units "we repeated Hofstede's factor analysis at the group level (43 observations). The factor solution has an explained variance (EV) of $56.1 \%$, and showed three lactors which were named "work centrality" ( $E V=17.5 \%$ ), "power distance/uncertainty avoidance" ( $E V=15,6 \%$ ), and "work intrinsic vs work extrinsic' $(E V=11.7 \%)$. Although this procedure may be more appropriate for the assessment of organizational culture (Robinson, 1960), these new dimensions were not significantly correlated to performance. MANOVAs, t-tests, and (partial) correlation analyses failed to demonstrate the existence of economies of atmosphere regarding work-related culture. One may conclude that even if the validity of the VSM were improwed, no relationship between work-related culture and performance could be detected. Since the procedure mentioned above did not include reformulation of the items (in order to focus them on the organizational rather than the national level), the quality of the instrument was only partially improved. Thus, not all sources of measurement error have been eliminated.

\subsubsection{Re-Interpretation Argument}

Since our cultural measure is inappropriate, the predictor variables which entered the discriminant function may be inspected. This leads to an interpretation of the existing data which favors the economies of atmosphere hypotheses. This interpretation, however, is debatable, because it is ad hoc, yet there may be some justification because of an unexpected finding, which, moreover, has intrigued the members of the research team and the advisory council, and has been the source of bold conjectures. This is the negative relationship between reward expectation and clinical research performance. We conjectured that high performers would expect more financial (career) rewards for conducting research than for patient care. The incentive system of high performing units would be more favorable for high research efforts. Note that all members of high performing units, including the supervisors (t-test; $p=.05$ ), spend more time on research than members of low performing units ( $t$-lest; $p=.02)$. In addition, they have more frequent working discussions with colleagues on research topics. (t-test; $p=.08)$, and they teel more responsible for their research task (t-test; $p=01)$. In the neoclassical paradigm, individuals are assumed to maximize their subjective expected utilities. If members of clinical research units were profit maximizers, they would only do so in the expectation of a pay off. In contrast to this reasoning, it appeared that high performers expected that (a) patient care is more appreciated than research ( 1 -test; $p=.05$ ), and that (b) in comparison to research, patient care offers better opportunities for their career development (t-test; $p=.02$ ). Although the high performers are aware of the fact that patient care generates the best pay-off, they mainly invested their time and efforts in medicall research. 
Consequently, it may be concluded that high performers in medicine are intrinsically motivated in research. For them, participating in high quality research is a goal in itself. They are dedicated researchers - driven by the motivation to increase medical knowledge (and indirectly, improving patient care) rather than by pecuniary pay-offs. From a neoclassical point of view, their behavior is (reciprocal) altruistic rather than calculative. Though not expected, this finding is consistent with Staw's conjecture on faculty motivation: "Instead of viewing the individual faculty member as an intense calculator of personal costs and benefits, activities like services, and perhaps even aspects of teaching and research, might be better explained by altruistic motivation" (Staw, 1984, p. 78). Although motivation is an attribute of individuals, it is more plausible that altruistic motivation in research is a group attribute influenced by professional norms including thigh quality requirements. A high degree of personnel control is exerciized by these internalized norms. Take as contrast the low performers. The low performers are more consistent with the hedonistic image of man. Their expectations are more "rational". They invest their time in patient care rather than in research. Moreover, they spend significantly more time on privale ('off-hospital') patient care practices (which is generally known to be more profitable than patient care in the hospital not to speak of research) than thigh performers. In terms of individual financial performance, the low performers are better off. However, at the team level - in terms of research performance - it is the non-calculative attitude (call it research dedication or atmosphere) which increases the effectiveness. Of course, these are interpretations of the data. Another plausible interpretation is that high performers do make cost-benefit analyses - but not concerning financial benefits. They are more motivated to reach immaterial targets such as international recognition for their work, publication in outstanding journals, etc. If this interpretation is plausible, the difference in atmosphere is that high performers (in research) are more stimulated by non-pecuniary incentives, whereas low performers (in research) are more stimulated by pecunlary incentives. Whether this atlitude is a general trait of staff members of research units in other disciplines, e.g. in economics, will be discussed in the subsequent chapters.

\subsubsection{Interim Conclusions}

In summary, there is some, though debatable, (ad hoc) evidence for the existence of a cultural difference between medical research units. The 'culture's consequences" in clinical medicine may be interpreted as economies of atmosphere, because they discriminate between high and low productivity. If the economies of atmosphere reinterpretation is plausible, it is worthwhile mentioning that reward expectation is the most important variable in the optimal discriminant function. Despite these arguments in favor of economies of atmosphere, cultural transformation is not a substitute, but rather a complement for improving the research 
infrastructure of medical units in university hospitals. Finally, some attention should be paid to removing some of the personal costs for the intrinsically molvated behavior of members of high performing units. Although research efforts may not be economically motivated in clinical medicine, they would undoubtedly be reduced in the long term when the opportunity costs remain high.

\subsection{Concluding Remarks and Discussion}

This chapter has explored economies of atmosphere in clinical departments of universily hospitals. Additional hypotheses have been tested concerning the advantages of scale, management, control, and communication. Since no empirical data were available regarding multi-product functions in medical flelds, economies of scope were not investigated. Univariate and mulivariate procedures were used in the analysis of data. Explaining large percentages of variance in the criterion variable, discriminant analysis confirmed a number of univariate findings.

In general, the conjectures on economies of scale, crattsmanship, and communication were corroborated; those on economies of atmosphere were not; and those concerning reward expectations were refuted. (i) Regarding scale, it was found that high performers evaluate the 'critical mass' of their human resources for research as adequate compared with low performers. Besides, high performers spent more time on research, and less time on patient care outside their hospital. (ii) Regarding atmosphere, no relation with scientific productivity could be detected. This is at least partially due to inappropriate measurement. (iii) Regarding management, it was found thatt craftsmanship is of crucial importance for clinical research. (iv) Regarding control, it was found that reward expectation for research is inversely related to performance in the multivariate analysis. On an ad hoc basis, this unexpected finding may be reinterpreted as an economies of almosphere effect. (v) Regarding communication, it was found that thigh performers have more international communications than low pertormers. Like all other predictor-criterion relations presented in the present study, it is unclear whether this is the cause or the effect of their superior scientific productivity. As mentioned before, the procedures used in the present study do not allow a test of the direction of the relationship between variables. Since a cross-section design was used, only the nature of the relationship can be investigated.

While study I focused on incentives and constraints of scientific productivity in clinical medicine, the follow-up study, study II, has dealt with the dieterminants of productivity in economics. The findings of the latter study are reported in the next chapter. 


\title{
Scientific Performance \\ in Economics $1-2$
}

\begin{abstract}
"The extreme clannishness, not to say xenophobia, of the Econ makes life among them difficult and perhaps even somewhat dangerous for the outsider. This probably accounts for the fact that the Econ have so far not been systematically studied (...) More research on this interesting tribe is badly meeded" (Leijonhufvud, 1963).
\end{abstract}

\subsection{Introduction}

In 1985 the Dutch government asked a review commission, the "Verkenningscommissie Economische Wetenschappen' (VEW), to evaluate the performance of university research in economics and to advise on possible improvements. The VEW issued its report in 1986, concluding that strong productivity differences existed between research units in Departments of Economics (which include units of business administration, bedrijfseconomie, in the Dutch system). On the one hand, there were units that published 180 (weighted) pages per person per year. On the other hand, there were units that did not publish al all. Comparisons with the productivity of U.S. economics departments, Graves, Marchand, and Thompson (1982), showed that the overall performance is rather low. This chapter makes an attempt to explain why performance records differ among departments of economics. It is assumed that, in principle, the same set of incentives and constraints influence research effectiveness as in clinical medicine.

1 For their stimulating critical comments, we owe thanks to A. van Heeringen (RAWB), W. Schautell (KUN), P. Wijkamp (VU), and J.S. Cramer (SEO).

2 Accepted for publication: Spangenberg, J.F.A. Buijnk, W., and Alfenaar, W., Some Incentives and Constraints of Scientific Performance in Departments of Economics, Part I: Predictor-Criterion Relations, Scientometrics, An International Journal for all Quantitative Aspects of the Science of Science and Science Policy, Elsevier Science Publishers, Val. 17. No. 5-6, November 1989 Issue.

Spangenberg, J.F.A., Breemhaar, B., Nifhuis, F.J.N., and Alfenaar, W., Some Incentives and Constraints of Scientific Performance in Departments of Economics, Part II: Validity and Robusiness, Scientometrics, An International Journal for all Quantitative Aspects of the Science of Science and Science Pollicy, Elsevier Science Publishers, Vol. 17, No. 5-6. November 4989 Isswe (forthcomingl. 
The VEW findings have been used for the classification in high and low performers. After collecting data on the organization of research units, univariate and multivariate statistics, including multiple regression analysis, have been applied to explore the research questions regarding competitive advantages in the scientific enterprise.

\subsection{Measurement of Performance}

The VEW has highlighted the need for the development of productivity indices in the uniwersity sector. Their own proposal is that performance of research units should be established on the basis of publications by staff based on numbers of pages published in the period 1979-1984 (six years). Journal articles were weighted according to a U.S. ranking based on citations. Llebowitz and Palmer (1984) have assessed the relative impact of economics journals, and provided a ranking of journals based on their relative influences on the writings of academics. either within the economics profession or in the world at large. The measure of journal impact used to create this ranking is the number of cittations that authors make to articles appearing in various journals. The authors have controlled for both journal size and age in constructing the measure. The values of their citation index $(\mathrm{Cl})$ varied between 0 and 100 . On the basis of Liebowitz and Palmer's set of journals the VEW differentiated $A$-journals $(C \mid \geq 10 \leq 100)$, $B$ journals $(\mathrm{Cl} \geq 1 \geq 10)$, and $C$-journals $(C \mid<1)$. Examples of A-journals are the American Economic Review, Econometrica, and the Journal of Money, Credit \& Banking. Examples of B.journals are Administrative Science Quarterly, European Economic Review, and Decision Science. Examples of $\mathrm{C}$ journals are History of Political Economy, International Journal of Industrial Organization, and Interfaces. Two categaries were added: D-journals and Ejournals. The scientific standing of these journals has been estimated to be low; so is their contribution to the growth of economic knowledge (VEW, 1986, p. 65-80). The following weighting factors were allocated to these journals: 4 (A-journall), $3(B), 2(C), 1(D), 1 / 2$ (E). Three kinds of publications were distinguished: journal articles [JA (unweighted), and JA(weighted), book articles [BA (Dutch), and BA (internavional)], and books [BK (Dutch), and $B K$ (international)].

Exhibit 7.1. shows the distribution of productivity per university. (Key: EUR is Erasmus University Rotterdam; UVA is University of Aimsterdam; KHT is University of Tilburg; RUG is University of Groningen; VU is Free University Amsterdamy. In total 93 research units were evaluated by the VEW. They were associated with departments of economics and with departments of other disciplines such as departments of law, and departments of management and organization. (The source of exhibit 7.1 . Is the VEW report (1986) Statistical appendix, table 19). 
Exhibit 7.1. Departmental Productivity in Dutch Economics

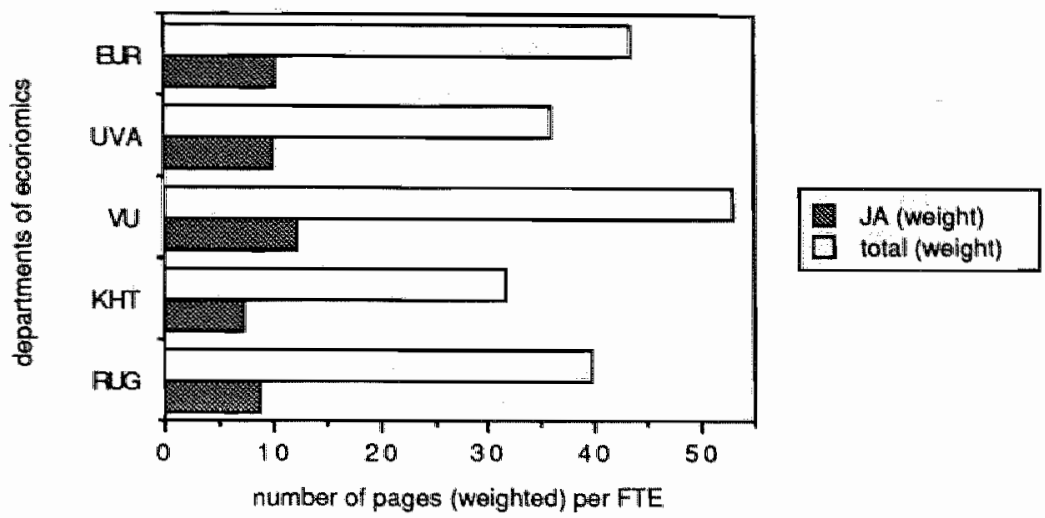

Journals were allso classified as to subject. The VEW made use of an amended version of the Journal of Economic Literature (JEL) index of classification codes (Cf. key Exhibit 7.2). Each publication has been classified under one subject only, so that double countings were excluded. It should be mentioned that the JEL index is essentially a classitication code for general economics (Dutch abbreviation: AE) and econometrics (KE). Business administration (BE) is included in its entirety in code 5. Nevertheless a largle portion of the staff of a Dutch department of economics $(30-50 \%)$ works in this area.

Exhibit 7.2. Illustrates the distribution of productivity per field per university. Only universities with a department of economics were requested to participate in the study. Since the evaluation period is 1979-1984, the Department of Economics of the Uniwersity of Limburg, which was officially established only in 1984, was not requested to participate in this study. The source of Exhibit 7.2. is the VEW report (1986) Statistical appendix, tablle 18. 


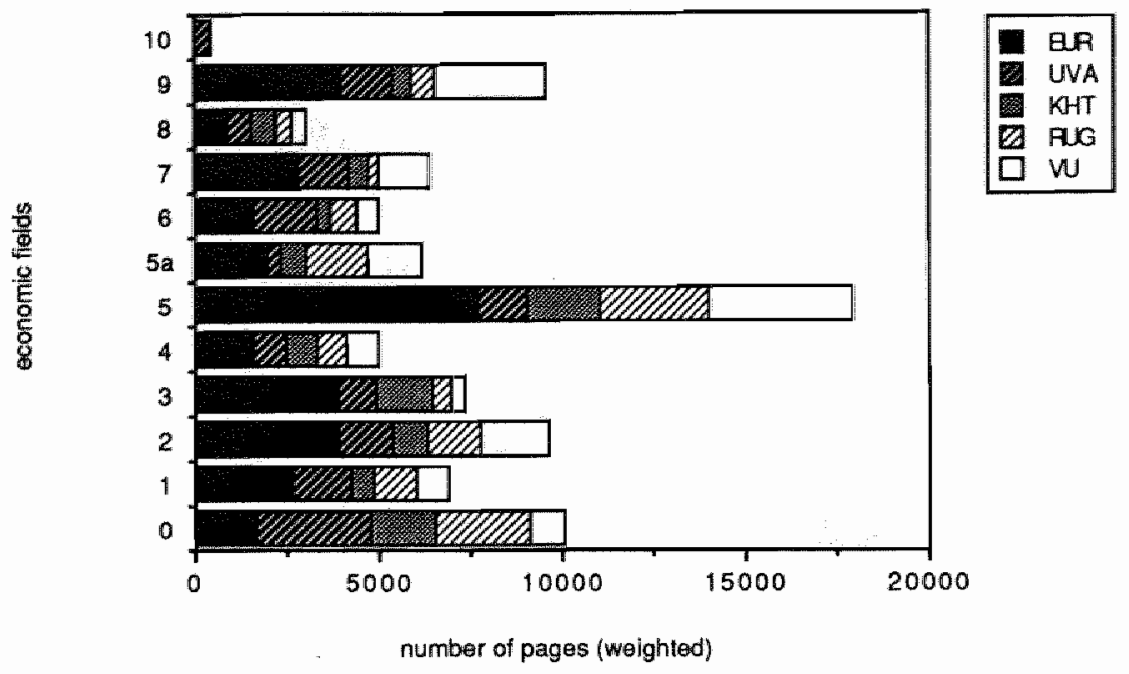

Key

o General economics; Theory; History; Systems

1 Economic Growth; Development; Planning; Fluctuations

2 Quantitative economic methods and data

3 Domestic monetary and fiscal theory and institutions

$4 . \quad$ Internationall economics

5 Administration; Business Finance; Marketting; Accounting

5 Decision science (distribution and llocation problems)

6 Industrial Organization; Technological Change; Industry Studies

7 Agriculture; Natural resources

8 Manpower; Labor; Popullation

9 Welfare Programs; Consumer economics; Urban and regional economics

10 Actuarial sciences 
However, the differences in the degree to which Dutch economists working in various fields contribute to the international literature (JA weighted; BA int and BK int) is graphically shown in Exhibit 6.3. Although theld 5 (Administration), for example, scores high in an absolute sense (total productivity), its contribution to the international growth of knowledge, according to U.S. standards, appears to be rather low. Its productivity is mainly caused by high output in local journals and books. More internationally oriented fields are economic growth (1). econometrics (2), and decision science (5a). Since one of the fields, 10, did not publish in the international literature, the next exhibil. will only show the contributions of the remaining 9 fields. (The source of the figure is the VEW report (1986) Table IV.2 - the table neglects field 10).

Exhibit 7.3. Contribution to the International Literature

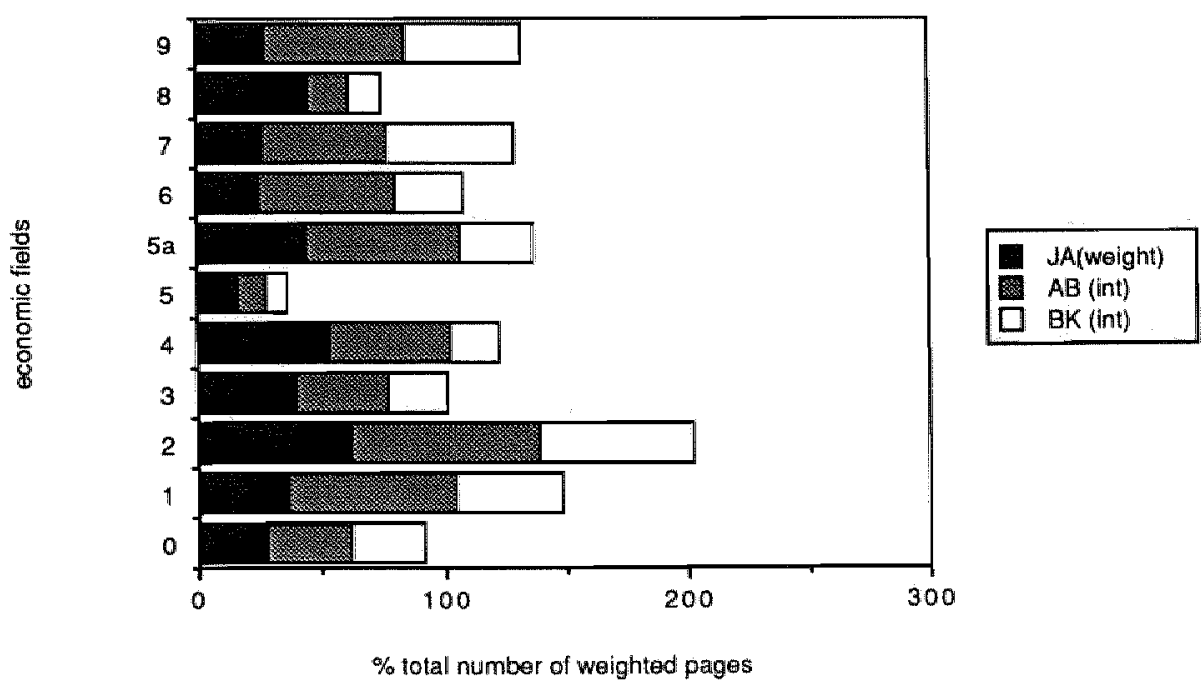

In contrast to the evaluation of medical research performance where a combination of 5 indices has been applied, only the results of publication countings (indicating 'total productivily' and 'contribution to the international literature') have been used for the ranking of departments and research units in economics. Citations have been counted, butt, in general, they proved to be uncorrelated to the productivily criterion. The same is true for the number of editorships. The number of Ph.D. theses per university was so low (average number per university in the 
period 1979-1984 was 31; min. 21, max. 47) that Ph.D. theses were meaningless as a measure of differential productivity.

These shortcomings ralse some doubt about the vallity of the productivity criterion as has been pointed out by several Dutch economists (Cramer, 1986). As a result of the lack of convergence between partial indicators, the findings of the VEW must be interpretted with caution. However, it cannot be denied that, up to now, they represent the best available evaluation of the performance of Dutch research units in economics. Therefore, the VEW evaluation has been the basils for study II which will be reported in the subsequent sections.

\subsection{Sample}

According to the procedure described in the prewious chapter, research units were classified as high and low performers. A wide variety of ecomomics fields has been selected for inclusion in the study: general economics (JEL code: 0), economic growth (1), quantitative economic melhods (2), domestic monetary and fiscal theory (3), internalionall economics (4), administration (5), decision science (5a), industrial organization (6), agriculture (7), manpower (8), and welfare programs (9). Per field a selection was made of one or more high performers and one or more low performers. Given our uncentainty about the validity of the VEW evaluation, the sample was restricted to those units with extreme (high or low) performance scores. Moreover, only units were considered that comblined above average performance (in the case of high performers) or below average performance levels (in the case of low performers) on both publication and citation indexes (VEW, 1986, table 47948.4). Thus, the convergence of performance indicators was introduced as a selection rulle restricting our sample of units. In tolal 29 units were requested to participatte in the study. Exhibit 7.4. shows the differences between high and low performers in the response samplle $(\mathrm{N}=16$ units) with regard to scientific productivity (relative deviation of the mean number of publications) and citation impact (relative deviation of the mean number of citations). On average, the Impact difference between high and low performers is considerably larger than the productivity difference. The lines between the performance scores are meaningless. 


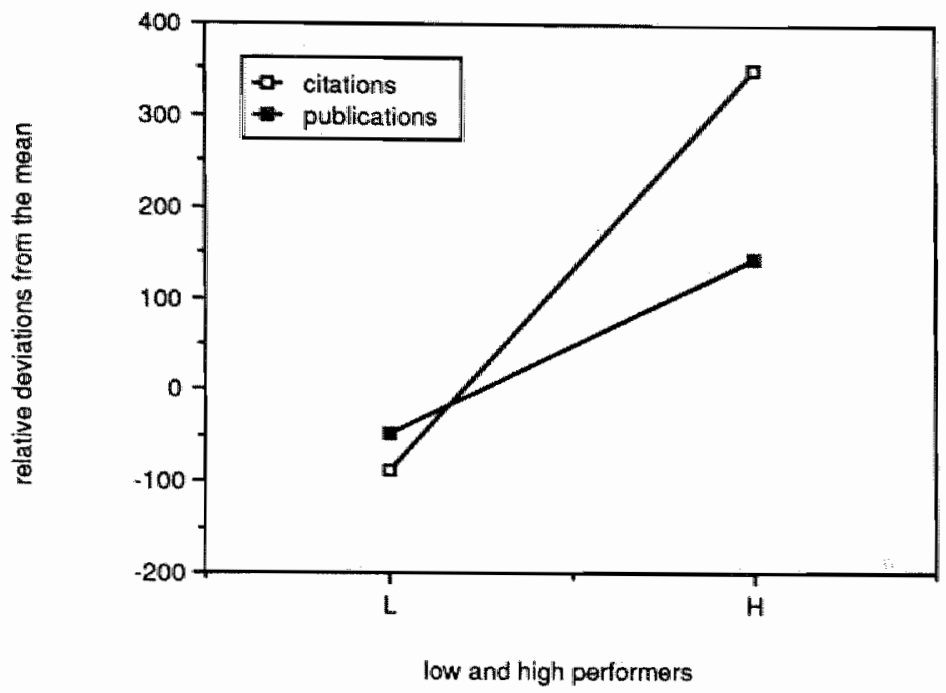

In order to check our classification a number of full professors of economics $(\mathbb{N}=7)$ working in various fiellds were consulted. These peer reviews were consistent with our classification of units on the basis of the VEW statistics.

\subsection{Data collection}

Data were collected in the period April-July 1987. A mail questionnaire was sent to the selected units, addressed to all stalf employees who (i) were academically educated (thus, excluding administrative and support staff), and (ii) were appointed to participate in economics research (thus excluding members with exclusively educational tasks). These criteria produced a population of 152 respondents of whom 86 were working in units with high performance, and 66 were working in units with low performance. In total 25 units (group response $86 \%$ ) responded to aur questionnaire. Only data from 16 units were analyzed, because 9 units were represented by less than $25 \%$ of their researchers. The sample consisted of 8 high performers (33 subjects; individual response $38 \%$ ) and 8 low performers (30 subjects; individual response $45 \%$ ). 
Nonresponse analysis showed that in the main two factors accounted for nonresponse on the unit or individual level: lack of time and lack of interest. It should be noted that the questionnaire was sent shorlly after the VEW evaluation, and that a large number of economists did not agree with the VEW procedure. Cramer (1986), for example, has noted that the quality of the content of economics research (cl. Pen, 1982) has not been assessed, and that economics in the Netherlands should be compared with the productivity of similar European coumtries (cf. RAWB, 1983b) - such as that of U.K., Belgian or Swedish depariments of economics rather than those in the U.S. Despite the apparent shortcomings, it has been argued that the VEW report is the best available evaluation of economics research effectiveness (Ad hoc Commissie Voorzitters Vaste Commissie Wetenschapsbeoefening, 1988).

Alhough the units are rather evenly distributed over universities, disciplines, and fields (with the exception of general economics - as will be shown in exhibit 7.6), we realize that the combination of the low response, the small number of observations, and the large number of variables restrict the generalizability of this study. These shortcomings may be partially overcome by comparing the findings with the outcome of other studies on the determinants af scientific productivity in economics (cl. section 7.9). The logic is that one can more rely upon the resulls when they are consistent despite the large differences in discipline.

As exhibit 7.5. indicates the distribution of high and low performers over universities (100\% $=16$ units) is fairly even. As mentioned before the youngest department of economics (University of Limburg) was not requested to participate in the study because it was not yet in existence in the time of the evaluation period 1979-1984, and consequently only very recent performance measures were available.

Exhibit 7.5. Response Distribution Universities

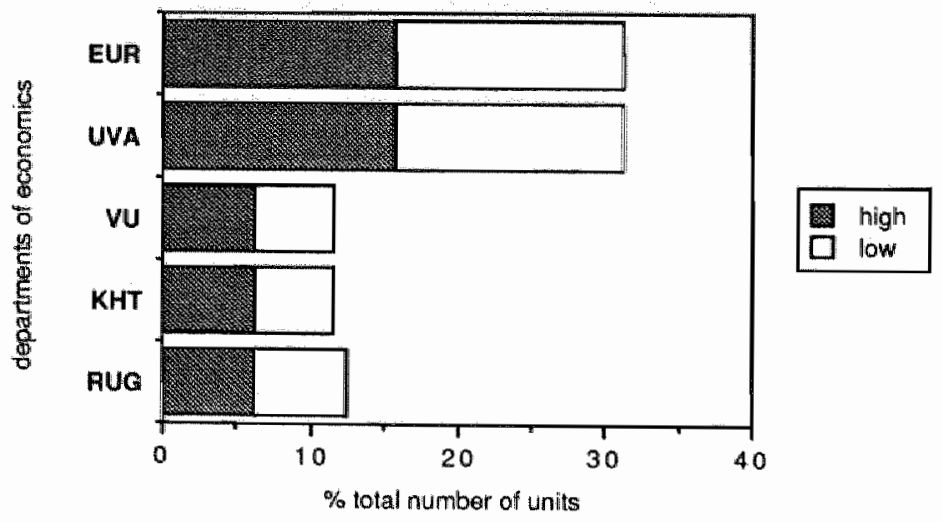


Exhibit 7.6. clarifies the distribution of high and low performers over three major disciplines in the Netherlands: econometrics (KE), business administration (BE), and general economics (AE). Econometrics and business administration are represented more by low than high performers. As a result of nonresponse, general economics is only represented by high performers - which, of course, does not mean that low performers do not exist in that field.

Exhibit 7.6. Response Distribution Disciplines

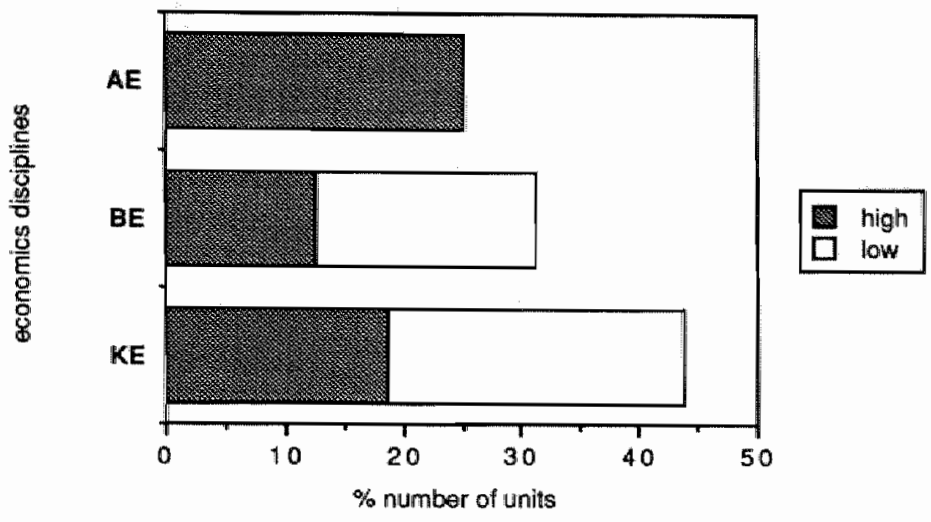

\subsection{Additional Hypotheses:}

De Groot (1984) has rightly emphasized that scientific research is a learning process. Consequently, what was learned from study I (ciinical medicine) that could improve study II (economics)? Learning effects will be discussed concerning atmosphere, scale, input mix, and performance.

\subsubsection{Atmosphere}

Study I has confirmed that Hofstede's value survey module (VSM) is an inappropriate instrument for the measurement of organizational culture. Therefore, we added the organizational culture module (OCM) to our questionnaire. The OCM was developed by Hofstede and colleagues (1988) in a large scale survey of 20 organizations in the Netherlands and Demmark. Hofstede and his co-workers found that the OCM adequately showed differences in general values at the organizational level ('practices'), whereas the VSM only elicits the national value differences. The OCM consilsts of 18 items indicating 6 dimensions. The dimensions were found by factor analysis. They were labelled: (ii) process oriented $(=$ bureaucratic) vs. results oriented (non-bureaucralic), (ii) employee oriented vs. job 
oriented, (iii) parochial vs. professional, (iv) apen system vs. closed system, (v) loose vs. tight control, (vi) normative vs. pragmatic.

Only two of the six OCM dimensions proved to have an acceptable internal consistency in the sample: bureaucratic culture (Cronbach's alpha OCM1 is .63) and normative culture (Cronbach's alpha OCM6 is .70). The bureaucratic dimension (OCM1) opposes a concern with goals and products (results oriented) to a concern with means and procedures (means oriented). The key items show that in results oriented non-bureaucratic cultures, people perceive themselves as comfortable in unfamiliar situations and putting in a maximal effort. while each clay is felt to bring new challenges. In process oriented or bureaucratic cultures people perceive themselves as avolding risks and spending only a limited effort, while every day is pretty much the same. Results oriented cultures can be found in professional organizations (e.g. R\&D laboratories), while bureaucratic organizations tend to have process oriented cultures.

The other dimension (OCM6) deals with customer orientation: pragmatic units are marketdriven, while units with a normative culture perceive their lasks towards the oulside world (e.g. the scientific forum) as the implementation of fixed rules. As we assume that high performers are more oriented to the international forum and would have more rigorous professional standards, it was conjectured that high performers are more normative (Ritti, 1968), whilie low performers are more pragmatic (variable 26). In addition, we assume that high performers would be more innovative, and, consequently, less bureaucratic (process oriented) than low performers (variable 27 ).

\subsubsection{Scale}

Measures were inserted to assess capital inputs - since they were underemphasized in the prevlous study. The following items concern economies of scale: (i) number of full time research equivalents (FTE size - variable 22), and (ii) total research expenditures in 1986 (variable 23). We expected that high performers would have more FTEs for research. Study 1 failed to demonstrate the relationship between unit size (in terms of number of staff members) and performance, and we conjectured that this failure may have been caused by not weighting staff members for the degree to which they were appointed to do research. The 'full time equivalent' enables the weilighting of unit size for research intensitty. Furthermore, we conjectured that high performers would operate on a larger scale so that they would thave higher research expenditures than low performers. 


\subsubsection{Input Mix}

Note that additional measures have been developed for study II. While study I only deals with human inpults in the "staff mix", capital inputs were rated as well in study II. Consequently, it is more appropriate to speak of 'input mix' rather than staff mix. The following llems concern the input mix: (i) cash flow mix (variable 24) and (ii) tenure intensity (variable 25) in the research unit. The cash flow mix indicattes the distribution of 'primary cash flow and "secondary cash flow' (mainly basic research) versus the 'tertiary cash flow' (mainly contract research)(Central Bureau for Statistics, 1988). Tenure intensity indicates the distribution of tenured versus non-tenured in the research unit. Regarding the cash flow mix, we assumed that high performers will be more oriented towards basic research than towards contract research in comparison with low performers. It is widely assumed that basic research leads more often (or more quickly) to (international) dissemination of knowledge. According to this view, contract research seldom leads to such dissemination, because of property rights - especially when the customer operates in a market environment. Adequate as this may be for high tech research, high performers in economics are hypothesized to have higher percentages of secondary and tertiary funding. With regard to tenure intensity, we assumed that increasing the proportion of tenures in a research unit would lower the overall incentive to perform, so that fewer tenures were expected in high performing units.

\subsubsection{Scope}

Although the economies of scope variable is not a learning effect of the previous study, itt certainly is a new variable. Unfortunately, it was not feasible to assess economies of scope in study I. In the present study, however, the VEW report provided a point of departure to approximate economies of scope. Economies of scope are realized in team production activity in which joint use of inputs yields a larger output than the sum of the products of the separately used inputs. It will be recalled that knowhow may represent a shared Inpul which can find a variety of end product applications. Whenever the knowledge can serve as a common input into two or more production processes, joint production (utllizing common resources) will produce economies of scope. Thus, if the skills to publish in econometric journals display economies of scale, and these economies are not exhausted, and if the knowhow can also be used in publishing in business administration journals, e.g. finance, then economies of scope will exist in the production of scientific knowledge. In general , economies of scope can be defined as arising from inputs that are shared or utilized jointly. The shared factor may be imperfecily divisible, or some human or physical capitall may be a public input (Jones and Hill, 1988). 
Economies of scope exist when for all outputs, $y_{1}$ and $y_{2}$, the cost of joint production is less than the cost (c) of producing each output (y) separately. That is, it is the condition for all $y_{1}$ and $y_{2}$.

$c\left(y_{1}, y_{2}\right)<c\left(y_{1}, 0\right)+c\left(0, y_{2}\right)$.

With economies of scope, joint production of knowledge in two fields is less cosily than the combined costs of production of two specialized research units. The present study has defined scope as joined production of knowledge in more than one field but within the same discipline, 1.a. economics. Diversification was indicated by publishing in more than one research fields $(N=10)$. Note that the fields were classified according to the Journal of Economic Literature (JEL) index. The VEW report contained useful data concerning the mulli-product functions of unils in terms of their JEL publications. These data, however, had to be transformed since publishing in one field with 1 publication, while the largest output of that unit in another field consists of 100 publications, cannot seriously be defined as joint production in two fields. Consequently, a simple decison rule was applied to assess whether a unit publishes substantially in another field. The $25 \%$ criterion regarded a unit to be active in another field when it publishes the equivalent of at least $25 \%$ of its largest research output (in terms of weighted pages) in one field, the principal field, in that other field. The $10 \%$ criterion regarded a unit to be active in another field when it publishes at least $10 \%$ of the publications in the princlpal field in the other field.

\subsubsection{Performance}

An exploratory study conducted by Cramer (1988) suggested that meimbers of research unils in economics may be rather mobile. Consequently, it would be the best procedure to assess the organization and performance of these units simultaneously. The VEW has evaluated the performance of research units in the period 1979-84. How can these performance outcomes be attributed to organizational characteristics of units diagnosed in 1987? Of course, it may be argued that the evaluation outcome has also been reviewed by peers so that they may be regarded as fairly up-to date. Nevertheless, it may be argued that the classification of high and low performers would be more plausible if it were validated by recent, if posibible independent, ratings. As a consequence, items were added to our questlionnaire regarding the indlvidual output of subjects in 1986. It was expected that members who were assacilated with high performing units would have a higher score on their individual performance index (variable 28) than those of low performing units. 
Since publications are more highly valued than working papers and international publications are more highly valued than national publications, individuall performance $(Y)$ was indexed as follows:

$Y=\Sigma W P+2 \Sigma D J A+3 \Sigma i J A_{*}$

WP: number of working papers

DUA: number of articles written in Dutch journals

IJA: number of articles written in international journals

The VEW report (1986, table 479), in which quantitative data were presented about the performance of research units, prowided two objective measures: (i) the unit's relative deviation of the average productivity score (scientific productivity), and the (ii) unit's rellative deviation of the average citation score (citation impact). In contrast to the individual performance index, scientific productivity and citation impact were not independent of overall performance (classification of research unit into high and low performers). The statistical relationship between overall performance and the single criterila will be discussed later.

In sum, both predictor (independent) and criterion (dependent) variables were added to our original list of variables (Exhibit 5.2). Most of them can be conceived as the learning effects of study 1 . These additional hypotheses regarding study III are summarized in Exhibit 7.7 . 
In comparison with low pertormers, high performers (...)

1. Scale

22. have more full time research equivalents

FTE UNIT SIZE

23. have higher research expenditures

RESEARCH EXPENDTURES

2. Inpul Mix

24. have higher percentages of secondary

and tertiary funding

CASH FLOW MIIX

25. have a lower tenure intensity

TENURE INTENSITY

4. atmosphere

26. have a less bureaucratic culture

27. have a more normative culture

BUREAUCRATIC CULTURE

9. Scope

31. According to $10 \%$ criterion

32. According to $25 \%$ criterion

NORMATIVE CULTURE

$10 \%$ SCOPE

$25 \%$ SCOPE

Single criterion variables

VARIABLE NAMES

In comparison with "low performers' (VEW measure), "high performers' (...)

\section{Performance}

28. have a higher individual performance index

29. deviate positively from the average product. score

30. deviate positively from the average citat. score 
Exhibit 7.8 shows the reliability scores (Cronbach's alpha coefficient) of these new variables. Some of them have been developed in cooperation with $W$. Buijink who is associated with the accounting department of the University of Limburg.

Exhibil 7.8. Reliability of additional measures

Variable name

(number of items)
Source

Rellability

(decimal points omitted)

\section{Scale}

22. FTE unit size (1)

23. research expenditures (3)

2. Input Mix

24. cash flow mix (3)

25. number of tenures (1)

4. Atmosphere

26. bureaucratic culture (3)

27. normative culture (3)

B. Performance

28. individual performance index (3)

29. scientific productivity (1)

30. citation impact (1)

9. Scope

31 according to the $10 \%$ criterion

32 . according to the $25 \%$ criterion

A

Buijink

@

Centrall Bureau of Statistics n.a.

A

Hofstede et al.

63

Hofstede et al.

62

Buijink

VEW' report

VEW report

68

VEW report

VEW report (a)

@

@

62

\section{a.}

(C)

Key: $A=$ author; $@=$ not applicable ( 1 item only); n.a. = not applicable (items do not form a scale)

\subsection{Measurement of Additional Variables}

The mew variables were included in the Dutch-language questionnaire that was used in study II. For each additional predictor (22-27) and criterion (28) variable, one or two items will be given as an example. The numbers of the items (22-2B) refer to the variable names in exhibit 7.7. A complete list of the variables including more than one item is given in appendix 2 . ltems 29-32 refer to measures (derived) of the VEW report which were not included in the questionnaire. 
22. Indicate the number of full time research equivalents in your research unit.

23. What were your research expenditures in the last year ( $=1986$ ) in terms of (i) gross salaries for research assistants, and (ii) other research expenditures (mailing costs, software purchase, travel costs)? Divide your total research expenditures by the number of colleagues with whom you share this money.

24. How much of your total research expenditures $(=100 \%)$ originates from (i) primary cash flow (\% direct governmental contribution to your department), (ii) secondary cash flow (\% governmental contribution allocated by the national science foundation - in Dutch: NWO - Ecozoek), (iii) tertiary cash flow (\% revenues from contract research)?

25. Are you employed on a (1) permanent basis (2) temporary basis with tenure perspectives (3) temporary basis without tenure perspectives?

26. Where I work people do nol feel comfortable in unknown situallions; they attempt to avoid risk taking (1-2-3-4-5) Where I work people feel comfortable in unknown situalions; they do not mind to take risks.

26. Where I work, people exert only a limited effort (1-2-3-4-5) Where I work, everybody puts in a maximal effort.

27. Where I work, the emphasis is on the wishes of the customer (e.g. contract research)

(1-2-3.4-5) Where I work, the emphasis is on the application of the correct procedures.

28. Indicate the number of articles which you have had published in Dutch scientific journals in 1986 (no predictor variable).

28. Indicate the number of articles which you have had published in international scientific journals in 1986 (no prediclor variable).

29. Indicate the unit's relative deviation of the average productivity score in terms of journal and book pages (VEW report).

30. Indicate the unit's relative deviation of the average (national) citation score in terms of journal and book pages (VEW report).

31. Indicate the number of fields a unit is active in. The $10 \%$ criterion conceives a unit as active in another field (B) if it publishes the equivalent of at least $10 \%$ of its largest research oulput (in terms of weighted pages) in a field $(A)$ in $B$.

32. Indicate the number of fields a unit is active in. The $25 \%$ criterion conceives a unit as active in another field $(B)$ if it publishes the equivalent of all least $25 \%$ of its largest research output (in terms of weighted pages) in a field (A) in B. 


\subsection{Univariate Results}

Exhibits 5.3. and 7.8. have shown that the instruments are fairly reliable with Cronbach"s alpha's varying between .58 (only one variable was $<.60$ ) and . 88 . Data were collected at the individual level and aggregated to the unit level. To check the reliability of the aggregated scores, the differences between units in the variance of individual scores (Bartlett F-box) were tested. Except for one item (unrelated to overall performance), the test revealed no significant differences between units in the homogeneity of the answers of individual scientists within high and low performing units. The next section discusses the relation between overall performance and the single performance indices. The subsequent sections will discuss the relationship between the predictor variables and overall performance. The relation between the predictor and single criterion variables will be dealt with in discussing multiple regression analysis.

\subsubsection{Relation between Criterion Variables}

Hypotheses were tested by examining the differences between high and low pertormers. Evidently, the validity of our results is dependent of the validity of the output measurement. We added the individual output index (variable 20) as an extra check for the validity of our classification in high and low performers. Consistent with our expectations, the analyses showed that high performers (as abserved by the VEW) have a higher individual output index than low performers: they produce more working papers iduring a period of three years $)(r=.28 ; p=.04)$, and more international journal articles $(r=.31 ; p=.03)$. Their production in terms of articles in Dutch journals, however, appeared to be lower than that of low performers $(t=-.35 ; p=01)$. This surprising finding is consistent with the evaluation of the VEW (1987). The VEW found a remarkable contrast between tatall productivity and weighted productivity (corrected for international contributions). Groups that were found to be very productive when total produclion was considered (exhibit 7.2). turned out to be poor performers when contribution to the international literature (exhibit 7.3) was considered. 
Since the classification into high and low pertormers and the two VEW performance measures partially originate from the same source, it was not surprising to find significant correlations between scientific productivity, and citation impact, on the one hand, and owerall performance on the other hand. The next table shows the statistical relation between overall performance (classification in high and low performers) and the single scientometric indicators. The results suggest convergent validity of the performance measurement. The highest significance levels exist with reglard to the correlation between citation impact (unit's relative deviation of the average cltation score) and scientific productivity (the unit's relative deviation of the average productivity score), and with regard to the correllation of the latter with overall performance (classification into high versus low performers).

Exhibit 7.9. Relationship between scientometric indicators

\section{Pearson correlations (significance)}

\begin{tabular}{|c|c|c|c|c|c|c|c|}
\hline & 1 & & 2 & & 3 & & 4 \\
\hline $\begin{array}{l}\text { 1. Overall Performance } \\
\text { 2. Scientific Productivity } \\
\text { 3. Citation limpact } \\
\text { 4. Individual Performance Index }\end{array}$ & $\begin{array}{l}x \times \\
69 \\
48 \\
60\end{array}$ & $\begin{array}{l}(.01) \\
(.08) \\
(.03)\end{array}$ & $\begin{array}{l}x x \\
85 \\
61\end{array}$ & $\begin{array}{l}(.001) \\
(.03)\end{array}$ & $\begin{array}{l}\times \times \\
51\end{array}$ & $(.07)$ & $x x$ \\
\hline
\end{tabular}

\subsubsection{Relation between Predictor Variables and Overall Performance}

The main uniwariate tests which we used were t-lests and correlation analysis. Since the results of the 1-tests mainly corroborated those of the correlation analysis, only the latter are reported. Exhibit 7.10. shows the correlation between the predictor variables and overall performance. A general point is that the supportive power of the positive but low correlations is a very modest one, sometimes almost negligible. Furthermore, the high number of significant correlations may be influenced by the low number of observations. Consequently. the univariate resulls are presented with caution. Conclusive evidence can only be demonstrated on the basis of the combinalion of univariate and multivariate results as compared to other findings concerning the determinanls of scientific performance in economics. 


\section{Scale}

human resources

unit size

41

.004

FTE unit size

project size

n.s.

35

30

.02

time research

time non-research (education)

33

$-32$

.03

capitall resources

in.s.

research expenditures

n.s.

2. Input mix

age

$-34$

human capilta:

(ii) research experience during study

3.4

(ii) research experience on the job

n.s.

(iii) research experience abroad

n.s.

tenure intensity

$-33$

interdisciplinary mix

n.s.

cash flow mix

$-30$

\section{Scope}

according to the $10 \%$ criterion

49

.04

according to the $25 \%$ criterion

n.s.

4. Atmosphere

innovative climate

71

58

.000

publication climate

n.s.

.71

.000

bureaucratic culture

n.s.

normative culture

6. Control*

motivation

43

33

.003

reward expectation

24

.02

within unit communication

between unit communication

47

.07

international communication:

39

.001

(i) having international communication

$-47$

.006

(ii) stimulating international communication

n.s.

* all management variables (group 5) proved to be insignificant with regard to overall performance 


\subsubsection{Economies of scale}

Human Resources - The Pearson correlations provide strong support for economies of scale with respect to the human resources. In comparison with low performers, more high pertormers bellieve that the human resources of their unit are sufficient to conduct the research effectively. Consistent with this subjective assessment are the following observations: high performing units are farger in terms of full time research equivalents, and in manpower per project. High performers were not larger in terms of absolute number of staff members (unit size - uncorrected for FTE). The members of high performing units spend more time on research, and less time on education.

Capital Resources - The economies of scale hypothesis was not confirmed when capital resources are considered. In contrast to our expectations, no significant relation was found between capital resources or research expenditures and periormance. High performers do not have a larger research budget neither do they spend more money on research. Surprising as this may be, we should remember the facts and figures mentioned in section 5.5. The ratio of capital resources to human resources is .16 in economics, and .82 in medicine. In contrast to medicine, economics is not a capital intensive discipline. While the performance of medical researchers is strongly dependent on hardware and physical capital (e.g. laboratory facilittes), economics is more a 'paper and pencil' discipline. Human capital is the main capitali asset of an economics research unit, while the physical capital assets are a negligible factor. Our findings are consistent with these observations: academic research performance is related to the volume of capital resources in medicine $(r=.37 ; p=.05)$, but not related to the volume of capital resources and research expendilures in economics.

\subsubsection{Input Mix}

Human assets - Regarding the composition of human assets, we have found that the average member of high performing units is younger, but has had more research experience during his masters training. Age was related to learning by doing (on the job research experience), and international research experience, but not to masters degree research experience. On-the-job experience, and international research experience were unrelated to performance. Apparently, productive research is facilitated when the learning process occurs at a younger age. All an older age counterproductive research habils (de Groot, 1984) may already have been established. Of course, allternative interpretation may be plausible too. For example, it might be argued that high performing units are more successiul in getting their research funded. Research which is paid out of the secondary and tertiary flow of money is generally carried out by (non-tenured) junior scientists. Consequently, high performing units have younger 
members on average than low performing units. This interpretation would be consistent with the results. The expectation that high performers have a lower tenure intensity has been confirmed. Age and tenure intensity were, not surprisingly. positivelly correlated $(r=.50$; $p=00)$. No relation appeared to exist between interdisciplinary staffing and research performance.

Capital assets - Regarding, the composition of capital assets, the analyses showed a negative correllation between the contribution of the primary cash flow fdirect governmentall contribution) and research pertormance. The lower the primary cash llow, the higher the contribution of the secondary and tertiary cash flow. Thus, it is suggested that a higher proportion of the research budget of high performers is acquired in a competitive situation, i.e. paid by the national science foundation (secondary cash flow) or contract research customers (tertiary cash flow).

\subsubsection{Economiles of Scope}

th will be recalled that the VEW report contained useful data concerning the mulli-production functions of units in terms of their JEL publications. These data, however, were transformed by a simple decison rule which determined whether a unit publishes in more than one field in a substantial manner. The $25 \%$ criterion regarded a unit to be active in another field (B) when it publishes the equivalent of at least $25 \%$ of its largest research output (in terms of weighted pages) in one field (A) in $B$. The $10 \%$ criterion regarded a unit to be active in $B$ when it publishes the equivalent of at least $10 \%$ of its $A$ output in $B$.

The data suggest that economies of scope were captured by departments of economics, since a certain degree of diversification (according to the $10 \%$ criterion) appeared to be related to their performance. However, scope was unrelated to performance when the $25 \%$ criterion was used. In comparison to the $10 \%$ criterion, the $25 \%$ criterion decreases the variance in the economies of scope variable, because the production of units is less likely to be conceived as foint production in more than one field. This finding suggests that thresholds exist concerning the existence of scope economies. Whether economies of scope are captured by a research unil is dependent upon the definition of scope. Apparently, further research is required to improve the assessment of the economies of scope variable, and to test further its construct validity. 


\subsubsection{Economies of Atmosphere}

Unlike the previous sudy, study II provides unambigous empirical evidence for economies of atmosphere. There was stronger pressure to publish in thigh performing units (publication climate). Furthermore, high performers had a more innovative climate. Finally, it appeared that high pertormers were less process oriented, i.e. they had a less bureaucratic atmosphere than low performers. No indications were found for differences with respect to normative cullure (OCM6). As expected, no relations were found between the VSM dimensions and performance.

\subsubsection{Management}

Contrary to the expectations, research management was not related to performance. All univarlate tests failed to show that relation. Neither the craftsmanship nor the leadership qualities of the supervisor appeared to be correlated with academic research performance. Does this mean that coordination is a negligible factor? Not necessarily, since it appeared that management was strongly related to the correlates of performance. The following independent variables were positively related to the leadership and the craftsmanship of the unit supervisor: thuman resources $\left(r={ }_{*} 32 ; p=.003\right)$, publication climate $(r=.45 ; p=.00)$. innovative climate $(r=.56 ; p=.00)$, bureaucratic culture $(r=-.44 ; p=0)$; reward expectation $(r=.22 ; p=.01)$, within unit communication $(r=.18 ; p=.04)$, and internalional communication $(r=43 ; p=.00)$. An efficiency function may certainly be attributed to the coordination of the unit, but in an indirect way - 1.e. with respect to the boundary conditions for efficient production. This non-directive leadership is consistent with the existence of a non bureaucratic corporate cullure. To paraphrase Adam Smith, the supervision of a department of economics has to operate like an 'invisible hand" rather than as a 'visible hand" in order to be productive.

\subsubsection{Control}

The existence of a strong publication tradition is consistent with the oulcome of the control variables. High performers expected more pecuniary rewards (better career opportumilies) when they perform well in research than in education. The average economist researcher is not driven by altruistic motivation - a finding that should not be surprising. This result is consistent with Graves, Marchand, and Thompson (1982) who found a positive relation between the salaries of full professors in economics and publicalion performance. Whille salaries at lower ranks appear to be inversely related to publication performance, this may still be explained by a utiltarian framework: "(...) young academics pay a premilum to 
associate with productive faculties" (Graves, Marchand, and Thompson, 1982, p. 1137. 1139). This is also consistent with Cargile and Bublitz's (1986) findings in U.S. accounting departments. In comparison with teaching, policy, and service, published research was perceived to have the greatest relatiwe importance as a determining factor of their present place of employment in decisions on promotion. tenure, and salary increases. Though nol expected, this was even true for nondoctoral programs which have an emphasis on teaching rather than on research. Recently, Sauer (1988) estimated the returns of quality in academic research. He found that the incrementall return from a (AER-equivalent) page in a top-ranked economics journal (including the additional effects of being cited) is 0.17 percent of sialary which is $\$ 72.27$ in 1982 dollars for his sample mean (consisting of 140 academic economists who are member of the associate or full professor rank at seven 'top 40 ' departments). His findings clearly indicate that pecuniary returns of research quality in academia are measurably large and provide incentives to produce high-quality research in the economics profession. When comparing economics and medicine, it should be noted that the alternative for the economist (education) is, of course, less financially rewarding than the alternative for the medical specialist (patient care), so that the opportunity costs are considerably higher for the medical researcher than for the economist. With regard to personal control, it appeared that high performers were more motivated toward research than toward education. These findings are consistent with the previous observations concerning the time spent on research (more) and on education (less) of high performers.

\subsubsection{Communication}

High performers appear to have more working communications with their colleagues within the unit. Moreover, they communicated more frequently with peers of other research units in the Netherlands (between unit communication), and abroad (having international communication). Having more international communications in fact, the members of high performing units were less stimulated 10 communicate with international peers /stimulating international communication). They already have more international communicalions. As a result, they do not have to be encouraged.

Interdisciplinary commmumication - Having communications with colleagues of other disciplines was not related to performance. This is consistent with study I. Moreover, it is consistent with the above mentioned result that there is no relation, neither positive nor negative, between the interdisciplinary composition of the staff and overall research performance, Finally, and contrary to what might be expected "interdisciplinarity appears to be unrelated to economies of scope. 
A possible explanation for this zero correlation is that we have stressed international publication productivity in our performance measurement. It is unlikely that interdisciplinary research is productive in this narrow sense, because the review board of thigh standing journals is often monodisciplinary. Interdisciplinary joumals such as the Journal of Law and Economics, and the Joumal of Economic. Behavior and Organization belong to the minority of A-joumals in the field of Economics. Since the exilsting review procedures may be a constraint on interdisciplinary research productivity. further research is needed to investigate the complex relationship between interdisciplinarity and research performance:

\subsubsection{Summary of Univariate Results}

1. In brief, the analyses support the economies of scale hypothesis, especially regarding the volume of human resources (FTE unit size, project size). The volume of capilal resources and research expenditures are unrelated to economics research performance.

2. The input mix matters, since high performers are younger and have a lower tenure intensity. In terms of research experience, however, they have a larger human capital, because high performers have had more research experience during their master degree study.

Regarding the cash flow mix, a higher proportion of the research budget of high performers is acquired in a competitive siluation, i.e. paid by the national science foundation (secondary casth flow) or contract research customers (terllary cash flow).

3. Whether empirical support is found for economies of atmosphere proves to be rather dependent on the definition of scope. Application of the $10 \%$ critlerion showed that high performers are more diversified in their research production than low performers. However, the $25 \%$ criterion failed to show the relationship.

4. Confirmation was also found for the economies of atmosphere hypothesis. As we expected, high performers have a non-bureaucratic (result oriented) corporate culture. Moreover, they have a more innovative climate, and a climate emphasizing publication. Due to inappropriate measurement, no relationships could be demonstrated between work-related atmosphere and performance.

5. In contrast with our expectations, research management (variable 7.8 ) was unrelated to research performance. Since craftsmanship and leadership appear to be strongly related to the correlates of performance (human resources, motivation, climate), an indirect rather than a direct relationship between the coordination and the performance exists in economics research units. This would be consistent with the view of universities as "organized anarchies' (Cohen and March, 1974; Weick, 1984).

6. Control variables matter in research, since high performers are more motivated towards research than towards education. Incentives were important too, since high performers expect better career opportunities when they perform well in research rather than in education. 
7. Positive confirmation has been found for the hypotheses concerning between-unit, international, and within unit communication (in that very order). Scientific communication is indeed the "central nervous system" of the academic system - both in medicine and economics. No support was found for the interdisciplinarity hypothesis.

8. The classification of research units in high and low performers has been validated, since, on average, high performers have a higher individual performance index. In addition, high performers deviate positively from the average productivity score, and from the average cilation score.

The previous analyses showed that high performers spend more time on research than low performers. The differences with regard to time concerning variables such as international communication and publication climate may be the effect of the amount of time devoted to research. An examination of the relative impact of other inputs on the production of scientific publications, would require the time spent on research to be held constant. However, the product moment correlational analyses were not repeated partializing for time spent on research, because the low number of observations $(\mathrm{N}=16)$ increases chance capitalization in partial correlation results.

\subsection{Multivariate Results}

Study II has both combined dichotomous (high versus low performance), and single criterion measures like number of publications and citations. The Fisher linear discriminant analysis is analogous to a multiple regression analysis in which the criterion variable, $Y$, assumes only two values, each indicating membership in one or other of two groups. In other words, discriminant analysis is an appropriate statistical method when the criterion variable is dichotomous. In study 11 , performance, however, is also indicated by non-dicholomous variables, i.e. Individual performance index (questionnaire), scientific productivity (VEW report), and citation impact (VEW repori). Since these three criterion variables are non. dichotomous measures, i.e. they can have values ranging from $0-n$, it is meaningfull to apply multiple regression analysis in addition to the discriminant analysis.

Because the number of variables included in the multivariate analyses is quite high relative to the sample size, the results of our analyses will be tentative. Consequently, the discriminant and regression analyses were not used to discover the best predictive equation but rather to control crudely for the interaction between the predictor variables when trying to establish differences between high and low performers. Chance capitalization is minimized by running the analyses on the univariately significant predictor variables. The results of the 
discriminant analysis are presented in the next section. Subsequently, we will discuss the results of the muttiple regression analysis.

\subsubsection{Discriminant analysis}

To explain more efficiently the difference befween high and low performers, discriminam analysis was conducted with the univariately significant variables. Since the interest here is in the impact of scale, scope, and atmosphere on performance, we will first (i) analyze the data regarding the input variables (scale and input mix), then (ii) the data regarding scalie, scope, and atmosphere, and finally, (iii) the data will be analyzed regarding all variables that have been selected in the discriminant function (including management, control, and communication). The total number of cases in the sample is 16 . All variables in the discriminant aquations are presented in the order of stepwise selection.

\section{$Z_{1}$ (Scale and Input Mix)}

First, a stepwise, standardized discriminant analysis on all univariatelly significant scale and input mix variables has been performed. The following discriminant function resulted for ail 16 cases in our sample $\left(R=.81 ; R^{2}=.66 ; X^{2}=11.1 ;\right.$ d.t. $=3 ; p$ (function $\left.)=.01\right)$ :

$Z_{1}=1.51 \mathrm{HMCP}-1.71 \mathrm{AGE}+.57 \mathrm{FTE}_{\mathrm{r}}$

Where HMCP = human capital (reserarch experience during study)

$A G E=$ age

FTE $=$ FTE unit size

correctly classified $94 \%$

Mean discriminant score high performers: 1.10

Mean discriminant score low performers: 1.46

\section{$Z_{2-3}$ (Scale, Input Mix, Scope, and Atmosphere)}

For the scale, input mix, scope, and atmosphere variables together, two standardized discriminant functions were satisfactory. Evaluation criteria for these functions have already been discussed in the previous chapter. A function, $Z_{i}$, is regarded as optimal when (i) the probability of misclassification is minimized, (ii) the function has a larger discriminatory power $\left(\mathrm{R}^{2}\right)$. (iii) $\mathrm{p}$ (function) has a higher significance, and (iv) the sample contains more cases. In practice, human judgement is required to select a function because there are tradeofts 
between these criteria. One of the functions, $Z_{2}\left(R=.65 ; R^{2}=.42 ; x^{2}=6.49 ; d f=2 ; p\right.$ (function) $=.04)$, included the following variables for 16 cases:

$\mathrm{Z}_{2}=.93 \mathrm{FTE}-.59 \mathrm{OCM1}$

where FTE $=$ FTE unit size

OCM1 = bureaucratic culture

correctly classified $=81 \%$

mean high performers $=.68$

meian low performers $=-.84$

This function, however, is outperformed by $Z_{3}$ which combines a higher significant function with more accuracy in classification for 15 cases $\left(R=.74 ; R^{2}=.55 ; \quad X 2 m 7.81 ; d . f .=2 ; p\right.$ (function) $=.02$ )

$Z_{3}=.77 \mathrm{HMCP}+.99 \mathrm{SCPE}$

Where HMCP = human capital (research experience during study)

SCPE $=$ SCOPE $(10 \%)$

correctly classified: $87 \%$

inean high performers: .93

mean low performers: -1.08

\section{$Z_{4-6}$ (all predictor variables)}

When we take into account all univariately significant variables, the following 10 varlables entered the discriminant function in the order of stepwise selection: FTE unit size, human capiltall (research experience during study), age, scope $(10 \%)$, between unit communication, bureaucratic culture, reward expectation, motivation, human resources, and international communication (having). The function was highly significant $\left(\mathbb{R}=.99 ; R^{2}=.98 ; X^{2}=43.09\right.$; $d . f .=8 ; p$ (function) $=.000 ;$ correct classification $=93 \%$ ). The disadvantagle of this function is the large number of variables included in the function. Since this study is interested in an efficient prediction of performance, the above mentioned list of variables was conceived as a useful starting poinı for Irying oul a number of allernative combinations of variables. 
Again more than one satisfactory function has been found. In one of the functions, $Z_{4}$. which applied to 15 cases in our sample, scope entered as the first variable in the function. $Z_{4}(\mathrm{~A}=$ $.82 ; A^{2}=67 ; X^{2}=10.54 ; d . f,=3 ; p$ (function) $=.01$ ) is a linear combination of the following variables:

$Z_{4}=1.05$ SCPE -.52 OCM $1+.80 \mathrm{INTC}$

where $\mathrm{SCPE}=$ scope $(10 \%)$

OCM1 = bureaucratic culture

INTC = international commurication

correct classification $=87 \%$

mean high performers $=.1 .21$

mean low pertormers $=-1.42$

Another function, $Z_{5}\left(R=.88 ; R^{2}=.77 ; X^{2}=13.86 ;\right.$ d.f. $=3 ; p$ (function) $\left.=.003\right)$, combines classificatory success with a higher level of significance for 15 cases:

$Z_{5}=1.05$ SCPE -.69 OCM $1+.97$ BTWUC

whare SCPE $=$ scope

OCM1 = bureaucratic culture

BTWUC = between unit communication

correct classification $=87 \%$

mean high performers $=1.55$

mean low performers $=-1.81$

For reasons that will subsequently be explained, the next funclion, $Z_{6}\left(\mathrm{~A}=.90 ; \mathrm{A}^{2}=.81 ; X^{2}=\right.$ 15.09 ; (function) .0045). may be conceived as the optimal discriminant function emerging for 15 cases in the sample.

$Z_{6}=.52 \mathrm{FTE}+.93 \mathrm{SCPE}-.75$ OCM1 +.76 BTWUC,

where FTE = FTE unit size

SCPE $=$ SCOpe $(10 \%)$

OCM1 = bureaucratic culture

BTWUC $=$ between unit communication 
correct classification $=93 \%$

mean thigh performers $=1.77$

mean low performers $=-2.07$

Comparison of the classificatory success of $Z_{6} \quad(93 \%)$ with $Z_{1}(94 \%)$ shows that adding scope and aumosphere (and other variables) to scalle does not significantly improve the results of the discriminant analysis. However, adding these variables does improve the signifficance of the

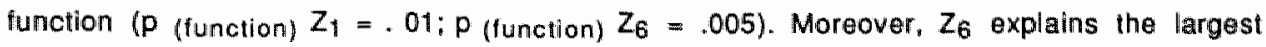
percentage of variance in the criterion variable $\left(R^{2}=81\right) . Z_{6}$ is an efficient equation since it classities units on the basis of 4 variables with the same degree of accuracy as the equation with 10 variables $(93 \%)$.

Exhibil 7.11. gives a graphical presentation of the $93 \%$ match between predicted (correctly classified) and observed performance in the sample of 15 cases in $Z_{6}$. The match is $7 / 8(88 \%)$ for low performers and $7 / 7(100 \%)$ for high periormers.

Exhibit 7.11. Match between predicted and observed performance

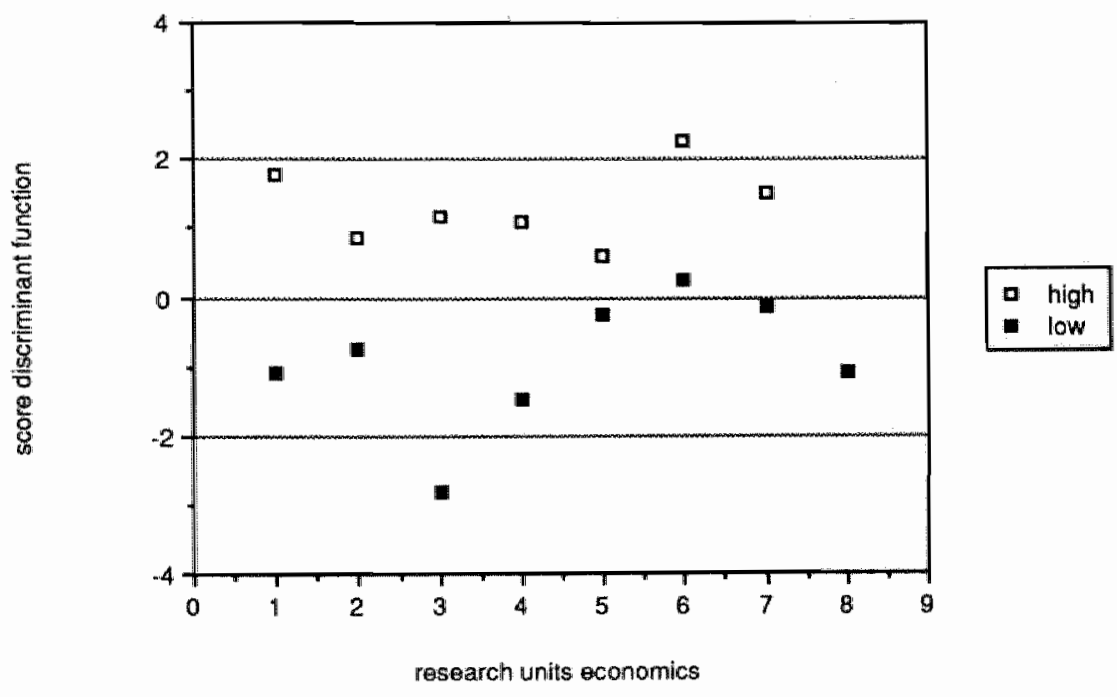


Exhibit 7.12. presents the predictor variables which have entered the above mentioned discriminant turictions:

Exhibit 7.12. Standardized Canonical Discriminant Coefficient Variables

\begin{tabular}{|c|c|c|}
\hline variables & times entered & sign \\
\hline \multicolumn{3}{|l|}{ scalle } \\
\hline $\begin{array}{l}\text { FTE unit sizea } \\
\text { Input } \mathrm{mix}\end{array}$ & $3^{* *}$ & + \\
\hline age & 1 & - \\
\hline $\begin{array}{l}\text { human capilal } \\
\text { scope }\end{array}$ & $2 *$ & + \\
\hline $\begin{array}{l}\text { according to the } 10 \% \text { criterion } \\
\text { atmosphere }\end{array}$ & $4 \cdots$ & 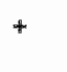 \\
\hline $\begin{array}{l}\text { bureaucratic culture } \\
\text { communication }\end{array}$ & 4 & - \\
\hline between unit communication & 2 & + \\
\hline international communication & 1 & + \\
\hline
\end{tabular}

"Imdication of Wilks' Lambda minimization; " note that the variables mentioned in this table have not had an equal number of opportunities to enter a discriminant function.

In general, the results confirm the correlational findings. Moreover, they explained a very high percentage of the variance in the dichotomous criterion variable. The results demonstrate the importance of economies of scale, scope, and atmosphere in departments of economics and business administration. In addition, communication with other units, in the Netherlands and abroad, appears to be very significant to research perlormance in economics.

\subsubsection{Multiple Regression Analysis}

Multiple regression analysis is not a substitute for discriminant analysis, since each of the single criterion variables represent imperfect measures of research performance. While the criterion variable in the discriminant analyses is based on the combination of indicators (high versus low performance), multiple regression analysis has been performed on single performance indicators. These single crilterion measures, however, are all correlated with the combined performance measure (exhibit 7,9 ). 
The basis for the multiple regression analysis was the selection of the predictor variables which were univariately related to the continuous criterion measures. Exhibit 7.13 presents the results of Pearson correlation analysies. Mention is made only of variables which are correlated with one or more of the performance indices.

Exhibit 7.13. Correlation between predictors and single performance indices

Pearson correlations (significance)

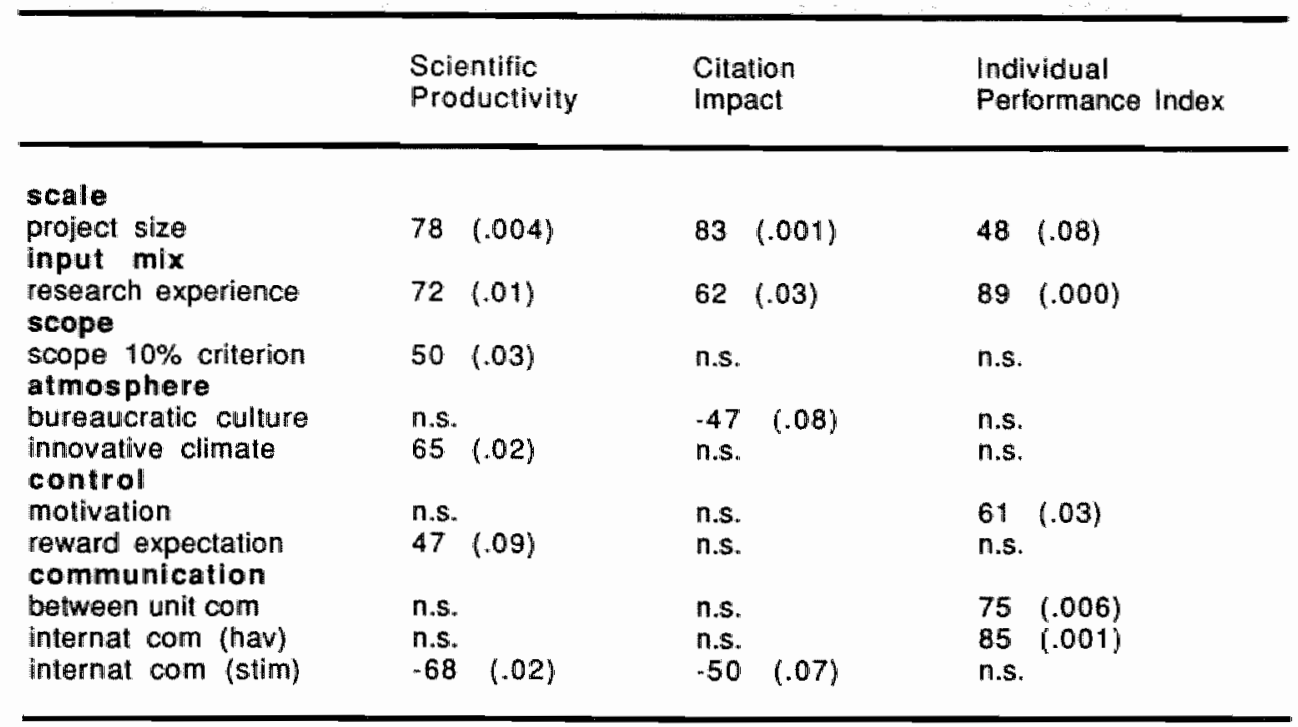

In contrast to the preceding analyses concerning the composite performance measure, the results mentioned above concern single performance measures. These univariate results prove to be fairly consistent with the provious analyses. Parlicularly, when scientific productivity is considered, it is shown that advantages are taken of scalle, scope, and atmosphere. This is not very surprising since analysis of criterion variables has shown that scientific productivity correlates with overall performance at a higher significance level in comparison with the other indices. Citation impact is particularly related to scale, input mix, and atmosphere; Individuall performance to scale, input mix, and control. 
Communication is related to all performance indices. The analyses show that units producing more publications and receiving more citalions are less stimulated to communicate with colleagues abroad (stim). When their individual performance index is considered, it appears that they do not need to be stimulated, because they aiready have more intemational communications than low performers (hav).

For each single criterion, a stepwise muttiple regression analysis was performed including the univariately significant predictor variables mentioned above. As will be shown in the next table, a significant function emerged for each criterion. 
Scientific

Productivily
Citation

Impact
Individual

Pertormance

Index

\begin{tabular}{|c|c|c|c|c|c|c|}
\hline & B & $F$ & B & $F$ & $B$ & $F$ \\
\hline \multicolumn{7}{|l|}{ scale } \\
\hline $\begin{array}{l}\text { proiect size } \\
\text { input mix }\end{array}$ & 70 & $8.8^{* *}$ & 82 & $19^{* *}$ & .008 & .001 \\
\hline $\begin{array}{l}\text { research experience } \\
\text { scope }\end{array}$ & 41 & 2.27 & 17 & .52 & 46 & $4.6^{*}$ \\
\hline \multirow{2}{*}{$\begin{array}{l}\text { scope } 10 \% \text { criterion } \\
\text { atimosphere } \\
\text { bureaucratic culture } \\
\text { innovative climate } \\
\text { control }\end{array}$} & 30 & 1.48 & $@$ & @ & $@$ & @ \\
\hline & $\varliminf_{13}$ & $\begin{array}{l}@ \\
.24\end{array}$ & $\begin{array}{l}-18 \\
@\end{array}$ & .94 & $@$ & $@$ \\
\hline \multirow{3}{*}{$\begin{array}{l}\text { motivation } \\
\text { reward expectation } \\
\text { communication } \\
\text { between unit com }\end{array}$} & $@$ & $@$ & $@$ & $@$ & 9 & 2.1 \\
\hline & 14 & .28 & @ & $@$ & @ & $@$ \\
\hline & $@$ & $@$ & $@$ & $@$ & 12 & 17 \\
\hline Internat com $b$ & $@$ & (a) & $@$ & $@$ & 52 & $5.9^{*}$ \\
\hline internat $\operatorname{com}^{\mathrm{C}}$ & -39 & 1.9 & -11 & .21 & $@$ & @ \\
\hline \multirow{3}{*}{$\begin{array}{l}\text { Multiple } R \\
R^{2} \\
\text { Adjusted } R^{2}\end{array}$} & \multicolumn{2}{|l|}{70} & \multicolumn{2}{|l|}{82} & \multicolumn{2}{|l|}{92} \\
\hline & \multicolumn{2}{|l|}{49} & \multicolumn{2}{|l|}{68} & \multirow{2}{*}{\multicolumn{2}{|c|}{$\begin{array}{l}85 \\
82\end{array}$}} \\
\hline & \multicolumn{2}{|l|}{43} & \multicolumn{2}{|l|}{64} & & \\
\hline \multirow{3}{*}{$\begin{array}{l}\text { d.f. (regression) } \\
\text { overall } F \\
\text { p (function) }\end{array}$} & \multirow{2}{*}{\multicolumn{2}{|c|}{$\begin{array}{l}1 \\
8.8\end{array}$}} & \multirow{2}{*}{\multicolumn{2}{|c|}{$\begin{array}{c}1 \\
19.31\end{array}$}} & \multirow{2}{*}{\multicolumn{2}{|c|}{24.30}} \\
\hline & & & & & & \\
\hline & \multicolumn{2}{|l|}{.02} & \multicolumn{2}{|l|}{.002} & \multicolumn{2}{|l|}{.0004} \\
\hline
\end{tabular}

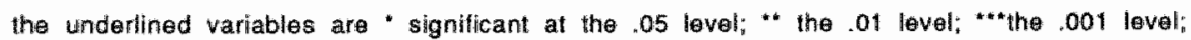

a during study; b having / $c$ stimulating intermational communications 
Most of all, the results show that the contribution of economies of scale in explaining scientific performance is larger than those of economies of scope and atmosphere.

The regression equation consists of project size $(F=8,8 ; p=.02$ with regard to scientific productivity; $F=19 ; p=002$ wrt citation impact) for two of the performance indicators. The regression equalion for individual performance index consists of two variables, i.e. research experience $(F=4.6 ; p=.06)$, and international communication (hav) $(F=5.9 ; p=.04)$.

In order to examine the partial contribution of the variables which were not included in the regression equations, a second stepwise regression analysis was performed. All but the multivariately significant variables mentioned above were included in the second analysis. Again a significant function emerged for each of the single criteria. The regression equation for two of the criteria consists of research experience (wrt scientific productivity multiple $R=68 ; R^{2}=47$; adjusted $R^{2}=41 ;$ d.t (function) $=1$; overall $F=8 ; p=.02$; wrt citation impact multiple $R=67 ; R^{2}=45$; adjusted $R^{2}=29 ; d . f=1$; overall $F=5.17 ; p$ (function) $=.05$ ). The regression equation for individual performance index consists of international communication (multiple $R=67 ; R^{2}=45$; adjusted $R^{2}=39 ; d . f=1$; overall $F=7.46 ; p$ (function) $=.02$ ). Again economies of scope and atmosphere did not show up.

\subsubsection{Summary of the Multivariate Results}

Because of the high number of (univariately significant) variables relative to the sample size, discriminant and regression analysis were mainly used as crude control for the interaction effects of the predictor variables. Consequently "the multivariate results should be presented with a degree of reservation. Tentative as they are, however, they confirm the univariate findings, and explain a high percentage of the variance in the overall performance and the single criterion measures. In particular, they support the hypotheses regarding economies of scale, scope, and atmosphere in scientific organizations. Concerning their differential impact. the results show that scale and input mix variables feature prominenily.

1. Regarding scale, it was found that high performing units are larger in terms of full time research equivalents. Repeatedly, FTE unit size entered a significant discriminant function as the first variable, thus minimizing Wilks' lambda. Project size seems to be important too. Multiple regression analyses showed that it is significantly related to the single performance measures.

2. Regarding input mix, it was found that members of the high performing units, younger as they are, have had more research experience (acquired during their masters degree training). 
Moreover, research experience proves to be multivariately related to individual performances index, citation impact, and scientific productivity.

3. Regarding scope, it was found that high performers have a higher diversification in their production (in terms of publication in JEL fields according to the $10 \%$ criterion). Scope entered significant discriminant functions, but was not included with a significant coefficient in a regression equation.

4. Regarding, atmosphere it was found that the variable "bureaucratic culture' is inversely related to performance. Repeatedly, bureaucratic culture entered the significant discriminant function - including the optimal function. However, atmosphere was not included in the regression equations with a significant coefficient. Apparently, further research is needed to test the robustness of economies of atmosphere.

5. The univariate results are not multivariately confirmed where the control variables are concerned. Regression analyses failed to show a contribution of reward expectation and motivation to the explanation of variance in the single performance measures.

6. Regarding communication, it was found that between unit communication and international communication repeatedly entered significant discriminant functions. Unlike medicine, communication with domestic research units is somewhat more important for economics than international communication, since the $\mathrm{R}^{2}$ increases when international communication is substituted by between unit communication. Regression analyses have confirmed the importance of between unit communication. With regard to international communication, it was shown that low performers (in terms of publications and citation) are more encouraged to have international communications, while high performers (in terms of the individual performance index) simply have thase contacts. As the saying goes: good wine needs no bushl

\subsection{International Comparison}

A large number of publications on the performance of economics departments have recently appeared since 1980 (cl. Dawis and Papanek, 1984). The literature on the determinants of academic research quality, however, is very scarce. Two large scale surveys have been conducted recently. The first study was been conducled in 240 U.S. departments of economics. In addition to publication counlings (in the lop twenty-four joumals, 1974-1978), Graves, Marchand and Thompson (1982) surveyed economics departments regarding teaching load, teaching and research assistance, secretarial resources, and student/faculty ratio"s. As a consequence, insights can be obtained, not only on absolute departmental quality, but also on quality relative to constraints on publishing and incentives to publish. The authors believe that, while ability no doubt varies greatly among departments, costs and returns on publications relative to other academic pursuits are also likely to vary. 
The second study was conducted in 40 U.K. departments of economics. Johnes (1988) has ranked British universittes according to research performance indicators based upon publications in a selection of American Economic Review-equivalent economics journals. Johnes not only found considerable variation in productiwity between departments in different universittes, but also that considerable varialion exists in the resources avallable to researchers at these institutions.

The independent variables in the study of Graves, Marchand and Thompson were (i) average salary, (ii) average teaching load in hours per week, (iii) secretary-to-faculty ratios. (iv) student-10-faculty ratios, (iv) support services (phone, photocopy, etc.), and (v) teaching and research assistance. Their expectation had been that high teaching loads and student-staff ratios inhibit publication output, and that the other variables facilitate research productivity.

Johnes expected that performance is constrained by the following two inpull variables: the number of university staff aged over 55 years per thousand staff. Younger staff tend to have stronger incentives to publish in order to obtain tenure, to pass the efficiency bar and to gain promotion. The second constraint is the student/staff ratio, since teaching and administrative duties all tend to rise with the student-staff ralio. Furthermore, he conjectured that economies and diseconomies of scale might exist within economics departments - as in any other unit of production. The total number of university staff members and the total number of (non PhD) members, although, they are younger graduate students, were regarded as economies of scale variables. The extensiveness of research facilities (as indicated by the stock of library book) is expected positively to influence research productivity. Interestingly, it was also hypothesized that "privalisation" (indiced by the number of university staff per thousand who are financed by external sources) facilitates research outpul, since contract research may stimulate productivity. Furthermore, he expected that a department in which a large proportion of staff has achieved professional status to publish more than an otherwise similar department elsewhere. Finally, since research students often relieve staff of some of their teaching duties, the ratio of full-time doctoral research students to staff (ix) was expected to facillitate research output.

\subsubsection{Differences in Research Design}

Before comparing the findings of Graves, Marchand and Thompson, those of Johnes, and the findings of the Netherlands investigation, some attention should be paid to the differences between the various research designs. First of all, differemces exist concerning output measurement and level of analysis. The first two studies have ranked departments on the basis of publications, while the present study has classified research units working within the same 
field. Furthermore, US, U.K, and Dutch departments differ in the degree to which they include business administration. US departments do not include business administration units, UK departments vary, and Dutch departments always include business adminstration units. The unit has been chosen as the appropriate level of analysis, since units within departments may vary considerably in their publication behavior and research performance. Furthermore, we have used more than one indicator of research effectiveness. The following indicators were used: publication countings, citation countings, and peer reviews. The convergence of these imperfect indicators has been used as a selection rule in the partitioning of our sample. Another difference concerns the research model. Johnes (1988) and Graves, Marchand and Thompson (1982) adopted a typical input-output model, whereas our model has investigated not only scale and input mix varilables, but also throughputs. Differences also exist in the measurement of inputs. While Johnes, and Graves, Marchand, and Thompson have employed the institutional method, we have used the questionnaire method. Obviously, cognitive distortions and memory effects are more probable in the questioninaire method. On the other hand, the items in a questionnaire are often more specific will regard to the salient research question. Finally, our investigation is a small scale study - including fewer observations than the earlier studies. This shortcoming, however, makes a comparison with Johnes, and Graves, Marchand, and Thompson's findings increasingly valuable, since consistency of the findings can be regarded as an indication of the convergent validity of the study presented here.

\subsubsection{Results}

Exhibit 7.15. summarizes the results of Graves, Marchand and Thompson (Study A), Johnes (Study B), and the present study (study C) regarding the main scale and input mix variables. Although the three studies have used different measures of inpuls and outputs, the results are highly consistent. 
Correlation with research performance

Input variables

Study A Study B Study C

USA UK Netherlands

1. Scale

(FTE) unit size

time spent on education (teaching load)

teaching/research assistance

secretary/faculty ratio

stock of library books

support services

$\begin{array}{lll}+ & + & + \\ + & \div & - \\ + & @ & @ \\ + & @ & @ \\ + & + & @\end{array}$

2. Input $M i x$

human assets:

student/staif ratio

Ph.D. student/staff ratio

number of (non PhD)graduates

average age staff

research experience (during study)

capitall assells:

average salaries protessors

average salaries assistant profesisors

external finaneing (privatisation)

$\begin{array}{lll}@ & + & @ \\ @ & + & @ \\ @ & + & 0 \\ + & @ & + \\ + & @ & @ \\ & + & +\end{array}$

Kay: relationship with performance $(+)$ positive $(0)$ zero $(-)$ negative (@) not investigated.

The international comparison learns that the univariate and multivariate findings regarding to the input variables in the present study are fairly valid. At an international level, evidence has been demonstrated regarding:

Economies of scale - (i) High performers in economics operate on a larger scale than low performers. Studies A-B show that they are larger in terms of their absolute unit size, whereas the present study $C$ shows that they are larger in terms of full time equivalents. (FTEs) for research. Besides, they have more research facilities - indicated by a higher degree of secretarial, teaching, research, and library support. The comparison suggests that high performers have reached their optimal size of plant. In general, the larger the department (unit) the more productive is the average member of that department (unit), up to a certain lovel (56 staff in study B). (ii) A high teaching load as well as an unfavorable studenustaff ralio are serious constraints of scientific productivity.

Inpult Mix - (i) On average, members of high performing units are younger. This is not inconsistent with greater research experience (during the masters degree study). 
Furthermore it is consistent with the higher Ph.D. student/staff ratio, and the larger number of graduates in successful departments. Presumably, age in itself is not the explanation for high performance, but the combination of age, research experience (acquired at a relatively young age), research motivation (indicated by being a Ph.D. student in a field where the job market is favorable), and research incentives (younger staff members have more incentives to publish in order to gain promotion and to obtain a tenure position). (ii) Regarding the mix of capital assets, high performers seem to be more successful in the acquisition of external (secondary and tertiary) cash llows. The larger degree of external financing (which is often caused by senior researchers with a good reputation) is consistent with the younger average age of members of high performing units, since funded research often enables the employment of additional young, non-tenured researchers.

\subsubsection{Interilm Conclusions}

Comparison of the present findings with thase of study $A$ and $B$ is constrained by the differences in research design. A comparison, however, remains very valuable, since consistency of the present (explorative) findings with those of Graves, Marchand and Thompson, and those of Johnes can be regarded as a indication of convergent validity. Comparing the findings shows consistency of findings concerning economies of scale and input mix variables. Since the comparison groups consist of US and UK departments of economics, it may be argued that business administration thas been excluded from the comparison. However, Cargilie and Bublitz. (1986) have conducted a study on factors contributing to published research by accounting faculties. The response to a questionnaire mailed to a sample of 840 U.S. accounting faculty members (208 usable responses) showed the importance of five facilitators: reduced teaching load, access to the computer, research abilities of fellow faculty members, high quality graduate students, and reduced number of committee assignmenis. Especlally expanding the time fior conducting research projects appears to be an important facilitator, as evidenced by the high ramkings attached to reduced teaching loads and reduced committe assignments. Thus, 11 may be concluded that scale economies are no less important in at least one branch of business administration as compared to economics. 


\section{10. Concluding Remarks and Discussion}

Assuming that the same sell of incentives and consitraints influence research productivity as in medicine, this chapter has made an attempt to explain why performance records differ among departments of economics. A large-scale evaluation of the performance of university economics in the Netherlands has been used for the classification of units in high and low performers. After formulating additional hypotheses, univariate and multivariate statistics were used to explore the research questions regarding compettive advantages in the scientific enterprise. The results suggest that economies of scale, economies of scope, and economiles of atmosphere are captured in research units. However, when the relative contributions of these economies are inspected, the economies of scale variable and the input mix variable feature prominently. In contrast to the (organizational theory) literature, which suggests that atmosphere is a dominant characteristic of excellent organizations, the economies captured by atmosphere here prove to be rather marginal in comparison with scale economies. It may be speculated that low performers in economics operate at a suboptimal scale, i.e. they have not yet reached their minimal optimal scaile of unil. The compelitive advantage of the high performers is that they have already reached the minimum optimal scale of unit, that is the minimum unit for project) size at which the economies of scale are fully realized by the research unit. Apparently, when the minimum optimal scale of unit is similar to all participants within a scientific discipline, operating on a suboptimal scale is a competitive disadvantage which is only partially compensaled by ecomomies of atmosphere. Although the scale of a research unit is the most important predictor, scale is obviously not a sufficient condition for high performance. The discriminant analyses thave shown that it is rather the combination of scale and other predictor variables such as atmosphere, scope or communication which produced the most efficient prediction. The existence of more than one combination of predicted high performance seems to suggest that there is no one best way for quality control in university research. The next chapter of this book will discuss the consistency between the findings of study I and II. Furthermore, some implications for research policy will be discussed. 


\section{8}

\section{Quality Control in Science 1}

\subsection{Introduction}

Medicine and economics are different disciplines. Since they deal with different subject matters, they differ in their technology and organizational structure as well (Whitley, 1984). In addition, they operate on different scale. Medicine is more capital and labor intensive, and resembles 'big science' more than economics. The previous chapters have reported results concerning determinants of scientific productivity in these disciplines. The present chapter summarizes the main results, and focuses on their consistency. When consistency between the findings of study I and II can be observed, despite the considerable distance between the disciplines, this supports the external validity or generalizability of the findings to other beta and gamma disciplines. As a result, the findings give suggestions for quality control in at least some of the beta (medicine) and gamma (economics) sciences. Exhibit 8.1. summarizes the main similarities and differences in the observed predictor-criterion relations.

\footnotetext{
1 For their stimulating comments on the methodological limits and policy implications of the studies presented in this book. we owe thaniks to $C$. van Dorp. Science Policy unit of the Netherlands Ministry of Education and Science, Zoetermeer, and A. van Heeringen, Advisory Council for Science Policy (RAWB) in the Netherlands, The Hague.
} 


$$
\text { Medicine (I) Economics (II }
$$

\begin{tabular}{|c|c|c|c|c|}
\hline Univariate / Multivariate Test & $u$ & $M$ & $\mathbb{U}$ & M \\
\hline \multicolumn{5}{|l|}{$8 c$ alle } \\
\hline human resources (c) & + & + & + & + \\
\hline unit size (c) & 0 & 0 & 0 & 0 \\
\hline FTE (unit) size & $@$ & @ & + & * \\
\hline project size (ic) & 0 & 0 & + & 0 \\
\hline time research (c) & + & + & + & 0 \\
\hline time non research (c) & - & - & - & 0 \\
\hline capital resourcas (ic) & + & 0 & 0 & 0 \\
\hline research expenditures & @ & (c) & 0 & 0 \\
\hline
\end{tabular}

\section{Input mix}

age (ic)

human capilal (ic)

interdiscipl composition (c)

tenure intensity

cash flow mix (privatisation)

$\begin{array}{ll}0 & 0 \\ 0 & 0 \\ 0 & 0 \\ @ & @ \\ 0 & @\end{array}$

$\begin{array}{ll}- & - \\ + & * \\ + & 0 \\ + & +\end{array}$

\section{scope}

scope ( $25 \%$ criterion)

scope ( $10 \%$ criterion)

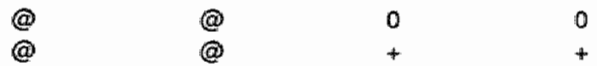

\begin{tabular}{|c|c|c|c|c|}
\hline atimosphere & & & & \\
\hline Innovative climate $(\mathrm{c})$ & + & 0 & + & 0 \\
\hline publication climate (c) & + & 0 & + & + \\
\hline work-related culture (c) & 0 & 0 & 0 & 0 \\
\hline bureaucratic culture & $@$ & $@$ &. & . \\
\hline normative culture & $@$ & 9 & 0 & 0 \\
\hline management & & & & \\
\hline craftumanship (ic) & + & * & 0 & 0 \\
\hline lodershlo (c) & 0 & 0 & 0 & 0 \\
\hline oontrol & & & & \\
\hline molivation (lo) & 0 & 0 & + & 0 \\
\hline reward oxpectattion $(\mathrm{c})$ & $\cdot$ & - & + & * \\
\hline communlcallon & & & & \\
\hline within unit comm (c) & + & 0 & + & 0 \\
\hline botwoen unil comm (c) & + & 0 & + & + \\
\hline International comm (c) & + & + & * & + \\
\hline interdiscipl comm (c) & 0 & 0 & 0 & 0 \\
\hline
\end{tabular}


Key - (c) indicates consistency of results in study $\mathrm{I}$ and study $\mathrm{II}_{;}$(ic) inconsistency in findings: univariate results indicate that predictor-criterion relationships are $(+)$ positive, $(0)$ zero or $(-)$ negative; multivariate results indicate that the variable has entered a significant discriminant or regression function: (@) indicates that the predictor variable has exclusively boen measured in study 11. Multivariate results refer to discriminant rather than to multiple regression analysis (which was anly performed in one of the disciplines).

How can we operationalize the concept of consistency? Two criteria have been used. Consislency in a strong sense is said to exist when all tests demonstrate similar findings in two studies, i.e. a positive, a negative or a zero predictor-criterion relation. This is the case, for instance, for the scale of human resources and for work-related culture. Consistency in a weaker sense is said to exist when the univariate tests show similar results in both studies, such as for publication climate and within-unit communication. The latter operationalization has been chosen because the multivariate results are rather tentative, especially in study II. Consequently, more emphasis is given to the consistency of univariate results. The added condition, however, is that the univariate results should not contradict the multivariate results, i.e. they should not have a reversed sign. When, for example, the univariate results of the studies are positive, and the multivariate results of one of the studias is negative (due to interaction effects), the results would be interpreted as inconsistent.

Assuming this operational definition of consistency, it appears that 13 predictor variables have a consistent influence, while 8 do not. Given the considerable distance between the disciplines, this finding may be interpreted as an indication of external validity. Studies on scientific productivity which were conducted in a large variety of disciplines in the U.S. and Europe confirm the generalizability of most of the predictor variables (Pelz and Andrews, 1966: Andrews, 1979). The next sections discuss three possibilities: (i) consistent predictor-criterion relations, (ii) consistent zero predictor-criterion relations, and (iii) inconsistent predictor-criterion relations.

\subsection{Consistent Predictor-Criterion Relations}

The variables that surwived the univariate and multivariate tests in both disciplines are: human resources $(t)$, and international communication $(t)$. Consistent univariately significant variables are: time research $(+)$, time non-research $(-)$, innovalive climate $(+)$, publication climate $(+)$, within-unit communication $(+)$, and between-unit communication $(+)$. Therefore economies of scale, atmosphere, and communication are the most robust variables in the present research model. 


\subsubsection{Economies of Scale}

human resources - In contrast with high performers low performers in medicine and economics regard their human resources available to conducit research as insufficient. The difference in manpower levels between the disciplines - more than 4,000 medical scientists and less than 1,000 economists working in universities (CBS, 1988) - suggest that the minimum optimum scale of anit will be lower in economics than in medicine. it has been suggested that a critical mass of 4.10 staff members is required to capture economies of scalle in economics at the research group task level (VEW, 1986, Hare and Wyatt, 1988). Johnes (1988:175), however, has pointed out that there is evidence here of a significant non linearity - least at the departmental level. "In general, the larger the department the more productive the average member of that department is, up to 56 staff. Departments with more than 56 staff members are above the optimal size". Although the optimal number of full time equivalents may differ from discipline to discipline - and within the disciplines probably also from fleld to field, having critical mass seems to be a necessary condition for scientific productivity.

time allocation - High performers in medicine and economics spend more time on research (multivariately significant in medicine), and less time on activities like patient care (multivarlately significant in medicine) and education (univariately significant in economics). These two findings are, of course, not independent. Having a large share of patient care or teaching loads proves to be a serious constraint. This latter findings is also consistent with International studies (Graves et al. 1982; Johnes, 1988). Given the tradeoff between time devated to research and patient care/education, a purposeful allocation of time is critical for high performance in research.

\subsubsection{Economies of Atmosphere}

climate - Having an innovative climate implies that new ideas are taken seriously, even (and perhaps especially) when they originate from junior staff. Having a publication climate indicates that everybody manages to do research (being research minded is reinforced), and that dissemination of results in (international) journals is strongly encouraged. Having a favorable innovative and publication climate proves to be productive for scientific research. This finding is consistent with targe-scale studies conducted in the IJ.S. (Pelz and Andrews, 1966) and Europe (Androws, 1979). 


\subsubsection{Communication}

In several respects, high performers are more 'extravert' in this sense that they interact with more colleagues from other units than do low performers. They have more within and between unit communications (univariately significant), and more international communications (multivariately significant). Low performers are more stimulated to make international contacts (study II), but high performers have more of them (both studies). The problem with communication, especially with international communication, is, of course, that it may be conceived as cause and effect of scientific productivity, since there are no high performers without frequent international contacts. As mentioned before, whether these contacts are a consequence of their thigh productivity or an input factor cannot be established from our crosssectional study. Presumably, a two-directional causality (performance and communication reinforce each other) is the most plausible interpretation..

\subsection{Consistent Zero Predictor-Criterion Relations}

Varliables which are not related to scientific productivity, neither in medicine nor in economics, are unit size (uncorrected for full time research equivalents), interdisciplinary composition and interdisciplinary communication, work-related culture, and leadership.

\subsubsection{Economies of Scale}

unit size - Since a rather crude measure of unit size has been used, the non-relationship between unit size and productivity may be a measurement artefact. Evidence for this assumption is given in study II where a correction was made for full time research equivalents. The new size variable - FTE unit size - survived the univariate and multivariate tests, thus showing the importance of economies of scale. This finding is consistent with the findings concerning critical mass and time spent on research mentioned above, and with the internationall literature concerning scientific productivity in economics (Graves et al., 1982; Johnes, 1988).

\subsubsection{Input Mix/Communication}

interdiscipllinarity - Neither of the studies presented here revealed a relationship between interdisciplinarity and scientific productivity. In general, the reseirch literature is rather ambiguous where the impact of interdisciplinarity on scientific productivity is concerned. Moderately positive (Andrews, 1979) and negative relations (Spangenberg and Nihuis. 1986) have been found in empirical research. The present studies show that there is no 
relationship between interdisciplinarity - neither as an input mix variable (interdisciplinary composition of the staff) nor as a throughput variable (interdisciplinary communication). This does not mean that only specialization is favorable, since study ill shows that high performers capture economies of scope, indicating that a certain degree of product diversification can be effective. Economies of scope, however, are not necessarily captured by interdisciplinary teams. In fact, the second study showed that economies of scope are not correlated with interdisciplinarity.

Considering transaction costs, it may be argued that interdisciplinary science is more expensive than monadisciplinary science. The parties of the interdisciplinary contract have to find each other, develop a common language, and exchange information. Since they cannot rely on a common stock of knowledge, common competences, and common professional values, a time consuming investment has to be made before their work can become productive. Consequently, interdisciplinary teams have a cost-disadwantage as compared to monodisciplinary teams. Since their higher casts are not compensated by higher performance levels, it may be concluded that Interdisciplinary units are less cost effective than monodisciplinary units. On the other hand, given the constraints of interdisciplinary work, the conjecture that interdisciplinarity is negatively related to scientific performance would be highly plausible. Thus, the nonrelationship between interdisciplinarity and performance may indicate that interdisciplinary units compensate their disadvantages by realizing higher performance levels than monodisciplinary units.

Interdisciplinary cooperation is generally recommended because it minimizes duplication of costly research (Commissie Financieringsstructuur Onderzoek en Ontwikkeling, 1985), and because it is expected to contribute to technological innovation or to solving socio-economic problems such as interdisciplinary health problems and environmental problems in the long term (Ministerie van Onderwijs en Wetenschappen, 1988). These recommendations are nol inconsilstent with our findings, since we have demonstrated that interdisciplinarity is uncorrelated to sclentific productivity - not to creativity or problem solving. Moreover, the research was conducted in two rather monodisciplinary sciences, medicine and economics, so that different observations may be made in multidisciplinary sciences such as biochemisiry and neuropsychology.

\subsubsection{Economies of Atmosphere}

work-related cullture - The zero-relationship between culture and performance may be an artefact, since the measurement instrument that was used to measure work-related culture has been developed to differentiate at the mational level (Hofstede, 1980) - not at the 
organizational levell. When an adequate measure of organizational culture, the OCM, was used, economies of atmosphere showed up (study II). The finding that non-bureaucratic cultures are efficient when innowating activities are concemed is nott only highly plausible (Mintzberg. 1979), but also consistent with well-known studies such as Burns and Stalker (1961) who found that 'organistic' (non-bureaucratic) performed better than 'mechanistic" (bureaucratic) organizations in innovating industries. Following the efficient culture hypothesis, it was conjectured in chapters 4-5 that high performers would capture economies of atmosphere. The studies presented here thend to confirm the hypothesis. However, as compared to economies of scale, the returns of atmosphere captured by high performers are rather modest.

\section{B.3.4. Management}

leadership - no support could be found for the hypothesis that leadership qualities are decisive for high performance. An explanation for this zero-relationship is that the agents here are professional scientists, who may find craftsmanship more convincing than personally trails in their leaders (study ). The latter finding (which was, however, not validated in the follow-up study) suggests that being excellent as a scientist is more important in university research management than having good lleadership qualities. It does not follow from this that leadership is unimportant. Following Knorr ell al. (in Andrews, 1979), who hawe demonstrated that leadership affects research climate (morale), and research climate affects scientific performance, it may be argued that research leaders who are able to stimulate the other members of the unit, provided that the leader is respected because of his or her professional craftsmanship, have an indirect impact on unit performance because they affect morale. The univariate relations found between management variables and predictor variables in the discriminant function of the studies presented here tend to support this interpretation.

\subsection{Inconsistent Predictor-Criterion Relattions}

The only varliable showing an (unexpected) negative predictor-criterion relation in the first discipline and a positive relation in the latter is the control variable 'reward expectation'.

\subsubsection{Contral}

reward expectation - The control variable appears to be negatively related to scientific productivity in medicine, and positiwely in economics. High performers in medicine are aware that they can best serve their financial interesit when they specialize in patient care rather than in research. When one makes a speculative attempt to explain the inconsistency "the following argument emerges: as a result of the difference in opportunity costs of scientific: 
research (clinical medicirve: high as compared to patient care; economics: low as compared to education) medical researchers should behave like altruists to perform better, while economists can (fortunately) behave like profit-maximizers, because the incentive system in departments of economics is more aligned to scientific research than in university hospitals. An plausible, alternative explanation is that high performers in clinical medicine are not altruists, but non-pecuniary profit maximizers. They maximize personal benefits such as job satisfaction (associated with preferences for research activities), international recognition," reputation, and publication in the most outstanding journals at the cost of time spent on medical education and patient care.

Although the results with regard to reward expectation are inconsistent, the multivarialely signiticant results in both of the studies clearly demonstrate that reward expectations affect scientific performance. The results remind us of the fact that any well-designed system of incentives has to take into account non-pecuniary as well as pecuniary interests, perhaps in particular in the lleld of science.

\section{B.5. Research Pollicy Implications}

Some preconditions are easier to manipulate than others. Following Franklin (1988), it may be concluded that straightforward means of improving project effectiveness include (not surprisingly) the provision of additional funding and manpower, and the supply of the time necessary to conduct high quality research. For research units working under their minimum optimal scale, this may be the only way to ensure that they will perform at an acceptable level. In addition, collaboration with foreign sclentists has been shown to be instrumental in providing a fruitful research environment. On behalf of national research policy this section summarizes the practical conclusions that can be drawn from the findings. The obvious, overall conclusion is that 'organization matters'. Excellence in science is dependent not only on intellectual capabilities, but also on the research infrastructure. University research units may capture competilive advantages by develloping economies of scale, and atmosphere. In addition, the outcomes appear to suggest that the scienlific performance of research units can be enhanced by improving their (international) communication struclure, and by designing an optimal incentive system for research. Finally, the results remind us of the fact that science is a distinctive craft. In order to operate successfully, technical craftsmanship should not only be selected for but also be encouraged in the superwision and the routines of staff members.

Of course, national research policy is an important framework within which academic research units operate, at least in the Netherlands staff levels and funds depend critically upon national budgetary mechanisms, for instance. Hence, the appropriate design of such mechanisms is a 
crucial factor in fostering high performance. It should be kept in mind, however, that national policy can at best only facilitite high performance. The actual creation of (the factors conducive to) high performance is mainly lacated at the micro task level, live. the research group level (Hazeu, 1989). Accordingly, many of the significant relationships presented here can be relevant for national research policy but ultimately have to be crafted within the research unit itself.

\subsubsection{Consistency with Research Policy}

Universities play a vital role in creating and maintaining excellence in the scientific disciplines upon which the long-term competitiveness of national industries depends. The Netherlands has a large university sector, probably one of the largest in Europe in proportion to the size of the country. The governmental research expenditures in 1985 were 3,900 million guilders of which 1,800 million is spent on subsidizing university research (primary cash flow oniy). In the last few years, an impressive number of initiatives have been taken in the field of research policy, and still others in the field of implemenlation - of. the report of the Commissie Financieringsstructuur Onderzoek en Ontwikkeling (1985), the strategic HOOP: Hoger Onderwijs- en Onderzoeksplan (Ministerie van Onderwijs en Wetenschappen, 1987), and the recent HOAK: Hoger onderwijs: autonomie en kwaliteit report (lbid, 1988), which all emphasize decentralization (decreasing bureaucracy) and increased quallity control in systems of higher education.

In general the present findings are rather consistent with the latest R\&D policy (Ministerie van Onderwijs en Wetenschappen, $1988 \mathrm{~b}$ and 1989b). Thus, the studies here suggest the (latent) rationality in these measures and recommendations by attributing an efficiency function to some of the recommendations in an independent and statistical way. This is especially the case for the national science and technology review (OECD, 1986). The next sections sellectively discuss some of the main OECD recommendations concerning university research. In general, the importance of the factors mentioned below has also been underlined by the policy reports mentioned above, and by research managers at various responsibility levels in the research pyramil (e.g. Borgman, 1988/89) and in various disciplines, e.g. experimental physics (Dynamus, 1987), clinical medicine (Schweizer et all, 1987) "and economics (VEW report, 1986).

\subsubsection{Scale Economics and Centers of Excellence}

In their review, the OECD examiners stress the importance of economies of scale in university research. They have emphasized a certain diwision of labor among universities and more 
coordination between research units. A vigorous move towards more specialization and concentration through the creation of centers of excellence is recommended. In addition, more opportunities should be offered for teamwork.

Differences between disciplines in criticall mass required for research should, however, be taken into account as well. As Chandler (forthcoming) has pointed out for indusirlal enterprises. different production technologies have different scale (and scope) economies. Like industries, scientific (sub)disciplines will also difter in their minimum efficient size. In addition, the cost curve gradient may be steeper, and the penalties of producing below minimum efficient size may be more severe in 'big science' (e.g. physics) than in scientific disciplines which operate on a smaller scale (e.g. economics). It should be noted as well that critical mass is not a sufficient condition for high performance. The law of diminishing returns is applicable once the resources are in place and treated as fixed costs. Nevertheless, research units capturing economies of scale are expected to have a competitive advantage. Assuming that there is a minimum efficicient size for each (sub)discipline, future policy research may be more directed towards the assessment of the unique critical mass for each discipline, so that an optimum use is made of scale advantages.

\subsubsection{Decentralization and Economies of Atmosphere}

Streiss is also laid in the review on the ilmportance of decentralization which is understood as increased administrative and financial autonomy, and, consequently, increased flexibility. The OECD emphasizes the need for decentralized decision making which is associated with a non. bureaucratic atmosphere promoling flexibility and innovation rather than standardization. Of course, there are limits to such an atmosphere. The Commissie Financieringsstructuur Onderzoek en Ontwikkeling (1985) has argued that the research system has a shared and stratified responsibility structure (Hazeu, 1989). Consequently, an equilibrium has to be found between bottom-up and top-down planning. In the view of this commission, the organization of the research system is neither an anarchy of self-sufficient kingdoms in which only academic treedom reigns, nor a centrallized rank-and-file structure in which the top decides and the boltom applies. If decentralization is associated with the existence of a nonbureaucratic culture in the unit, the findings presented here suggest that bottom-up planning is more advantageous in terms of the scientific performance of university research units than bureaucratic measures. To put it differently, scientific excellence is more likely to emerge in an innovative 'studio" type of environment than on an assembly line. 


\subsubsection{International Exchange In Sclence}

Consistent with the findings presented here, the OECD suggests that exchanges between research units, particularly international exchanges, should be encouraged. In the Netherlands, an increase of international diffusion of results is recommended, because "a country which exports and imports the equivalent of half of its gross national product is by necessity a part of the international economy and exchange system. This implies that international developments thave to be taken into account more than in other countries which are less dependent on international trade" (OECD, 1986: 7). Nowadays, it is recognized that an international outlook and international cooperation are of particular importance for a small country like the Netherlands which accounts for only about one percent of R\&D efforts in the world. The Ministerie van Onderwijs en Wetenschappen (1989b; 12) states that "research contributes to the expansion of the world-wide reservoir of knowledge. Equally, it is essential thall researchers remain alert and are able to tap developments in that reservoir. Generally speaking, if researchers are to function properly they must be part of an international network, be it formal or informal, of fellow researchers". Internationalization is a necessity for quality assurance (by the international Forum function of science) and to monitor interesting developments at an early stage. Moreover, it is recognized that some subjects are of such a nature (e.g. transnational environmental problems, the war against cancer or international finance) that they can only be studied properly in an international context. A strategic consideration is that, in order to compete with the USA and Japan, it is essenfial for Europe that there is a multinational pooling of scarce scientific and technological knowhow. Consequently, promoting an international outlook and strengthening international cooperation in academic research is one of the policy intentions of the Ministry of Education and Science. In this context, the Netherlands could possibly take Belgium as an example, where figures indicate that between $50 \%$ and $60 \%$ of publicly-funded research occurs in an international context (Ministerie van Onderwijs en Wetenschappen, 1988b: 24).

\subsubsection{Market-oriented Incentive Systems}

Finally, increased flexibility is recommended in reward systems. Excellence should be encouraged and mediocrity discouraged, for instance, by market-oriented incentive schemes, and the creation of new temporary posts which, moreover, offer opportumities for increased mobility between universities. The Wolfson commission has pointed out that increasing fllexibility should not injure the continuily of high quality long-term research programs (Commissie Financieringssiructuur Onderzoek en Ontwikkeling, 1985). Nevertheless, there is increasing recognition of the competitive disadvantages of non-market orienled incentive systems, e.g. the buy-out of scientific potential by large companies or the brain drain to 
outstanding U.S. universities which provide better salaries and, perhaps even more important, more autonomy and more satistying facilities to conduct scientific research.

\subsection{Concluding Remarks}

The present chapter shows that economies of scale, atmosphere, and international communication are the most robust variables predicting scientific performance. The results with regard to reward expectation are inconsistent, but the multivariately significant results remind us of the fact that a well-designed system of incentives may be vital as well. Important variables which are not related to performance are interdisciplinarity and leadership. Since most of the results are rather consistent, despile the considerable distance between clinical medicine and economics, it may be argued that the findings are fairly well generalizable to other beta (natural) and gamma (economics and similar social sciences) disciplines. This claim is supported by a comparison of the findings here and other contributions, but should be placed in perspective by taking into account the shortcomings and strengths of the research methodology.

The present findings prove to be in line with the latest research policy, particularly concerning (1) concentration and increasing the scale of scientific research somewhat (ii) increasing autonomy and decentrallization, (iii) designing incentive schemes which take market developments into account, and (iv) internationalizing the scope of Dutch university research. This is i among other things, the case for some of the recommendations in the latest National Sclence and Technology Review of the OECD (1986). The studies presented here have not revealed the 'one best way to organize' scientific research. Furthermore, there are methodological shortcomings which have to be taken into account as well. Finally, none of these measures can effectively be implemented unrestrictedly or in a mechanistic way. Given the robustness of the findings, however it may be said that a small set of variables have been Identifled which can be neglected only al the risk of low performance in (some of) the beta and gamma sciences. 


\section{Summary and Discussion}

The first section of this general discussion will summarize and discuss some of the main findings of this study against the background of the available empirical data on economles of atmosphere. The second section deals with the shortcomings and strengths of the study. The third section of this discussion provides some suggestions for further research.

\subsection{Main Research Findings}

This book has argued that decision makers rely partially on habits, operational routines, and rules of thumb which consist of fixed rather than flexible, rational responses. Although many of our decisions will be inferior to those a fully informed rational agent would have made, we aften have no better alternative. Given scarce cognitive resources, to rely, partially on rules of thumb and other (non) choice decision rules may be the best possible solution. Some of these decision rules are provided to individuals by an atmosphere which affects their mental programs and behavior - both at the national and the organizational level. This siudy has focused on the economies and diseconomies of allmosphere, i.e. the profitable and harmful effects of atmosphere, especially at the organizational level.

The theoretical part of this study has been concerned with the economic rationale for atmosphere. The main questions explored are (i) whether atmosphere affect costs and performance; (ii) if so, what are the economic reasons for this; (iii) what are the costs of supplying an (in)adequate atmosphere? A review of the literature on economics and business administration revealed that atmosphere does matter. As a routine or fixed reponse, it can be a source of technical efficiency. However, from a dynamic (or quasil-static) point of view, it can also become a source of inefficiency. Several economic reasons can be given why atmosphere is associated with competitive (dis)advantages at the national, industry, and firm level of analysis. The reasons given depend on the theoretical perspective and the level of analysis. While the literature on welfare economics emphasizes atmosphere as a public good, the literature on strategic management centers on eniry barriers, uncertain imitability, and 
durable, superior economic performances of firms. While the iterature on international management emphasizes the impact of national work-related values on GNP, the economics of organization focuses on the shirking problem (team theory), incomplete contracting and focal equillibria (agency theory), and the efficiency imperative: transactions should be so organized as to economize on bounded rationality, while simultaneously sateguarding against the hazards of opportunism (transaction cost economics). These are, of course, interpretations of the theories mentioned above. Only Williamson (1973) has explicitly dealt with the "economics of almosphere:

What about the costs of supplying an appropriate atmosphere? Following the rather broad definition of atmosphere presented in this book (values, codes, information, competences)" atmosphere is an unavoidable investment - you will always have one. The only alternative for a given atmosphere is an allernative atmosphere. When the switching casts of moving to another atmosphere exceed the benefits or when firms simply fail to ignore sunk costs (note that atmosphere is an irreversible, non-marketable investment), the firm is locked into the present atmosphere, and this may becomes a source of inertia and myopia. Since it 'takes ages and costs fortunes' to develop an alternative atmosphere, firms will only change their atmosphere when there are good reasons to do so. The amount of switching cosis is dependent on the level of aggregation, i.e. Hhigher levels have higher switchings costs and are therefore lower in the response times hierarchy. Consequently, implementing an allernative atmosphere is less dlfficult (and will take less time) for firms than for industries, and less difficult for industries than for nations - nol to speak of networks of nations such as the European Economic Community.

Demonstrating that there is an economic rationale for atmosphere does not necessarily imply that there is empirical evidence for economies of atmosphere. While the first Section of this book, (Section 1), has focused on the economic rationale for atmosphere, the remaining parts reported on the design (Section II) and the findings (Section III) of the empirical studies aiming to test the economies of atmosphere hypothesis. As compared to the rich body of theory on this subject and the large number of conceivable hypotheses generated by the economies of atmosphere framework (chapter 1), the empirical studies have a somewhat restricted focus. In Simon's [1954] terminology, the tension between the theoretical (broad) and empirical (restricted) locus of this research project may well be conceived as an illustration of bounded rationality, because it shows that the capacity of the author to formulate and solve problems is very small compared to the size and complexity of the problems whose solutions are required. By selecting a narrow focus, the empirical studies have attempted to economize on bounded rationality at the cost of restricted generalizability. 
What is the contribution of the empirical studies presented here to the existing body of knowledge? Implications can only be discussed concerning the organizationall level, since the empirical studies ignored other levels of analysis. In my opinion, their main contribution is that they put the efficiency claims of much of the literature on corporate culture somewhat in perspective. Many authors bellieve that 'corporate culture', which is a catch-all term for a heterogeneous assortment of intangible assets such as values, beliefs, and rituals, plays a critical role in excellent organizations. Some conceive atmosphere as the most important condition when team performance is concerned. In contrast to this literature, the findings presented here show that the impact of atmosphere on the performance of research organizations is, in fact, rather modest - even in an organizational form which tends to favor economies of atmosphere (chapter 4: the efficient culture hypothesis). It is the interplay between economies of atmosphere and other (even more important) predictors such as economies of scale and international information flows which account for performance as measured by various qualitative and quantitative scientometric indicators (chapter 5) - at least in university research organizations.

Several reasons can be given why the empirical studies presented here failed to show the decisive role of atmosphere. First of all, an imperfecl measure has been used to assess one of the dimensions of atmosphere. Obviously, the Value Survey Module (VSM) is not an appropriate instrument to assess work-related values at the organizational level. Second, standardized measures have been used to assess the other dimensions of atmosphere, li.e. the organizational culture module (OCM) and the climate measures. Only the climate measures were adapted to the specific work dimensions of universily research units. Third, cross-section research has been carried out in existing units. Consequently, dynamic aspects were not observed. As a result, the alternative hypothesis cannot be excluded that atmosphere plays a decisive role in an early stage, while only playing a minor role in the mature stage of the unit's lifecycle which has been investigated in our anallysis. Finally, comparisons have been made of high and low performers within the same discipline, clinical medicine or economics. This procedure has been selected in order to establish internal validily (comparing 'like with like') at the cost of minimizing the varilance (in occupational cullure) between the research units. 
Exhibit 9.1 combines Dutch VSM data on clinical medicine (study I; Bally et al. 1987). economic departments in universities (study 11 ) "economic departments in the Central Office of Statistics (CBS) and banks (data collected by the author during study II), and accounting firms (Soeters and Schreuder, 1988). The figure is only shown lo llustrate that the withindiscipline variance, l.e. the variance between between high and low performers tends to be smaller than the between-discipline variance, i.e. the variance between clinical medicine and economics. The latter discipline is represented by the university departments of study II, the Central Office of Statistics (CBS), economics departments in a number of banks, and the average of Dutch and 'Big Eight" accounting firms. The lines between the items are meaningless, but they are helpful in observing gllobal differences in the profiles of the two disciplines.

\section{Exhibit 9.1. VSM trends within and between disciplines}

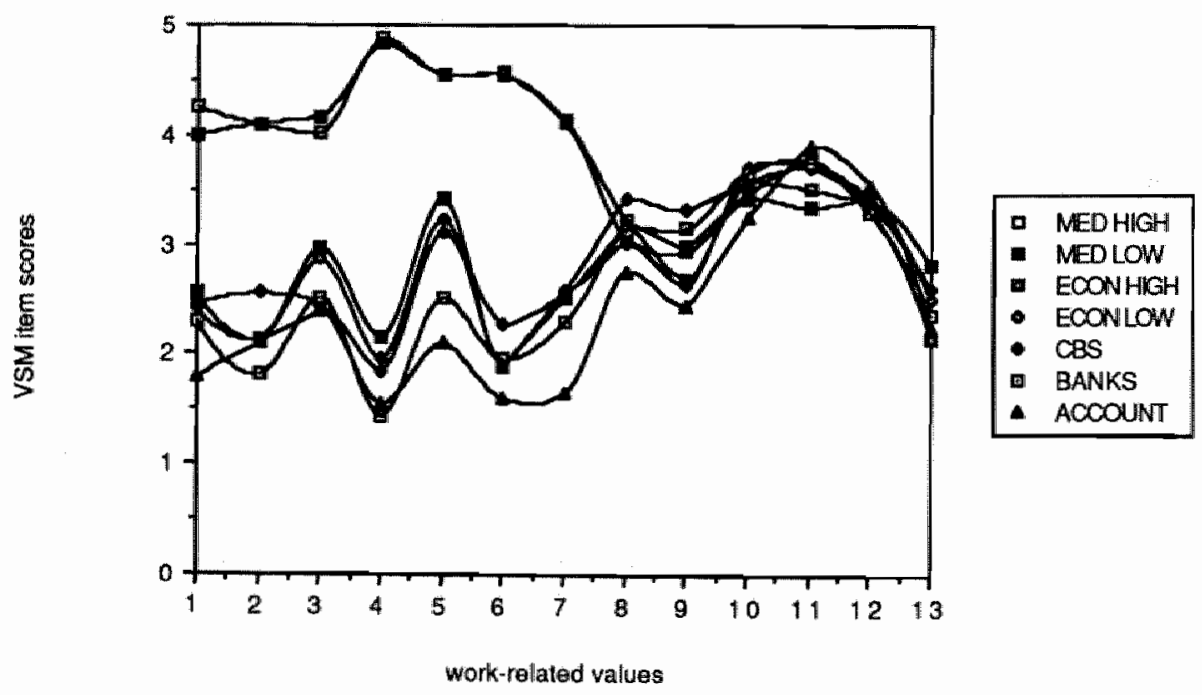

Hofstede (1980) distinguishes four value dimensions: (i) Individualism is item 1, 2, 4, and 6 ; (ii) masculinity is items 3,4 (double), 5, and 7; (iii) power distance is items 8,9 , and 12; (iv) uncertainty avoidance is ltems 10,11, and 13. The dimensions are computed on the basis of formulas which are given in the VSM scoring guide (Hofstede, 1982). The weights of the items in the formulas are derived from the factor loadings of the original IBM study. Comparing the VSM scores of several organizations within the same country, however, is not a very fruitful approach, since the VSM was developed to compare country rather than organizational 
scores. In addition, interpreting the differences in atmosphere at the item level would be pure chance capitalization. The figure is only given tho illustrate that efforts to keep production technology constant by comparing high and low performers within the same discipline results in a restriction of variance in the professional atmosphere linked to these specific production technologies. The values and competences of high and low performers reflect more the places: that they are trained at than the institutions they are at (personal communication, Mclaughilin. University of North Carolina). Consequently, it may be conjectured that the relattonship between atmosphere and performance would be stronger when predictor-criterion relations are examined in a combined sample consisting of clinical imedicine and economics, thus maximizing the variance in atmosphere. However, such an approach would not be very convincing since it would be difficult to be interpreted given the heterogeneity introduced in the sample and the performance measures.

These are methodological explanations which may always be used as an excuse for not drawing firm conclusions. As I belleve, performance differences can only be attributed to atmosphere in an exclusive way when ather sources of efficiency have been siown not to provide a contribution. Given the complexity of the efficiency problem and the variety of efficiency sources, it is rather naive to capilalize exclusively on atmosphere when alming for technical efficiency. The contribution to the 'economics of atmosphere' by this project may be summarized in three critical propositions, which may as well be conceived as conjectures for future research.

(i) From an empirical perspective, economies of atmosphere have less impact than is generally believed - although there is certainly an economic rationale for the existence of atmosphere from an analytical point of view.

(ii) It is the dynamic interplay between atmosphere and other sources of efficiency rather than atmosphere alone which accounts for the varlance in technical efficiency between organizations.

(iii) Economies of scale tend to be more important than economies of atmosphere. Units working without sufficient 'critical mass" may not be able 10 compensate thelir scale disadvantage by developing a superior atmosphere.

\subsubsection{An Example of Economies of Atmosphere}

What is the rationale for economies of atmopshere? Perhaps the most intriguing (though debatable) result of one of the studies presented here is the negative relationship between reward expectation and performance in clinical medicine. It was conjectured that high performers would expect more pecuniary rewards for conducting research than for patien! 
care. This would not be surprising, since all members of high performing units, including the supervisors, spend more time on research than members of low pertorming units. In addition, they have more frequent working discussions with colleagues on research topics, and feel more responsible for their research task. This conjecture would be perfectly consistent with the neoclassical paradigm in which individuals are assumed to maximize their subjective expected utillities. If members of clinical research units were pecuniary profit maximizers, they would only do so in the expectation of a pay-off.

In contrast to this reasoning, the findings show that high performers expected significantly better opportunities for their career development in patient care rather than in research. Thus, they invest their time in research, although they are aware that patient care generates a much higher pecuniary return. What can be rationale for this behavior? It may be concluded that high performers in clinical medicine are dedicated scientists, i.e. they are intrinsically motivated to do research. For them, the game of science is a goal in itself. It may also be argued that they are dedicated human beings - driven rather by the motivation to increase medical knowledge (and indireclly, improve the quality of patient care) than by seeking their own narrow self interests. From this perspective, their behavior is altruistic rather than calculative in a narrow sense. High performers may truly want to promote causes which are not identical to their own welfare in a limited sense, and which they do not perceive as their own narrow self-interest.

Take as a contrast the low performers in clinical medicine who are more consisttent with the limited version of the utilitarian image of man. From an orthodox maximizing perspective, their behaviors are much more 'rational'. They invest their time in patient care rather than in scilence. Moreover, they spend significantly more time on private patient care practice offhospital (which is generally known to be more profitable in a pecuniary sense than in-hospital care) than high performers. In terms of individual incomes, the low performers are presumably better off than the high performers. When the mutual gains of team production are considered, it is the non-calculative attitude, the dedication to research, which increases the scientific perlormance.

Concerning rational behavior, the neoclassical paradigm can be applied more or less. rigidly. As usual, the "mainstream literature", represented by the institulion of the microeconomics handbooks, tends to be more rigid, while the classics (from Adam Smith to Marshall and Hennipman) and recent journal articles describing well-designed choice theoretic models tend to favor flexible uses. Recently, a detalled argument in favor of the flexibility of the maximizing framework has been presented (Van Witteloostuijn, 1988). When maximizing models leave room for the introduction of 'non-economic' determinants of behavior in a 
maximizing framework, it may be argued that high performers in clinical medicine locus on reputation effects rather than income effects. These effects may, of course, be interdependent, e.g. income effects may be a long term effect of international scientific recognition. Thus, the high performers in clinical medicine are guided by quasi-altruism or long term self-interest rather than true altruism. Finally, one may introduce science as a kind of lart pour lart in the utility function of the scientific utility maximizer or equivalently, consider it as a means to satisfy higher needs. Hence, it is partly a definitional matter whether one wants to designate this behavior as rational or not. Stretching the concept of rationality, however, introduces the risk of circularity and non-operationality. For example, "revealed preferences' are derived from behavior, whereas behavior is evaluated as rational when it is consistent wilh these very preferences.

Of course, these are ad hoc interpretations. But if they are correct, they suggest that the difference in mental programming (or in needs) between high and low performers does matter. Especially when the targets (maximizing research performance) and the incentive system (rewarding patient care efforts rather than research efforts) of the organization (university hospitall) are not consistent, the "folly of aiming at A and rewarding B", mentall programming can help in generating investment decisions favorable to research despite the high opportunity costs of which all high performers are aware. This is, of course, but one case. The "altruistic' or "dedicated" mental programming is not necessarily a general trail of high performers in universities, since the second study showed that high performers in departments of economics expect the higher returns from research. Their behavior is perfectly rational in a more orthodox neoclassical sense. Consistent with their (realistic) expectations, and perhaps also with their intrinsic moliviation to conduct research, they spend most of their time on research.

\subsection{Strengths and Shortcomings}

An evaluation of this study enables both strengths and shortcomings to be distinguished. Before discussing the former, it is important to consider the main shortcomings.

1. First of all ${ }_{i}$ the theoretical focus of the empirical studies is restricted. While the economies of atmosphere framework (oullined in chapter 1) centers on the impact of values, codes, information and competences on (praduction and transaction) costs and performance levels, the empirical studies were centered on the impact of values and practices on pertormance. Clearly. further research is needed to explore economies of atmosphere, but future empirical research

will undoubtedly be constrained by other operationalization difficulties, especially concerning 
'transaction costs'. This cost concept is very useful for analytical purposes, but is hard to use in empirical research.

2. Second, a cross-section design has been used; that is, most of the (independient) measures are taken at only one point in time. This approach enables a prediction of the sign of the statistical predictor-criterion relations. It is, however, well-known that it does not reduce uncertainty concerning the causall direction of the predictor-criterion relation which is often crucial for policy. Statistical association does not imply causation, though it may be a requisite. The use of longitudinal or quasi-experimental designs would be a solution. However, collecting longitudinal data is a costly enterprise, while quasi-experimental research is, in general, not feasible in real life organizations.

3. Third, the empirical studies represent an analytical approach - the research proceeds from a distance, through standardized questionnaires. As a result, the research is subject to Miller and Friesen"s (1984: 18) criticism: "The detachment of the researcher from the context of the research precludes the collection and examination of anecdolal data. Typically, researchers end up with a set of general measures of a few rather abstract variables. How are they supposed to probe into causation and interpret these findings? Even if the findings do have some deeper meaning, will the researchers be able to find it?" Studies 1 and II have focused on testing for circumscribed, linear predilctor-criterion relationships instead of searching for a multiplicity of rich, revealing patterns. In their case for configuration, the authors would suggest that the studies presented here should at least be complemented by well-designed case studies. However, costs have to be taken into account in the sellection of the research method, since the case study is an extremelly time-consuming activity. An alternative would be to develop a more sensitive questionnaire than we have used, on the basis of in-depth interviews wilh members of high and low performing groups. The interview procedure may also be used to complement the siurvey-method as has been done in the extended report of study I (Bally et all., 1987: chapter 9).

4. Other criticisms may center on obvious defects of the empirical studies presented here such as the low number of observations resulting in an unfavorable variable/observation ratio for multivariate analyses, especially in study 11 . In addition, criticism may be formulated regarding the low response rates, and the uncertainty with regard to the representativeness of the data. As a result, caution should be observed in generalizing the findings reported here. Moreover, there are undoubtedly important factors not considered in this study, and measurement imperfections may be pointed oul with regard to some of the variables. 
5. Regarding the policy implications, it should be mentioned that documents on research policy are generally written from a governmental point of view. Although consistency between our findings (which are based on analyses al the organizational level) and aspects of national research policy recommendations (which are based on the nationall levell) may be observed, the findings presented here cannot be directly translated in national research policy recommendations. In fact, given the level of analysis, the findings are more relevant for the middle management level than for the policy maker. Since they prove to be consistent with at least some recommendations at the national level, they may have more value for the research manager, because they are likely to be supported by top management. Although national research policy is an important framework, the actual creation of high performance is mainly located at the micro level. Accordingly, many of the significant relationships presented here can be relevant for the national research policy level but ultimately have to be crafted by the members and the managers of the research unit itself.

Despite these shortcomings, there are a number of strengths in the study presented here.

1. First of all, it may be argued that there is a theoretical foundation for the selection of the central predictor variables, i.e. scale, scope, and atmosphere. While economies of scale and economies of scope have become well-recognized causes of technicall efficiency in the microeconomic literature, Section I of this book has attempted to demonstrate that there is an economic rationale for the existence of economies of atmosphere as well, especially in certain organizational structures which are similar to the research unit because of uncertainty in the production technology.

2. Second, use was made of the best available national performance evaluations for the classification of research units in clinical medicine and economics. While most effectiveness studies center on subjective self-ratings, study I and II could rely upon a multitude of fairly accurate scientometric indicators. As expected, most of these performance indicators appeared to be convergent.

3. Third, multivariate analyses were restricted to the univariately significant variables in order to reduce chance capitalization. Furthermore, the multivariate procedure resulted in fairly accurate and efficient predictions, l.e. a small set of predictor variables explained a large amount of the variance in the criterion variable at the unit level of analysis. In addition, it is shown that different combinations of predictor variables may result in an efficient prediction, tie. there is no one best way to organize scientific research. The predictor variables do not constitute a blueprint that should be followed in every case. 
4. Since there is a large variance between the disciplines which were selected for the study. economics and clinical medicine, the external validity of the predictor-criterion relations could be examined. Despite the large differences between the disciplines, the comparison has shown rather consistent results. Consequently, the results may to some extent be generalized to other beta and gamma sciences.

5. Comparison of the findings of study I and II with international scientometric studies which are not affected by the low response/low number of observations problem reveals that the results are fairly consistent - even when totally different disciplines are involved. Recently, Franklin (1988) reported the findings of a llarge scale study in European Commumity countries. The research was conducted in 92 disciplines covering the mathematical, natural, life, and engineering sciences in the EC. It was based on a survey of 5,615 research scientists conducted in 10 EC countries. Analyses were performed on three levels of analysis: the individual level, the project level, and the disciplinary level. The two correlates of effectiveness which were least affected by aggregation are associated with two of the predictor variables which emerged from study $I$ and 1 , l.e. time spent on research (one of the indicators of scale) and international communication. "(...) although we cannot yet speak about the causes of effectiveness, this chapter has certainly uncovered some features of the research scientist and his environment that are associated with research effectiveness in a non-trivial manner. One of these is an intemational orientation, which plays an important part in enabling us to predict effectiveness at all three levels of analysis with which we have been concerned. The only other variable to play a significant role at every level is the length of the working week. Longer hours lead to more effective research output, at discipline, individual and project level" (Franklin, 1988: 229). Picasso used to state that like crafts, the arts are more associated with transpiration than inspiration. Given the importance of long working hours this may be true for scientific craftsmanship as well.

\subsection{Suggestlons for Continued Research}

This book is "to some extent, an exploration into new territiory In particular, the territory that lies between neatly defined disciplines such as economics and psychology has been explored. Thus, it may provide synergy effects in a field where monodisciplinary efforts are more common. Since the game of science is, in principle, without end, (in contrast with the time of the analyst which is rather limited), further research is recommended. The main steps to be taken next, in my opinion. are listed below.

(i) Given the fact that only a limited number of hypotheses generated by the economies of atmosphere framework were tested, the impact of values, information and competences on costs 
and benefits in a variety of public and private sector organizations should be explored empirically.

(ii) In order to increase our knowledge on (reciprocal) cause-effect relations in scientific organizations scientometric studies are recommended using longitudinal or quasiexperimental designs. In order to increase our in-depth understanding of the dynamics of research organizations, well-designed longitudinal case studies are recommended.

(iii) Further integration and formalization (Kreps, 1984) of the concept of atmosphere within microeconomic theory is recommended. Many economists have already demonstrated the tangible impact of intangible assets such as information (Arrow, 1971), trust (Sen, 1983), honesty (Akerlol, 1979), reputation (Schelling, 1978), and altruism (Becker, 1976). Within a flexible maximizing framework, it is widely recognized that these 'noneconomic" factors contribute to the explanation of economic phenomena. Elementary trust relations. between buyers and sellers are, for example, conceived as a necessary, not a sufficient, condition for the market mechanism to exist. Dishonesty and suspicion have been recognized as causing market fallures in the market for lemons (Akerlof, 1971) and medical services (Arrow, 1971). Moreover, it is recognized that the exchange process itself can be a source of value. Whether they are paid for giving blood or not matters to blood donors. Whether they are monitored or not, and to what degree, matter to agents working in a professional organization. Simillarly, whether a man pays a woman for sex directly (in cash) or indirectly (by renting an appartment for her and paying for meals, etc.) makes a difference to both sides (comment of an anonymous referee of Management Science). Integration of intangible assets such as almosphere in neoclassical theory will, in the long run, enhance the explanatory power of the economic discipline and may as well contribute to the 'microfoundation of macroeconomics" to use a famous phrase in contemporary economic discourse.

(iv) Finally, further logical inquiry is encouraged regarding the rationality assumption in neoclassical economics. Analyzing atmosphere leads to the recognition that maximizing behavior does not exclusively entail maximizalion of self-interest in a narrow sense. The utilily function can include other goals, values and commitments. Even within a predictive perspective (Friedman, 1953), there is little ewidence that assuming self-inlerest maximization would yield the best predictions. The narrow sell-interest maximization hypothesis is, for example, inefficient for prediction, in addition to being a bad description, in South East Asian countries such as Japam which has strong norms of behavior. Recently, it has also been recognized that a too narrow motivation structure of employees is counterproductive for Western organizations as well. Atmosphere as a sel of values assumes that people may not relentlessly pursue their own goals. They may be guided by the recognition of interdependences 
Following Adarn Smith's Theory of Moral Sentiments [1759], Sen has argued that when goals of different people are partly congruent and partly conflicting, then the pursuit of individual goals in isolation may not be a sensible thing to do for people working in organizations and living in the society. This leads to the subject of habits, routines, and behavior according to norms which Adam Smith particularly emphasized: "These general rulles of conduct, when they have been fixed in our mind by habitual reflection, are of greal use in correcting misrepresentations of self-love concerning what is fit and proper to be done in our particular sfluation" (Sen 1989 in: Klamer, 1989: 144). The ullimate objective is that, given strategic interdependencies, all of us manage to achleve our respective goals better. This is what the economics of atmosphere is about: many systems flourish precisely because there are codes of conduct which may violate short term self-interest goals, at least to some entent. Thus, atmosphere may create a game which has a superior collective outcome when not only the narrow self-interest of each player is persuaded, but interdependencies are taken into account as well. Simple decency, a sense of duty, and regard for others are examples of values which cannot always be incorporated in an efficiency calculus, but ultimately are indispensable for our well-being. 


\section{References}

Ad Hoc Commissie Vooritters Vaste Commissie Wetenschapsbeoefening 1988: Naar een meeten monitoringsysteem van productiviteit/kwaliteit van het onderzoek in de Economische Faculteiten. Utrecht: VSNU.

Administrative Science Quarterly 1983, 28: Special Issue on Organizational Culture.

Akerlof, G. 1979: The Market for 'Lemons": Quality, Uncertainty, and the Market Mechanism. Quarterly Journall of Economics, 488-500.

1980: A Theory of Social Custom, of Which Unemployment May Be One Consequence. The Quarterly Journal of Economics, 94, 749-75.

Alchlan, A.A. and Demsetz, $H_{n}$ 1972: Production, Information Closts, and Economic Organization, American Economic Review, 5, 777-95.

and Woodward, S. 1988: The Firm Is Dead: Long Live the Firm. A Review of Olver E.

Williamson's The Economic Institutions of Capitalism, Journal of Economic Literature, 65-79.

Allen, Th. 1977: Managing the Flow of Technology, Boston: MIT Press.

Altman, E.I. 1982: Corporate Financial Distress, New York: John Wiley.

Anderson, J.A. 1973: Logistic Discrimination with Medical Applications. In: Cacoullos, T. (Ed.), Discriminant Applications, London: Academic Press, 1-16.

Andrews, F.M. (Ed.) 1979: Scientific Productivity. The Effectiveness of Fiesearch Groups in Six Countries, Cambridge and Paris: Cambridge University Press/UNESCO.

Ansoff, H.I. and Baker, Th.E. 1986: Is Corporate Culture the Ultimate Answer? In: Lamb, R., and Shrivastava, P. (Eds) 1986: Advances in Strategic Management (Volume: 4: B1-93), Greenwilch: JAl Press.

Anthony, R.N. 1965: Planning and Control Systems. A Framework for Analysis. Division of Research, Graduate School of Business Administration, Harvard University: Boston. Irwìn.

and Herzlinger, R.E. 1975: Managemenl: Control in Non-Profit Organizations, Homiewood:

Aolki, M. 1984a: The Co-operative Game Theory of the Firm, New York: Oxtord Universily" Press.

(Ed.) 1984b: The Economic Analysis of the Japanese Firm, Amsterdam, New York, Oxford: North Holland.

Arrow, K.J. 1963: Uncertainty and the Welfare Economics of Medical Care, American Economic Review, 53, 941-73. 
1964: Control in Large Organizations, Management Science, 10, 397-408.

1968: The Economics of Moral Hazard: Further Comment, American Economic Review, 58, $537-39$.

1971: Essays in the Theory of Risk Bearing, Amsterdam: North Holland.

1973: Social Responsibility and Economic Efficiency, Public Policy, 21, 303-318.

1974a: The Limits of Organization. Fels Lectures on Public Policy Analysis, New York and London: Norton \& Co.

1974b: Gifts and Exchangles, Philosophy and Public Aflairs, 4, 342-62.

1978: The Future and the Present in Economic Life, Economic Inquiry, 16, 157-169.

1984: The Economics of Information. Collected Papers of Kenneth J. Arrow, Cambridge:

The Belknap Press of Harvard University Press.

and Debreu, G. 1954: Existence of an Equilibrium for a Competitive Economy,

Econometrica, 22, 265-290.

Axelrod, R. 1984: The Evolulion of Cooperation, New York: Basic Books.

Bakke, EW. 1950: Bonds of Organization. New York: Harper \& Bross.

Bakker, P. and Rigter "H. 1985: Editors of Medical Journals: Who and from Where?

Sclentometrics, 1-2, 11-22.

Bally, Y.W., Spangenberg, J.F.A. and Starmans, A. 1987: Achtergronden van de kwaliteit van het patientgebonden onderzoek in Nederland,'s-Gravenhage: Staatsuitgewerij.

Banfield, E.C. 1958: The Moral Basis of Backward Society, New York: Basic Books.

Barnard, Ch. 1954 [1938]: The Functions of the Executive, Cambridge: Harvard University Press.

Barney, J.B. 1986: Organizational Culture: Can it be a Source of Sustained Competitive Advantage? Academy of Management Review, 11, 656-65.

1986: Strategic Factor Markets: Expectations, Luck, and Business Strategy, Management Science, $1231-1241$.

and Ouchi ${ }_{i}$ W.G. 1986: Organizational Economics, San Francisco: Jossey-Bass.

Baumol, W. 1975: Business Responsibility and Economic Behavior. In: Phelps, E.S. (Ed.), Altrulism, Morality, and Economic Theory, New York: Russell Sage Foundation, 45-56.

- Panzar, J.C., and Willig, R.D. 1982: Contestable Markets and The Theory of Industry Structure. New York: Harcourt Brace Jovanovich.

Becker, G.S. 1964: Human Capital, New York: Columbia University Press.

1976: Altruism, Egoism, and Genettic Fitness: Economics and Sociobliology, Journal of Economic Literature, 817-26.

Becker, H.D. and van Raan. A.F.J. 1985: Kwaliteit in de wetenschap: een meetbaar begrip? Leiden: DSWO Press. 
Bess, J.L. (Ed.) 1984: College and University Organization, New York: NY University Press.

Blaw, P.M. and Scott. W.R. 1962" Formal Organizations. A Comparative Approach, San Francisco: Chandler.

Boisot, M.H. 1986: Markets and Hierarchies in a Culturall Perspective, Organization Studies, $2,135-58$.

Bollie, F. 1983: On Sen"s Second-Order Preferences, Morals, and Decision Theory, Erkenntnis, 20,195-205.

Borgman, J. 198:8/89: Hoger onderwijs en onderzoek: trends voor de jaren "90. Universiteit en Hogeschool $, 35,4,141-50$.

Bosland, N. 1984: Some Studies on the Value Survey Module, M.A. Thesis, Tilburg: Katholieke Universiteit Brabant.

Boulding, K.E. 1973: The Economy of Love and Fear. A Preftace to Graint Economics. Belmont: Wadsworth.

Breemhaar, B., Bally, Y.W., Starmans, R., Nijhuis, F.J.N., and Spangenberg, J.F.A. 1988: Organisatiekenmerken en de kwaliteit van het patiëntgebonden onderzoek, TSG, 3, 69-72.

Bresser, R.K. and Dunbar, R.L.M. 1986: Context, Structure, and Academic Effectiveness: Evidence from West Germany, Organization Studies, 1, 1-24.

Buchanan, J.M. 1971: The Bases for Collective Action, New York: General Learning Corporation.

1985: Ethics, Elficiency, and the Market, Towota: Rowman \& Allanheld.

Burns, T. and Staker, G.M. 1961: The Management of Innovation, London: Tavistock.

Burrell, G. and Morgan, G. 1979: Sociological Paradigms and Organizational Analysis, London: Heineman.

Business Week, Who's Excellent Now? November, 46-55.

Camerer ${ }_{n}$ C. and Vepsalainen, A. 1988: The Economic Efficiency of Corporate Culture, Strategic Management Journal, 115-126.

Cameron, K.S. and Whetten, D.A. 1983: Organizational Effectiveness: A Comparison of Multiple Models, Orlando: Harcourt Brace Jovanovich.

Campbell, D.T. and Fiske, D.W. 1959: Convergent and Discriminant Validation by the Multitrait-Multimethod Matrix, Psychological Bulletin, 81-105.

and Stanley, J.C. 1966: Experimental and Quasi-Experimental Designs for Research, Chicago: Rand McNally.

Cargile, B. and Bublitz, B 1986: Factors Contributing to Published Research by Accounting Faculty, Accounting Review, 1, 158-78.

Cayseele, P. van 1986: Spillovers and the Cost of Multiproject R\&D, Managerial and Decision Economics, 7, 133-39. 
1987: Economies of Scope in Pesearch and Development, Joumal of Economics, 47, 3; 273-285.

and Schreuder, H. 1988: De economische inbreng in de strategiebepaling van ondernemingen, Mimeo, Maastricht: Faculteit der Economische Wetenschappen.

Centraal Bureau voor de Statistiek (CBS) 1985: Universitair Onderwijs en Onderzoek 1982/1983. De tjjdsbesteding van het wetenschappelijk personeel van universiteiten en hogescholen en academische ziekenhuizen, "s-Gravenhage: Staatsuitgeverij.

Staatsuitgeverij.

(CBS) 1988: Speur- en ontwilkkelingswerk in Nederland, 's-Gravenhage:

Chandler, A.D., Jr. 1977: The Visible Hand. The Managerial Revolution in American Business, Cambridge: Harvard University Press.

(forthcoming): Scalle, Scope, and Organizational Capabilities, Essay in: Chandler, A.D., Scale and Scope, The Dynamics of Industrial Entreprise, Boston: Harvard University Press.

Coase, R. 1937: The Nature of the Firm, Econometrica, 4 (1937): 386-405.

Cohen, M.D. and March, J.G. 1984: Leadership and Ambiguity: The American College President, Now York: McGraw-Hill.

Cole, J.R. and Cole, S. 1973: Social Siratification in Science, Chicago: Chicago University Press. Press.

1981: Peer Review in the National Science Foundation, Wahsington D.C.: National Academy

Collard, D. 1978: Altruism and Economics, Oxford: Robertson.

Commissie Financieringsstructuur Onderzoek en Ontwikkeling 1985: Rekenschap van creativiteit. Eindrapport van de CFOO, 's-Gravenhage: Staattsuitgeverij.

Commons, ل.R. 1951: The Economics of Collective Action, New York: MacMillan.

Cramer, J.S. 1986: Een academische verkenning van hel universitaire economische onderzoek, ESB, 8, 838-40.

1988: De productiviteit van Economische Vakgroepen nader bezien, Kwantitatieve Methoden, 29, 5-12.

Crémer, J. 1986: Cooperation in Ongoing Organizations, The Quarterly Journal of Economics, 33-49.

1987: Corporate Cullure: Cognilive Aspects, Mimeo, Blacksburg: Virginia Polytechnic.

Cyert, R.M. and March, J.G. 1963: A Behavioral Theory of the Firm, Englewood Cliffs:

Prentice-Hall.

Danielsen, A.L. and Delorme, C.D. 1976: Some Empirical Evidence on the Variables Associated with the Aanking of Economics Journals, Southern Economic Journal, 1149-1160.

Davis, P. and Papanek, G.F. 1984: Faculty Ratings of Major Economics Departments by Citations, American Economic Review, 225-230.

Deal, T.E. and Kennedy, A.A. 1982: Corporate Cultures, Reading: Addison-Wesley. 


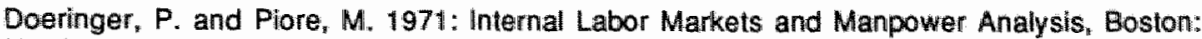
Heath.

Dombrov, G.M. and Tonkal, V.E. 1985: Comparative Analysis and Estimation of Competence of Research Units, Scientometrics, 3-6, 309-25.

Dunn, M.G., Norburn, D., and Birley, S. 1985: Corporate Culture; A Positive Correlation with Marketing Effectiveness, International Journal of Advertising, 65-73.

Durkheim, E. 1960 [1893]: De la division du travail social, Paris: Press Universitaires de France.

Dynamus, A. 1987: Universitair onderzoeksbeleid: Quo vadis? Nijmegen: Katholieke Universiteit.

Elkena, Y., Lerderber, J., Merton, R.K., Thackray, A., and Zuckerman, H. 1978: Toward a Metric of Science: The Advent of Science Indicators, New York: John Wiley.

Etzioni, A. 1961: A Comparative Analysis of Complex Organizations, New York: Froe Press. 1988: The Moral Dimension, Toward a New Economics, New York and London: Free Press.

Fama, E. 1980: Agency Problems and the Theory of the Firm, Journal of Political Economy, 88: $288-307$.

and Jensen, M. 1983b: Separation of Ownership and Control, Journal of Law and Economics, 26: 301-26.

and Jensen, M. 1983b: Agency Problems and Residual Claims, Journal of Law and Economics, $26: 327-49.56$

Farrell, J. and Saloner, G. 1985: Standardization, Compatibility, and Innovation, Rand Journal of Economics, 16, 1, 70-83.

Feyerabend, P. 1975: Against Method. Outline of an Anarchistic Theory of Knowledge, London: Verso.

Fishbein, M. 1979: A Theory of Reasoned Action: Some Applications and Implications, in: Howe, H.E., Jr. and Page, M.M. (Eds) 1979: Nebraska Symposium on Motivation. Lincoin/London: University of Nebraska Press, 65-115.

Fleck, L. 1980 [1935]: Entstehung und Entwicklung einer Wissenschaftlichen Tatsache, Frankfurt a. Main: Suhrkamp.

Fombrun, C.J. 1984: Corporate Culture and Competitive Strategy. In: Fombrun, C.J. ef al. 1984: Strategic Human Resources Management, New York, 203-16.

Franklin, M.N. 1988: The Community of Science in Europe. Preconditions for Research Effectiveness in European Community Countries, Aldershot: Gower/EEC.

Freeman, C. 1982: The Economics of Industrial Innovalion, London: Francis Pinter.

French, L. et al. 1985: Organizational Culture and Climate. In: French, L. et al. 1985: Understanding Human Behavior in Organizations, New York: Harper \& Row, 521-46.

Friedman, M. 1953: The Methodology of Positive Economics, in: Friedman, M. 1953: Essays in Positive Economics, Chicago: University of Chicago Press. 
Friedman, J.W. 1986: Game Theory with Applications to Economics, New York: Oxford University Pless.

Frost, P.J., Moore, L.F., Louis, M.R., Lundberg, C... ${ }_{*}$ and Martin, J. (Eds) 1985:

Organizational Culture, Beverly Hills: Sage.

Galbraith, J.R. 1974: Organization Design: An Information Processing View, Interfaces 3, 2836.

Garfleld, E. 1979: Citation Indexing. Its Theory and Application in Science, Technology, and Humanitles, Now York: John Wiley.

Glick, W.1985: Conceptualizing and Measuring Orglanizational and Psychological Climate: Pitfalls in Multilevel Research, Academy of Management Review, 10, 3: 601-16.

Goldberg, V. 1976: Toward an Expanded Economic Theory of Contract, Journal of Economic Issues, $45-62$.

Goto, A. 1982: Business Groups in a Market Economy, European Economic Review, 53-70.

Gouldner, A.W. 1961: The Norm of Reciprocity, American Sociological Review 161-79.

Graves, P.E., Marchand, J.R., and Thompson, R. 1982: Economics Departmental Rankings: Research Incentives, Constraints, and Efficiency. American Economic Review, 5, 1131-41.

Groenewegen, J. 1989: Planning in een markteconomie, Academisch Proefschrift, Delft: Eburon.

Groot, A.D. de 1969: Methodology. Foundalions of Inferences and Research in the Behavioral Sciences, Amsterdam, Berlin, New York: Mouton Publishers. $230-59$. 1984: The Theory of the Science Forum: Subject and Purport, Methodology and Science, 4,

Groot, T.L.C.M. 1988, Management van universiteiten. Een onderzoek naar de mogelijkheden voor doellmatig en doeltreffend zelfbestuur. Groningen: Wolters/Noordhofl.

Guion, R.M. 1973: A Nole on Organizational Climate, Organizational Behavior and Human Performance, 120-25.

Gupta, J. et al. 1986: A Model for Studying the R\&D-Marketing Interface in the Product Innovation Process, Journal of Marketing, 7-17.

Hall, G. and Howell, S. 1985: The Experience Curve from the Economist's Perspective, Strategic Management Journal, 197-212.

Hardy, C., Langley, A., Mintzberg, $H_{\text {, }}$ and Rose, J. 1984: Sirategy Formation in the University Setting, in: Bess, J.L. 1984: College and University Organization, New York and London: New York Universily Press.

Hare, P. and Wyatt, G. 1988: Modelling the Determination of Research Output in British Universities, Research Policy, 17, 315-28. 
Hayek, F.A. Von 1937: Economics and Knowledge, Economica, 33-54.

1945: The Use of Knowledge in Society, American Economic Review, 35: 519-30.

Hazeu, C.A. 1989: Systeem en gedrag in het wetenschappelijk onderzoek. Een model voor toedeling van taken en verantwoordelijkheden in een multi-niweau systeem, toegepast op het universitaire onderzoek. 's-Gravehage: VUGA Uitgeverij $B$.V.

Heeringen, A. van, and Dijkwel, P.E. 1987: The Relalionships between Age, Mobility and Scientific Productivity, Scientometrics, 5-6, 267-80 (Part D), and 281-93 (Pant II).

Hendrikse, G.W.J. 1988: Economic Concepts Applied to Corporate Culture, Mimeo, Maastricht: Faculteit der Economicshe Wetenschappen.

and Schreuder, H. 1987: Economische organisatietheorieen, ESB, 810-15.

Heiner, R.A. 1983: The Origin of Predictable Behavior, American Economic Review, 4, 56095.

Hennipman, P. 1954: Economisch motiel en economisch principe. Amsterdam: Noord-

Hollandsche Uitgevers Maatschappij.

Heyssel, R. 1984: Constrained Resources in Medical Education and Research, Health Research, $110-16$.

Hicks, G.L. and Redding, S.C. 1983: The Story of the East Asian "Economic Miracle", Euro Asia Business Review, 4, 18-22.

Hirschmann, A.O. 1970: Exit, Voice, and Loyalty, Cambridge: Harvard University Press.

Hoistede, G.H. 1967: The Game of Budget Control, Assen: Van Gorcum.

Hills: Sage.

1980: Culture's Consequences:International Differences in Work-Related Values, Beverly

1981: Management Control of Public and Not-for-Profit Activities, Accounting,

Organizations and Society, 3, 193-211.

(Ed.) 1986: Organizational Culture and Control. Special Issue of Journal of Management Studies, 23, 3.

and Bond, M.H. 1984" Hotstede"s Culture Dimensions: An Independent Validation Using Rokeach's Value Survey, Journal of Cross-Cultural Psychology, 15, 417 433.

and Bond, M.H. 1988: The Confucius Connection: From Cultural Roots to Economic Growth, Organizational Dynamics, Spring, 5-21.

and Spangenberg, J.F.A. 1987: Measuring Individualism and Collectivism at Occupational and Organizational Levels. In: Kagitcibasi, C. (Ed.). Growth and Progress in Cross"Cultural Psychology, Berwyn and Lisse: Swets and Zeitlinger, 113-22.

and Spangenberg. J.F.A. (forthcoming): Technike der Internationale Verglelche. In:

Macharzina, K. und Welge, M.K. (Hrsg.), Handwörterbuch Export und internationale Unternehmung, Enzyklopädie der Betriebswissenschaftslehre, Stuttgart: C.E. Poaschel Verlag.

Neuilen, B., Ohavy, D., and Sanders, G. 1988: Organizational Cultures - Beyond the Fad. Working Paper 88-006. Facully of Economics and Business Administration: Maastricht. 
Hul, H. 1984: Individualism-Collectivism: Theory, Measurement, and its Relation to Reward Allociation, Unpublished Doctoral Thesis, University of Illinois, Urbana-Champaign.

Irvine, J. and Martin, B.R. 1985: Evaluating Big Science: CERN"s Past Performance and Future Prospects, Sclentometrics, 3-6, 281-308.

Itaml, H. 1984: Invisible Resources and Their Accumulation for Corporate Growth, Hitosubashi Journal of Commerce and Management, October, 20-39.

Press.

(with Roehl Th.) 1987: Mobilizing Invisible Assets, Cambridge: Harvard University

Itawa, R. 1982: Japanese Style Management: Its Foundation and Prospects, Tokyo: Asian Productivity Organization.

Jacoby, J. and Olson, J.C. (Eds) 1985: Perceived Quality: How Consumers Vlew Stores and Merchandises, Lexington: Heath.

Jacques, E. 1951: The Changing Culture of a Factory, London: Tavistock...

Jannis, I.L 1971: Groupthink, Psychology Today, 229-34.

Jensen, M.C. 1983: Organizational Theory and Methodology, Accounting Review, 58, 2: 319339.

Jensen, M. and Meckling, W. 1976: Theory of the Firm: Managerial Behavior, Agency Costs, and Ownership Structure, Journal of Financial Economics, 3, 305-60.

Johannesson, R.E. 1973: Some Problems in the Measurement of Organizational Climate, Organizational Behavior and Human Performance, 118-44.

Johnes, G. 1988: Delerminants of Research Output in Economics Departments in British Universities, Research Policy, 171-78.

Jones, G.R. 1983: Transaction Costs, Property Rights, and Organizational Culture: An Exchange Perspective. Administrative Science Quarterly, 3, 454-67.

and Hill, C.W.L. 1988: Transaction Cost Analysis of Strategy-Structure Choice, Strategilc Management Journal, 159-72.

Journal of Management Studies 1986: Special Issue (Organizatlonal Culture and Control, Guest editor: Geerl Hofstede) 23, 3.

Kanter, R.M. 1973: Commitment and Community, Cambridge: Harvard University Press.

Kaen, F.R. and Rosenman, R.E. 1986: Predictable Behawior in Financial Markets: Some

Evidence in Heiner"s Hypothesils, American Economic Review, 212-20.

Kahn, H. 1979: World Economic Development: 1979 and Beyond, London: Croom Helm.

Kahneman, D., Knetsch, J.L., and Thaller, R. 1986: Fairness as a Constraint on Profil Seeking:

Entitiements in the Market, American Economic Review, 4, 731-41.

Kaplan, R.S. 1983: Measuring Manutacturing Performance: A New Challenge for Managerial Accounting Research, Accounting Review, 4, 686-705. 
Kapteyn, P. and Wansbeek. T.J. 1985: Publicaties en kwaliteitsmeting bij economisch onderzoek. In: Becker, H.A. and van Raan, A.F.J. (Red.), Kwaliteit in de wetenschap - een meetbaar begrip? Leiden: DSWO Press.

Keizer, P.K. and Soeters, J. (Red.) 1987: Economie, sociologie en psychologie: visies op integratie. Assen/Maastricht: Van Gorcum.

Keller, R.T. 1986: Predictions of the Performance of Project Groups in R\&D Organizations, Academy of Management Journal, 4, 715-26.

Kerlinger, F.N. 1973: Foundations of Behavioral Research, New York: Holt, Rinehart and Winston.

and Pedhazur, E.J. 1973: Multiple Regression in Behavioral Research, New York: Holt, Rinehart and Winston.

Keys, J.B. and Miller, T.R. 1984: The Japanese Management Theory Jungle, Academy of Management Review, 9: 342-53.

Kilmann, R.H. et al. 1985: Gaining Control of the Corporate Culture, San Francisco: Jossey. Bass.

Kirkbride, P.S. 1987: The 'Culture' of Organizational Culture Research, Asia Pacific Journal of Management, 2, 124-29.

Knight, F.H. 1964 [192\|]: Risk, Uncertainly, and Profit, New York: Harper \& Row.

Koninklijke Nederlandse Academie voor Wetenschappen (KNAW) 1985: Advies voor het Deelpilan Onderzoek van het Disciplineplan Geneeskunde, Amsterdam.

(KNAW) 1988: Advies voor het Deelplan Onderzoek van het Disciplineplan Geneeskunde, Amsterdam.

Koutsoyiannis, A. 1979: Modern Microeconomics, Hong Kang: MacMillan.

Kreps, D.M. 1984: Corporate Culture and Economic Theory, Mimeo, Graduate School of Business, Stanford University.

Kuhn, T.S. 1970 [1962]: The Structure of Scientific Revolutions, Chicago: University of Chicago Press.

Kunst, P. 1986: An Operationalization of Control in Organizational Research, Working paper 86-10, Maastricht: Faculteit der Economische Wetenschappen.

Lakatos, I. 1970: Falsification and the Methodology of Scientific Research Programmes. In: Lakatos, 1. and Musgrave, A. (Eds) 1970: Criticism and the Growth of Knowledge, Cambridge: Cambridge University Press, 91-196.

Lammers, C.J. 1963: Het Koninklijke Instituut voor de Marine. Een sociologische analyse van de inleiding van groepen aspirant-officieren in de Zeemacht Assen: Van Gorcum.

1984: Organisaties vergelijkenderwijs, Utrecht/Antwerpen: Het Spectrum.

1986: De excellente onderneming als organisatiemodel, Harvard Holland Review, 18-27.

and Hickson, D. 1979: Organizations Alike and Unlike. International and Inter-

Institutional Studies in the Sociology of Organizations, London: Roulledge and Keglan Paul. 
Latour, B. and Woolgar, S. 1979: Laboratory Life. The Sociall Construction of Scientific Facts, London: Sage.

Lawrence, P.A. and Lorsch, J.W. 1967: Organization and Environment. Managing Differentiation and Integration. Boston: Division of Research, Graduate School of Business Administration, Harvard University.

Leibenstein, H. 1966: Allocative Efficiency vs. X-efficiency, American Economic Review, 56: 39.2-415.

1980: Beyond Economic Man. A New Foundation for Microeconomics, Cambridge: Harvard University Press. Press.

1987: Inside the Firm. The Inefficiencies of Hierarchy, Cambridge: Harvard University

Leijonhufvud, A. 1981: Information and Coordination. Essays in Macroeconomic Theory. New York: Oxford University Press, 1981, 347-59.

Lewin, K. 1948: Resolving Social Conflicts. Selected Papers on Group Dynamics, London: Harper \& Row.

1951: Field Theory in the Social Sciences, Westport: Greenwood.

Lippitt, R., and White, R.K. 1939: Patterns of Aggressive Behavior in Experimentally Created Social Climates, Journal of Social Psychology, 271.99.

Lieberman and Montgomery, 1988.. First Mover Advantages, Siralegic Management Journal.

Liebowitz, S.J. and Paimer, J.P. 1984: Assessing the Relative Impacts of Economic Journals, Journal of Economic Literature, 77-88.

Liebowitz, S.J. and Paimer, J.P. 1988.' Assessing Assessments of Economics Departments, Quarterly Review of Economics and Business, 28, 2: 88-113.

Likert, R. 1961: New Patterns of Management, New York: McGraw-Hill.

Lippman, S.A. and Rumelt, R. 1982: Uncertain Imitability: An Analysis of Interfirm Differences in Efficiency under Competition, Bell Journal of Economics and Management Science, Autumn, 418-38.

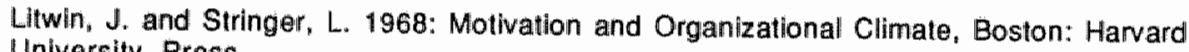
University Pross.

Llewellyn, K.N. 1931: What Price Contract? Yale Law Journal, 704-51.

Lorsch, J.W. 1985: Strategic Myopia: Culture as an Invisible Barrier to Change, in: Kilmann, F. et al (Eds), Gaining Control of the Corporate Culture. San Francisco, London: Jossey-Bass: 84-102.

Lukes, S. 1978; Methodological Individualism Reconsidered. In: Lukes, S. 1978: Essays in Social Theory, London; Basingstoke, 177-87. Macaulay, S. 1963: Non-Contractual Rellations in Business: A Preliminary Study, American
Sociological Review, 55-66. MacNeil, 1.R. 1974: The Many Futures of Contract, Southern Californian Law Review, 69 11-
816 . 
1978: Contracts: Adjustment of Long-Term Economic Relations under Classical, Neoclassical, and Contract Law, Northwestern University Law Review, 854-906.

Maitland, I., Bryson, J., and van de Ven, A. 1985: Sociologists, Economists, and Opportunism, Academy of Management Review, 59-65.

March, J.G. 1987: Ambiguity and Accounting: The Elusive Link between linformation and Decision Making. In: Cushing, B.E. 1987: Accounting and Culture, New Yark: American Accounting Association, 31-49.

and Simon, H.A. 1958: Organizations, New York, London and Sydney: John Willey.

"Cohen, M.D., and Olsen, J.P. 1972: A Garbage Cab Model of Organizational Choice, Administrative Science Quarterly, 1.

Marschalk, J. and Radner, R, 1972": Economic Theory of Teams, New Haven and London: Yale University Press.

McGuire, A., Henderson, J., and Mooney, G. 1988: The Economics of Heallh Care, London and New York: Routledge and Kegan Paul.

Mckean, 1975, im: Phelps, Ex. (Ed.) 1975: Alluism, Morality, and Economic Theory, New York: Russell Sage Foundation.

Meade, J. 1952: External Economies and Diseconomies in a Competitive Situation, The Economic Jourmal, March, 56-67.

Merchant, K.A. 1985: Control un Business Organizations, Boston." Pitman.

Merton, R.K. 1982: The Normative Struclure of Science. In: Merton, R.K. 1982: Social Research and the Practizing Professions, Cambridge: Abt Books, 3-16

and Gieryn 1982: Institutionalized Altruism: The Case of the Prolessions. In: Merton, R.K. 1982: Social Research and the Practizing Protessions, Cambridge: Abt Books, 109-34.

Miller, D. and Friesen, P. 1984: Organizations: A Quantum View, Englewood Cliffs: Prentice Hiall.

Ministerie van Onderwijs en Wetenschappen (MOW) 1985: Hoger onderwijs: autonomie en kwaliteil (HOAK), 's-Gravenhage: Staatsuitgeverij.

1987: Hoger onderwijs- en onderzogksplan (HOOP), "s-Gravenhage: Staatsultgeverij.

1988a: Dutch Higher Education and Research. Major Issuies, Facts and Figures, 's'

Gravenhage: Staatsuitgeverij. Office.

1988b: Towards a Science Policy for the 1990s. Working Paper. The Hague: State Printing

1989a: 10 jaar wetenschapsbeleid (themanummer). Wetenschapsbeleid, 10 ,

December/Januari.

1989b: Internationalisation of Education and Research. Policy Memorandum. The Hague: State Printing Office.

Mintzberg, H. 1976: Planning on the Left Side and Managing on the Right, Harvard Business Review, July-August, 49-58. 
1979: The structuring of Organizations, Englewood Cliffis: Prentice-Hall.

1983: The Missionary. In Mintzberg, H. 1983: Power in and Around Organizations,

Englewood Cliff: Prentice Hall, 367-87.

and Waters, J.A. 1985: Of Strategy: Deliberate and Emergent, Strategic Management Journal, $257-72$.

$11-32$.

1987: The Strategy Concept I: Five P's for Strategy, California Managment Review. 1 ,

Moed, H.F., Burger, W.J.M., Frankfurt, F.G., and van Raan, A.F.J.G. 1985a: The Use of

Bibliometric Data for the Measurement of University Research Performance. Research Policy, 131.149.

1985b: The Application of Bibliometric Indicators: Important Field- and Time-Dependent Factors to be Considered, Scientometrics, 3-4, 177-203.

1985c: A Comparative Study of Bibliometric Past Performance and Peer Judgement, Scientometrics, $3-4,149-49$.

Morita, A. (with Rheingold, E.M. and Shimomura, M.) 1987: Made in Japan. Akio Morita and Sony: Reading: Fontana.

Murnane, R.J. and Nelson, R. 1978: Production and Innovation when Techniques are Tacit: The Case of Education, Journal of Economic Behavior and Organization, 353-73.

Nagatani, 1984, in: Aok, M. (Ed.) 1984: The Economic Analysis of the Japanese Firm, Amsterdam, New York "Oxford: North-Holland.

Nagel, E. 1974: The Structure of Science. Problems in the Logic of Scientific Explanantion, London: Routledge and Kegan Paul.

Narin, F. 1987: Ciltation Analysis. Bibliometric Techniques in the Evaluation of Research Programs, Science and Tochnology Policy, 2, 99-106.

Nederhof, A.J. and van Raan, A.F.J. 1987: Peer Review and Biblliometric Indicators of Scientific Performance: A Comparison of Cum Laude Doctorates with Ordinary Doctorates in Physics, Scientometrics, 5-6.

Nelson, R. and Winter, S.G. 1982: An Evolutionary Theory of Economic Change, Cambridge and London: Belknap Harvard.

Nielsen, R.P. 1988: Cooperative Strategy, Strategic Mangement Journal "9, 475-492.

Nijhuis, F.J.N."1984: Beoordeling van organisatiekenmerken, Academisch Proefschrift, Maastricht: Rijksuniversittelt Limburg.

Nijhuis, F.J.N. and Spangenberg, J.F.A. 1986: The Impact of Interdisciplinarity on Research Performance, Mimeo, Maastricht: Faculteit der Economische Wetenschappen.

Nijkamp, P. 1977: Theory and Application of Environmental Economics, Amsierdam. New York, Oxford: North-Holland.

Noreen, E. 1988: The Economics of Ethics: A New Perspective on Agency Theory, Accounting, Organizations and Society, 4, 359-69.

Norusis, M.J. 1985: SPSS Advanced Statistics, New York: McGraw-Hill. 
Nunually, J.C. 1981: Psychometric Theory, New Delphi: McGraw-Hill.

Okrasa, W. 1987: Differences in Scientific Productivity of Research Units: Measurement and Analysis of Output Inequality. Scientometrïcs, 3-4, 221-239.

Okun, A. 1981: Prices and Quantities: A Macroeconomic Analysis ${ }_{n}$ Washington: The Brookings Institute.

Olson, M. 1965: The Logic of Collective Action, Cambridge: Harvard University Press.

Oppenheim, A.N. 1966: Questionnaire Design and Attitude Measurement, New York: Basic Books.

Organisation for Economic Co-operation and Development (OESD: Directorate for Science, Technology, and Industry) 1986: Review of National Science and Technology Policies: The Netherlands, Paris.

Organizational Dynamics 1983: Special Issue on Organizational Culture, Autumn.

Oster, S. 1980: The Optimal Order for Submitting Manuscripts, American Economic Rieview, $444-48$.

Ouchi, W.G. 1977: The Relationship between Organizational Structure and Organizational Control, Administrative Science Quarterly, March, 95-113.

1979: A Conceptual Framework for the Design of Organizationall Control Mechanisms, Management Science, 9, 833-48.

1980: Markets, Bureaucracies, and Clans, Administrative Science Quarterly, 120-141.

1981: Theory Z. How American Business can meet the Japanese Challenge, Reading:

Addison-Wesley.

and Johnson, J.B. 1978: Types of Organizational Control and their Relationship to Emotional Well-Being, Administrative Science Quarterly, 2, 293-317.

Panzar, J.C. and Willig, R.D. 1975: Economies of Scale in Multi-Output Production, Quarterly Journal of Economics, August, 481-93.

1981: Economies of Scope, American Economic Review, May, 268-72.

Pascale, A.T, and Athos, A.G. 1981: The Art of Japanese Management: Applicalions for American Executives, New York: Simon and Schuster.

Pelz, D. and Andrews, F.M. 1976: Scientists in Organizations. Productive Climattes for Research and Development, New York, London, and Sydney: John Wiley.

Pen J. 1982: Prioriteiten in het economisch onderzoek. In: Wolff-Albers, A.D. en Crombagn H.F.M. 11982: Visies op onderzoek in enkele sociale wetenschappen. Pre-adviezen ten behoeve van de beleidsnota Maatschappij- en Gedragswetenschappen, "s-Gravenhage, 25-40.

Pennings, J.M. 1975: The Relevance of the Structural-Contingency Model for Organizational Effectiveness, Administrative Science Quarterly, 20, 393-410.

and Gresov, C.G. 1986: Technoeconomic and Structural Correlates of Organizational Culture: An Integrative Framework, Organization Studies, 7, 317-34. 
Peters, T.J. and Waterman, R.H. 1982: In Search for Excellence: Lessons from America's Besit Run Compariles, New York: Harper \& Row.

Pfeffer, J. 1986: Organizational Demography: Implications for Management, California Management Rewlew, 2,67-81.

Phelps, E.S. (Ed.) 1975: Altruism, Morality, and Economic Theory, New York: Russell Sage Foundation.

Phelps, E.S. 1985: Political Economy. An Introductory Text, New York: Norton and Company.

Philipsen, H. 1969: Steekproeven, Leiden: Universitaire Pers.

Poel, J. wan de 1985: Judgement and Control. Individual and Organizational Aspects of Pertormance Evaluation, Groningen: Wolters-Noordhoff.

Polanyi, M. 1962 [1958]: Personal Knowledge: Towards a Post Critical Philosophy, London: Routledga and Kegan Paul.

Poole, S.M. 1986: Communication and Organizational Climates. In: McPhee, R.D. and Tompkins, Ph. (Eds), Organizational Communication, Beverly Hills and London: Sage, 79-108.

Popper, K.R. 1966 [1959]: The Lagic of Scientific Discovery, London: Hutchinson.

Porter, M. 1980: Competitive Stralegy. Techniques for Anallyzing Industries and Compelitors, New York: Froe Press.

Porter, A.L., Chubin, D.E., and Xiao-Yin Jin, T. 1988: Citations and Scientific Progress: Comparing Bibliometric Measures with Scientific Judgements, Scientometrics, 3-4.

Prakke, F. 1974: The Management of the R\&D-Marketing Interface and Its Effect on Successful Technological Innovation in Large Industrial Innovations, PhD Thesis, Boston: MIT.

Prescott, E. and Visscher, M. 1980: Organizational Capital, Journal of Political Economy, 3, $446-61$.

Price, J.L. and Mueller, C.W. 1986: Handbook of Organizational Measurement, Marshfield: Pitman, 1986.

Putlerman, L. 1987: The Economic Nature of the Firm, Cambridge: Cambridge University Press.

Raad van Advies voor the Wetenschapsbeleid (RAWB) 1983a: De omwang en aard van het gezondheidsonderzoek in Nederland, 's-Gravenhage: Stalatsuitgeverij.

(RAWB) 1983b: De prestaties van het Nederlandse gezondheidszorgonderzoek, is-Gravenhage: Staatsuitgeverij.

Aedding, S.G.. 1977: Managerial Mediation and the Role of Organizational Subcultures, Mimeo, Hong Kong: Hong Kong University.

Revans, R.W. 1964: Standards for Morale, Cause and Effect in Hospitals, London: Published for the Nuffield Provincial Hospitals Trust by the Oxford University Press.

Reynolds, P.D. 1986: Organizational Culture as Related to Industry, Position, and Performance, Journal of Management Studies, $3,333-46$. 
Rigter, H. 1986: Evaluation of Periormance of Health Research in the Netheriands, Research Pollicy, $15,33-48$.

Ritti, R.R. 1968: Work Goals of Scientists and Engineers, Industrial Relations, 7, 2, 118-31.

Rumelt, R. 1987: Theory, Strategy, and Entrepeneurship. In* Teece, D. (Ed.) 1987: The Competitive Challenge. Cambridge: Ballinger, 137-58.

Robinson, W.S. 1950: Ecological Correlations and the Behavior of Individuals, American Sociological Review, 15, 351-57.

Samuelson, P.A. 1980: Economics, Tokyo: McGraw-Hill.

Sauer, R.D. 1988: Estimates of the Returns to Quality and Coauthorship in Economic Academia, Journal of Political Economy, 96, 4: 855-866.

Schaufeli, W. 1988: Unemployment and Psychological Health, An Investigation among Dutch Professionals, Ph.D. Thesis, Groningen.

Schein, E. 1983: The Role of the Founder in Creating Organizational Culture, Organizational Dynamics, Symmer, 13-28.

2. 3-16.

1984: Coming to a New Awareness of Organizational Culture, Sloan Management Review,

1985: Organizational Culture and Leadership, San Francisco: Jossey Bass.

Schelling, T.C. 1963: The Strategy of Conflict, Cambridge: Harvard University Press.

1978: Micromotives and Macrobehavior. Fels Lectures on Public Policy Analysis, New York and London: Norton.

Scherer, F.M. 1970: Industrial Market Siructure and Economic Performance, Chicago: Rand MoNally.

Schneider, B. 1980: The Service Organization: Climate is Crucial, Organizational Dynamics, Autumn, 52-65.

and Bartlett, C.J. 1970: Individual Performance and Organizational Climate II, Personnel Psychology, 23: 493-512.

and Snyder, R. 1975: Some Relationships between Job Satisfaction and Organizattonal Climate, Journal of Applied Psychology, 60, 318-28.

and Reichers, A.E. 1983: On the Etiology of Climates, Personnel Psychology, 19.39.

and Bowen, D.E. 1985: Employee and Customer Perceptions of Service in Banks:

Replication and Extension, Journal of Applied Psychollogy, 3, 423-33.

Parkington, J.J., and Buxion, V.M. 1980: Employee and Customer Perceptions of Service in Banks, Administrative Sclence Quarterly, 25, 252-67.

Schreuder, H. 1981: Maatschappelijke verantwoordelijkheid en maatschappelijke berichlgeving van ondernemingen. Bedriffseconomische Monografieën 62, Leiden: Stenfert Kroese.

1983: Economic Theories of Organization, Research Memorandum, Maastricht: Faculteilt

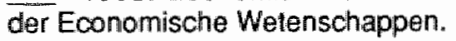


Schreuder, H. "Spangenberg, J.F.A., Kunst, P., Romme, S. 1988: The Structure of Organizations. "An Empirical Test of Minizberg"s Configurational Hypothesis, Brussels:

European Institute for Adwanced Studies in Management.

Schwartz, H. and Davies, S. 1981: Matching Corporate Culture and Business Strategy, Organizational Dynamics, Summer, $30-48$.

Schwoizer, A.Th. (chairman), Hulsmann, W.C., Mandema, E. Querido, A., Touber, J.L., Wellens, H.J.J., and van Dorp, C.A. (secretary) 1987: Commentaar en aanbevelingen van de begeleiding scommissie. In: Bally, Y.W., Spangenberg, J.F.A. and Silarmans, R. 1987:

Achtergronden van de kwalliteit van het patièntgebonden onderzoek. $s$-Gravenhage:

Staatstuitgeverii), I-XVII (deell I).

Selznick, Ph. 1957: Leadership in Administration, New York: Harper \& Row.

Sen, A. 1977: Rational Fools: A Critique of the Behavioral Foundations of Economic Theory" Philosophy and Public Affairs, 6, 317-344.

1983: Choice, Welfare, and Measurement, Oxford: Basill Blackwell.

1989: in: Klamer, A. 1989: A Conversation with Amartya Sen, Journal of Economic Perspectives, $3,135-50$.

Shepherd, W.G. 1979: The Economics of Industrial Organization, Englewood Cliffs: PrenticeHall, 1979.

Simon, H.A. 1976 [1954]: Administrative Behavior. A Sludy of Decision Making Process in Administralive Organization, New York and London: Free Press.

1982: Comparatiwe Statislics and the Measurement of Efficiency. In: Simon, H.A. 1982: Models of Bounded Aationality, Vol. I: Economic Analysis and Public Policy, Boston: MIT Press.

Smith, A. 1976 [1759]: The Theory of Moral Sentiments (Ediled by Raphael, D.D. and Macfie, A.K.), Oxford: Clarendon Press.

1937 [1776]: The Wealth of Nations (Edited by Cannan, E.). New York: Random House.

Soeters J. 1986: Excellent Companies as Social Movements, Journal of Management Studies, 3. $299-312$.

and Schreuder, H. 1986a: Nationale en organisatieculturen in accountaniskantoren, Sociologische Gids, 100-21.

and Schreuder, H. 1986b: Werkprestaties in accountaniskantoren, Maandbilad voor

Accountancy en Bedriffshuishoudkunde, 11, 75-85.

and Schreuder, H. 1988: The Interaction between National and Organizational Culture in Accounting Firms, Accounting, Organizations, and Society, 1, 75-85.

Solla Price, J. Da, 1963: Little Science. Big Science, New York: Columbia University Press.

Spangenberg, J.F.A. and Jaspers, P. 1987. The R\&D-Marketing Interface within the Framework of the New Product: Development Process and the Product Llfe Cycle. Abstract in: Proceedings National Academy of Management, New Orleans.

Bally, Y.W., Starmans, R., Breemhaar, B., Nijhuis, F.J.N., and van Dorp, C.

(forthcoming): Prediction of Scientific Performance in Clinical Medicine, Research Policy. 
Buijink, $W_{\mathrm{c}}$ and Alfenaar 1989: Some lncentives and Constraints of Scientific

Performance in Departments of Economics, Part I: Predictor-Criterion Relations,

Scientlometrics, Vol. 17, No. 5-6 (forthcoming)

Breemhaar, B., Nijhuis, F.J.N., and W. Alfenaar 1989: Some Incenives and Consitraints of Scientific Performance in Departments of Economics, Part II: Validity and Sensilivity Analysis, Scientometrics, Vol. 17, No. 5-6 (forthcoming),

Stahl, M.J, Leap, T.L., and Wei, Z.Z. 1988: Publication in Leading Management Journals as a Measure of Institutional Research Productivity, Academy of Management Journal, 3, 707-20.

Staten, M.E. and J. Umbeck, Information Costs and Incentives to Shirk: Disability Compensation of Air Traffic Controllers, American Economic Review, 72, 5: 1023-37.

Staw, B.M. 1984: Motivation Research versus the Art of Faculty Management. In: Bess, J.L (Ed.) 1984: College and University Organization, New York and London, 63-80.

Stigler, G.J. 1958: The Economics of Scale, Journal of Law and Economics, 1, 54-71.

Stiglitz, J.E. 1987: Human Nature and Economic Organization, unpublished manuscript (Jacob Marschak Lecture).

Swales, J. 1986: What has happened to Academic Medicine? The Lancet, May, 1194-96.

Swedish Natural Science Research Council (SNSRC) 1981: International Evaluations of Research Projects Supported by the SNSRC. Summary of Reports, Achiewements, and Criticisms, 1977-80, Stockholm.

Tachibanaki, 1984, in: Aoki, M. (Ed.) 1984: The Economic Analysis of the Japanese Firm, Amsterdam, New York, Oxford: North-Holland.

Takatera, S. and Harimoto, M. 1987: The Cultural Significance of Accounting in Japan. Paper presented at the Workshop on Accounting and Culture, Brussels: European Inslitute for Advanced Studies in Management.

Tatsuoka, M.M 1970: Discriminant Analysis: The Study of Group Differences ${ }_{n}$ Champaign: Institute for Personality and Ability Testing.

1971: Multivariate Anallysis, New York: John Wiley.

Teece, D.J. 1984: Economic Analysis and Strategic Management, California Management Review, Spring, B7-110.

1980: Economies of Scope and the Scope of the Enterprise, Journal of Economic Behavior and Organization, 1, 223-57.

(Ed.) 1987: The Competitive Challenge, Strategies for Industrial Innovation and Renewal, Cambridge: Ballinger.

Thaler, R. 1980: Towards a Positive Theory of Consumer Choice, Journal of Economic Behavior and Organization, 1 (1980): 39-60.

The Economist 1985: The Importance of Being Nice, Retaliatory. Forgiving, and Clear, November, 99-102.

The Lancet 1979: Academic Medicine - Threatened Institution (Editorial), Sept. 29,677-81.

The New Palgrave 1987: A Dictionary of Economics, Basingstoke: MacMillan. 
Titmuss, R.M. 1970: The Gift Relationship. From Human Blood to Social Policy , New York: Allen \& Unwin.

Triandis, H.C. (Ed.) 1972: The Analysis of Subjective Culture, New York: John Wiley.

1985: Cross-Cultural Industrial and Organizational Psychology. Mimeo, Champaign: University of Illinols.

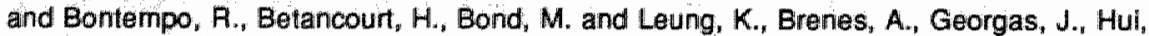

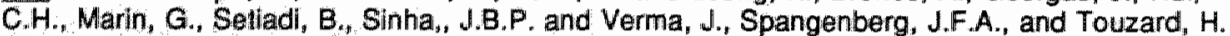
and de Montmollin, G. 1986: The Measurement of the Etic Aspects of Individualism and Collectivism across Cultures, Australian Journal of Psychology, 3, 257-67.

Tversky, A. and Kahneman, D. 1974: Judgement under Uncertainty: Heuristics and Biases. Science, September, 1124-31.

U.S. House of Representatives 1980: Toward the Endless Frontier. History of the Committee on Science and Technology, 1957-79, Washington: U.S. Government Printing Office.

Ven, A.H. Van de 1986: Central Problems in the Management of Innovation, Management Sclence, 5, 590-607.

Ven, A.H. Van de, and Ferry, D.C., 1985: Measuring and Assessing Organizations, New York: John Wiley.

Vendrilk M. 1988: Preference Drifts in Labor Supply; Towards an Integration of Economic and Psychological Motivation Theories, Research Memorandum 88-029. Maastricht: Faculteit der Economische Wetenschappen.

Verkenningscommissie Economische Wetenschappen (VEW) 1986: Academisch economisch onderzoek in Nederland: productie, productiviteit en profilering. Eindrapport van de VEW, 's-Giravenhage: Staatsuitgeverij.

Vinkler, P. 1986: Management System for a Scientific Research Institute Based on the Assessment of Scientific Publications. Research Policy, 15, 77-87.

Vroom, V.H. 1984 : Leaders and Leadership in Academia, in: Bess, J.L. (Ed.) 1984: College and

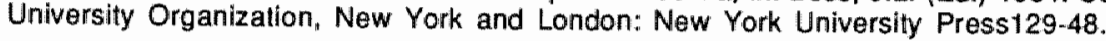

Warwick, D.P. and Osherson, S. 1973: Comparative Research Methods, Englewood Cliffs:

Prontice Hall.

Wobb, E.J., Campbell, D.T.* Schwartz, R.D. and Sechrest, L. 1966: Unobtrusive Measures:

Mon-Reactive Measures in the Social Sciences, Chicago: Rand McNally.

Weber, M. 1956 [1922]: Dle Veralltaeglichung des Charisma, in: Weber, M. [1922], Wirtschaft und Gesellschaft, Tuebingen: Mohr.

_ 1976 [1930]: The Protestanlic Ethic and the Spirit of Capitalism, London: Allen \& Unwin.

Weick, K.E., 1984: Contradictions in a Community of Scholars: The Cohesion-Accuracy

Tradeoff, In: Bess, J.L. (Ed.), College and University Organizalion, New York and Londlon: New York University Press: 15-30.

1985: The Significance of Corporate Culture, in: Frost, P.J. ef al. (Eds): Organizational Culture. Beverly Hills: Sage, 381-89. 
1987: Organizational Cufture as a Source of High Reliability, Callfornia Management Rewiew, 2, $112-27$.

Whittey, R.D. 1984: The Social and Intellectual Organization of the Sciences, Oxford: Oxford University Press.

Wilkins, A.L. and Ouchi, W.G. 1983: Efficient Cultures. Exploring the Relationship between Culture and Economic Performance, Administrative Science Quarterly, 28, 468-81.

Wilkins, A.L. and Patterson, K.J. 1985: You Can't Get There From Here: What Will Make Culture-Change Projects Fall, in: Kilmann, ef al. (Eds), Gaining Control of the Corporate Culture, San Francisco, London: Jossey-Bass: 262-91.

Williamson, O.E. ,1973: Some Nates on the Economics of Almosphere, Discussion Paper \#29, Fels Center of Government, University of Pensylvania: Philadelphia, March.

Press.

1975: Markets and Hierarchies. Analysis and Antitrust Implications, New York: Free

1979: Transaction Cost Economics: The Governance of Contractual Relations, Journal of Law and Economics, 22, 233-61.

1981: The Modern Corporation: Origins, Evolution, Atributtes, Journal of Economic Lititerature, $1537-68$.

1983: Credible Commitments: Using Hostages to Support Exchange, American Economic Review, June, 519-40.

1985: The Economic Institutions of Capitalism. Firms, Markels, Relational Contracting. New York: Free Press.

1987: Transaction Cost Economics: The Comparative Contracting Perspective, Journal of Economic Behavior and Organization.

1988: Corporatte Finance and Corporate Governance, The Journal of Finance, $3_{\sharp} 567-591$.

and Ouchi, W.G. 1981: The Markets and Hierarchies Perspective: Origins, Implications, Prospects. In: Van de Ven, A. and Joyce, W.F. (Eds) 1981: Assessing Organization Design and Performance, New York: John Wiley.

Wachter, M.L., and Harris, J.E. 1975: Understanding the Employment Relation: The Analysis of Idiosyncratic Exchange, Bell Journal of Economics, Spring, 250-280.

Winter, S. 1987: Knowledge and Competence as Strategic Assets, in: Teece, D. (Ed.) 1987: The Competitive Challenge, Strategies for Industrial Innovation and Renewal, Cambridge: Ballingler, $159-8.4$.

Witteloostuijn, A. van 1988: Maximising and Satisficing. Opposite or Equivalent Concepls? Journal of Economic Psychology 9, 289-313.

Wong, G.Y. and Bilmbaum, Ph. H. 1988: Impact of Culture on Organizational Structure of Banks in Hong Kong, Mimeo, Hong Kong: Department of Management Studies "Hong Kong University.

Wittgenstein, L., 1978: Lectures and Conversations (Ediled by C. Barrelt), Oxford: Basill Blackwell. 
Yao, D.A. 1988: Beyond the Reach of the Invisible Hand: Impediments to Economic Activity, Market Failures, and Profitability, Strategic Management Joumal, 57-70.

Zohar, D. 1980: Safety Climate in Industrial Organizations: Theoretical and Applied Implications, Journal of Applied Psychology, 65, 96-102.

Zuckerman, H. 1977: Scientific Elltes. Nobel Laureates in the U.S., New York: Free Press. 


\section{Appendices}

\section{1: List of Interviews}

Interviews were held with research managers working in (i) multinational firms, and (ii) large governmental research institutes, with (iii) agents from governmental research councils, and (iv) with (high performing) university professors. Most of the interviews were held in the period January-June 1986. The average length of an interview was 2.5 hours. The main topics discussed were: performance evaluation of R\&D/scientific research, facilitators and inhibitors of R\&D/ scientific research in the public and privale sector, contribution of R\&D to the company's welfare (only private sector).

(i) Industry

- Pannenborg, PHILIPS

- Kramers, AKZO

- Revallier, DSM

- Houwink, ORGANON

- de Flines, GIST BROCADES

- Beckers, SHELL

(ii) Large Governmental Research Institutes

- Kistienmaker, FOM

- Chang, FOM

- Le Pailr, NTW

- Rórsch, TNO 
(iii) Governmental Advisory Councils

- Van Bueren, RAWB

- Van der Spiegel, Ministry of Education and Sciences

(iv) University departments

- Dee Zeeuw, Agricultural University, Wageningen

- Allessie, Department of Physiology (RL), Maastricht

- Querido, (Emeritus professor) University Hospital Leiden

- Kapteyn, CentER/Department of Econometrics (KUB), Tilburg

- Does, Department of Medical Information and Statistics (RL), Maastricht 


\section{2: Questionnaire Scale Items}

Ghapters 5 and 7 have presented the operationalization of all variables that are measured by one item. The operationalization of the 'scale' variables that have been measured by more than one item are presented in the appendix. The operationalization of VAR 12 ( work-related culture) is given in Holstede (1980: 419-42.2)

(" item study $1 ; * *$ item study $11 ; R=$ items were recoded in the data analysis)

\section{VAR 1: Human Resources}

De huidige personeelscapaciteit om het onderzoek met succes uit te voeren is ontoereikend (12-3-4-5) De huidige personeelscapaciteil om het onderzoek met succes uit te voeren is toereilkend"

Het onderzoeksteam van de vakgroep is te klein om het huidige onderzoek met succes uit te voeren 1-2-3-4-5 Het onderzoeksteam is groot genoeg om het huidige onderzoek met succes will te voeren

De vakgroep beschikt over een kwalititalief zwak anderzoeksteam (1-2-3-4-5) De vakgroep beschikt over een kwalitatief goed onderzoeksiteam

\section{VAR 4-5: Time Research / Non-Research}

Hoeveel tijd hereft $u$ het afgelopen kalenderjaar aan de volgende activiteiten besteed (totale werktijd is $100 \%$ ?

1. onderzoek

$\ldots \%$

2. patientenzorg binnen de eigen instelling (academisch zlekenhuis)*

$\ldots \%$

3. patientenzorg buiten de eigen instelling*

...\%

4. Onderwijs en training

$\ldots \%$

5. Bestuur en adminilstratie

$\ldots \%$

6. Maatschappelijke dienstverlening (inclusief advieswerk) ${ }^{* *}$ 


\section{VAR 6: Capital Resources}

Het huidige budget van de vakgroep is ontoereikend orm het anderzoek met succes uit te voeren $(1-2-3-4-5)$ Hel huidige budget van de vakgroep is toereikend om hell onderzoek met succes wit le voeren

De vakgroep beschikt niet over een ruim vakgroepsfonds (bijvoobeeld vanuit de particuliere patientenzorg) dat woor onderzoek kan worden aangewend $(1-2-3-4-5)$ De vakgroep beschikt over een ruim vakgroepfonds dall voor onderzoek kan worden aangewend"

\section{VAR 11 Innovative Climate}

In het algemeen heerst er een innovatieve sfeer en pioniersmentalitelit binnen de vakgroep ( 1 2-3-4-5) Er heerst een weinig innovatieve sfeer binnen de vakgroep ( $R$ )

Het onderzoek wordt door iedereen binnen de vakgroep met veel lloewijding verricht (1/-2-34-5) Het idee bestaat dat ledereen in de vakgroep alleen werkt om de kost te verdienen (R)

Aan bijna elk nieuw idee over onderzoek wordt gepast aandacht besteed (1-2-3-4-5) Aan zeer weinig nieuwe ideëen over onderzoek wordt gepaste aandacht besteed ( $R$ )

Nieuwe ideëen van junior stafleden worden oven serious genomen als de ideëen van senion stafleden (11-2-3-4-5) Nieuwe ideeen worden alleen serieus genomen indien zij afkomstig zijn van senior stalleden (A)

In onze vakgroep worden zeer vaak anderzoeksbijeenkomsten gehouden (1-2-3-4-5) In onze vakgroep worden zeer zelden onderzoeksbileenkomsten gehouden ( $R$ )

\section{VAR 12 Publication Climate}

in onze vakgroep komt iedereen $\tan$ onderzoek toe (1-2-3-4-5) in onze vakgroep komt niemand aan onderzoek toe $(\mathrm{P})$

In onze vakgroep worden iedereen aangemoedigd om onderzoek te publiceren $(1-2-3-4-5)$ in onze vakgroep worden mensen niet aangemoedigd om onderzoek te publiceren $(R)$

In onze vakgroep wordt publiceren in internationale tijdschriften aangemoedigd (1-2-3-4-5) In onze vakgroep wordt publiceren in internationale tijdschriften niet aangemoedigd (R) 
VAR 14-15: Research Management

Ik ben zeer tevreden met milin directe supervisor mib.t. zijn haar (...) (1-2-3-4-5) ontevreden met mijn directe supenvisor m.b.l. zijn/haar (...):

\section{VAR 14: Craftsmanship Supervisor}

professionele onderzoeksbekwaamheid $(R)$

$1 \cdot 2 \cdot 3-4 \cdot 5$

kennis van het onderzoeksgebied waarop de vakgroop actief is $(R)$

$1 \cdot 2 \cdot 3 \cdot 4 \cdot 5$

\section{VAR 15: Leadership Supervisor}

persoonlijkheid en karakter (R)

leiderschapskwaliteiten (R)

de hoeveelheid onderzoek die hil/zil verricht $(\mathbb{R})$

ondersteuning van mijn onderzoek (R)

enthousiasme voor het onderzoek van de vakgroep $(\mathrm{R})$
$1-2-3-4-5$

$1-2 \cdot 3-4 \cdot 5$

$1-2 \cdot 3-4 \cdot 5$

$1-2-3-4-5$

$1-2-3-4-5$

(supervisoren worden verzocht de bovenstaande vragen niet te beantwoorden)

\section{VAR 16: Motivatlon}

Ik ben liever een goede onderzoeker dan een goede arts*/docent** (1-2-3-4-5) Ik ben llever een goede arts*/docent"** dan een goede onderzoeker $(R)$

In de vakgroep wordt onderzoek hoger gewaardeerd dan patientenzorg */onderwils" * (1-2-3" 4-5) In de vakgroep wordt patientenzorg*/onderwijs"** hoger gewaardeerd dan onderzoek (R)

Mijn routine-patiëntenzorgtaken zijn interessanter dan mijn onderzoekstaken (1-2-3-4-5) Mijn onderzoekstaken zijn interessanter dan mijn routine-patiöntenzorgtaken * $(\mathrm{R})$

Ik verricht op vrijwillige basis meer overuren voor onderzoek dan voor routine palientenzorg (1-2-3-4-5) ik verricht op wrijwillige basis meer overwerk voor routine-patientenzorg dan voor onderzoek " $(R)$

Ik steek meer energie in mijn onderzoekslaken dan in mijn routine-patientenzorgtaken (1-23-4-5) Ik steek meer energie in mijn patièntenzorgtaken dan in mijn onderzoekstaken* (R). 
Ik heb de afgelopen maanden meer pogingen ondernomen om mijh onderzoeksprestaties le verbeteren dan mijn rouline-patientenzorgprestaties (1-2-3-4-5) ik heb de afgelopen maanden meer pogingen ondernomen om mijn patientenzorg te verbeteren dan mijn onderzoeksprestaties (R)

\section{VAR 17: Expectation of Rewards (and Punishments)}

Als $u$ goede onderzoeksprestatles levert, hoe waarschijnlijk is het dan dat (...)

1 witgesloten

2 wrij onwaarschijnilik

$3=$ de kans dat dit gebeurt is $50 \%$

$4=$ vrij waarschijnlijk

$5=$ viljwel zeker

u waardering krijgt voor uw onderzoek

(bijvoorbeeld extra periodiek)

$1-2 \cdot 3-4-5$

u promotie maakt in uw vakgroep (gesteld dat dit mogelijk is)

$1-2-3-4-5$

Als u geen goede onderzoeksprestaties levert, hoe waarschijnlijk is het dan dat:

$\mathrm{u}$ berispt wordt, of te horen krijgt dat $\mathrm{u}$ beter onderzoek moet

afleveren

$1-2 \cdot 3-4 \cdot 5$

uw kansen op een goede loopbaan in uw vakgroep afnemen

$1 \cdot 2 \cdot 3 \cdot 4 \cdot 5$

Als u uw patlentenzorgtaken"/onderwilstaken*" goed uitvoert, hoe waarschijnlijk is het dan dal u:

waardering krijgt voor uw onderwijs

(bijvoarbeald extra periodiek)

$1 \cdot 2 \cdot 3-4 \cdot 5$

promotie maakt in uw vakgroep (gesteld dat dit mogelijk is)

$1 \cdot 2 \cdot 3 \cdot 4 \cdot 5$ 
Als u uw routine-patiêntenzorgtaken niet goed uitwoert, hoo waarschijnlijk is het dan dal $u^{*}$ :

berispt wordt, of te horen krijgt dat u beter werk moet afleveren

uw kansen op een goede loopbaan in uw vakgroep afnemen
$1-2-3 \cdot 4-5$

$1-2 \cdot 3-4-5$

\section{VAR 18-21: Communication}

Hoe vaak voert u inhoudelijke besprekingen over uw onderzoek met (...) 1-2-3-4-5

1 = dagelijks

2 = wekelijks

$3=$ maandelijks

4 = eens per kwartaal

$5=$ (minder dan) eens per laar

VAR 18: Within Unit Communication

collega"s van uw eigen vakgroep $(R)$

$1-2 \cdot 3-4-5$

uw onderzoekssupervisor

(R)

$1 \cdot 2 \cdot 3 \cdot 4 \cdot 5$

\section{VAR 19: Between Unit Communication}

collega's van Nederlandse medische*/

economische** vakgroepen (R)

$1-2-3 \cdot 4-5$

collega's van buitenlandse medische*

leconomische ${ }^{* * *}$ vakgroepen $(R)$

VAR 20: (Hawing) International Communication

collega's van buittenlandse medische"

leconomische** vakgroepen (F)

$1-2 \cdot 3-4 \cdot 5$ 


\section{VAR 21: Interdisciplinary Communication}

collega"s van medische"/

economische** vakgroepen die actief zijn in

een ander onderzoeksgebied (R)

collega"s van andere disciplines (bijvoorbeeld preklinische disciplines* of wiskunde en gedragswetenschappen**)

\section{VAR 20: (Stimulating) International Communication}

$1=$ volkomen mee oneens

$3=$ enigszins mee eens

$5=$ volkomen mee eens

Hel bezoek aan internationale wetenschappelijke congressen wordt binnen de vakgroep sterk gestimulleerd

Stafleden worden sterk gestimuleerd om gedurende lange tijd in het buitenland onderzoek te doen

\section{VAR 23: Research Expendlitures**}

Onder onderzoeksulitgaven worden alle materiaal-, reis-, en personele kosten ten behoeve van uw onderzoek verstaan (uitgezonderd uw elgen bruto jaarsalaris)

Hooveel heeft u persoonlijk het afgelopen kalenderjaar bij benadering uitgegieven (eerste. tweede en derde geldstroomonderzoek)

bruto jaarsalarissen student-assistenten" on ander

onderzoekspersoneel**

II

exploitatliekosten (druk- en portokosten, software reiskosten)

fl $\ldots \ldots \ldots . . . .$.

"gemiddelde kosten per maand/eenheid student-assistent is $f 13250$, -

* gemiddelde kosten per maand/eenheid onderzoeksassistent is fl 3850, "- 
Met hoeveel collega's uit uw eigen vakgroep deelt u de bovenstaande uitgaven?

$11=0 ; 2=1 ; 3=2 ; 4=3 ; 5 \geq 4)$

\section{VAR 24: Cash Flow Mix**}

Hoeveel procent van uw totale onderzoeksuitgaven $(=100 \%)$ is afkomstig uit de wolgende inancieringsbronnen?

de eerste geldstroom (rechtstreekse bijdrage van het Riljk aan de Facultelt)

$\ldots \%$

de tweede geldstroom (bijdrage van het Rijk aan de Faculteit via NWO: Ecozoek)?

$\ldots \%$

de derde geldstroom (bijdrage van de opdrachtgever, bijvoorbeeld contraclonderzoek overheid of bedriffsleven)

\section{VAR 26-27: Organizational Culture}

Waar ik werk $(. .$.

\section{VAR 26: Bureaucratic Culture**}

spannen mensen zich zo weinig mogelijk in (1-2-3-4-5) doet ledereen altijd zijn/haar uiterste best

brengt elke dag nieuwe uitdagingen met zich mee (1-2-3-4-5) is ellke dag $20^{\prime \prime} n$ beetje hetzelfde (R)

voelen mensen zich niet op hun gemak in onbekende situaties" ze proberen het nemen van risico's te vermijden (1-2-3-4-5) voelen mensen zich op hun gemak in onbekende silualties; ze vinden thet niett erg om risico's te nemen

\section{VAR 27: Normative Culture"*}

ligt de grootste nadruk op het tegenmoetkomen aan de wensen van de opdrachtgever (bijvoorbeeld contract research) $(1-2-3-4-5)$ lligt de grootste madruk op het correct toepassen van de procedures (methodologie) 
zijn juiste procedures (methoden) belangrijker dan resultaten $(1-2-3-4-5)$ zijn resultaten belangrijker dan het wolgen van luiste procedures $(R)$

houden we er hoge normen op na over de ethiek van het onderzoek, zelfs wanneer dit ten kosten zou gaan van resilttaten op korte termijn $(1-2-3-4-5)$ zijn we wat betreft ethiek en eerlijkheid in onderzoek eerder pragmatisch, niet dogmatisch ( $\mathrm{A})$

\section{VAR 28: Individuall Performance Index**}

Hoeveel working papers (WPs) - bijvoorbeeld naar aanleiding van congresbijdragen - heeft u het algelopen kalenderjaar geschreven? WPs

Hoeveel artikelen (NTAs)heeft u het afgelopen kalenderjaar gepubliceerd in Nederlandse wetenschappelijke tijdschriften? NTAS

Hoeveel artkelen (IJAs) heeft u het afgelopen kalenderjaar gepubliceerd in internationale wetenschappelijke tijdschriften? 


\section{Summary}

Economies of atmosphere are defined as the joint, positive impact of a distinct set of values, (tacit) knowledge, and competences on the technical efficiency of a firm. The book is composed of three parts. The first Section (chapters 1-3) deals with the costs and benefits of atmosphere. In addition, it attempts to develop an economic rationale for atmosphere. Thus, it deals not only with the question whether atmosphere can affect cosis and performance, but also why certain aspects of atmosphere would increase or decrease economic efficiency. These questions are explored with regard to the national and industry level and to the arganizational level. The emphasis is on internal economies of atmosphere which are explored from various perspectives, including transaction cost economics, agency theory, and information economics.

When it can be demonstrated that there is an economic rationale for atmosphere, this does not imply that there is also empirical evidence for economies of atmosphere. The empirical Sections of this book (Sections IIIIII) are concerned with demonstrating empirical evidence. The impact of atmosphere on performance is compared with scale and scope in university research units. The university research unit is selected because it is a task environment where the central coordinating mechanism is generally conjectured to be atmosphere rather than (bureacratic) rules or (market) prices.

Section II (chapters 4-5) attempts to integrate three fields:" (i) organizational theory providing a theoretical basis for the partitioning of the sample, (ii) organizational behavior supplying proxies of atmosphere (culture and climate measures)" and (iii) university research management which provides scientometric measures of research output. Section $\| l l$ (chapters 6-8) reports the findings of two empirical sludies. Study \| explores economies of scale and atmosphere in clinical depariments of university hospitals. Univariate and multivariate results are reported on the differential impacit of scale, atmosphere, and other predictors such as input mix, management, control, and communication (chapter 6). Study II reports the findings of a study on the impact of scale, scope, and atmosphere on scientific performance in departments of economics (chapter 7). Both studies rely on large-sicale, national performance evaluations which have used a variety of scientometric indicators. Comparing the predictor-criterion relations of study " (clinical medicine) and study $\|$ (economics) it appears that more than half of the predictor variables have a consistent impact 
on scientific performance (chapter 8). Given the large wariance between the scientific disciplines investigated here, the findings may therefore be conceived as fairly robust.

Three conclusions can be drawn from the empirical studies. First of all, although there is an economic rationale for atmosphere, economies of atmosphere have less impact than is generally believed. Second, it is the dynamic interplay between atmosphere and other sources of technical efficiency rather than atmosphere alone which accounts for the variance in performance. Third, economies of scale appear to be far more important than economies of atmosphere. Scale is a necessary, not a sufficient, condition for scientific performance. Units working with Insufficient 'critlcal mass' are not expected to compensate their scale disadvantage by developing a superior atmosphere.

This study is a preformal attempt to explain the impact of atmosphere on (transaction) cost minimization and performance maximization. In addition, cross-section empirical evidence is given for the joint impact of scale, scope, and atmosphere on scientific performance. The final chapter (9) discusses the main shortcomings and strengths of this study. In addition, suggestions are given for conlinued research. 


\section{Samenvatting}

Deze studie sluit aan bij de recente belangstelling voor excellente ondernemingen, waarbil superieure financieel-economische prestaties worden toegeschreven aan kenmerken van de organisatie. In de economische literatuur worden verschillende bronnen van (technische) efficiency onderscheiden. In dil proefschrift staan schaalvoordelen (economies of scale), assortimentseffecten (economies of scope) en cultuureffecten (economies af atmosphere) centraal. Van "economies of atmosphere" is sprake wanneer er kostenvoordelen uitgaan wan de specilieke waarden, kennis (tacit knowledge) en competenties van organisatieleden. In het onderzoek staan de economische effecten van deze niet tastbare investeringen centraal.

Deze studie bestaat uit drie delen. In het analytische deel (Sectle 1: hoofdstuk 1-3) wordt onderzocht of er een economische rationale bestaat voor de samenhang tussen cultuur en bedrijfseconomische prestaties. Definities van atmosfeer en efficiency worden gegeven in het eerste hoofdstuk. In de volgende hoofdsiukken wordt ingegaan op economies of atmosphere op het nationale on bedrijistakniveau (hoofdstuk 2) en op organisatieniveau (hoofdstuk 3). Hat zwaartepunt ligi op het microniveau: de organisatie. Hierbij wordt gebruik gemaakt van de transactiekostenbenadering, de agency theorie en de informatie economie.

In de volgende delen (Sectie II-III) wordt vastgesteld of er empirische evidentie is voor economies of atmosphere. Hiervoor wordt gebruik gemaakt van een taxonomie die ontwikkeld is in de organisatie theorie (market-bureaucracy-clan) en van meetinstrumenten die onlwikkeld zijn in organisatie diagnoses (hoofdstuk 4). Voor de prestatiemetingen werd gebruik gomaakt van de grootschalige output- en impacitmetingen verricht door de Raad voor Advies van het Wetenschapsbeleid en de Verkenningscommissie Economische Wetenschappen (hoofdstuk 5).

Het derde deel (hoofdstuk 6-9) beschrift het onderzoeksdesign en de cross-sectie resultaten. Twee (multivariate) sludies worden beschreven. Studie I vond plaats in Nederlandse academische ziekenhuizen onder vakgroepen die patiëntgebonden onderzoek verrichtien (hoofdstuk 6). Dit onderzoek werd uitgevoerd in samenwerking met Y.W. Bally, R. Starmans, B.Breemhaar en F.J.N. Nijhuis. Studie II vond plaats in vakgroepen van Nederlandse Faculteiten der Economische Wetenschappen (hoofdstuk 7). De vergelijking tussen de bovengenoemde 
sectoren geeft en indlicatie van de robuustheid der bevindingen (hoofdstuk 8). Deze geven tevens een indicatie voor kwaliteitsverbetering in (enkele) bejta en gamma wetenschappen.

Op basis wan de empirische gegevens kunnen een drietal conclusie worden getrokken. Ten eerste zijn cultuureffecten minder stterk dan de literatuur doorgaans suggereert. Zelfs in een taakomgeving waarin de productietechnologie relatief gunstig is voor hel optreden van cultuureffecten (universiltaire vakgroepen) zijn de effecten marginaal. Ten tweede worden wetenschappelijke prestaties niel uitsluitend bepaald door én (organisatie)kenmerk, maar door het samenispel van meerdere efficiencybroninen. Ten derde laat multivariate analyse van schaalwoordelen, assortimentseffecten on cultureffecten zien, dal universitaire onderzoeksprestaties het meest gevoelig zijn voor schaalvoordelen. Het exploiteren van schaalvoordelen is een noodzakelijke, geen voldoende, voorwaarde voor het leweren van bovenmatige vakgroepsprestaties in de klinische geneeskunde en de economie.

Resumerend: in de eerste Sectie van dit proefschrift wordt getracht een economische rationale te ontwikkelen voor cultuureffecten. In Sectie II en III wordt vastgesteld of er empirische evidentie bestaat voor dit verschijnsel en worden de effecten op teamprestaties vergeleken mel die van altematieve efficiencybromnen. In het laatste hoofdstuk (9) wordt een samenvatting gegeven van de analytische en empirische bevindingen. Tevens worden de sterke en zwakke kanten van de studie beschreven en worden er suggesties gedaan voor toekomstig onderzoek. 


\section{Curriculum Vitae}

De auteur van dit proefschrift werd op 9 meil 1954 te Djakarta, Indonesie, geboren. Aan het Henric van Veldeke College te Maastricht werd in 1972 het HBS A diploma behaald. Tot 1976 studeerde hij beeldende kunsten aan de Stadsacademie te Maastricht en de Rietveld Academie te Amsterdam. In 1982 werd de studie Filosofie aan de Centrale Interfaculteit der Rijksuniversiteit Groningen afgesioten. In 1985 werd de studie Psychologie aan de Faculteit der Sociale Wetenschappen der Rijksumiversiteit Groningen afgesloten. Tijdens de studie werden assistentschappen vervuld aan de Rijksuniwersiteit Groningen en de Technische Hogeschool Twente. In de periode 1982-85 was hij als wetenschappelijk medewerker/universitair docent werkzaam aan de Faculteit der Geneeskunde en de Faculteit der Gezondheidswetenschappen der Rijksuniversiteil Limburg. In de periode 1985-89 verrichtte hili promotie-onderzoek aan de Faculteit der Economische Wetenschappen der Rijksuniversiteil Limburg. Zijn postdoctorale scholing in de economie bestond, naast de education permanente binnen de Vakgroep Bedrijseconomie, ondermeer uit deelname aan cursussen van Bouma (grondslagen). Mintzberg (strategie en organisatie), Daems (industrible economie) Schreuder/Pennings (interne orglanisatie) en Hopwood/van de Poel (management accounting). In de periode november-december 1985 studeerde hij bij Triandis aan de University of Illinois te Champaign (U.S.A.). Vanaf 1986 voerde hij contract onderzoek uit - onder mear voor het Ministerie van $O$ en $W$ (kwalliteit patientgebonden onderzoek) en het Ministerle van WVC (kosteneffectiviteit intensive care units). In 1989 werd hij aangesteld als senior consultant bij Hay Management Consultants (Saatchi \& Saatchi). Hij heeft daar een speciale verantwoordelijkheid voor de Europese markt voor intramurale gezondheidszorg. 